\title{
Broadcasting Policy Advice 1986-88: a critical evaluation of New Zealand's broadcasting policy framework
}

\section{David Robert Hay}

Thesis submitted in partial fulfilment of the requirements for the degree of Master of Public Policy

Victoria University of Wellington

June 1999 
In August 1988, the Labour Government announced its policy to deregulate the broadcasting industry. The policy was comprised two of major initiatives;

1. Commercialising the Broadcasting Corporation of New Zealand, and

2. Creating property rights out of the right to broadcast and establishing a market mechanism to allocate these.

The policy was based on an economic analysis of "the Economics of Broadcasting and Government Intervention” presented to the Royal Commission on Broadcasting and Related Telecommunications in a submission devised and presented independently of any political authority or mandate by the New Zealand Treasury.

This thesis is presented as a piece of "public" policy analysis, in the sense that it seeks to explain, to a non-expert audience, the strengths, weaknesses and ethical implications of Treasury's analysis as well as the outcomes or effects that deregulation has had for New Zealand society.

In doing this, it seeks also to explain to the community of policy analysts and advisors using, as much as possible, the language of modern public administration and economics - the limitations of applying 'orthodox' economic theory to the role the media plays in mediating the relationship among audiences, the state, the market and society. 


\section{Table of Contents}

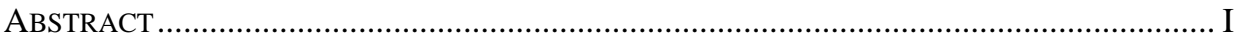

TABLE OF CONTENTS............................................................................................

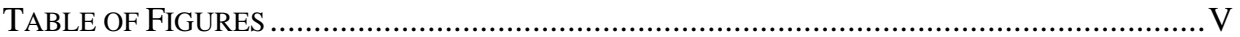

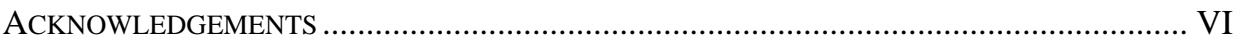

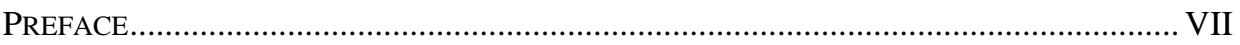

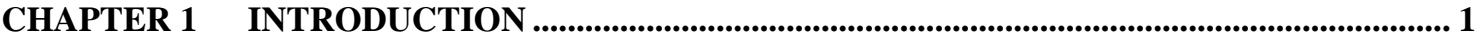

MAORI BROADCASTING............................................................................................

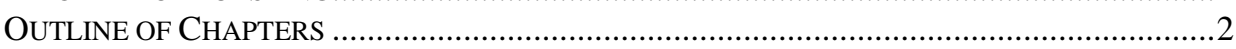

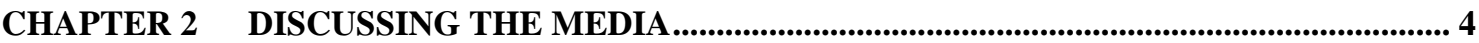

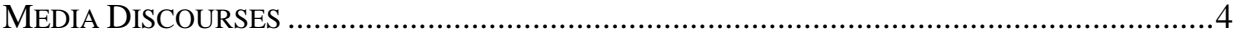

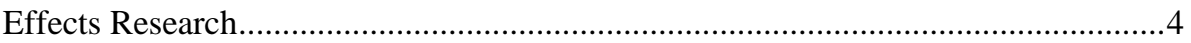

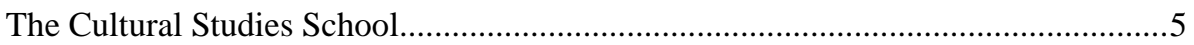

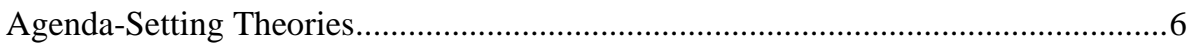

The Spiral of Silence........................................................................................6

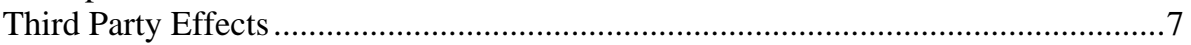

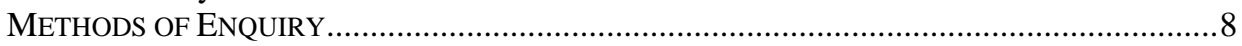

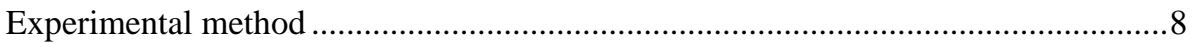

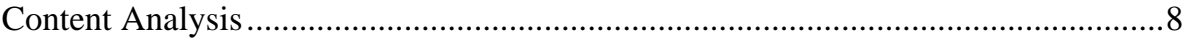

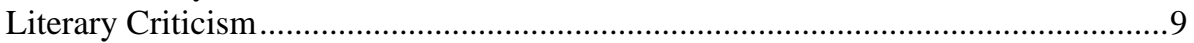

ECONOMICS AND PUBLIC ADMINISTRATION ............................................................10

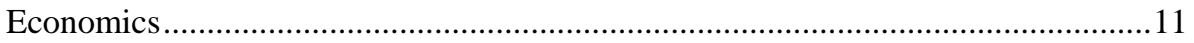

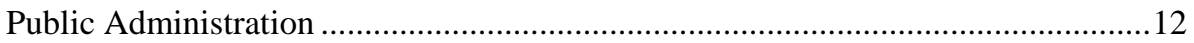

PHILOSOPHY AND BELIEFS ................................................................................13

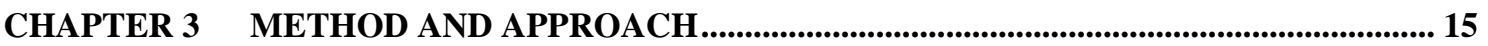

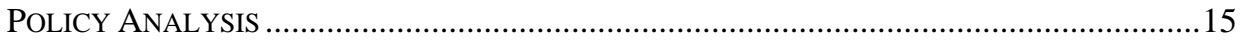

The Policy Process ………………………………………........................................17

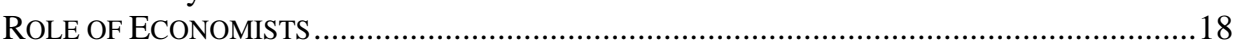

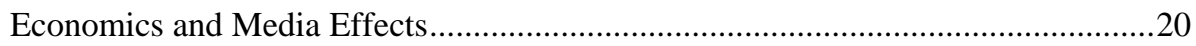

AN APPROACH TO “METHOD” ......................................................................................21

CHAPTER 4 SOCIAL AND POLITICAL CONTEXT ….......................................................... 22

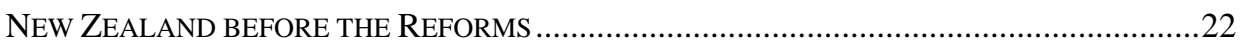

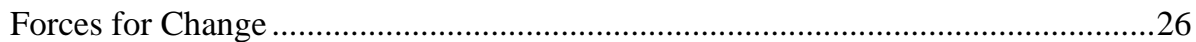

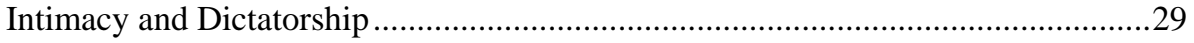

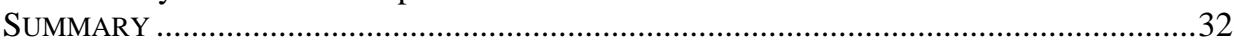

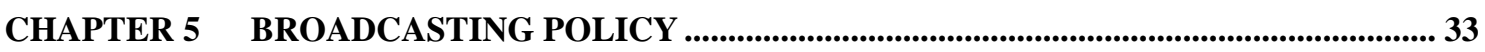

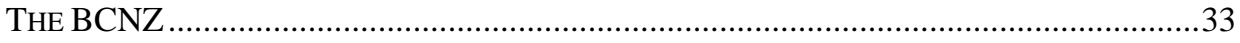

THE BROADCASTING TRIBUNAL …………………………………………………....33

The Third Television Channel Hearings ....................................................................34

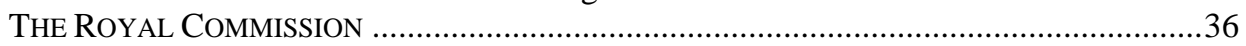

TREASURY POLICY ………………………………….................................................

The Rennie Committee ..............................................................................................43

The Officials' Co-ordinating Committee ……………………..................................43

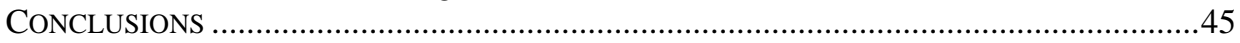

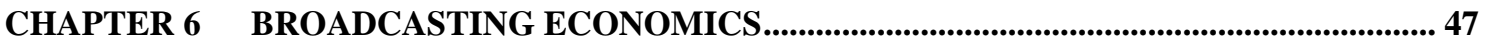

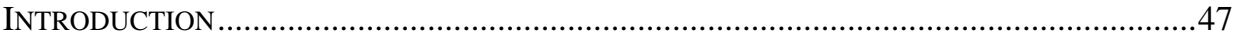

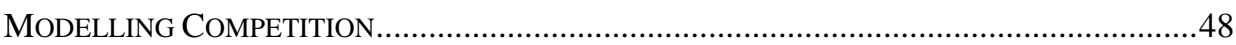

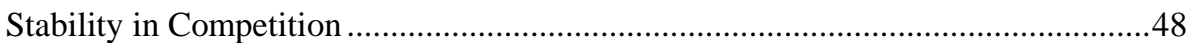

Competition and Market Entry...............................................................................50

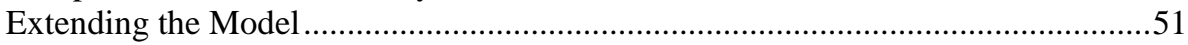

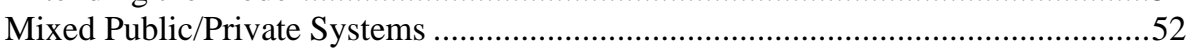

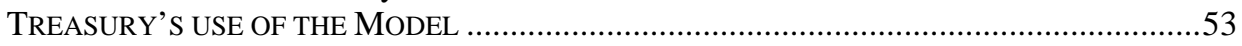

The Effects of Deregulation ...................................................................................53 


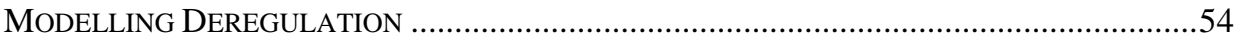

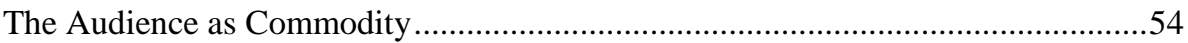

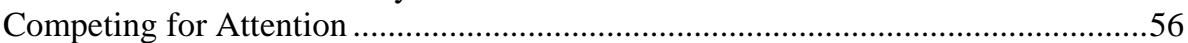

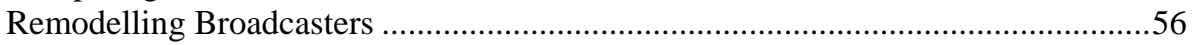

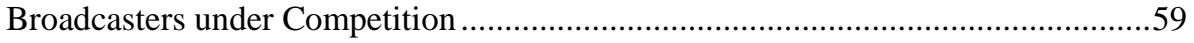

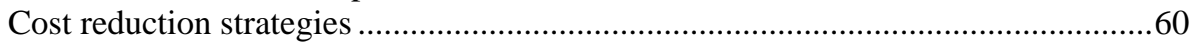

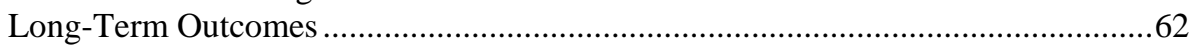

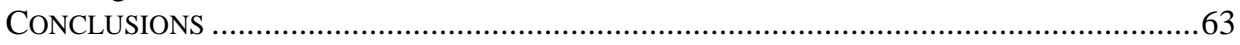

CHAPTER 7 WELFARE AND CONSUMER PREFERENCES ............................................66

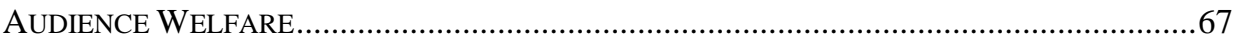

Welfare and Market Failure ............................................................................69

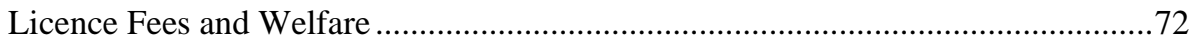

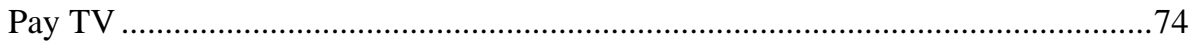

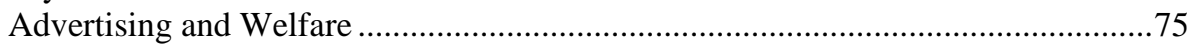

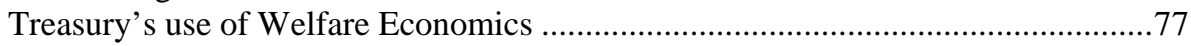

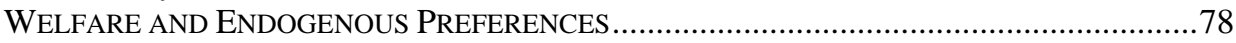

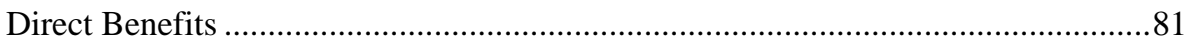

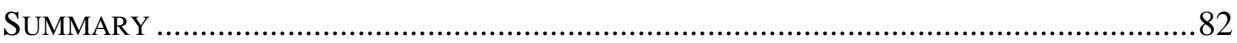

CHAPTER 8 RIGHTS AND PROPERTY RIGHTS...................................................................8 84

THE COASE THEOREM AND ALLOCATIVE EFFICIENCY ............................................84

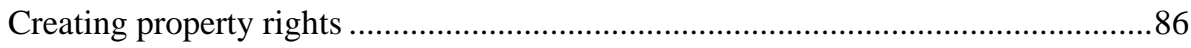

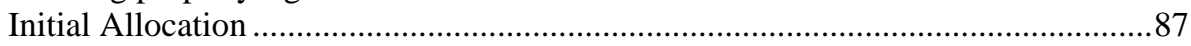

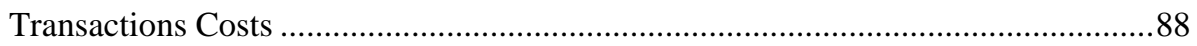

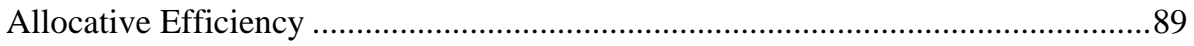

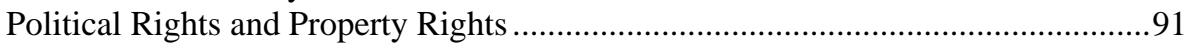

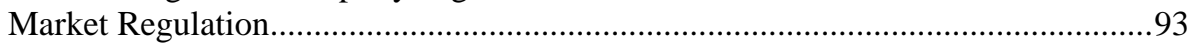

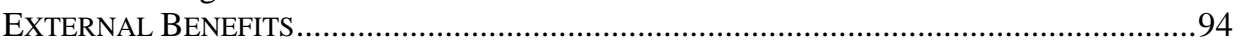

Contribution to Cultural Heritage ....................................................................95

Experimental Value.................................................................................95

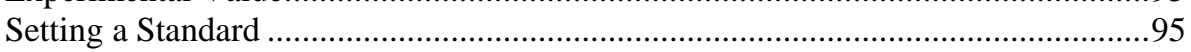

Diversity in Public Affairs Programming .........................................................96

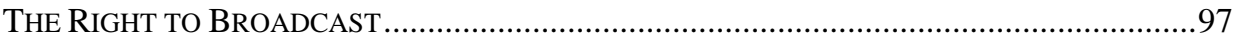

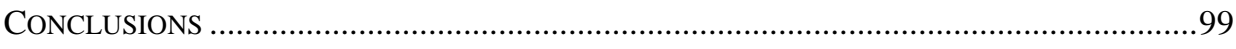

CHAPTER 9 BROADCASTING POLICY AND LAW ......................................................... 101

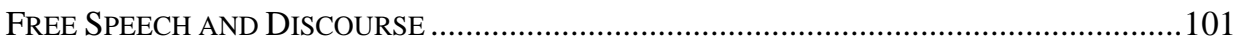

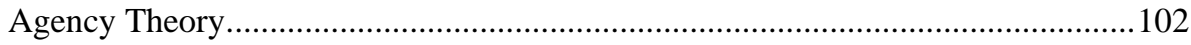

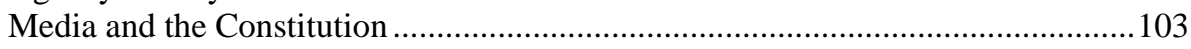

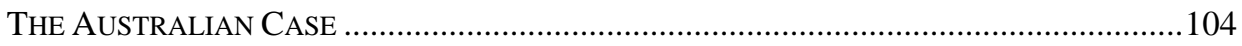

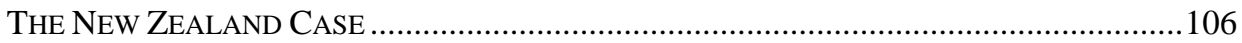

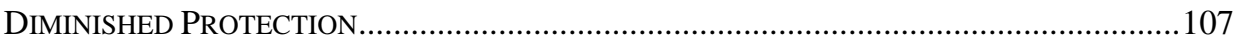

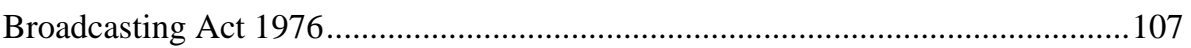

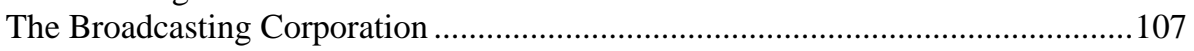

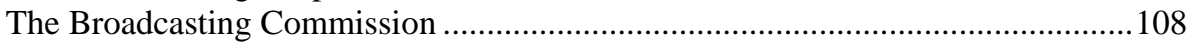

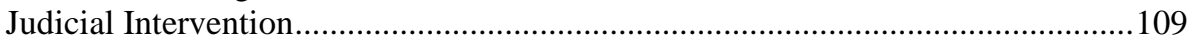

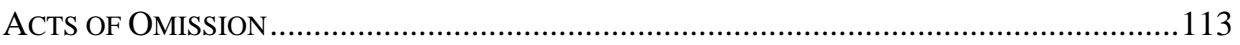

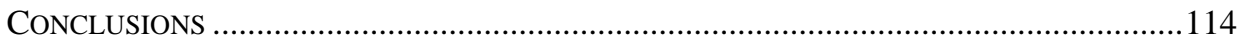

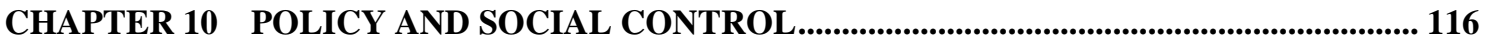

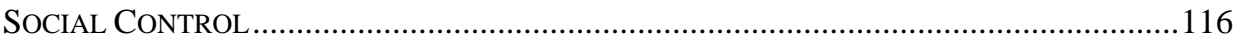

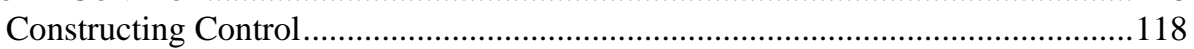

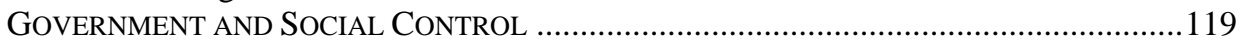

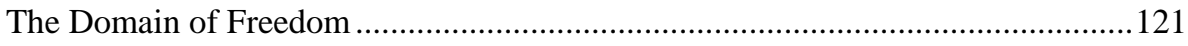

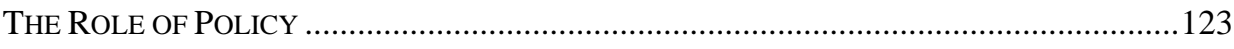

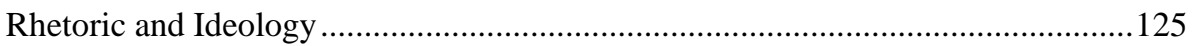

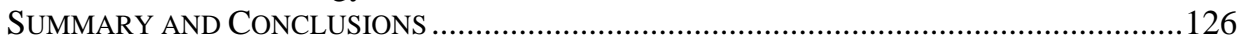

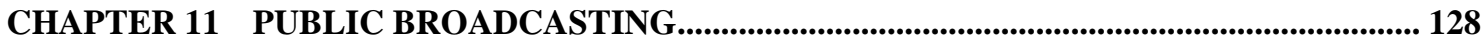

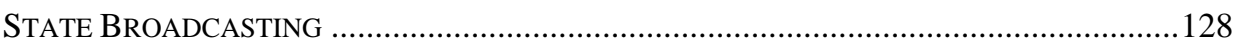

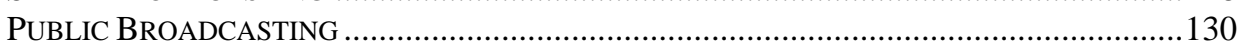

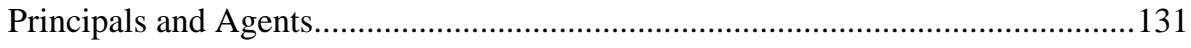




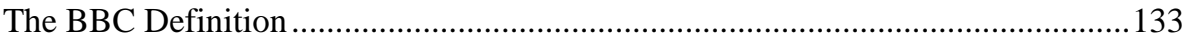

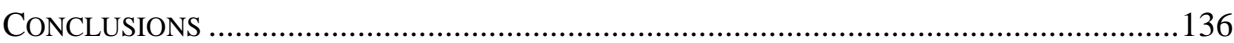

CHAPTER 12 CONCLUSIONS AND RECOMMENDATIONS.................................................. 137

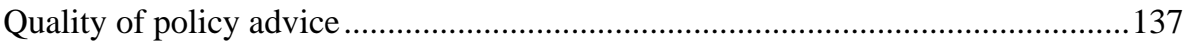

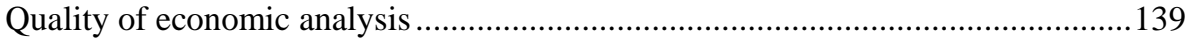

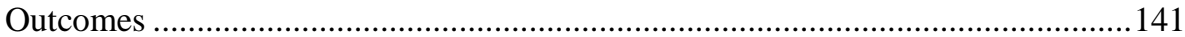

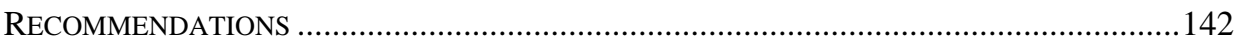

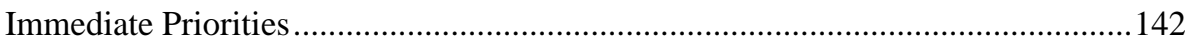

Broadcasting Policy Review ...................................................................... 143

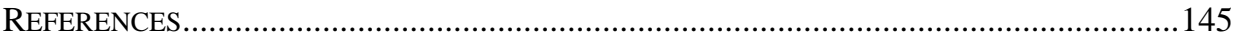




\section{Table of Figures}

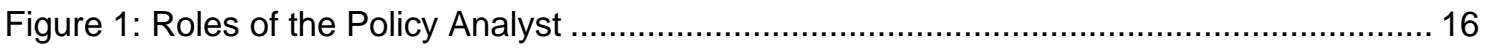

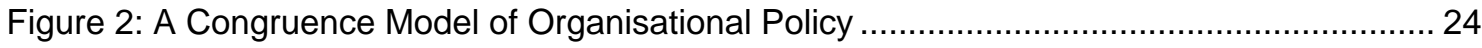

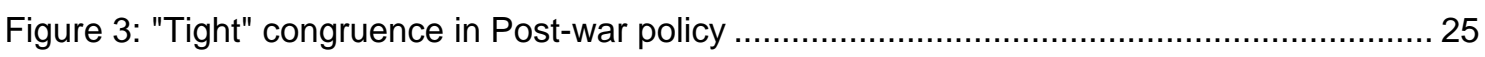

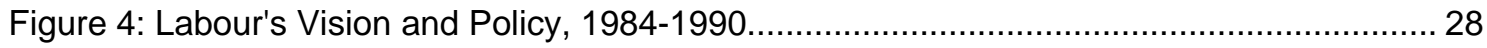

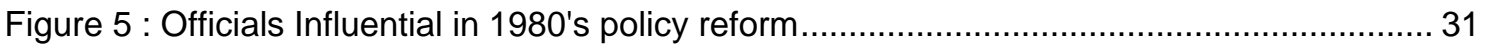

Figure 6: Output Purchasing in the Broadcasting Act 1989 ................................................ 45

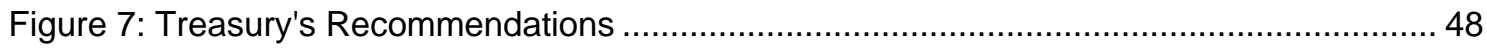

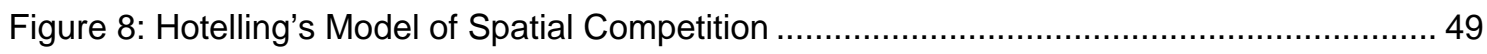

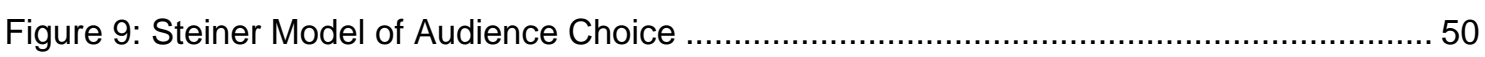

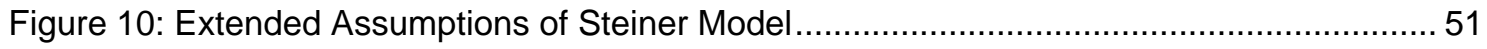

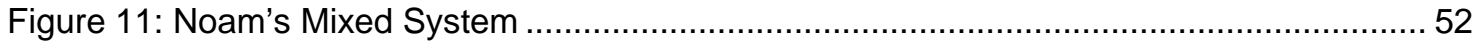

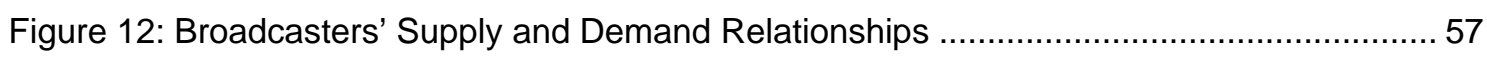

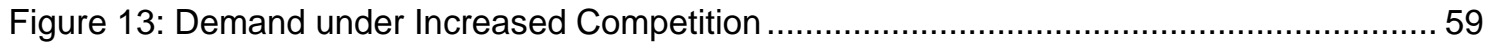

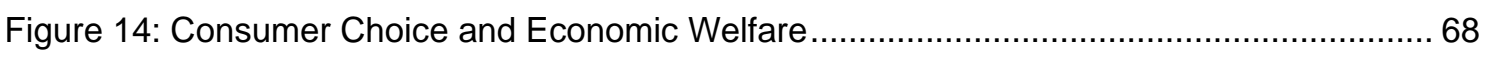

Figure 15: Comparative Welfare of Programmes ................................................................. 70

Figure 16: Accounting vs Welfare Analysis of Programme Choice ....................................... 72

Figure 17: Welfare and Level of Licence Fee ................................................................. 73

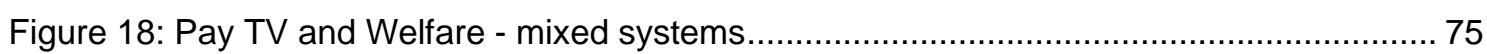

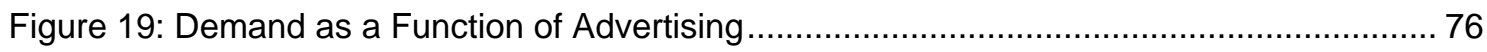

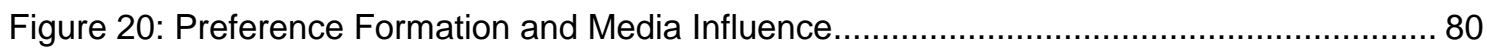

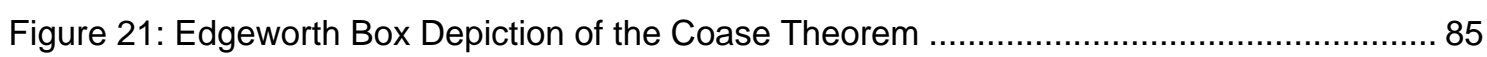

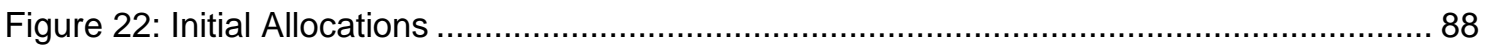

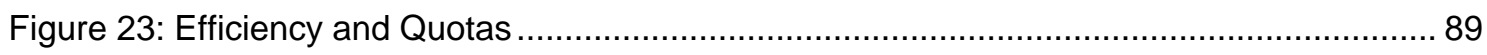

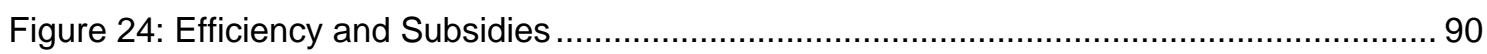

Figure 25: Media in the New Zealand Constitutional System ............................................... 103

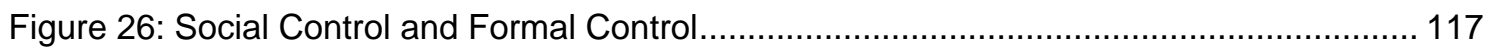

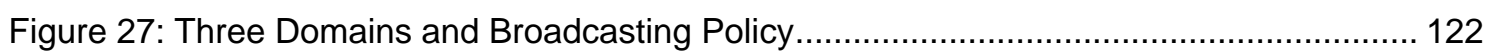

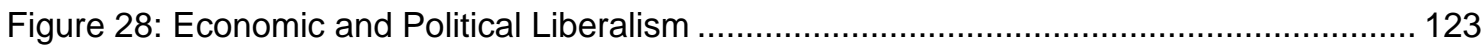

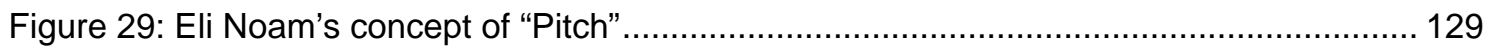

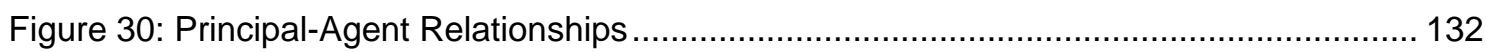

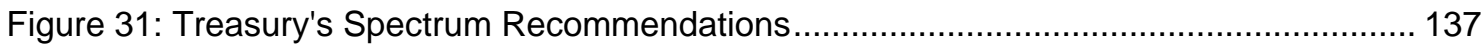

Figure 32: Treasury's Commercialisation Recommendations ............................................ 138

Figure 33: Economic Relationships among Audience, Broadcaster and Advertiser ................ 140 


\section{Acknowledgements}

Many people have helped and supported me, in many ways, to writing this thesis. I could not hope to acknowledge them all adequately. However, a there are a few who deserve special mention:

- The staff and students of the New Zealand Broadcasting School, where the idea for this thesis was born. Donna Beatson and Ruth Zanker deserve special thanks for their support and inspiration. The School itself provided me with a few weeks of paid research time, which was greatly appreciated.

- Ruth Harley, who challenged me to undertake a Master of Public Policy. If she had not told me, “...it depends whether you're good enough to get in..”, none of this would have happened.

- Bob Gregory, my supervisor, who had the good sense to leave me to struggle with the topic, was always available when I needed him, returned my draft chapters promptly and forced me to make the economics comprehensible to a non-economist.

- Participants in a stakeholder survey, abandoned in the early stages of the research, whom I have not personally thanked for their responses.

- Sir Geoffrey Palmer, who gave generously of his time to discuss issues in constitutional and administrative law.

The scholar's work sometimes seems intensely personal and introspective. Yet it also involves conversations begun by other scholars, and carried on over years from every corner of the globe. It has been a great pleasure to get to know, even a little, the contributors to these conversations.

Finally, and most importantly, my friends. Working full-time and studying part-time for the best part of four years has meant I have seen far too little, of far too many, of the people whom I most treasure. To them I can only apologise and beg their forgiveness and understanding. 


\section{Preface}

I am constantly reminded that the community of people actively engaged in broadcasting policy is very small in New Zealand, and passions occasionally run high. This piece of work will be likely to stimulate some debate, in which I fully expect my motives to be brought into question.

I have had a history of involvement in broadcasting and broadcasting policy, which should be declared in the interests of transparency:

- Radio Advertising Copywriter, (2CH, Sydney)

- Manager of a community access radio station (2RSR fm, Sydney).

- Policy analyst/Researcher for the New Zealand Maori Council, developing a plan for the iwi-based Maori radio network.

- Researcher/Analyst for New Zealand Maori Council and Nga Whakapumau i te Reo, on their Waitangi Tribunal claim on the airwaves.

- Beneficiary of the Crown's policy of selling spectrum rights. In 1991 I bought a UHF television frequency for $\$ 0.00$, and used the resulting media attention to criticise the policy of spectrum sales.

- Researcher/Analyst for New Zealand Maori Council, on the Broadcasting Assets case at the High Court.

While my experience that undoubtedly motivated me to pose the questions asked in this thesis, my awareness of the scrutiny and debate likely to arise from it has shaped the way I have attempted to answer them. I have sought to test the current broadcasting policy and the ideas upon which it is based, as rigorously as possible. I have also attempted to treat the subject matter in a fair and balanced manner as far as possible. I only ask that those who dispute the analysis will reciprocate on similar terms. 


\section{Chapter 1 Introduction}

In September 1988, the Royal Commission on Broadcasting and Related Telecommunications (RCBRT) delivered its report to Parliament. Two years later, in August 1988, the Hon. Richard Prebble, Minister of Broadcasting, announced a programme of reform for New Zealand broadcasting.

These reforms, embodied in the Broadcasting Act 1989 and the Radiocommunications Act 1990, owed little to the findings of the RCBRT. Rather, they closely resembled the policy prescriptions presented to the RCBRT in a submission written by Treasury officials.

The third section of the Treasury submission, titled "Economics of Broadcasting and Government Intervention" provided the philosophical foundations New Zealand's current broadcasting framework.

This thesis explores the reasons for this dramatic change of policy and describes the process by which it occurred. The core of the thesis is a critical evaluation of the way the economics of broadcasting were employed in the third section of the Treasury submission.

There are three key questions addressed in the course of the analysis:

- 'Was the Treasury submission to the RCBRT good policy advice?'

- 'Was the Treasury submission good use of economic theory to this policy issue?'

- 'What should be the outcomes (or social impacts) of broadcasting policy?'

The thesis is presented as a piece of 'public' policy analysis in the sense that it strives to illuminate the issues in a way that an interested citizen can engage with and understand them. It is also a piece of advice to the Government on the an issue of public policy. The recommendations made in the last chapter are therefore presented in the form expected of recommendations to a Cabinet committee.

\section{Maori Broadcasting}

The broadcasting policy reforms have had an enormous impact on Maori broadcasting, particularly Maori radio. There are now more than 20 Maori radio stations, there is an independent agency for allocating funding to Maori radio and television, and there may soon be a Maori television channel. Also, Maori claims before the Waitangi Tribunal over the allocation of broadcasting rights (or radio frequency spectrum), and successive court cases refuting the Crown's right to sell broadcasting assets, have thrown up the most significant challenges to the policy framework. However, in this thesis Maori broadcasting is mentioned mainly to provide examples and illuminate points of the analysis. The choice is deliberate, and requires an explanation.

First, the story of how Maori radio emerged out of the policy changes in 1980s and early 1990s deserves a sustained analysis and discussion in its own right, and there are others who will undoubtedly take up that task. 
Second, the claims in respect of broadcasting have predominantly been made under the second article of the Treaty of Waitangi. They derive from the guarantee to Maori of their tino rangatiratanga over o ratou taonga katoa, which was taken by the Waitangi Tribunal to mean the "fullness of control" over "all their valued customs and possessions". The Maori claims in broadcasting rely on the Tribunal's acceptance that the Maori language is a taonga, within the meaning of the second article of the Treaty (Hay, 1996).

This thesis discusses issues that fall within the provenance of article three of the Treaty, which guarantees Maori the rights and protections due to all British citizens. The citizens of New Zealand have no explicit rights in regard to the political and social role of the media. To the extent they have implied or de facto rights, the nature and extent of these are currently determined by Government policy. This matter is of concern to Maori just as much, if not more, than it is to other citizens. The emphasis on funding for Maori language content has inhibited the development of broader social and political roles in Maori broadcasting. Derek Fox makes this point, for instance:

"By restricting the focus (of funding policy) to Maori language programmes, the Crown positions itself quite nicely in a number of ways....

“...the upside for the government is that (an English language Maori news service) would help put an end to the ignorance of Maori issues enveloping most of Pakeha New Zealand. And that would hasten the day when those issues might be dealt with properly." (Fox, 1998: 24-25)

By addressing the question 'what should be the outcomes of broadcasting policy?' this thesis also directly addresses the rights of Maori under the third article of the Treaty.

\section{Outline of Chapters}

As an index is not provided, here is a summary of the contents of each chapter:

Chapter 2: Discussing the Media familiarises the reader with the major theoretical tools that may be brought to bear on the study of media in society. It the outlines the strengths and weaknesses of the methods of enquiry employed in studying the media. Finally, it describes the key ideas in economic theory and public administration that were applied in New Zealand's reforms.

Chapter 3: Method and Approach explores some of the debates in public administration journals about what constitutes good policy analysis and a good policy process. It also explores the role of the economist in the policy process and the idea that economics may be a form of rhetoric, and used rhetorically in policy debates. This leads to some conclusions about how this thesis ought to proceed as a piece of policy analysis and how it should treat economic theory.

Chapter 4: Social and Political Context presents an overview of the social and political context into which the current broadcasting policy framework was introduced. This is important to understanding how and why the reforms were introduced. It also lays the foundation for the discussion of broadcasting policy outcomes in Chapter 10.

Chapter 5: Broadcasting Policy describes the situation before, and the events leading up to, the introduction of the broadcasting reforms. It traces the process by which the 
Treasury submission to the RCBRT replaced the Commission's report on the policy agenda, and the subsequent role played by officials from treasury and the Department of Trade and Industry in advising the Government on the reforms.

Chapter 6: Broadcasting Economics describes how an economic model of the effects of competition in broadcasting has evolved over time. It shows how Treasury used the model in its submission. This is followed by a summary of developments in the New Zealand broadcasting market since deregulation, which indicates how and why some of the predicted short-term outcomes have not been realised. Finally, it presents an original model of the broadcasting firm under competition, which demonstrates why the medium- to long-term outcomes of deregulation may have very different effects to those predicted in the model employed by Treasury.

Chapter 7: Welfare and Consumer Preferences demonstrates how welfare economics may be employed to assess the benefits to society of different methods for funding television broadcasting. It then outlines a critically important limitations for applying welfare economics to broadcasting markets. Finally, it reviews Treasury's use of these ideas.

Chapter 8: Rights and Property Rights introduces the economic theory of property rights and allocative efficiency. Deregulation may mean the specification and creation of property rights where none previously existed, or the transformation of other sorts of rights into property rights. It then goes on to review the issues of 'external benefit' justifications for public broadcasting and externalities generally.

Chapter 9: Broadcasting Policy and Law explores issues surrounding the relationship between the citizens and the state, and the nature and extent of the citizen's right to freedom of thought and expression. It also discusses the nature and extent of the state's obligation to defend and protect those rights expressed in law or implied by the constitution.

Chapter 10: Policy and Social Control explores some of the subtler implications of the idea that a free society permits and even encourages its members to enjoy the freedom of thought and expression, and some of the implications that has for social harmony and the legitimacy of the state. This leads to a discussion of the conflict between competing ideas of liberalism expressed in the broadcasting reforms, and the roles of ideology and economic rhetoric in the process of deregulation.

Chapter 11: Public Broadcasting analyses the difference between 'state' broadcasting and 'public' broadcasting. It then reviews some of the principles or characteristics of public broadcasting using economic concepts presented in this thesis and based on the principles espoused by the BBC.

Chapter 12: Conclusions and Recommendations provides answers to the questions stated at the beginning of this chapter. As this thesis is designed to be a piece of public policy advice, some recommendations are presented in the form of a draft cabinet minute. 


\section{Chapter 2 Discussing the Media}

This chapter explores some of the academic disciplines, or discourses, which we might employ to discuss media policy, and the strengths and weaknesses of some ways of investigating media effects. It also briefly describes the key ideas behind the New Zealand economic and public sector reforms.

\section{Media Discourses}

Broadcasting policy can be discussed using a variety of discourses. These are primarily: Political Science, Social Psychology, Sociology and Cultural Studies.

Political Science is concerned with the power of the media to influence political beliefs and voting patterns, how the media sets the "agenda" for public debate by reinforcing certain ideas and beliefs and marginalising others. It is concerned with the structure and role of the public sphere within which policy issues are debated.

Social Psychology is concerned with the effect of the media on shaping social norms and values, or personal identity and self-image, including the effects of media on mental health. The Mental Health Foundation has been an regular contributor to debates about broadcasting policy in New Zealand.

Sociology has sought to investigate how media shapes society, specifically the relationship of the media to particular groups within society: women, indigenous peoples, social sub-cultures. It is also concerned with how the media "legitimises" some groups and alienates or demonises others.

Cultural Studies is a relatively recent academic pursuit, arising out of a fusion of literary theory and sociology, but encompassing many aspects of the foregoing disciplines as they relate to the media. Its central premise is that media are "texts" that can be decoded by expert analysis.

A great deal has been written about the media within each of these disciplines. However, it is possible to speak of the developments across these disciplines as if they represented a single field of enquiry that has developed over the years, without doing excessive damage to any of them. What follows is a brief overview, based predominantly on similar outlines provided by Alan Cocker (1996) and Shirley Leitch (1992).

\section{Effects Research}

The effects research tradition developed predominantly in the United States after World War II. This research was intended to have direct policy applications, inasmuch as it attempted to "...identify the programming and broadcasting practices to be circumscribed and those to be encouraged” (Cocker 1996: 26). Underlying this research tradition was the notion that media messages had a relatively direct or "hypodermic" effect—as if media messages directly injected ideas into people's minds. Researchers sought to apply the method scientific experiment to discover these effects. 
By the end of the 1950s, it was evident that “...(this research) didn't show any dramatic results - nothing like the results that the early students of mass communication had anticipated” (Katz, 1988). Lasora, (1992, 164), makes this summary:

“...(Klapper, 1960) noted that mass communication 'ordinarily does not serve as a necessary and sufficient cause of audience effects, but rather functions among and through a nexus of mediating factors and influences,' including selective perception, exposure, attention and retention; group dynamics; and opinion leadership. More recent research has confirmed the indirect, subtle, and contingent nature of many, if not most, mass media effects on audience.”

Cumberpatch and Howitt (1989) were less generous, stating that effects research "...offered a desert of inconsequential findings." The failure of effects research to produce robust findings meant it had little influence on policy, and weakened the case for protective regulation of the media.

\section{The Cultural Studies School}

One response to the perceived failure of effects research was to turn the original question on its head: researchers sought to discover what the audience did with mass media, rather than what mass media did to the audience. This became known as "uses and gratifications" research. A broadcaster transmits the media "text" with a particular intention, but the audience uses it with different intentions-often to gratify particular social or psychological needs (Morley, 1980). At the extreme, the media is said to have little or no influence over beliefs and behaviour. Rather, audiences bring their prior life experience and cultural beliefs to media "texts" and interpret them in ways that render the ideological influence of the media redundant. This line of thought became known as “active audiences” theory (Fiske, 1987).

The cultural studies approach followed from Louis Althusser's (1971) neo-Marxist concept that the mass media are among the "Ideological State Apparatuses" (along with religious, educational and cultural institutions), that constantly reproduce and reinforce capitalist dominance over western societies. One school of thought arising from Althusser's theory is that the proletariat may be unable to overcome the combined power of Ideological State Apparatuses. Another is that the proletariat might be empowered by popular culture to redefine its ideological condition. In both cases, theorists are fundamentally opposed to the way mainstream media constructs social reality. For Cunningham (1992: 9), the difference of opinion lies between the optimists and the pessimists about the possibility of proletarian resistance to the ideology of capitalism. The optimists, like Fiske, reject the notion that Ideological State Apparatuses are effective, while the pessimists condemn the media generally, and public broadcasting in particular, for being a tools of the ruling class. What both had in common was a "...reliance on the utopian notion that an end to the market economy was around the corner.” (Alvarado and Thompson, 1990: 2).

As public broadcasting came increasingly under threat from neo-liberal theorists in Europe during the 1980's, it became apparent that the perspectives of the popular culture theorists had "...been incorporated into neo-liberal rhetoric to justify the destruction of public service broadcasting." (Curran, 1990: 156) This has led to reappraisal and revisionism within cultural studies, where it is now argued that a noncommercial public broadcaster is somehow “...more open to popular opposition movements than the more 'closed' organisations of the popular press.” (157) 
In some quarters, a move away from a stance of opposition and resistance, toward positive engagement in policy debates has been envisaged. Cunningham (1992) painstakingly, and almost apologetically, plots such course, which “...implies that students of cultural studies should be exposed to studies of politics, public administration, entertainment economics and industrial relations,... Studies in rhetoric and discourse analysis are similarly appropriate..." (179). Windschuttle (1995) questions the utility of the entire approach, especially for instructing journalism and media students.

\section{Agenda-Setting Theories}

Empirical research into media effects did not entirely stop in response to the inconclusive findings of effects research. In the United States "Research eventually turned, elsewhere, away from persuasion, to the equally sinister possibility... that media may determine what the public takes to be important.” (Iyengar et al., 1982). This socalled agenda-setting function of the media is encapsulated by the idea that "The press may not be successful in telling people what to think, but it is stunningly successful in telling its readers what to think about.” (Cohen, 1963: 13)

Research has generally supported the validity of the idea, but indicates that agendasetting effect is not a simple phenomenon (McCombs and Shaw, 1972; Weaver, 1987). It is more pronounced in regard to issues, such as US foreign policy, where the audience has little or no possibility of direct experience and limited alternative sources of information, (Iyengar et al., 1982). It is less pronounced if audiences have direct experience of events or multiple sources of information providing a variety of perspectives.

Lang and Lang (1983) claim that the lack of "effects" indicates the media may be more effective at reinforcing beliefs than changing them. In setting an "agenda" the media agenda diverts attention away from potentially important political issues and marginalises alternative viewpoints. This is consistent with results found by early effects researchers in the 1940s (Leitch, 1992: 50). Derek Fox (1988) describes how the Maori community in New Zealand has experienced this marginalising effect. The "invisibility" of Maori language, culture and political perspectives in New Zealand's media over many years has provided a powerful impetus for the establishment of independent Maori radio, television and print media.

\section{The Spiral of Silence}

In Europe, the research of Elisabeth Noelle-Neumann (1987), into what she describes as the "Spiral of Silence" has generated a significant amount of research and academic debate. Salmon and Moh (1992) review Noelle-Neumann's theories, and the many empirical studies, critiques, counter-critiques and commentaries that have attempted to replicate, test, challenge or assess the theory. They summarise her idea thus:

"Noelle-Neumann contends that individuals have a virtually innate fear of social isolation. To be alone, apart from, or at odds with the crowd is more than most individuals can endure. To wear an unpopular fashion or to express an idea that many consider old-fashioned or, even worse, socially unacceptable is to risk incurring the wrath of others, a prospect that most find too unattractive to risk. As a result of this concern, individuals must constantly monitor the environment, searching for cues regarding which sentiments, ideas, knowledge, or fashions are shared by many or only by a few." (148) 
Noelle-Neumann claims the mass media are a powerful source of these cues, because they are ubiquitous and consonant. That is, electronic and print media pervade society, and produce a remarkably similar diet of news and information (reinforcing the notion of a media "agenda"). In such an environment, people who have strong social and belongingness needs tend to suppress opinions they believe run counter to prevailing public opinion. Noelle-Neumann bases this notion on the ideas of German sociologist Ferdinand Tonnies who conceived of public opinion as a social force, an informal mechanism of social control: "Public opinion always claims to be authoritative. It demands consent or at least compels silence, or abstention from contradiction" (Tonnies, 1922: 138). ${ }^{1}$

However, it is difficult to generalise about the "spiral of silence". Its power may be attributable, among other causes, to the prevailing culture of the society itself. The effect may be weaker in a society that condones diversity and free speech, than in a society that has a cultural tradition of homogeneity and conformity, for instance.

This view of society has important implications for public opinion research. NoelleNeumann's Spiral of Silence model sought to explain the events she had witnessed as a journalist in Germany during World War II. Her research suggests that the opinions of others and the general social climate significantly influence poll respondents' answers. Another model, developed in the United States by George Gallup and Saul Forbes Rae in the early 40's, sought to prevent the occurrence of such events. Their polling technique starts from the assumption that poll respondents are "...interested, knowledgeable and rational (i.e. not motivated by fear), regarding a social issue, and that polling provides a mechanism for an individual's participation in the political system...” (Salmon and Moh: 153). Noelle-Neumann's research findings imply that Gallup and Rae's ideal is normative, (says what ought to happen) rather than descriptive (describes what actually does happen).

\section{Third Party Effects}

In America, Davison has developed a line of enquiry into "Third-Person Effects", or the idea that:

“... a message might lead to action not because of its direct impact on those presumed to be its target but because others (third persons) believe it will have such an impact on that audience and they act on that belief, regardless of whether or not the message has direct effects on the presumed target audience at all.” (Lasora, 1992: 165)

Empirical studies indicate that between $30-50 \%$ of polled respondents tended to believe that media messages will have a more powerful effect on others than on themselves, 40$50 \%$ perceive equal effects between themselves and others. The residual 5-7\% believed that the media has a more powerful effect on themselves than on others.

The idea of third party "effects" is really not about media effects at all, but about how media policy is debated. It refers to the element of "moral panic" often involved in

Abraham Maslow's theory of psychological health, in Motivation and Personality (1987), provides support for this idea: in his hierarchy of human needs, social and belongingness needs come immediately after the fundamental needs for food, clothing shelter and safety. 
debates about the media and media policy, especially when the "third parties" include children or any section of society deemed to be more susceptible to media influence than others. Such claims occur in many areas of policy debate, where the common good is at issue. Protagonists in such debates may invoke the welfare of the general public, or of other individuals, to mask self-interest or to promote personal beliefs - as Davison's idea implies. However, his sweeping generalisation is unfair to those who may be genuinely concerned about the impacts of policy on people unable or unwilling to represent themselves.

\section{Methods of Enquiry}

The strengths and weaknesses of the various ways of discussing media effects are intimately connected with the methods of enquiry employed. This section describes some of the different methods and their strengths and weaknesses for the analysis of media policy.

\section{Experimental method}

The method of scientific experiment ostensibly provides the greatest degree of rigour for determining media effects. However, it suffers from the problems of applying scientific experiments to social policy issues generally. The idea of a "scientific experiment" refers to a replicable experiment, with valid control groups, which demonstrates strict causality and accurately predicts future events. There are some problems of applying such a method to media effects research:

- The studies will be culturally specific: people in different societies may react differently to the same media message, depending on their culture and beliefs. A study of media effects undertaken in one society may not be replicable in another.

- Societies and cultures change, often quite rapidly. Therefore, the results of experiments made at one point in time may not accurately predict similar effects in the future.

- Societies change in response to the media, but the media also changes, in both form and content, in response to social and cultural change. Therefore the direction of causality cannot be determined in the long term.

- Media effects may be indirect, as the effects researchers discovered, so the nature of causality is obscure.

- There can be no effective "control” group. Media is so ubiquitous that any group of people not exposed to the media would be unrepresentative of the general population.

The experimental method therefore cannot produce hard and fast universal truths about media influence. However, it can produce plausible conclusions, which will be fairly reliable within particular social and historical contexts.

\section{Content Analysis}

Content analysis refers to the measurement and interpretation of specific aspects of media "texts". The approach takes two general forms: objective measurement or subjective analysis, although both may appear in a single study. 
Objective measurement techniques quantify and classify selected aspects of media texts. Atkinson (1994) took this approach, measuring the length of sound bites, camera shots and item lengths on Television One's network news. Atkinson criticises the quality of television news since deregulation on the basis that the average duration of news stories, and the quotations used in them, has become shorter. He reports quantifiable facts that imply the existence of a problem, but do not prove it: does shorter item length mean that reporting is worse, or simply more concise?

The subjective style of content analysis attempts to assess the meaning of a media text. This inevitably requires the researcher to make subjective judgements regarding both denotation and connotation. ${ }^{2}$ It is possible to control for consistency among a team of researchers, however this will only ensure the analysis is consistently subjective. McGregor and Comrie's (1995) report on the qualities of "balance and fairness" in New Zealand's broadcast news, commissioned by the Broadcasting Standards Authority and New Zealand on Air, provides an example of this approach.

The difficulty with content analysis is that it provides evidence and analysis of symptoms, when the cause of those symptoms will generally lie elsewhere. It therefore provides a weak platform for policy development. It would be ridiculous to regulate the length of sound bites, as a way of improving the quality of the news, for instance. It would be fair to say that neither Jo Atkinson's study nor McGregor and Comrie's have had tangible effects on policy.

\section{Literary Criticism}

The term "literary criticism" is used here to encompass and conflate a range of ideas, including structuralism, post-structuralism, relativism and post-modernism.

All of these approaches start from the idea that humans are born into the world with minds empty of content and the world is perceived through the senses. ${ }^{3}$ Our understanding of the world is built from seeing, hearing and experience. Our knowledge of society, its rules, norms and expectations, is communicated to us through "texts" (or perceptions imbued with meaning). Therefore, textual analysis or literary criticism can be used to determine the truth about the social world. Just as, by reading and analysing ("decoding” or "de-constructing"), the encoded messages and meanings in a book we can better understand the intentions of the author, so we can better understand the nature of a society by understanding its language, symbolism, etc.

The basis of anthropological Structuralism is the claim that we can understand the nature of society by understanding how different societies construct their social realities using symbolism and communication. Post-structuralism arises from the idea that when we study societies in this way we are unavoidably employing the precepts of our own culture, ideology or personal psychology.

2 Denotation refers to the literal qualities of the text: the actual words and symbols used. Connotation refers to the meaning that the message has in a particular context and for a particular reader.

3 That is, philisophical materialism, as opposed to idealism, which holds that our minds possess some form of prior knowledge or ability to independently "know" the world. 
Cultural Relativism follows from the idea that if society is "socially constructed", there is no proper or natural form a society should take. This idea provides theoretical support for utopian social reform movements, as it implies the possibility of explicitly choosing and creating a future society. Some feminists and other social activists believe changing a society's language can bring about social change (Fairclough, 1992:135). In the Marxist version of this approach, texts contain the encoded ideology of the ruling class, and Marxists hope that deconstruction will help the proletariat discern the difference between 'science' (i.e. Marxism) and ‘ideology' (anything else).

Post-structuralism and cultural relativism give rise to post-modernism: the idea that there is no authoritative "meaning" attributable to a text - subjective appreciation is the only valid measure of worth. Applied to the study of society, it implies that any social structure is good if its inhabitants believe it is.

In the more extreme versions of the literary metaphor, texts become more important than the social events to which they refer. This constitutes the social condition of "hyperreality", according to Baudrillard (1995), in The Gulf War did not really take place. Events since the Gulf War, including the O.J. Simpson trial and Princess Diana's funeral, lend credence to the point: the social meaning of an event may be less a function of the event itself than of the way the media covers it. The newsreader becomes more newsworthy than the news.

Literary criticism hardly appears to provide a robust platform for public policy discussion. It does not constitute a formal or rigorous method of enquiry, and many of its insights offer a critical view of society, rather than constructive proposals for change. However, the ideas outlined above can be boiled down to a few ideas that are very important to policy development:

- The act of policy-making involves communication and the manipulation of symbols.

- Policy does “construct” society in profoundly important ways.

- Groups and individuals use rhetoric to promote or mask their political interests, and understanding their use of rhetoric can be useful in policy debate and analysis.

- There is often no one "right" answer to a policy issue, and the outcome will rely heavily on the personal values and positional power of policy advisors, as well as the political beliefs of political decision-makers.

- Many people have little or no contact with the world of politics and policy-making other than through the media. The media's coverage of an election campaign may be of significant influence in determining its outcomes.

Obviously, ideas based on the metaphor of literary criticism do provide a rich source of insight, and often challenge the way that we think about the world. They should not be too lightly dismissed.

\section{Economics and Public Administration}

The broadcasting policy reforms were heavily influenced concepts from economic and public administration theory that were widely applied during the 1980s. Understanding these concepts is crucial for evaluating the current policy framework. 


\section{Economics}

The economic ideas that pertain to broadcasting will be explained in detail in later chapters. In this section we look at the key ideas applied to the New Zealand economy and the public sector generally. The central idea was the need for microeconomic reform in the pursuit of allocative efficiency. Essential to both notions is the idea of consumer sovereignty. Secondary to these concepts are some supporting ideas: that the private sector generally manages enterprises better than the public sector; that the government should exit inessential business activities, leaving them to the private sector.

Microeconomic reform generally meant the removal of regulations, tariffs, subsidies and other government interventions that "distorted" the allocation of goods and services (in consumption), and resources (in production), that would otherwise occur in a free market.

Allocative Efficiency is the concept that, when two or more parties enter a voluntary arrangement to trade, the aggregated welfare of both parties will be maximised. ${ }^{4}$ An improvement in efficiency means that at least one party to a transaction will be better off after the transaction has taken place, and neither party will be worse off. Note this is different from the idea of technical efficiency in economics. When technical efficiency improves, a greater amount of output is produced with a given amount of input or, equally, the same amount of output is produced with a lesser amount of input.

Consumer Sovereignty is the idea that each individual is the best judge of her own needs and, if given the opportunity and incentives to do so, will make better consumption and savings choices than those made for them by the state. The best possible outcome for society is achieved, indeed can only be achieved, by summing over all consumers' personal choices. It is a fundamental principle of economics that we should not look under the veil of personal psychology or social influence to investigate an individual's choices—-hence the notion of "sovereignty". ${ }^{5}$

The idea of individual sovereignty is deeply embedded in the structure of English philosophy and jurisprudence. It is associated with the thinking of Thomas Hobbes who claimed that "man is alone in a state of nature", and the natural condition of mankind is that of an individual wandering in the wilderness, entering human society only for the protection it offers. The place of the human being in economic theory can be traced to the thinking of Jeremy Bentham, who saw homo economicus as an individual who calculates the personal pleasure or pain associated with every decision and chooses to maximise his utility accordingly.

This is sometimes referred to as Pareto efficiency after Vilfredo Pareto, the Italian sociologist and economist who conceived the idea.

5 This assumption poses problems for the analysis of mass media, since creating mass influence over consumers' choices is the primary function of the commercial media. This issue is discussed in greater detail below. 


\section{Public Administration}

Boston, et al, (1996; 16-40) set out the key ideas about public administration which underpinned the public sector reforms. These may be paraphrased as:

Public Choice Theory is an extension of the precept in economic theory that all individuals are rational utility-maximisers. If all human behaviour is motivated by selfinterest, then politicians' actions are determined primarily by their desire to maximise future votes, government officials by their desire to increase departmental budgets, and so forth. Public choice theory may be used as a rhetorical device to argue that politicians and administrators make "irrational" decisions that distort the allocations the market would otherwise create. Such decisions reflect politicians' prejudices and/or the outcomes desired by interest groups, neither of which is in the best interests of all consumers.

Agency Theory emerged from analysis of the problems arising from the separation of ownership and management of firms. Social and political relationships can be understood as 'contracts' in which the principal binds the agent to do her bidding, in return for a reward. The idea of a contract is broadly defined, and may include the relationships arising out of marriage, elections, and employer-employee or fiduciary relationships, for instance. Agency theory asserts that agents do not necessarily act to maximise the welfare of principals. The behaviour of agents is difficult for principals to monitor, and may lead to "shirking, deception, cheating and opportunism". Overcoming these possibilities is the primary focus of agency theory The principals' options include: monitoring, offering incentives, and enforcing a bond by instruments such as guarantees. These all impose "agency costs" on the principal. Although principals may also compromise the relationship, by acting opportunistically, this idea does not figure strongly in the literature.

Transaction-Cost Economics (TCE) closely related to agency theory. It focuses on the nature and extent of the costs involved in creating a contractual relationship, and how these affect the governance structures that are created. Transactions costs can be separated into ex ante costs and ex post costs. Ex ante costs are those of negotiating and specifying a contract which fall before the contract is agreed. Ex post costs are those of monitoring, enforcing and altering contracts once they are in place. TCE presumes agents are prone to opportunism, or "self-interest seeking with guile". Both parties enter the contract with limited information (or "bounded rationality"), and the cost of obtaining information may be a transaction cost for either party. Either party may possess information the other does not, which they may use strategically to obtain benefit from the transaction.

Managerialism implies that there is a body of theory and practice called "management" that can be applied to any organised productive activity, whether in the public or private sector. Easton (1997) has described this as commercialisation “...which may be defined as 'the application of business (or commercial) principles to the public sector (or a particular public sector activity)'.” (25) Commercialisation implies that private ownership is more efficient than public ownership. It makes a somewhat ill defined connection between allocative efficiency and technical efficiency, with the former supposedly giving rise to the latter. Commercialisation gives rise to the idea that StateOwned Enterprises (SOEs) should separate their purely commercial functions from their purely social functions to the greatest extent possible, in the interests of transparency. 
Where possible, the Government should then purchase outputs that it deems socially important from SOEs, as if from a commercial supplier.

New Public Management (NPM) is managerialism applied to the public sector. It involves shifting the focus of control from processes to results, devolution of management control from politicians to administrators, adoption of private-sector management practices such as mission statements, strategic planning, performancelinked pay, improved management information systems and a greater focus on efficiency and corporate identity.

NPM and managerialism (but not commercialisation) are associated with an eclectic body of management literature and thinking. Businesses are insatiable in their appetite to adopt and test ideas of psychology, sociology, and anthropology - anything that will provide even a temporary competitive advantage. They provide a testing ground for ideas about organisational structure and organisational change, and over time, these ideas have evolved in many interesting directions. The management literature and therefore the New Public Management make few claims toward internal consistency or desire to be accepted as an intellectual system. ${ }^{6}$ This contrasts with TCE, Public Choice theory, Principal-Agent theory and commercialisation, which all follow from the application of economic theory to administration and organisation, and which can all be linked to the concepts of consumer sovereignty, microeconomic reform, and allocative efficiency.

\section{Philosophy and Beliefs}

The application of neo-liberal economic ideas and related public administration concepts to broadcasting policy can be described as "ideological". That is, these ideas take on the character of a political philosophy or a system of belief.

The basis of this philosophy could be expressed as “...the belief that the moving force in society is or should be self-interest." (Jesson, 1987: 120) The aggregation of individuals' rational choices can and will lead to the best possible social outcomes. This implies that the state will play a minimal role in society, expressed by the idea of the neutral state, in which:

“...it is not the function of the state to impose the pursuit of any particular set of ends upon its citizens. Rather, the state should leave its citizens to set their own goals, to shape their own lives, and should confine itself to establishing arrangements which allow each citizen to pursue his own goals as he sees fit-consistent with every other citizen's being able to do the same.” (Jones, 1989: 9)

To assess the quality of Treasury's economic analysis and the political neutrality of the policy advice provided by officials to the government, we may need to identify when the application of a concept of set of concepts takes on the character of a belief system or political philosophy. Leslie Stevenson (1987) offers the following definition of a 'closed system' of belief:

$6 \quad$ Charles Fox (1996) critiques Osborne and Gabler's (1993) Reinventing Government along these lines, accusing the authors of inconsistency, self-contradiction and even post-modernism. 
"There are two main ways in which a belief can be maintained in the face of intellectual difficulties. If a theory of human nature is maintained by these two devices - (1) of not allowing any conceivable evidence to count against the theory, and (2) of disposing of criticism by analysing the motivations of the critic in terms of the theory itself - then I shall say that the theory is held as a 'closed system'.” (15)

In order to decide whether the first of these devices is being employed, we have to be aware whether the statement concerned is normative or positive. That is, whether it is "...a value judgement, saying what ought to be the case, rather than a statement of fact, about what is the case" (17). ${ }^{7}$ Another indicator is when an analytic statement is passed off as a synthetic statement. An analytic statement is true by definition “...the statement that all men are animals does not really make any assertion about the facts about men, but only reveals part of what we mean by the word 'man'."(19) Being an analytic statement, it can neither be proven nor disproven by any evidence. A synthetic statement, on the other hand, does attempt to make genuine assertions about facts, and at least implies that the truth of the statement might be proven.

These distinctions - between normative and positive statements, and between analytic and synthetic statements - provide us with two simple tests, which may help us decide whether or not a statement has the character of a value judgement. We may also be able to identify when ideas, particularly ideas from economic theory, are being employed as part of a "closed system" of belief.

This is one of the tests of what makes 'good' policy advice. If advice from officials to a government has the character of a value judgement, or if it represents the product of a “closed system” of belief, then its political neutrality might be called into question.

$7 \quad$ We have already seen this conflict expressed in the different approaches taken to survey research by Gallup and Rae and by Elisabeth Noelle-Neumann. 


\section{Chapter 3 Method and Approach}

The previous chapter has briefly reviewed the main discourses and methods of enquiry we might employ to analyse media policy. How, might we use these various and sometimes conflicting ideas to talk about broadcasting policy?

This chapter will look at debates regarding the role and function of policy analysis, the process of policy development, the role of the economist in policy debates, and the ability of economics to build persuasive arguments. The method and approach of this thesis reflect choices that should be seen in the context of these debates.

\section{Policy Analysis}

According to Wildavsky (1979), the function of policy analysis, as a discipline, is to bring rigorous analysis to the political process. Its fundamental mission is to "speak truth to power". Capturing reliable data and using robust analytical techniques to formulate conclusions is an essential aspect of "speaking truth to power". Wildavsky therefore proposes a rational and objective, or modernist, mode of enquiry.

On the other hand, the practice of advising, formulating and developing policy is largely about persuasion - it is rhetorical. There is a small and relatively recent literature about the rhetoric of policy analysis in the policy analysis journals. ${ }^{8}$ Danziger (1995) notes that the debate has much deeper roots, which can be traced back to ancient Greece:

"The underlying sophist assumption... is that “ "truth" for any man was what he could be persuaded of.' Plato, on the other hand... insists that the public needs a philosopher king to counteract its ignorance. To simplify a somewhat heated ongoing policy debate, the sophist teachers of rhetoric championed a democratic practice, while the more traditional philosophers who criticized them were profoundly anti-democratic and advocated philosophical expertise as the key criterion for political power. In short, the ancient advocates of rhetoric would be opposed vehemently to the proponents of truth as technical expertise.”(437)

Deleon (1994) has pointed to the increasingly technocratic and disempowering orientation of the policy sciences. He calls for the return to policy sciences with a more multidisciplinary character, in order to enhance democratic participation and governance and thereby improve their value and usefulness:

"The policy sciences have been well accepted within the halls of power but their record of discernible successes has not been especially striking. The reasons for these shortfalls can be attributed to an over reliance on instrumental rationality (in general, the effects of positivism, in particular, the influence of neoclassical economics), the complexity of the problem contexts, and an increasingly technocratic, undemocratic orientation.”( 82)

$8 \quad$ See, for instance: Majone (1989), Throgmorton (1991), Farmer (1995), Danziger (1995) 
Throgmorton (1991), analysing policy debates surrounding the Love Canal environmental disaster, emphasises the rhetorical nature of the sphere of activity within which policy formulation occurs: “...policy analysts are embedded in a complex rhetorical situation created by the interaction of three broad communities (or audiences): scientists, lay advocates and politicians....”(153) Each of these communities has its own normal discourse and agreed-upon conventions of persuasion. The diagram below shows the role of the policy analyst in the interactions among these three spheres. In applying the model to the subject matter of this thesis, it may help to substitute the word "economist" for "scientist" in the lower circle.

\section{Figure 1: Roles of the Policy Analyst}

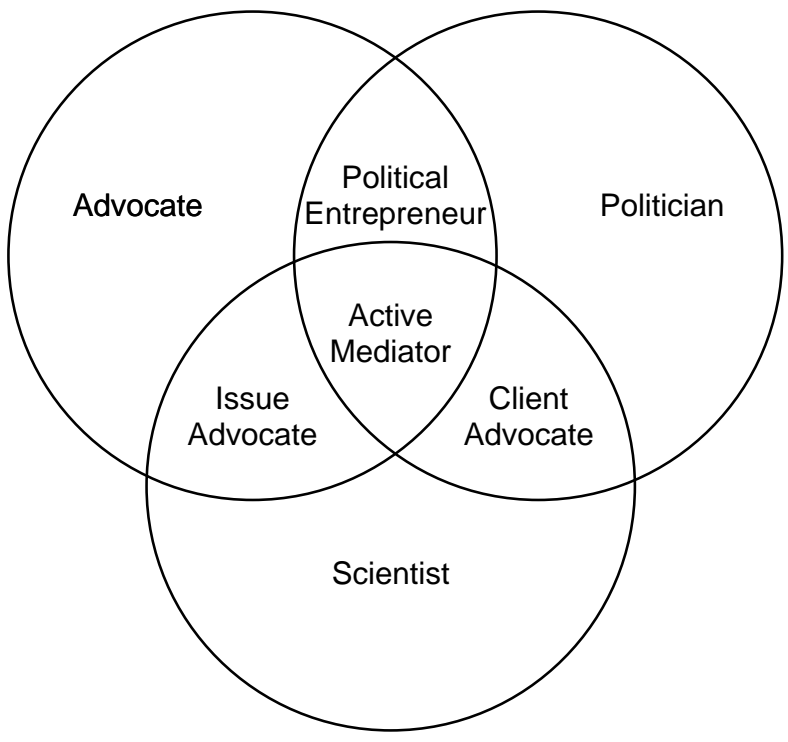

Throgmorton (1991), presents the analyst as somewhat trapped in this nexus of relationships:

"By acting as advocates for clients, analysts can directly influence decision making. But they do so at the risk of losing legitimacy in the eyes of advocacy communities.... By acting as issue advocates, analysts earn greater credibility and legitimacy with particular communities. But they do so at the risk of losing the trust of elected officials.... And by acting as mobilizers, analysts are more likely to get things done in a way that satisfies both elected officials and particular groups. But they do so at the risk of being seen by scientists of producing decisions that are ineffective and guided by emotion.”(167)

He sees the 'ideal' policy analyst as an active mediator, working with the participants in a sphere where conflict between opposing points of view occurs. He argues that "The role of the policy analyst is to help create (through honest argument directed at those audiences), a community that is technically competent, politically astute, and legitimate.”(153) His prescription for the analyst to engage in "active mediation" neither implies that a synthesis of these distinct discourses can be achieved nor that there should be consensus among parties to the policy discussion.

Danziger (1995), supports this point about conflict, and emphasises that the role of rhetoric in mediating among conflicting interests should be clearly understood in the policy process: 
“...conflict generates understanding, clarification, change, and sometimes even consensus. The goal for policy analysis is not to avoid conflict, or to avoid rhetoric-because it is an inescapable aspect of public policymaking. Students must learn to apply it constructively, recognize its strengths and limitations, and minimize its power to distort and do harm.” (447)

What shall we make of all this? First, recognising the need for rhetoric in policy analysis does not preclude the need for accurately collecting, analysing and reporting facts if they are available. Although active mediation may be the most preferred role, an analyst may play any of the proposed roles, depending on what is needed at the time. In the absence of any one of these communities of interest, in a given situation, the analyst may choose to act as the devil's advocate on that community's behalf, for instance. Finally, in the presence of conflict, it behoves the analyst to provide input and advice without fear or favour.

\section{The Policy Process}

Differing perceptions about the proper role of a policy analyst are reflected in debates about what is, or should be, a good policy development processes.

In 1959, Charles Lindblom published “The Science of Muddling Through", which contrasted two models of policy-making, the rational/deductive and the incrementalist (or "muddling through"). He elaborated his ideas in a number of subsequent publications. These have been summarised by Bob Gregory (1989), who identifies six interrelated ideas about policy making in Lindblom's writings:

- Policy makers' level of theoretical understanding of the relationships among relevant variables is low.

- Policy makers tend to confine themselves to consideration of variables, values and consequences of immediate concern that differ marginally from the status quo.

- In the face of limited information and theoretical input, policy movements tend to be based on marginal, trial and error interventions.

- Policy and/or political change therefore occur marginally, or "incrementally".

- Policy making is a process of political and social interaction among competing interests and values, which Lindblom describes this as "partisan mutual adjustment”.

- Political and policy change is not a function of any coherent set of transcendent objective goals.

The first three points concern the role of formal analysis in policy-making, and emphasise Simon's (1947) notion of "bounded rationality"-the notion that the knowledge contributing to any decision is only ever partial and contingent. The second group of three points describes the reality of the policy process, as Lindblom sees it.

Critics of the "muddling through" concept tend to object to the prescriptive element in Lindblom's writing, which emphasises the democratic and participatory nature of the policy process. Gregory notes that: "Goodin... is concerned with formal theory in policy making. His proposition is that incrementalists either fail to use formal theory at all; or, if they do, they do not use enough, or they use it too cautiously."(141) Champions of the rational-deductive model tend to criticise "incrementalism" as for appearing to support irrationality in policy development and argue that it is inappropriate for introducing comprehensive and rapid change. 
Lindblom was not necessarily in favour of "irrationality”. In his later works, especially, he is more explicit about the main thrust of his ideas, which is "...that public policy making has to be understood essentially as a political process, rather than an analytical, problem-solving one." (Gregory, 147) Lindblom sees the rational-deductive ideal as possessing dangerously anti-democratic and ideological tendencies, and refutes the claim that "incrementalism" cannot manage comprehensive and rapid change. A multitude of incremental changes can have comprehensive effects if they are implemented concurrently and with a common direction.

As far as policy process is concerned, the choice of a rational/deductive or incrementalist approach is really contingent on a number of factors. These include the urgency and scope of the policy issue, the state of theoretical sophistication and availability of facts. In all cases, the democracy nature of the process is paramount - but that does not preclude a rational/deductive process in the presence of firm and clear of political principles espoused by elected politicians.

Finally, if we acknowledge that the role of the analyst may require the use of rhetoric, this does not mean that policy analysis and development is, or could be described as, post-modern. Post-modernism implies that all cultural and social viewpoints are equally valid, and people are, or should be, free to construct their own realities as they please. Fox (1996), points out that this form of social pluralism complicates the idea of a common good, and militates against the possibility of purposive political action. Policy analysts and decision-makers are intimately involved in the process of constructing social realities. Policy analysis, evaluation and implementation ultimately result in the creation of specific laws, regulations and institutions. These necessarily entail a "distribution of sacrifice" among competing interests and conceptions of what constitutes a good society. ${ }^{9}$ The very idea of policy-of making, legitimising and enforcing laws, regulations and incentives-is inherently normative. To the extent that policies imply there is a right way of doing a particular thing, and imposes that decision on society, it is an irreducibly modernist undertaking.

\section{Role of Economists}

According to Nelson (1987), the role of the economist in policy debates during the twentieth century has evolved through three distinct stages. At the turn of the century the economist was seen as a Progressive Neutral Expert (52). The progressive outlook reflected confidence in science and human progress, so the economist was seen as being a value-neutral scientist or technician, providing advice on the means of implementing policy that would fulfil society's chosen ends. This reflected both a dichotomy between politics and administration, and a precedence of one over the other.

By mid-century, the political process came to be seen not as a rational pursuit of a unified public good but a contest, or a process of bargaining, among competing interest groups. The economist became an Entrepreneur for Efficiency, whose role had a noble purpose:

$9 \quad$ This idea is explicated below, in the section titled "Error! Reference source not found.”, page

Error! Bookmark not defined. 
“...as spokesmen for the diffuse and otherwise weakly represented interests of the general citizenry, acting as a counterweight to the pervasive special interest pressures exerted by the beneficiaries of particular government programs.”(55)

This translated into an increasing concern for allocative efficiency and support for the consumer sovereignty. Economists also had to become more skilled as policy advocates, finding allies and building coalitions of support for their view (56).

Alongside this change in practice, there emerged significant challenges to the progressive belief in scientific rationality, from libertarians and environmentalists. The libertarians such as Hayek $(1945,1952)$ saw the technocratic states created by Hitler and Stalin as the logical outcome of applying scientific rationality to social organisation. Hayek's ideas were not popular immediately after the war, but began to gain favour in the late 1970's, as the problems associated with Keynesian economic management became evident. Environmentalists were also expressing scepticism in the value to humanity of science and technology. In response to these challenges, economists had to become Ideological Combatants, as Nelson puts it:

"Because ideological debate has played a greater role in public policy making, economists have been pressed to assume a new role, as defenders of economic ideas against ideological attacks.” (57)

While Nelson portrays American economists as resisting the Hayek's critique of central planning, in New Zealand the opposite was true. Libertarian ideals provided a tonic to those dismayed by Muldoon's economic management style, and Treasury economists (in particular) can be seen as Ideological Combatants in favour of Hayek's ideas.

At the end of his article, Nelson argues that for economists to become more effective proponents of the perspectives that economics has to offer the policy process, they need to be both less rigidly ideological in their approach, and more persuasive in their presentation. (86)

Since Nelson's article was published, there has been a lively if somewhat limited debate on this issue in the economic literature, which first gained prominence with Donald McCloskey's The Rhetoric of Economics (1986).$^{10}$ He says that, if economists need to present their ideas persuasively, they should apply disciplines such as the art of classical rhetoric. McCloskey has met with disapproval from those, such as Rosenberg (1988), who treat economic theory as a body of scientific knowledge, modelling their mode of enquiry on Physics. According to Throgmorton (1991: 158), they "...do not think of their talk as 'rhetoric'. Defining themselves as objective researchers who let the facts speak for themselves, they are 'anti-rhetoricians' who consciously try to expurgate their discourse of unproductive stylistic flourishes."

At times, McCloskey appears to support a post-modern approach. For instance, he believes it is an error to teach economics as a canon of immutable principles. Rather, it should be taught as an ongoing conversation:

10 A useful overview of the arguments about economic rhetoric can be found in Klamer et al. (1988) 
“...the way we teach is the way we think.... It is hardest of all to teach how to argue like an economist, that is, to enter into the conversation of the field. Students come to think of the formal economics as the economics; when they teach others they teach by theorem and 'observable implication' rather than by argument and figure of speech. Modernism breeds modernism.” (178-179)

Some may interpret statements like this as a claim that economics is ideologically biased and an exhortation to economists to deconstruct their rhetoric in order to be more self-conscious of its ideological content. However, that is probably going too far. McCloskey follows Marshall (1961 [1898]), seeing economic theory as a toolbox of concepts from which one chooses the appropriate elements to analyse a policy problem and argue for or against a policy accordingly. These tools are:

“... economic theory in its verbal and mathematical forms, statistical theory and practice, familiarity with certain accounting conventions and statistical sources, and a background of stylized historical fact and worldly experience. The use of such tools to fashion sturdy little arguments is the métier of the economist, the economist's method.” (24)

McCloskey also states the values appropriate for employing these tools: the economist must be self-conscious about the social and historical context of the analysis, careful to explain the use of simplifying assumptions and, most of all, considerate of the needs of its audience and other points of view:

“..at the peak of scholarly enterprise, stand the conversational norms of civilization. The German philosopher Jürgen Habermas and his tradition call these Sprachethik.... Don't lie; pay attention; don't sneer; cooperate; don't shout; let other people talk; be open-minded; explain yourself when asked; don't resort to violence or conspiracy in aid of your ideas. We cannot imagine good conversation or good intellectual life deficient in these.”(24)

So McCloskey is not 'deconstructing' economics, but defending it, and possibly seeking to rescue it from the ridicule and disparagement that any discipline deserves when applied dogmatically and without self-conscious awareness of the values and beliefs which it entails.

\section{Economics and Media Effects}

Other social sciences have given inconclusive answers to the question of whether the media is influential, and in which ways it influences behaviour. What could economics contribute to this debate?

One of the "sturdy little arguments" of economics provides a straightforward answer: the existence of a multi-billion dollar global advertising and public relations industry indicates that it is the collective view, of a great number of rational economic actors, that the media is influential. Also, that it is influential across different times and different cultures.

The economic idea underlying this is that if a product or service is not effective, the market will not provide it. Rational consumers may act mistakenly, in the short-term, and the market will therefore provide some products of little or no value. However, consumers will learn from their mistakes, and therefore act rationally in the long-term. A product or service that is valuable will therefore persist in the market. 
The advertising, marketing and public relations industries seek to influence attitudes and behaviours. They have not merely persisted for the greater part of this century but rapidly grown in size and scope. This indicates either that a great number of people have been systematically mistaken for a very long period of time, or that the media does effectively influence peoples' attitudes, beliefs and behaviours.

This is a simple argument, built on one observable "stylised fact" and a highly plausible assumption about human behaviour. It doesn't tell us a great deal about how media influences behaviour, or what policy responses might be appropriate. But it does help us to unequivocally state that media effects exist and they are influential.

\section{An approach to "method"}

We began this chapter by asking how we might use a variety of ideas and discourses to talk about broadcasting policy. There is no philosophical or theoretical framework that stands over and above all of these ideas, approaches and discourses that represents a methodological approach. McCloskey has proposed, however, that there may be an ethical approach.

The purpose of this thesis is to investigate the manner in which Treasury used economic theory in its submission to the RCBRT, and whether or not Treasury's arguments in favour of deregulation were an honestly explained and thoughtfully applied use of the tools that economics provides. In doing this, it seeks to treat the economic theory of broadcasting as a conversation, and often a debate, about matters of policy, situated in particular social and historical contexts. Where possible, therefore, specific examples from the New Zealand situation have been used to illustrate the economic ideas.

This thesis is also intentionally didactic. That is, it assumes the reader has little more than a passing knowledge of broadcasting policy, the broadcasting industry, economics, political science or public administration. The intention is to lead readers through the analysis in such a way that they can understand the key policy issues and they will therefore be empowered to engage in debate about them. This might be understood as a means of overcoming some of the bounded rationality of the participants in a policy debate, and making possible a form of active mediation between competing ideologies and interests.

Finally, in the closing chapters, this thesis seeks to persuade the reader that a particular course of action is desirable. To that extent, it is explicitly rhetorical - although it aims to be transparently so. The method of this thesis therefore resides in its style and the structure of its exposition. It is an attempt to create a transparent analysis employing a range of discourses that all bear significantly on the policy issues at hand. 


\section{Chapter $4 \quad$ Social and Political Context}

The changes made to broadcasting policy in the 1980s were part of a broader process of change in New Zealand society and have to be understood in that context. This chapter describes New Zealand before, during and after the reforms of the 1984-1990 Labour Governments.

\section{New Zealand before the Reforms}

This section reviews three perspectives on New Zealand society and its economy in the period leading up to the reforms of the fourth Labour Government. The picture presented here consists of three glimpses, written by commentators who provide viewpoints that can be described as Liberal, Conservative and Marxist. None of these completely captures the period, but each illuminates different aspects of it.

Austin Mitchell captures the essence of New Zealand society in this era, in his affectionate and satirical book The Half-Gallon Quarter Acre Pavlova Paradise (1972). His portrait of the New Zealand economy demonstrates the accuracy of his observation:

"Since there are three million New Zealanders, not just the 100,000 which economic logic would dictate, they have taken the protective measure of building a fence of tariffs and licenses around the economy so that a pampered industry can develop” (29)

He goes on to say that New Zealand's industrial and service sectors existed primarily to redistribute the wealth created by the agricultural sector "Agricultural exports provide enough for all to live on...(therefore) Industry exists not to make things, but to make work." (32) The situation was untenable, in economic theory, but it produced the outcomes New Zealanders sought:

"Being practical men, New Zealanders are not concerned with hypothetical questions such as would Adam Smith or even Robert McNamara, approve of our economy, but does it work? It does. The people have jobs, a good standard of living, a car and a lovely home each.... They are not concerned with the problem of whether the system could work better.... (it) works so well and has made the inhabitants so contented that they are the world's most stable, and probably most conservative society.”(32)

In The Quiet Revolution, Colin James (1986) paints a picture of New Zealand society as essentially individualist, in which people use the state to pursue individual or narrow sectoral ambition:

“...the dominant 'idea' of how society should run in European New Zealand, that is, majority New Zealand, has been...individualist.... This is not the rugged individualism of frontier myths. It is a defensive individualism of getting for oneself a good and secure share of the fruits of the economy, keeping that share for oneself, and using the state to make life easy by removing the vicissitudes of economic life.”(14)

"New Zealanders have been by and large for more state spending on things they have seen themselves benefiting from: free education for their children, free medical care, subsidised housing and a pension at the end of the day. But they 
have been much less enthusiastic about social welfare spending: the unemployed have been frequently seen as layabouts who don't want to work; solo mothers have been seen as either irresponsible in getting pregnant or having too lightly skipped their marriage.”(15)

According to James, New Zealanders join groups to serve their individuals interests. The National Party has owed its success to its contact with groups such as the Manufacturers Federation, Federated Farmers, Chambers of Commerce and down into the less formal groups such as sports clubs and service organisations. By contrast, Labour's social links have always been weaker and more fragmented, as the minority ideology of collectivism has less legitimacy in New Zealand. Its bases have been in Māoridom, in the collectivism of the women's movement of the 1970's and 80's and in the union movement. ${ }^{11}$

In Behind the Mirror Glass Bruce Jesson (1987) paints a different picture of the roots of New Zealand's supposed egalitarianism. We have a class structure; it was, however, different to that which Wakefield had sought to export from England: "Social class in New Zealand has been stripped of the trivia of heredity and status and reduced to its barest essential: economics”(11). The rapidity of change in New Zealand during the 1980 's was due to delayed change. The disintegration of the British Empire after World War II was not much discussed in New Zealand, and we carried on as if nothing had changed. Jesson attributes this to an external focus: the baby boom generation protested against Apartheid in South Africa or the Vietnam War, they didn't apply their critiques to New Zealand society itself:

"Our political landscape was marked by the things that weren't there. There wasn't a politically conscious union movement. There wasn't an intellectual tradition of critical enquiry. There wasn't even an intelligent conservatism.”(9)

These three commentators, taken together, paint a picture of a stable, contented and pragmatic society.

To understand how this stability was achieved and sustained, we will use a model borrowed from management literature on strategic planning. Its premise is that an organisation that successfully achieves its mission and strategy must create this "congruence" among its organisational mission, leadership, critical tasks, human resources policies, business processes and organisational culture. The model presented in Figure 2, below appears in Tushman and O'Reilly (1997: 59). It shows how an organisation's strategic choices may be distilled into a few critical tasks, which determine the rest of the structure. Decisions must be made about the people required for those tasks, the formal organisational structure that will support them, and the organisational culture required for achieving them. Finally, the component elements are tested for congruence: people with culture, people with processes, and processes with culture.

11 It could be argued that ideological collectivism in the unions has resided in the unions' hierarchies, more so than in the rank and file. 
The key roles of executive leadership (as opposed to simply "management") are to make strategic choices, define the critical tasks, and create a strong organisational culture.

\section{Figure 2: A Congruence Model of Organisational Policy}

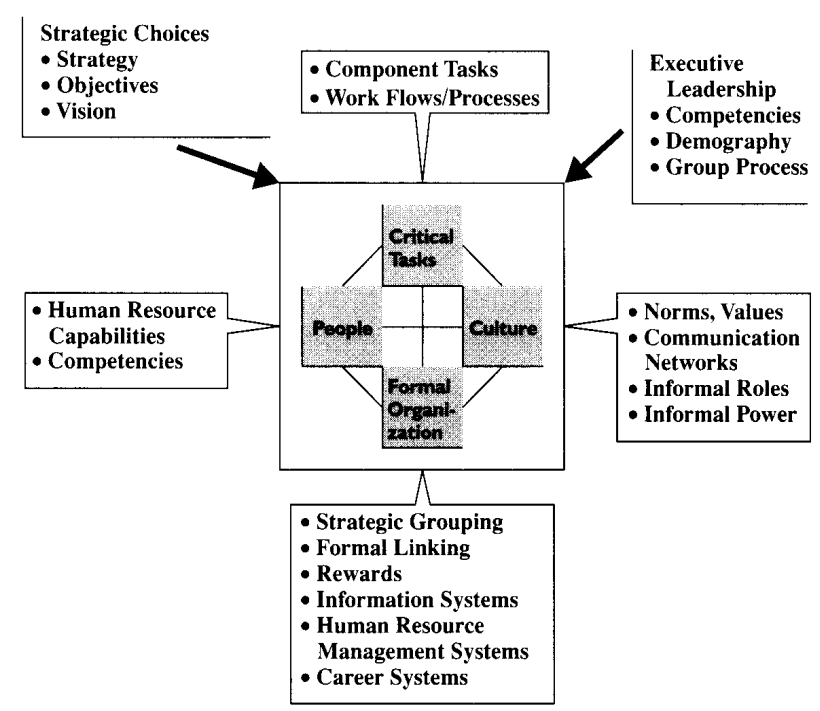

This model can be adapted to provide a way look for congruence in social and political change, and the integration of cultural policies, including broadcasting policy, within a strategic policy context. ${ }^{12}$

The Figure 3, below, shows the policy congruence that emerged and became prevalent in New Zealand between World War II and the early 1980s.

- Critical Tasks: Our critical task was to obtain social and economic security. This included full employment and a welfare state for the labouring classes; regulated privileges and guaranteed returns to capital. One could say this bred a "claimant" culture for both workers and capitalists.

- Law and Economy: The economy was regulated to deliver security to workers via full employment policies, a labour market based on regulated wage rounds and arbitration and universal entitlements to welfare. It provided security to local and British investors via regulation that provided economic privileges and guaranteed returns. A large public sector allowed the government to use fiscal policy to manage domestic demand.

- People: Policies that affect reproduction, immigration, education and health determine who we are: our society's "human resources". Policies tended to favour the white, male over Maori and women. The congruence fits with popular culture based in mainly male pursuits, and the assumption that the male is a wage earner in a primary industry or the protected manufacturing sector.

12 For the moment, we will ignore the question of how leadership is selected and mandated, which is central to understanding this as a political model. That issue will be addressed in Chapter 9 . 
- Culture: Our cultural policies were monocultural and assimilationist. We looked to Britain and Europe for our elite culture, for which government provided limited support. Popular culture was also imported, based on English sports that were maleoriented and team-based. Racing was an industry regulated for elite privilege.

Figure 3: "Tight" congruence in Post-war policy

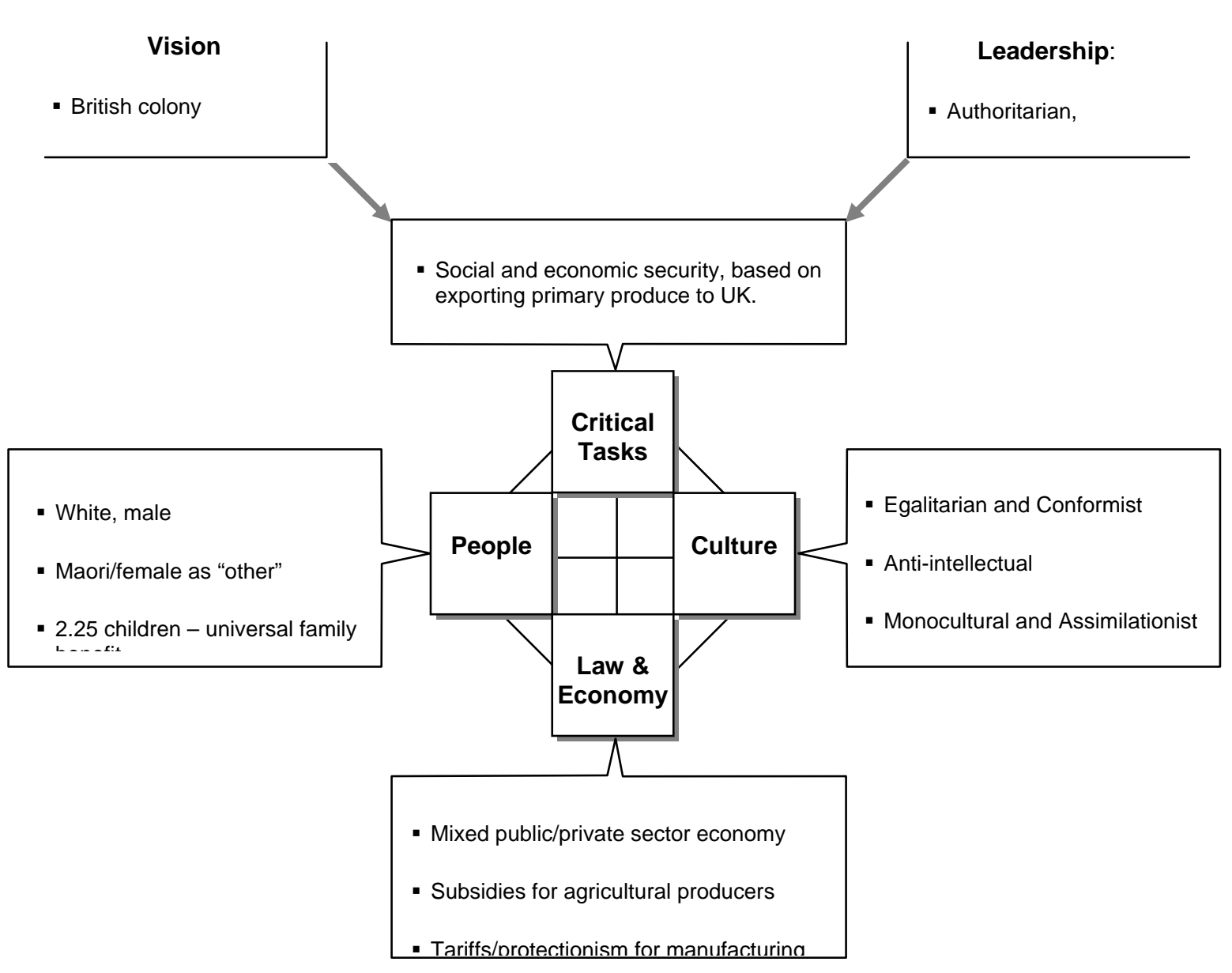

Our broadcasting system was well integrated with this model. We had a monopolistic, monocultural, state-owned broadcasting industry, providing a steady fare of either British, or BBC-styled, television and radio programming. Radio New Zealand saw its mission as being to bring high culture from the outside world to lift our aesthetic standards. The license fee was used to ensure universal coverage, in keeping with Colin James' view of New Zealanders' characteristic selfish egalitarianism. As Bruce Jesson noted, it generally provided little place for informed social and political debate. It is reasonable to claim that significant "Spiral of Silence" could be observed in New Zealand during this era.

One can see that there was a tight congruence between the elements of this policy model; each part reinforced the others. The critical tasks aligned well with the strategic vision, and the elements of policy fitted together in a mutually reinforcing manner. It was safe, secure, and monotonous. The very tightness of the model may be an 
explanatory factor in New Zealand's inability to adapt or change when change was required.

\section{Forces for Change}

The source of wealth on which New Zealand's security was founded was eroded by Europe's into the EEC, the OPEC oil shocks, and the period of global stagflation that occurred as America financed the Vietnam War with budget deficits. The economy had to diversify, which put pressure on the domestic economy and the mechanisms that regulated it (Easton, 1994b). Social movements in the 1970s-feminism and Maori activism especially - threatened the white male monoculture. In broadcasting, Radio Hauraki represented the challenge of a younger generation and a new spirit of antauthoritarianism and private enterprise.

In the years up to 1987 the government, under Sir Robert Muldoon's leadership, sought to resist or contain the forces for social change and keep the congruent model intact. Meanwhile the economy was changing around him, and with it, power relations within business the elite:

"The National government between 1975 and 1984 represented a political economy that was becoming outmoded. Maintenance of its power base required the support of an élite whose significance was diminishing with the changing economic structure, most notably pastoral farmers and associated rural and commercial interests.” (Easton 1994b: 79)

This resistance to economic change was characterised by and the 1984-86 wage and price freeze, and to social change by the events surrounding the 1981 Springbok tour. According to Jesson (1989), social liberals joined the Labour Party in droves, during the lead up to the 1984 election, specifically to unseat Sir Robert Muldoon. The social groups of which this cohort was comprised-the women's lobby, Māori, unions and gays had little in common. They were informed by an emotional moralism and a strong sense of social justice, but were essentially apolitical and unable to participate intelligently in economic debate. ${ }^{13}$

The Labour government came to power with a sense of urgency, and in the midst of a currency crisis. The Treasury's post-election briefing to the government, titled Economic Management (1984) was a blueprint for wide-ranging change, which would destroy the familiar institutions of the existing order. Although Jesson was scathing about the free-market philosophy embodied in Treasury's advice, he acknowledged that the prevailing economic conditions lent considerable power to arguments is favour of free-market policies:

"The strongest arguments for the free-market policies are actually the negative ones. We couldn't continue subsidising agriculture and forestry, protecting inefficient industries, maintaining an unrealistic exchange rate. We couldn't run up enormous overseas debts to maintain our traditional way of life. We couldn't continue with policies of ad hoc interventions. Our economy had to be reconstructed, and New Zealand had to change.”(Jesson, 1987: 6)

13 Jesson may be implying that these members of the Labour Party were uninformed by a coherent political theory, such as Marxism. 
For Jesson, periods of economic and social reform in New Zealand were historically characterised by conflict between reforming governments and the incumbent social and business elite. Out of these phases of conflict, new economic development and growth had occurred. The reforms of the 1980's were different, as business moved in unison with government.

Colin James (1986) presented the revolution as driven largely by the events of demographic, historical and economic cycles. James proposes that change in New Zealand society occurs every second generation, and at a time when the social status quo is experiencing social and economic tensions. This leads to the emergence of a "big change generation” which wields influence as it comes into its late 30's - mid 40's:

"Michael Moore, socialist Cabinet minister, and Michael Fay, free-enterprise merchant banker, have enormously different ideologies. But they get on famously together. They like each other's enthusiasm and delight in new ideas. Rob Campbell, socialist union leader and Labour Party executive member, and Ron Brierley, international investment capitalist, gravitate naturally towards each other in a room, all smiles and animated conversation. All four are part of a revolution.... It is not the policy content of Rogernomics that is the revolution. It is the sharp change of attitude it reflects, represents and stimulates.” (165)

Jesson takes a less benign view of these relationships, noting that soon after the 1984 election power shifted, within the government “...to a small group of hard-line rightwingers in Treasury, the Reserve bank, business and some university departments. In a country as small and claustrophobic as New Zealand it is easy for a network of contacts to develop and for a common purpose to form" (10). That common purpose was built around a philosophy of free-market reform, which he calls “...the philosophy of acquisitive individualism, the belief that the moving force in society is or should be selfinterest.”(120)

In 1989, Professor Richard Mulgan gave a public lecture at Auckland University. ${ }^{14}$ His topic was the way in which the1984 Labour Government married the social liberalism of its party members to the neo-liberal theory of the free market. Labour's social-liberal emphasis on individual rights was expressed in policies such as homosexual law reform. It captured the women's vote on issues such as health and women's rights against the power of the medical establishment. The rhetoric of devolution appealed to Māori. The economic-liberal theory of the free market promised economic growth and the creation of greater wealth for all to share. The enduring image of Labour's promise in those years is the promise that it could deliver both equity and efficiency: social autonomy and economic security, nurtured at the breast of capitalism. Mulgan's lecture also noted the curious lack of an overarching vision in the reforms:

“..if one looks back to Seddon and Savage one sees they articulated, in however general and idealistic a form, a vision of where their reforms were leading. When one looks to the present government, however, and to those who support its programme, one usually searches in vain for their vision of who we are or where we are going.”

14 The lecture was titled "The New Radicalism", reported in the NZ Herald, as "Socialism lure dimmed by rival from right”; 8 June 1989, pg 2. Professor Mulgan kindly supplied the author with a copy of his speech notes. 
The new model of policy presented in Figure 4 demonstrates the comprehensive nature of the transformation, when compared with the previous policy framework presented in Figure 3. The vision of a "neutral state" represents the deliberate absence of political or social leadership.

Figure 4: Labour's Vision and Policy, 1984-1990

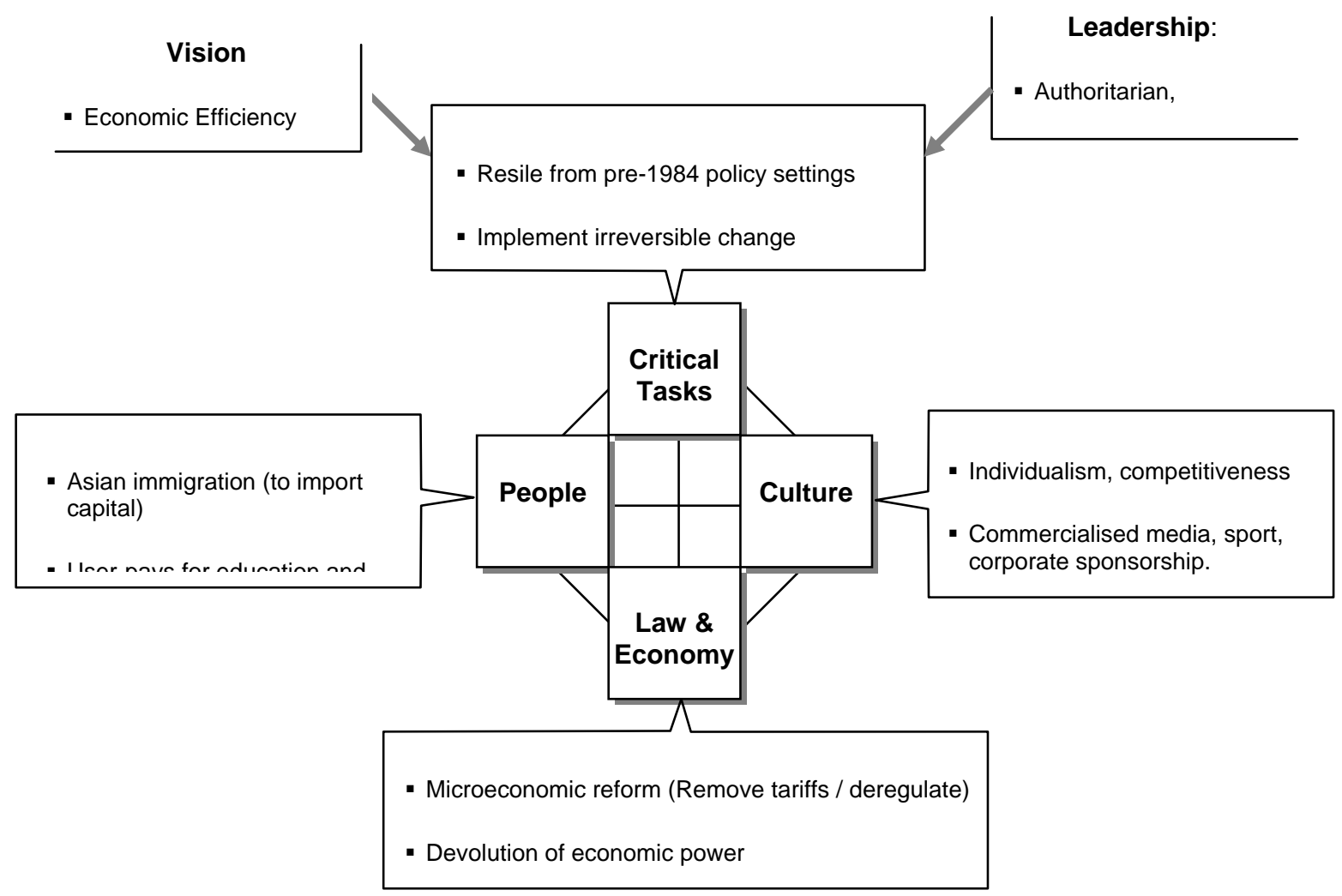

The pursuit of economic efficiency dominated the agenda, as did the critical task of addressing the Government deficit by introducing widespread microeconomic reform and implementing irreversible change. To a lesser extent, Labour's social liberals introduced policies that provided greater rights for Māori, women and other groups such as homosexuals.

While social liberal policies changed the social and political position of Maori and women, these benefits accrued predominantly to the upper and middle classes. Microeconomic reform devastated the lives of working class Māori, who were thrown out of work in thousands as jobs were stripped out of protected industries and inefficient state-owned enterprises. Targeted entitlements reduced women's access to childcare and other services. Women also suffered job losses and reduction in household income as lower skilled jobs were stripped out of the economy.

Immigration policy did not change significantly under Labour, but subsequently under National was altered in favour of immigrants able to import capital. Wealth, rather than skill, education or ethnicity, became the primary criterion for citizenship. 
The cultural picture became confused, as conflicting images of New Zealand society were promoted by different elite segments. The Government promoted biculturalism, and to a lesser extent multiculturalism, which was picked up and promoted by the churches, teachers and other traditionally social liberal groupings. The media, especially the business press, promoted an image of competitive individualism, and the pursuit of self-interest as a social virtue. The corporate world gave us sponsorship and advertising appeared all over the All Blacks and virtually anything else that moved.

The model established under Labour does not require significant modification to represent the years 1990 to 1999. The National government from 1990 to 1993, removed social equity from the agenda and focused almost exclusively on continuing the drive for economic efficiency. Since the introduction of MMP, National's coalition partners have reintroduced other concerns to the policy agenda, but these have tended to be issue-specific and marginal. There is no sense that the coalition is bound together by an overarching or common vision for New Zealand society.

\section{Intimacy and Dictatorship}

In order to introduce rapid and irreversible microeconomic reform, the Cabinet particularly members of Labour's Cabinet Policy Committee - dominated the Caucus and largely ignored the desires and protests of the Labour Party rank and file. To understand how the changes were introduced, it is necessary to understand some characteristics of New Zealand's political environment.

Much has been written about the "intimate" nature of politics in New Zealand. Paul Harris (1995) identifies 14 separate articles or books in which this idea of political intimacy has appeared. He is critical of the notion that this idea of political intimacy refers to a close relationship between citizens and their elected representatives. He does, however, propose that:

“...a small polity may give rise to an intimate politics at another level. If a small country is likely to have a small political elite, it may be likely that the relationships within this elite will exhibit intimacy, whether or not intimacy also exists in citizen-representative relationships. Evidence pointing to an intimate political elite might include its size, social composition, ideological coherence, the social networks that exist within it, and its ability and willingness to act in a unified way on various issues.”(9)

The key to understanding the notion of intimacy in New Zealand politics, and how that intimacy affects the political process, is entailed in what Mulgan (1992a) refers to as New Zealand's “Elective Dictatorship”. The term dictatorship, when used to condemn, is levelled at governments that "... are unlimited in their power. Like the dictators of old, they are above the law and the constitution, free to act at will or according to whim" (513). While this is not the actual case in New Zealand, our constitutional arrangements lend themselves to the domination of Parliament by the Government, of Government by Cabinet, and in some eras, of the Cabinet by a single individual or a small group of cabinet ministers (Palmer, 1987).

The Cabinet, as the source of executive power and controller of the legislative programme, is the source of power in the New Zealand system. Without the legal or structural restraints of a written constitution, an entrenched Bill of Rights, or an upper house, the primary restraint on the power of cabinet is political influence. This may take the form of a concern for public opinion or the direct influence of other political parties-especially in a coalition government. 
If the government has a clear majority in Parliament and a strong cabinet, then one of these restraints is removed. If it shows little regard for public opinion, and acts to implement its programme without consultation and persuasion, then it may be deemed to be acting as a dictatorship. Mulgan (1992b) claims this is how the 1984-1990 Labour Governments and the subsequent National Government acted:

"Public opposition, expressed through traditional political channels, such as interest groups or party rank and file, is treated with disdain.... (Jim Bolger and his colleagues) like Labour before them, have allowed themselves to accept a view of politics which treats such disdain not as dishonest but as positively courageous and public-spirited.

"According to this view, government is a complex, serious business which must be entrusted to the public policy elite, to ministers and their expert advisers. These decisionmakers must not be deflected by 'political' influences from the wider public or by obviously foolish commitments made on the hustings. Such ideas permeate the corridors of power and the businessmen's clubs. They are the political theory which went with Rogernomics'Rogerpolitics'.”(16)

Atkinson (1989) claims there was a shift away from the intimacy of pre-reform politics, represented by National's close connection to its constituencies through service groups and clubs, toward a more professional style of political mediation. This new style employed survey research companies to gauge public response to policy initiatives and public relations consultants to market policies appropriately. Atkinson claims the "mediation" between government and governed thus became remoter, and less democratic, than it had been.

The intimacy among a small elite persisted, however. Goldfinch (1998) undertook a survey of business and political leaders thought to be likely to influence economic policymaking. They were asked to nominate individuals thought to be influential in a number of economic policy decisions during 1984-93. The study identifies a number of key policy initiatives and the individuals most closely associated with them from Parliament, the public service and private enterprise. The group is surprisingly small, and Goldfinch attributes this to the smallness of New Zealand society and the simplicity of its political institutions:

“...the key to understanding the New Zealand experience is to see economic policy-making dominated by a small number of key members of institutional elites largely from the Treasury, Cabinet, the Reserve Bank and the Business Roundtable.” (178)

These individuals are identified in Goldfinch's study, along with the specific policy initiatives they were influential in implementing. The final table in the article is reproduced below, with the names of public officials highlighted. The table highlights the number of government officials who were deemed by their peers to have been influential in designing and implementing key reforms. Of the 30 individuals named, 16 were public officials, 11 were politicians, and the remaining 3 were from the private sector. $^{15}$

15 Note that among the most influential of the officials is Pat Duignan, who played a significant part in the broadcasting reforms. According to Cocker (1996), Duignan was “...credited by (Doug) Andrew as being the co-author of the 1984 Treasury document for the incoming Labour government entitled Economic Management.”(183) He later worked on Treasury’s submission to the RCBRT, 
Figure 5 : Officials Influential in 1980's policy reform

PERSONS WITH INFLUENCE OVER SELECTED ECONOMIC POLICY
DECISIONS 1984-93

\begin{tabular}{lllll}
\hline 2 Decisions & 3 Decisions & 4 Decisions & 5 Decisions & $6+$ \\
\hline Birch & Andrew & Duignan & Caygill & Kerr \\
Bolger & De Cleene & Trotter & Deane & Scott \\
Cameron & Fancy & Wilkinson & Douglas & \\
Chetwin & Gibbs & & Lange & \\
Jones & McKenzie & & Myers & \\
Galvin & Richardson & & Palmer & \\
Marshall & & Prebble & \\
Martin & & & \\
Rodger, Stan & & & & \\
Russell & & & & \\
Stockdill & & & \\
Zohrab & & & \\
\hline
\end{tabular}

How was it possible that New Zealand could have such an intimate, elite "dictatorship"? According to Mulgan (1992a), the term "dictatorship" has not always been used pejoratively:

"Dictatorship, of course, was once an honourable calling. The original dictators of the early Roman Republic were usually elder statesmen or generals called on to save the state in a time of military or constitutional crisis. They held unlimited power subject to no appeal or veto, but the office was temporary, often lasting no more than half a year.” (513)

New Zealanders' acceptance of a benign authoritarianism is reflected in Bob Gregory's (1979) notion of an "overhead democracy":

"A new era of social unity was to be born out of the bitterness and conflict of the depression; Savage, the Minister in Charge of Broadcasting, was also an immensely popular Prime Minister, something of a political messiah who, it could be seen, was rightfully using radio to point his many followers in the direction of the promised land. Radio was thus instrumental in a New Zealand system of 'overhead democracy'. Far from this being a sinister use of an important public utility, it was - in terms of the public mood of the timean integral element in a revitalised crusade of state-led nation-building.” (47)

Thus, dictatorship may not be perceived by the public to be necessarily bad, if it represents leadership around a core set of social values. It could be argued that New Zealand's elective dictatorship enjoyed exactly this sort of popular support, or at least acquiescence, from Savage's era until Muldoon's. This may also help explain the ease

and was also a member of the Rennie Committee, which planned the corporatisation of the Broadcasting Corporation. 
with which New Zealand abandoned its upper house of Parliament in 1950, and the failure of the political system to evolve other checks and balances on executive power.

\section{Summary}

The congruence among New Zealand's strategy, critical tasks and policy settings in the post-war years led it to be regarded as one of the most satisfied, well-ordered countries in the world. New Zealanders' faith in their political leadership perhaps explained the erosion of a truly democratic polity and the emergence of an elective dictatorship. The tight congruence of policy and an elective dictatorship meant New Zealand was slow to implement economic change, when external forces required it, or respond to social change emerging from within.

When the congruent model finally came under too much pressure to resist change, the lack of checks and balances, and the way an "intimate" elite can wield enormous power in New Zealand policy environment, were critically important elements to the reform process.

It is arguable that New Zealand's political traditions and institutions are ill-suited to the challenges of leading an increasingly diverse economy, a multicultural society and a parliament elected by proportional representation. Perhaps this also explains why the post-reform policy framework reflects the emptiness of vision that lies at the heart of the 'neutral state' concept. 


\section{Chapter $5 \quad$ Broadcasting Policy}

This chapter outlines some of New Zealand's broadcasting institutions immediately prior to deregulation, including the Broadcasting Tribunal (especially in regard to the third television channel warrant hearings) and the Royal Commission on Broadcasting and Related Telecommunications (RCBRT).

We then explore events that played an important part in creating the new broadcasting policy framework, including the process that saw the RCBRT report dismissed in favour of the policy outlined in Treasury's submission.

\section{The BCNZ}

The BCNZ has emerged out of the NZBC, and before that the NZBS - which had been a full government department under Ministerial control (Gregory, 1985). In the mideighties the BCNZ was a relatively independent Corporation, established under the Broadcasting Act 1979, although it clearly displayed vestiges of its previous incarnations.

\section{The Broadcasting Tribunal}

The movement away from monopolistic state broadcasting began when Radio Hauraki commenced broadcasting from a boat outside the territorial limit. Unable to resist the pressure for private commercial radio, the government eventually introduced the Broadcasting Act 1976, which opened up the industry to limited private competition. Applicants for broadcasting licenses had to appear before the Broadcasting Tribunal and plead a case that, among other things:

- there was a public need for their proposed service, ${ }^{16}$ and

- that the service would be financially viable. ${ }^{17}$

After a warrant had been granted, a radio station could not easily change its programming to meet changing audience needs. If it had originally proposed a talkback

16 Section 80 provided for the Tribunal to have regard to “(a) The extent to which the proposed service is desirable in the public interest:... (b) the needs of New Zealand or the locality or localities proposed to be served, in respect of broadcasting services:... (h) the requirement that frequencies be best utilised in the public interest:”

17 Section 80 (b) stated that "[in considering any application for a warrant, the Tribunal shall have regard to] ..the economic effect which the establishment of the station... is likely to have in respect of broadcasting stations already in operation.” Section 80 (c) makes similar provisions for the BCNZ specifically. 
format, or a music format, or a programme to serve a particular age group, for instance, it had to apply to the Broadcasting Tribunal for permission to change its programming.

The economic role of regulatory agencies is theorised in Owen and Braeutigam's (1987) The Regulation Game. It makes an interesting and useful basis for analysing the role of the Broadcasting Tribunal. It is generally assumed that a regulatory agency fulfils a role as an "agent" of the public. However, a regulatory agency may also act in the interests of the industry it regulates. This is sometimes described as industry "capture", of which there are two varieties: In the first, agencies are established to guard the public interest, but become the captured by the industry they regulate. In the second, an agency is created explicitly to serve as a cartel manager for the industry.

It could be argued that the Broadcasting Tribunal fulfilled the role of 'cartel manager', by restricting entry into the market, ensuring incumbent broadcasters were faced with minimal competition and could produce monopoly "rents". However, the roles of public agent and cartel manager appeared to entail a quid pro quo. The Tribunal also protected the public interest by imposing conditions on broadcasters', compelling them to provide particular programme elements such as local news. Thus, the Tribunal effectively guaranteed broadcasters' "economic rents" and captured a portion of them for the audience's benefit.

The Tribunal system produced a mix of programming deemed to suit the public's needs, and maintained the radio industry (which it predominantly regulated, TVNZ being relatively independent), in a state of profitability. Under this regime, however, some audiences weren't served at all. Māori, for instance, had virtually no access to Maori language radio apart from minor contributions on National Radio.

The Tribunal also heard complaints about broadcasts, and one of the most powerful tools at the its disposal for disciplining errant broadcasters was its ability to impose conditions on their warrants. ${ }^{18}$

\section{The Third Television Channel Hearings}

Flaws in the Tribunal system began to emerge during the Third Television Channel hearings. In 1983 the Minister of Broadcasting, Dr Ian Shearer, instructed the Tribunal to allocate four regional television warrants and a separate programme warrant for a single news and current affairs service. The hearings commenced in 1985, and a decision was made in favour of TV3 in August 1987, but not formalised until September 1988, following a High Court judicial review. While all this was going on, TVNZ was preparing to face competition; restructuring and entering into long-term

18 A trawl through the first six years of Tribunal decisions provides a potted history of New Zealand politics: there are complaints about programmes on abortion law reform, overstayers, nudists, the Springbok Tour, homosexual law reform. An indefatigable Waikato resident made numerous complaints, holding 1XW and TVNZ to account for alcohol and cigarette advertising by subterfuge (NZ Gazette, 1977 - 83). 
programme purchasing deals that would effectively restrict the range of programming available to TV3. ${ }^{19}$

Again, Owen and Braeutigam's book The Regulation Game (1978) provides useful insights:

- Administrative processes are similar to those governing courts of law. All parties must be accorded due process, and there are ample opportunities for appeal within the agency and through the courts.

- The laudable desire for procedural fairness creates opportunities for any party to impose delays and expenses on other parties.

- Under these circumstances "Strategic use of the administrative process is at least as important to many industries as the traditional decision variables: prices, entry and innovation.”(2)

The authors note that they "...have chosen to write this as a "how to" manual.”(1) The section titled Strategic Use of Litigation is particularly instructive:

"Litigation costs are usually small compared to the stakes in a regulatory decision for an established firm or industry. On the other hand they are likely to be proportionally more important to new firms, prospective entrants, and public interest advocates.... The delay which can be purchased by litigation offers an opportunity to undertake other measures to reduce or eliminate the costs of an eventual adverse decision.... The agency cannot resist the effort to delay through exhaustion of process because this would be grounds for reversal on appeal to the courts.”(4-5)

The various players in the hearings, particularly the BCNZ, might well have read the book and taken these instructions to heart. Marcia Russell, TV3's head of news and current affairs, writing in the Sunday Star, reported the outcomes:

"It would take more than two years before the decision was made. The hearings turned into a marathon of legal and technical detail and adversarial proceedings. The ensuing paper war would have stripped a rainforest; the tedium was soul destroying; the legal bills incurred by the contenders would have built another Avalon. ${ }^{20}$

"...the BCNZ withdrew its financial support from the Aotearoa Broadcasting Trust, a consortium of Maori interests ... and decided to oppose the issue of warrants.

"The ensuing barney took six months. It involved the High Court (which upheld the Tribunal's view that as a non-contender and latecomer to the proceedings, the BCNZ had forsaken its rights to present evidence) and the Court of Appeal which reversed the decision. The state corporation was permitted to present its case that no warrants be issued while the contenders sat on their hands and paid the mounting legal bills.

"It was a breathtakingly cynical tactic. And all the more astonishing for being taken by a State corporation which, by statute, was obliged to 'be mindful of government policy'." (Russell, 1990)

19 It wasn’t until the channel was sold to CanWest, a Canadian television operator with global aspirations and established programme purchasing arrangements in the North American market, that it overcame this disadvantage.

20 Literally speaking, the television network centre in Lower Hutt, since sold. 
The third channel, in a regulated environment, would have been a license to print money. It attracted powerful business and media interests who were not pleased with the slow progress through the Tribunal or the BCNZ's game-playing. While the third television channel hearings were going on, the Tribunal's other work mounted up. By 1988 it had a backlog of 10 applications for radio warrants in Auckland alone. ${ }^{21}$ The whole debacle provided a powerful impetus for the demise of the Tribunal system.

\section{The Royal Commission}

The Labour Party had promised a Royal Commission on broadcasting in the run-up to the 1984 election. One of the first acts of the incoming Government was to establish the RCBRT, by vice-regal warrant dated 4 February 1985 . Its establishment at this early stage, before the nature and direction of the Labour Government's reforms were established, proved to be an important factor in the way its recommendations were later treated.

The Royal Commission could be seen as an example of the democratic or "muddling through" style of policy-making. This is quite explicit in the introduction to the Commission's (1986) Report:

"There are two major ways in which a Commission may act. It can launch the process of major change particularly where a situational problem has become rigid or intractable. Or it can make many and connected recommendations for the repair and better conduct of a situation which is under strain and faces change for other reasons to which it requires to adapt quickly on the basis of familiar institutions."

"It is hoped that as a Commission our recommendations will be recognised as the second kind.”(17)

What was missing from the Commission's approach was a clearly and explicitly stated framework or overall philosophy. The preamble to the Terms of Reference did state that the Commission should report on:

“...what changes are necessary or desirable to use in an economically efficient manner those advances in technology which fit New Zealand's circumstances and resources, to widen the choice, and improve the quality, of programmes, to secure independence, depth, and impartiality in news and current affairs programmes, and to reflect New Zealand's cultural and social variety so that the structure and resources of broadcasting may be better organised to serve all New Zealanders...” (8)

And indeed, the RCBRT's report is an attempt to respond to this exhortation. However, it did not grasp the opportunity to clarify and reinforce the meaning of this guiding statement, nor to directly relate its plethora of individual recommendations to it and so produce a more coherent and compelling set of findings. On the other hand, the Commission's Terms of Reference left little scope for a more comprehensive or strategic approach: they contained nine clauses with forty-one sub-clauses, mostly on matters specific to the existing broadcasting policy framework. Within the confines of these Terms of Reference, the Commission was more or less bound to only consider a

21 “Backlog led to Radio Decision” NZ Herald, 21 May, 1988: 5 
raft of relatively minor adjustments to the existing system, rather than a wholesale review.

This was unfortunate; by the time the RCBRT was ready to receive submissions in July 1985, the structural economic reforms introduced by the Labour Government had gained considerable momentum. The thrust toward deregulation and of the economy and commercialisation of SOEs was reflected in Treasury's submission, which was presented in September that year. The Treasury submission contained three major proposals:

1. That the radio frequency spectrum should be allocated by a market mechanism, rather than by regulatory agency.

2. That the government's social and cultural objectives in broadcasting should be achieved by government agencies contracting directly with broadcasters.

3. That the BCNZ should not be obliged to fulfil non-commercial objectives, and should have no advantage or disadvantage relative to private sector broadcasters

The RCBRT showed some interest in the first of these proposals, and suggested that it be grafted on to the role of the Broadcasting Tribunal. Competitive tendering would only take place after the Tribunal had decided on the nature of the service to be provided and the appropriateness of the potential tenderers (257-258). It dismissed the second proposal, on the grounds that it would “...represent a radical step back towards direct government control of a sector of broadcast programming more complete than anything in our past"(104). ${ }^{22}$ The Commission was sympathetic toward the third proposal, saying it understood “...Treasury's desire to clarify, define and differentiate the public service from the commercial side of television” (104). However, it decided that to do this would be an attempt to "... unbundle the unbundleable..." (105). To the Commission, the social objectives of broadcasting policy, as set out in the preamble to the Commission's Terms of Reference, were inseparable from the BCNZ's social objectives. The issues of funding and commercial transparency entered the picture only as a means to improve the efficiency and accountability of the Corporation.

Finally, the Commission explicitly rejected the concept - which crucially underpinned the Treasury proposal - that a free commercial market would naturally provide for these objectives, in response to consumer demand (254). ${ }^{23}$

It was clear that the RCBRT was not well prepared to hear an in-depth discussion of the application of economic theory to broadcasting, saying “...felt it was unable to make economic recommendations.... Instead (it) concentrated on a structure which was more concerned with protecting the political integrity of the public broadcasting system in terms of the existing arrangements” (Easton, 1990: 286). Although the Treasury submission was not well received by the RCBRT, and officials apparently had a torrid

22 However, government departments do now pursue social policy objectives, such as road safety campaigns, by advertising on radio and television. The concept of "social marketing" has recently emerged to support this type of activity (Kotler and Roberto, 1989; Andreasen, 1995).

23

The RCBRT's rejection is quoted in the conclusions to Chapter 6. 
time under cross-examination (Easton, 1990), it was later to become the basis of New Zealand's broadcasting policy framework. As Cocker noted:

“Although in Andrew's view the submission 'needed considerable more work done on it', it is notable that nearly all the conclusions of the Treasury case were to become key components of the legislation reforming broadcasting four years later.” (1996: 167) ${ }^{24}$

One commissioner, Laurie Cameron, wrote an Addendum to the main report, which appeared to be in agreement with the thrust of the Treasury argument. In this, he:

- Agreed with the idea of frequency allocation by competitive tendering.

- Agreed that the BCNZ's commercial and non-commercial activities should be separated, but not with the idea of making the BCNZ wholly commercial. Instead, he proposed that "...serious consideration should be given to the option of dedicating one television channel solely to public service television broadcasting” (453).

- Proposed that the BCNZ's “...non-commercial functions should be determined by a separate body - trustee-whose role is to apply the available funds to public service broadcasting"(453). In this respect, he was promoting the idea of greater transparency and accountability in the use of the public broadcasting fee.

This did not amount to full support for the fundamental assumptions presented in the Treasury submission, particularly those which proposed that the market would provide the bulk of socially desirable outcomes, while the government would fund explicit social objectives.

Cameron recalls that he wrote the addendum in one night, starting at 6 p.m. and working until 8:15 the next morning. ${ }^{25} \mathrm{He}$ had discovered that, although he had written extensive notes for the researchers drafting the report, the Commission was not intending to examine the economic issues raised by Treasury. The chairman of the Commission was, according to Brian Easton, “...concerned to keep the broadcasting system publicly accountable but out of the hands of the politicians.” (1987: 59) Cameron wrote to Brian Easton explained his reasons for writing the addendum:

"My concern was really that, if the Commission's report did not, at least, examine and discuss alternatives, other parties... would (do so) and, as a consequence, much of what is good in the overall Report would not be recognised.

“...I firmly believed it was the future as discussed by yourself and the Treasury officials, which would decide in the long term, the organisational and financial structures of broadcasting in New Zealand.

“...the limited time did not allow me to explain and express what I believed was essential to safeguard public service broadcasting which I feel is a democratic imperative in a society as complex as it is in New Zealand today.

"I also concluded that this democratic imperative could not be serviced by a commercial broadcasting system efficiently serving a marketing role in, what will be in the future, a

\footnotetext{
24 The internal quote is from an interview between Cocker and Doug Andrew at Treasury, on 14 March, 1994.

25 Telephone conversation, 8 June 1999.
} 
highly commercial and unregulated competitive society.” (1987) ${ }^{26}$

Despite Cameron's intentions, his worst fears were realised; the Royal Commission's report was largely dismissed as irrelevant and officials even his addendum to justify the broadcasting reforms that were later implemented. ${ }^{27}$ As Cocker (1996) put it: "The 'Cameron Addendum' was to have political utility while the full report was condemned and ignored by the reforming politicians” (174)

The Royal Commission process was lengthy, exhaustive, exhausting, expensive and ultimately irrelevant. The Commission was established by warrant in February 1985 and finally reported in September 1986, after obtaining an extension of time to complete its report. It sat for 71 days, received 282 submissions and listened to the oral supportive evidence of 117 organisations and individuals. The complete transcript totalled 9765 pages. The final report was 518 pages, and contained 186 recommendations. The whole exercise cost close to a million dollars. Cocker (1996) claims that the process was “...perceived as the public's long promised opportunity for input into the broadcasting policy process" (173). However, in the end:

“The Royal Commission's report served only to encompass the concerns of the interested parties who had made their submissions to it and gave them the illusory comfort that the views would be heeded when policy was enacted.”(174)

The sense of disillusionment that Cocker expresses arose because the RCBRT could not place its findings within the policy direction of the Government, which had emerged over its first year in office. In particular, its Terms of Reference did not permit it to adequately address the Government's policy in regard to SOEs, set out clearly for the first time in the Economic Statement of December 1985 (Easton, 1997: 22). As a result, its policy proposals were almost totally ignored.

\section{Treasury Policy}

The broadcasting policy reforms that were implemented in 1988 owed little or nothing to the RCBRT's report, and a great deal to the Treasury submission. So much so, that Cocker was moved to state:

“... there is clear and traceable policy-making by Treasury. From its portals came the theoretical framework, the shaping of the theory into a blueprint for structural change and, with the enthusiastic support of key ministers and other elements of the public bureaucracy, the enactment of that plan into legislation. This was achieved with the minimum of disputatious debate or any sign of 'muddling through'. It can be stated without equivocation that New Zealand's broadcasting policy is Treasury policy.” (1996: 159)

This statement could be taken to imply that officials were pursuing political agenda of their own, which would be a clear breach of constitutional conventions in respect of the

26 Brian Easton supplied the author with a copy of the letter, which Laurie Cameron kindly gave permission to quote from.

27 In evidence before the High Court, in New Zealand Maori Council v. Attorney General (unreported) 
public service. It is therefore worth reviewing the events that took place between September 1986 and the establishment of the officials' review of broadcasting, which began in March 1988.

While the RCBRT hearings and the third television channel hearings were in progress, reform in the state sector was well underway. A major thrust of the public sector reforms was to remove policy advice functions from trading departments. The Broadcasting Act 1976 Act stipulated that the BCNZ should “...advise the Minister in respect of matters relating to Broadcasting”. In the mid-1980s it was not clear which, if any, government department or Ministry had authority to provide contestable advice on matters of broadcasting policy.

The Post Office had a radio regulatory branch, which monitored the use of radio frequencies and allocated frequencies for purposes other than broadcasting (which were the Broadcasting Tribunal's responsibility). As part of the restructuring of the Post Office, this regulatory function was moved to the Department of Trade and Industry, which also had responsibility for providing advice on telecommunications policy. These functions all came under the management of J.R.A. (Jim) Stevenson, as Assistant Secretary for Communications. ${ }^{28}$ At that time, the BCNZ owned a microwave transmission network, which (before the construction of a fibre-optic cable network), provided the only potential competition for Telecom's long-distance toll call market. The Broadcasting Act stipulated that this could not be used for other purposes, and this created a problem for telecommunications deregulation.

Stevenson wrote to Richard Prebble, shortly after he had been appointed Minister of Broadcasting in 1987, proposing that telecommunications and radio regulatory policy should be reviewed together, as the biggest bottleneck to telecommunications deregulation was the availability of radio spectrum for non-broadcast purposes. He also proposed that Treasury and the Department of Trade and Industry (DTI) should do a report on broadcasting, which Prebble agreed to. This report took the form of a letter, dated 17 September 1987, from Jim Stevenson (for the Dept of Trade and Industry), and M.D. Curran (for Treasury) to the Minister of Broadcasting and Minister of Finance. ${ }^{29}$ The 7-page letter succinctly outlines a case and a programme for reform:

“...There is pressure, as evidenced by the recent third channel hearings, for greater competition to be permitted in television broadcasting and pressure stemming from the cumbersome and questionable method of allocating television warrants.... There are pressures within BCNZ arising from the conflicting commercial and public interests of broadcasting, with associated financial difficulties.”

"These examples point to the need for an in depth review of Government intervention in the broadcasting and related communications sector. The Royal Commission on Broadcasting... was charged with reviewing broadcasting policy in accordance with certain

28 Stevenson had been Assistant Secretary for Business Competition, and was Chairperson of the Officials Committee on the Regulatory Environment of State-Owned Enterprises, which was established to strip out all the regulatory impediments to competition. It is noteworthy that Stevenson had previously headed the division of DTI that had managed, and later dismantled, the wage and price freeze created by the Economic Stabilisation Act.

29 In an interview conducted in December 1998, Stevenson spoke of sending two letters to Prebble about this time. Only one could be identified, however, and it is assumed that this is the second of the two. 
terms of reference. In practical terms the majority Commission report did not really address the pressures facing the broadcasting sector and largely confirmed the existing policies applying to broadcasting.”(1)

“...The central aim of broadcasting policy should be to achieve the efficient use of broadcasting resources. This is essentially an economic aim and may well need to be qualified by social equity and other social considerations, such as cultural, educational and other qualitative aims.” (2)

"The BCNZ currently has conflicting commercial, non-commercial, regulatory and policy advice roles. There is a clear need to separate these functions, as has been the case in the reform of State Owned Enterprises...”(5)

The report pointed to DTI's responsibilities for telecommunications and radio spectrum regulation, and noted that "Broadcasting policy should be part of a coherent communications policy.”(5) It also noted Treasury's interest in the liberalisation of product markets and financial monitoring of the BCNZ, and proposed that the two departments undertake an officials' review under DTI co-ordination. The letter sets out a timetable for reform encompassing the establishment of a new Broadcasting Act, the restructuring of the BCNZ and changes to spectrum allocation regulations - all to be completed by 31 December 1988.

Officials from DTI and Treasury met with Prebble a few days later, on 21 September 1988. According to a file note of the meeting, Prebble gave his approval for an Officials' review of broadcasting, emphasising that “... he wanted to move quickly in this area. He emphasised that he wanted a pragmatic, rather than academic approach to the review." Apparently there was some discussion on this point, as the note then mentions that "Mr Curran suggested that the review should be done on a first principles approach. While the Minister agreed that officials might want to do this, he reiterated that he wanted a pragmatic approach.”30

This exchange ensured that the "in-depth review" envisaged by officials in the report would not occur. It is unclear what Officials might have envisaged. Certainly, we know from what happened subsequently what it would not involve: the economic analysis prepared by Treasury for the RCBRT would not be revisited, and the and the broad policy proposals which relied on that analysis would not be rigorously tested.

Officials then moved quickly, as Prebble requested. A draft report was sent to the Minister of Finance on 7 December 1987. The agenda of a meeting between Prebble and Treasury officials on 28 January 1988 notes: "Officials intend completing final draft of Ministerial paper to (Cabinet Policy Committee) by 11 February. Takes into account BCNZ submission, views of Tribunal and interested parties.” A letter from Treasury official Doug Andrew to the Minister of Finance, dated 22 February 1988, enclosed the final draft report. ${ }^{31}$ The letter notes "The final draft addresses satisfactorily almost all the issues which arose during the course of the review and were dealt with incompletely by the Royal Commission on Broadcasting and Related

\footnotetext{
30 The file note was obtained under the Official Information Act. Treasury file ref: COMP 10/7/9.

31 Treasury was unable to locate a copy of the report itself, or the earlier draft of 7 December 1988, to which the letter also refers.
} 
Telecommunications." Apparently the role that was later to be taken on by the Broadcasting Commission (NZ on Air) was to be played by a trust with a board of trustees. It notes that:

"The specification of the Government's social objectives in broadcasting are critical in determining the contract between the Government and the Board of Trustees.... In practice, the level of funding needed and the monitoring of the Trustees' performance in the meeting of Government's social objectives requires a clear view of these objectives.” (2)

The letter also notes the supposed benefits of allocating broadcasting rights in a commercial market, and that work was already underway to investigate the means for doing so:

"The Minister for State-Owned Enterprises has instructed the Department of Trade and Industry and Treasury to commission a study of the best means of allocating the radio spectrum to achieve efficiency. The removal if (sic) economic restrictions on the best use of spectrum linked with a high rate of technical change should allow for a much more diversified broadcasting market, with stations targetting (sic) quite specific common-interest groups."

Finally, it raises the spectre of the BCNZ's vested interest in maintaining the status quo:

"The possibility of the Broadcasting Corporation pre-empting any decision on the future of the Corporation in a revised broadcasting environment has been highlighted by many of the individuals we consulted as part of the review.”

Recommendations were made to the State Owned Enterprises cabinet subcommittee on 29 March 1998, along with a supplementary memorandum from the BCNZ, which pointed out that the draft policy redefined, and constituted a major reduction in, government's social service objectives in broadcasting. Specifically, because:

“(a) The minimum level of access to television and radio services has been reduced to one network in each medium;

(b) There is no requirement for the provision of an accurate and impartial news service;

(c) There is no provision securing diversity of choice in the range of programmes offered by television or by radio.

(d) There is no basic requirement for any service to be owned by and operated on behalf of the people of New Zealand.”

The Government subsequently agreed to the recommendations in the Treasury report, in a Cabinet meeting of 18 April 1988 (CM 88/14/13), incorporating the BCNZ's concerns into a list of "minimum public service objectives". The Cabinet directed officials to report to the Cabinet Policy Committee by 31 July 1988 on ways and means of implementing the recommendations it had accepted. Following this decision, two Officials' committees were formed:

- The Steering Committee on Broadcasting, which reported in July 1988, on the restructuring of the BCNZ on state owned enterprise principles.

- The Officials Co-ordinating Committee on Broadcasting, which reported in August 1988, on the implementation of broadcasting policy reform. 
Jim Stevenson was a member of the Rennie Committee, and chair of the Officials Coordinating Committee.

\section{The Rennie Committee}

The Steering Committee on Broadcasting is known as the "Rennie" Committee, after its Chairman Heughan (Hugh) Rennie - then also Chairman of the BCNZ. The report of the Rennie Committee recommended that:

- BCNZ be replaced by two state owned enterprises: Radio New Zealand (RNZ) and Television New Zealand (TVNZ).

- Radio New Zealand should establish a separate business unit to operate the noncommercial services (Concert Programme and National Programme).

- RNZ should have “...the freedom to buy, sell, franchise or establish joint venture radio stations”(iii). Once a competitive environment was established, RNZ's commercial stations could be privatised.

- Separate arrangements should be made for Maori radio.

- Certain strands of public service broadcasting should not be funded from the broadcasting fee, but by separate Parliamentary vote. The short wave service should be funded from Vote: Foreign Affairs and educational broadcasting should be funded by educational institutions.

- Television New Zealand should place greater emphasis on outsourcing programmes, rather than producing them.

- The Listener should be established as a separate business, jointly owned by RNZ and TVNZ.

- The NZ Symphony Orchestra should be managed by an independent trust board and management structure.

- The Broadcasting Services Division should be divided between RNZ and TVNZ. ${ }^{32}$

This amounted to the commercialisation (per Easton, 1997) of the BCNZ. The committee sought to separate the commercial activities from the social activities, and put in place arrangements that would allow the Government to purchase outputs that it deemed socially desirable from these and other suppliers. This led, eventually, to the sale of Radio New Zealand's commercial radio stations. ${ }^{33}$ However, the government retained ownership of Radio New Zealand's non-commercial networks-Concert FM and the National Programme.

\section{The Officials' Co-ordinating Committee}

Whereas the Rennie Committee worked on the plan for what was essentially an organisational restructuring of the BCNZ, the Officials' Committee report attended to other matters, especially the establishment of the Broadcasting Commission (New Zealand on Air) and the Broadcasting Standards Authority. In respect of these, it outlined the policy framework within which they would operate, and laid much of the

32 The TVNZ component was established as Broadcast Communications Limited (BCL).

33 Following a series of landmark court cases, in which Māori attempted to prevent the sale. 
groundwork for drafting the 1989 Broadcasting Act. The report of the Officials' Committee:

- Commented at length, approvingly, on the Rennie Committee's proposals for restructuring the BCNZ

- Recommended that special controls on overseas ownership were not required, especially as these would restrict the ability of broadcasters to exploit economies of scale (11).

- Commented on the need for special provisions in the Commerce Act to restrict the aggregation of media ownership. In this regard, it noted that:

"The main concern about the aggregation of control in broadcasting is that this could have an impact on the editorial independence of the media and restrict programme diversity. The general provisions of the Commerce Act which limit the ability to achieve or abuse a dominant position in an industry already apply to broadcasting.” (12)

- Reinforced earlier statements by officials regarding the outcomes of competition, saying: "Additional competition should also serve to increase the editorial independence and diversity of the media." (13)

- Set out proposals for the implementation of a grant scheme for funding government's social objectives in broadcasting, which eventually led to the establishment of New Zealand on Air.

- Set out proposals to maintain standards of "public decency and behaviour in the broadcasting media." This laid the foundation for establishing the Broadcasting Standards Authority.

These recommendations completed the arrangements necessary for the commercialisation of the BCNZ, while imposing only weak sanctions on broadcasters to prevent them from broadcasting indecent and undesirable material.

The rules for purchasing outputs (other than advertising and promotions purchased by Government Departments) were subsequently set out in the Broadcasting Act 1989, under the functions of the Broadcasting Commission (see Figure 6). 
36. FUNCTIONS OF COMMISSION-

The functions of the Commission are-

(a) To reflect and develop New Zealand identity and culture by-

(i) Promoting programmes about New Zealand and New Zealand interests; and

(ii) Promoting Maori language and Maori culture; and

(b) To maintain and, where the Commission considers that it is appropriate, extend the coverage of television and sound radio broadcasting to New Zealand communities that would otherwise not receive a commercially viable signal; and

(c) To ensure that a range of broadcasts is available to provide for the interests of-

(i) Women; and

(ii) Children; and

(iii) Persons with disabilities; and

(iv) Minorities in the community including ethnic minorities; and

(d) To encourage the establishment and operation of archives of programmes that are likely to be of historical interest in New Zealand--

by making funds available, on such terms and conditions as the Commission thinks fit, for-

(e) Broadcasting; and

(f) The production of programmes to be broadcast; and

(g) The archiving of programmes.

\section{Conclusions}

It could be said that the RCBRT exemplified the "incrementalist" approach to policymaking, and that the two Officials Committees, which designed and implemented the current policy framework, exemplified the technocratic or "rational-deductive" approach. Cocker holds the RCBRT up as a virtuous process, despite its duration, expense and lack of a coherent overall framework. He beleives the officials' committees and the role played by "Treasury" officials were undemocratic and ideologically driven:

"If Treasury power and influence generally fell short of the 'capture' of policy-making during the term of the Fourth labour Government, this was not the case with broadcasting.... No other stream of advice was taken note of and the findings of the (RCBRT), which represented an opposing policy schema, were ignored.” (1996: 159)

However, one might take a less baleful view of the officials' role than Cocker does. Undoubtedly the Royal Commission was out of step with the broader policy directions of the Labour Government (through no fault of its own), and it was confined by a prescriptive Terms of Reference. Stevenson took the initiative to solve a problem that affected more than one sector of the economy, and moved to resolve the deadlock in broadcasting policy. He and other officials acted with determination and vigour to deliver the outcomes desired and mandated by the government within its broad economic strategy. Due process was followed, and Ministers made the key decisions. Jim Stevenson, in a personal interview, put the position this way: 
"To say that officials drove it is true, but only in an environment of economic reform and fundamentals that didn't suggest other alternatives were going to take us very far, very fast. The Royal Commission was built on a different basis. We were now in the mid-to-late eighties when a lot of sister industries were changed radically...”

It is a moot point whether the policy process was "bad", and we might argue back and forth whether the role that officials played in the process was appropriate. What should concern us more, is whether the policy advice was sound and whether it has, or will, achieve desirable outcomes for New Zealand society.

It is evident from this overview presented in this chapter that:

- The current broadcasting policy framework was primarily based on advice contained in the Treasury submission to the RCBRT.

- The submission was acknowledged by officials to have required further work, and the opportunity to develop it further was not forthcoming. What is not clear, from the available evidence, is how strongly officials advised Prebble to undertake a more comprehensive review of broadcasting at their meeting in September 1987. It is clear, however, that Prebble chose not to.

- The policy advice presented in the Treasury submission has not been subjected to official scrutiny or review since the RCBRT hearings in 1986.

The purpose of this thesis is to critically evaluate the advice contained in the Treasury submission to the RCBRT, focussing specifically on the economic analysis of broadcasting contained therein, which provided a justification for the institutional changes later embodied in the Broadcasting Act 1989 and the Radiocommunications Act 1990. 


\section{Chapter $6 \quad$ Broadcasting Economics}

\section{Introduction}

The Treasury submission to the RCBRT is divided into four sections:

- Section I contains an introduction and a summary of conclusions.

- Section II discusses the management of the radio frequency spectrum. It proposes the abolition of the Broadcasting Tribunal, and the creation of a market mechanism for allocating the right to broadcast.

- Section III discusses the "Economics of Broadcasting and Government Intervention". Its recommendations are set out in detail below.

- Section IV discusses the "Role of the Broadcasting Corporation of New Zealand". It proposes that the BCNZ have as its primary objective, the most efficient use of its assets, the removal of its non-commercial objectives, the removal of privileges and advantages that it has over private sector competitors, and the abolition of the television licence fee.

Sections II and IV of the Treasury submission make recommendations regarding the institutional structures that give effect to policy. Section III makes recommendations regarding the type and nature of the broadcasting outputs that the government should either produce or encourage. This thesis focuses attention on the recommendations arising from Section III , which are reproduced in Figure 7 (Treasury, 1985: 2).

The recommendations numbered ix and x provide support for the concepts outlined in Section II, regarding the sale of broadcasting rights. The recommendations numbered xi and xii provide support for the recommendations made in Section IV, regarding the corporatisation of the BCNZ. Therefore it appears that Section III has been structured to support the creation of institutional structures. Our purpose here is not to review the institutional structures. Rather, it is to explore and evaluate the concepts contained in the supporting theoretical material. 


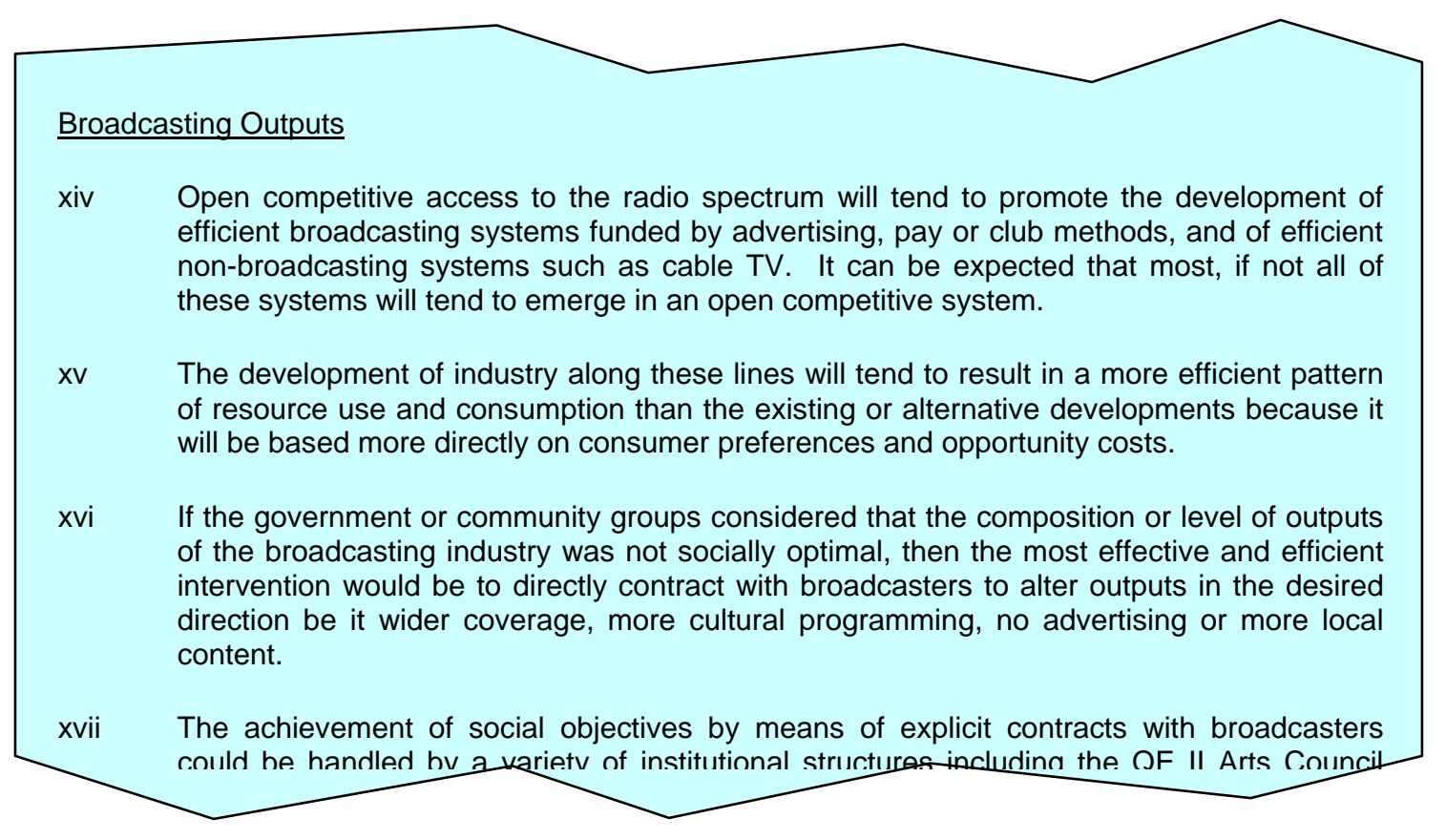

In this chapter, we discuss the theories and ideas that led to Treasury's first conclusion: that open competition in broadcasting will produce the optimal amount of diversity in programming. We will then review the way that Treasury used these theories in its submission. Finally, we will outline an extension to the existing body of theory, which reaches very different conclusions about competition and programme diversity.

\section{Modelling Competition}

We start with a simple example from economic theory, which demonstrates some key ideas about broadcasting and competition. It also demonstrates, for non-economists, the power and limitations of economic theory as a form of argument.

The subsequent sections of the chapter elaborate this idea, describe how it has evolved over time as an academic argument about broadcasting policy and show how Treasury used the model in its submission to the RCBRT.

\section{Stability in Competition}

We will begin with Hotelling's article on "Stability in Competition" (1929). He begins with the simple premise that customers for a business are uniformly distributed along a line such as a "...main street in a town or a transcontinental railway." (45). Two retailers, $\mathrm{A}$ and $\mathrm{B}$, have established businesses at either end of the line. They both supply the same goods, at the same price, so the only competitive variable is the cost that consumers pay-in money or convenience - to travel to their respective stores. 


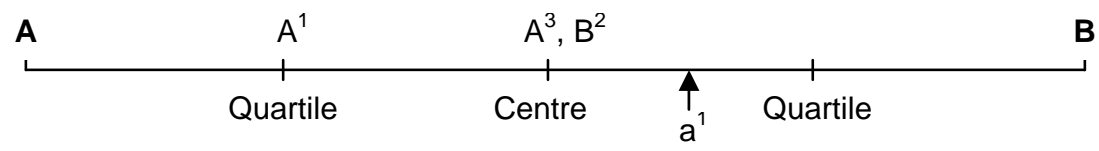

However, if business $A$ moved to point $A^{1}$, it would capture the consumers for the distance between points $A$ to $A^{1}$, and the consumers for half of the distance between points $A^{1}$ and $B$ (point $a^{1}$ ). B would therefore lose customers from the centre to point $\mathrm{a}^{1}$, representing a quarter of her market share.

B's response will be to move closer to $\mathrm{A}$, in order to re-capture market share. If $\mathrm{B}$ realises what the outcome of this game will be, she will move her store to the centre of the line. A will then follow and equilibrium will be restored, with both stores attracting an equal number of customers. ${ }^{34}$ However, the average travel distance incurred by both stores' customers will remain the same as it was at the beginning. The socially optimal location for the two stores would be at the quartile points on the line, as this would minimise the travel costs for all consumers.

Hotelling is making an argument that competition is not necessarily a good thing: "As more and more sellers of the same commodity arise, the tendency is not to become distributed in the socially optimal manner, but to cluster unduly"(53). This tendency to excessive sameness can be applied to a multitude of examples, including the sameness of programme formats in the radio market, or the tendency for political parties to compete for the "centre" of the political spectrum:

“...distance, as we have used it for illustration, is only a figurative term for a great congeries of qualities.... The tremendous standardisation of our furniture, our houses, our automobiles and our education are due in part to the economies of large-scale production, in part to fashion and imitation. But over and above these forces is the effect we have been discussing, the tendency to make only slight deviations in order to have for the new commodity as many buyers of the old as possible, to get, so to speak, between one's competitors and the mass of customers."(127, emphasis in original)

This model demonstrate some key ideas about "game theory":

- Two or more competing firms can play a "game” of subsequent strategic moves for competitive advantage.

- A firm is likely to consider its competitors' responses before making its next strategic move.

We can also see that the model is based on some strong assumptions:

34 There are a number of alternative moves and counter-moves in this "game”. This is a highly simplified version. 
- Travel cost is the only competitive variable.

- There is an even distribution of customers along the line. The competitive "game" would be different if the distribution of customers along the continuum is normal, skewed, or multi-modal (has more than one "hump").

- The competitors can move frictionlessly. There are no transactions costs or other impediments which prevent A and B from moving quickly to any point on the line they desire.

These are important concepts that will help us understand the model of broadcasting competition proposed by Steiner (1952).

\section{Competition and Market Entry}

Steiner argues that a single, monopolistic, broadcaster would provide a greater range of programmes than a competitive broadcasting industry. He uses a simple table to demonstrate this proposition. The model has three groups of viewers $(1,2,3)$. Each group is a different size $(5000,2500,1250)$, and each prefers to watch a particular type of programme (A, B, C). None will watch another programme type.

\section{Figure 9: Steiner Model of Audience Choice}

$\begin{array}{lccc}\text { Viewer Group: } & \mathbf{1} & \mathbf{2} & \mathbf{3} \\ \text { Size of Group: } & 5,000 & 2,500 & 1,250 \\ \text { First Preference: } & \text { A } & \text { B } & \text { C } \\ \text { Second Preference: } & \text { nil } & \text { nil } & \text { nil }\end{array}$

Under competition, the first entrant into the market would produce programme A, and get an audience of 5000 viewers. The second entrant could produce programme A or programme $B$ to get 2,500 viewers in either case. The third entrant will also produce either A or B - whichever the second entrant did not produce. The outcome, with three competitors, is that two broadcasters produce programme $\mathrm{A}$ and one produces programme B, serving 7,500 viewers. Those who prefer programme $\mathrm{C}$ do not get served at all. According to Steiner a single broadcaster would produce all three programmes, serving a total audience of 8,750. He concludes, “.... discriminating monopolist controlling all stations would produce a socially more beneficial program pattern”.

We can see how this model echoes Hotelling's argument that the effects of competition do not necessarily produce socially beneficial outcomes, and how it uses game theory, with sequential strategic moves by competitors, to make the point. However, Beebe (1977) points out the strong assumptions underlying the argument:

1. Viewer groups are unequal in size.

2. Viewers watch only their first preferences. 
3. Channel capacity is strictly limited.

4. Competitors producing the same programme will equally share the audience group.

5. Broadcasters equally value all viewers.

6. Programme costs are ignored.

Changing any of these assumptions will change the outcomes. Rothenberg (1962), for instance, changes the second of these assumptions to show that, if viewer groups 2 and 3 would accept programme A as their second preference (rather than not viewing at all), 5,000 viewers would receive their first choice of programme, the remaining 3,750 would receive their second choice and all viewers would be served.

\section{Extending the Model}

Beebe (1977) extended the Steiner model by replacing some of the six assumptions with a range of options, then tabulating the results, to show that it could be used to argue for a variety of policy options, depending on the assumptions chosen.

\section{Figure 10: Extended Assumptions of Steiner Model}

\begin{tabular}{|ll|}
\hline 1: Audience Distribution & $\begin{array}{l}\text { A skewed distribution (Steiner) } \\
\text { A mildly skewed distribution } \\
\text { An even distribution (Hotelling) }\end{array}$ \\
\hline 2: Viewer Preferences & $\begin{array}{l}\text { Watch first preference or none (Steiner) } \\
\text { Watch first or second preference, or none at all } \\
\text { Watch first, second or common denominator (Rothenberg) }\end{array}$ \\
\hline 3: Number of Channels & $\begin{array}{l}\text { Limited to three channels } \\
\text { Unlimited channels }\end{array}$ \\
\hline 4: Sharing audiences & $\begin{array}{l}\text { Not affected. Assume that, over time, competitors will equally } \\
\text { share an audience for a particular programme type. }\end{array}$ \\
\hline 5: Audience value & $\begin{array}{l}\text { Placing different values on audiences is equivalent to changing } \\
\text { the shape of the distribution. The options for assumption } 1 \\
\text { accommodate this assumption also. }\end{array}$ \\
\hline 6: Programme Costs & $\begin{array}{l}\text { Break-even audience size is 1,200 viewers } \\
\text { Break-even audience size is } 800 \text { viewers }\end{array}$ \\
\hline
\end{tabular}

Beebe's full table of outcomes is large and complex. Owen and Wildman (1992), reviewing Beebe's model, draw a series of conclusions, among which they link programme diversity to the value (to advertisers) of minority audiences:

"If minority audiences are worth more per viewer to advertisers,... minority programmes are more likely to appear under both competition and monopoly, and programme duplication is less likely to occur under competition. If mass audiences are worth more per viewer to advertisers (than minority audiences), then the opposite will hold true.” (91) 
In other words, an answer to the question "does competition produce greater programming diversity?” depends, critically, on whether small audiences are highly valued by advertisers.

\section{Mixed Public/Private Systems}

The presence of a public broadcaster will change the outcomes of competition. Noam (1988, 1991) argues that a public broadcaster in a competitive environment will have negative effects. Owen and Wildman (1992) summarise Noam's claims:

"His analysis of a mixed broadcast system with private and public channels generates three predictions. First, the program biases of commercial broadcasters create political demands for publicly sponsored programming targeted to minority audiences not served by commercial broadcasters. Second, private broadcasters may respond to public broadcaster programs by becoming even more majoritarian. Third, a proliferation of private broadcasters may undermine the political support for public broadcasting.”(141)

They demonstrate Noam's argument using a Steiner/Beebe model with the following assumptions: a skewed distribution, limited channels, Group 1 viewers who watch their first preference only, and Group 2 and 3 viewers who accept programmes A and B as their second preferences respectively, or watch nothing at all.

\section{Figure 11: Noam's Mixed System}

$\begin{array}{lccc}\text { Viewer Group: } & \mathbf{1} & \mathbf{2} & \mathbf{3} \\ \text { Size of Group: } & 1,100 & 400 & 200 \\ \text { First Choice } & \text { A } & \text { B } & \text { C } \\ \text { Second Choice } & \text { non-viewing } & \text { A } & \text { B } \\ \text { Third Choice } & \text { non-viewing } & \text { non-viewing } & \text { non-viewing }\end{array}$

Owen and Wildman show how Noam argues that, under two-channel competition, both channels would produce programme A, satisfying the first preferences of group 1 and the second preference of group 2, thereby attracting 750 viewers each. Noam says Group 3 would then apply political pressure for a public broadcaster to satisfy their first preference for programme C. If they succeeded, a third commercial broadcaster entering the market would also produce programme A, splitting the combined viewer groups 1 and 2 three ways (for 500 viewers each). Group 2's first preferences would remain unsatisfied. Owen and Wildman sum up the outcomes of further entry to the market:

"If the number of commercial channels continues to increase, eventually at least one commercial broadcaster will find it profitable to provide type three programs and share the type three audience. In this example, 15 commercial channels are sufficient to guarantee that one will provide type 3 programs. At this point, the political rationale for the public channel disappears.” (143)

This describes the basis of the argument in favour of deregulation and dismantling public broadcasting: when there was limited channel availability, public broadcasting had a useful role to play. However, with the increase in channels produced by the 
arrival of UHF, cable and satellite transmission all audiences could eventually be served by private competition.

\section{Treasury's use of the Model}

Noam's article had not been published when Treasury's (1985) submission to the RCBRT relied on a Steiner/Beebe model to make this claim:

“...a competitive market for broadcasters can be expected to yield greater programme diversity than would occur in a monopolistic market. The tendency of competition to duplicate mass audience programme types (when mass audiences exist) decreases significantly as the number of channels increases; on the other hand, a monopoly's tendency to produce lowest common denominator programmes does not decrease as the number of channels increases. A competitive system with a reasonable number of channels is likely to be much more responsive to first preferences than a comparable monopolistic system" (34)

We can see that the claim is based on some strong assumptions, which Treasury describes as "...more realistic..." (34) and “...most realistic...” (36). These are not explicitly stated, but we can infer that they include:

- A competitive system with a large number of channels,

- Low break-even audience size,

- The presence of relatively small audiences which are valuable to advertisers, and

- Audiences which tend not to watch their second or lowest common denominator choices.

Treasury did not attempt to assess whether these assumptions did exist, or were likely to exist, in New Zealand. The RCBRT explicitly rejected the idea: “...it strains belief to expect deregulation to yield much more [widespread coverage and service]. Already, indeed, the enterprise of private and public broadcasters has challenged if not defied economic logic” (253).

\section{The Effects of Deregulation}

We may usefully test the validity of Treasury's "most realistic" assumptions by the experience of market entry by radio stations since deregulation. Some radio stations have entered the market seeking small-but-lucrative audiences. These include World Service Radio, Radio Liberty and Fine Music FM, of which Liberty and Fine Music have failed, while (BBC) World Service Radio has struggled. Possible reasons for the problems experienced by these services include:

- These radio stations simply failed to appeal to the target audience due to inappropriate programming (i.e. a lack of positive utility produced by the station).

- The target audiences experience a high level of disutility from advertising, and substitutes are available that do not produce this level of disutility (i.e. the Concert Programme and National Radio).

- The target audience are not high consumers of radio, generally preferring other media (in Radio Liberty's case the more authoritative and less ideologically biased business newspapers, perhaps).

- Potential advertisers preferred other media, or other techniques, such as direct marketing, to access their target audicences. 
However, there have been examples of successful market entry for broadcasters targeting larger, if perhaps less valuable, audiences that were previously unserved. These include Mai FM (for a Māori/Polynesian youth audience), and Channel Z (for a "Generation Z" audience). Why did these services succeed, when the others failed?

Recall the strong assumption underlying Hotelling's model, that the cost of a strategic competitive move is frictionless. It is possible to hypothesise that the transactions costs and risks involved in entering the radio market are significant, and that entry is only possible when these can be overcome. An existing mass audience has a track record with advertisers, and broadcasters understand the programming that will attract the audience. Therefore, a new entrant may prefer to compete for smaller segments of an existing risk-free audience than serve the needs of a larger, more risky audience. Otherwise, new entrants need to develop a format that will attract the newly identified audience, and they need to be able to prove to advertisers that the audience exists and is valuable. This entails significant costs, and a degree of risk to broadcaster and advertiser alike.

In the case of Mai FM, New Zealand on Air underwrote the risk as part of its programme for funding Maori radio initiatives. It became apparent that Mai FM was a commercially successful station the funding ceased - in response to mounting political pressure - as it was attracting advertisers away from other broadcasters. In the case of Channel Z, students at the New Zealand Broadcasting School undertook an in-depth survey of the Christchurch radio market, then operated an eight-week pilot station, which targeted the Generation $\mathrm{Z}$ audience. The Broadcasting School underwrote the capital risk of the broadcast, and the students' free labour underwrote operating expenses (i.e. risk to working capital). The industry took note of the station's success and some months later Channel $\mathrm{Z}$ was launched.

These stories allow us to hypothesise that entry to the market is risky, and this may prevent the rapid entry of new entrants to serve diverse audience needs. The element of risk can be overcome if the entrant has sufficient working capital to stay in the market until it can create a viable audience, or if it can use research and/or test marketing to convince advertisers that a viable audience exists.

\section{Modelling Deregulation}

So far we have looked only at the problems facing new entrants to the market. However, deregulation may also affect existing broadcasters, as new entrants to the market subdivide the already proven, and therefore less risky, audiences. In this section, we develop a model that combines aspects of the Steiner/Beebe models with some of the ideas which appear in Noll, Peck and McGowan (1973), Owen and Wildman (1992; especially pages 127-129) and Masson, et al. (1990). This allows us to identify medium- and long-term effects of market entry on existing broadcasters.

\section{The Audience as Commodity}

Our understanding of market entry will be improved if we are clear about the commodity that is the subject of the economic analysis of broadcasting. Economists have not held a unanimous view on the subject. Owen, et al. (1974) claim that: 
"The first and most serious mistake that an analyst can make is to assume that TV stations are in the business to produce programs. They are not. TV stations are in the business of producing audiences. These audiences, or means of access to them, are sold to advertisers. The product of a TV station is measured in dimensions of people and time." (4, emphasis added)

Besen (1976) states categorically that "The basic service that a television station has to sell is the use of its time.” (435). Collins, et al, (1988) opine that “...it can cogently be argued that the appropriate unit of analysis is the programme segment, especially that segment between two successive commercial breaks, or the channel, or the total broadcasting service."(6) Their preferred definition is:

“...the total set of broadcasting output which results from the interaction between the set of audience needs which broadcasting attempts to satisfy and the historically given set of productive resources that the broadcasting industry has at its disposal for the fulfilment of that task.” (6)

Masson et al. (1990), agree with Owen, et al.: "For broadcast television the only true 'market' is the one for sales of audiences to advertisers." Brown and Cave (1992: 379), imply that the programmes shown on broadcast television are the commodities being consumed. They later note that: "Programs are made available 'free' to audiences, while those audiences are sold wholesale to advertisers... this process involves advertisers in an intermediate relationship between consumers and broadcasters” (380).

Whereas literature expresses a range of views, the prevailing opinion is that the fundamental commodity of commercial free-to-air broadcasting is an audience, which the broadcaster creates, packages and sells to advertisers. However, this definition does not accurately describe the position in pay television, nor does it acknowledge a role for public broadcasting. It also implies that the audience is a passive subject of the broadcasters’ and advertisers’ desires.

It would be more helpful to define the commodity of broadcasting as audience attention. By doing so, we explicitly recognise the following ideas:

- Audience attention is a scarce resource, since people have only so much attention to devote to any one activity.

- What the audience chooses to "pay" attention to is what determines the value of that audience to an advertiser.

- Audiences will treat the media as one among a number of substitutes to which they may switch their attention.

- Pay TV services, commercial free-to-air and public broadcasters all compete for audience attention, whereas only commercial free-to-air services sell audiences to advertisers.

- Broadcasting regulation may be aimed at preventing the audience from paying attention to inappropriate messages (i.e. violence), or toward appropriate messages (i.e. party political broadcasts). ${ }^{35}$

35 Section 78 (1) of the Broadcasting Act 1989 (repealed on 10 March 1990), stated that "Every election programme broadcast by means of free-to-air television broadcasting shall be broadcast 
This idea can clarify some of the economic analysis of broadcasting. Owen and Wildman base much of their analysis on the idea that the marginal cost of supplying $a$ programme to the marginal viewer is zero, which gives broadcasting the characteristics of a public good. However, an outcome of regarding audience attention as a scarce resource is that the marginal cost of attracting an extra viewer is positive, so the production of an audience bears a positive cost. The difference that this makes will become apparent in the following chapter.

\section{Competing for Attention}

If audience attention may be switched between near substitutes, then there is a competitive element involved in keeping the audience's attention. This is the basis of an article by Masson, et al. (1990), which treats advertising as a disutility for the audience "As a firm increases its number of advertising minutes, more viewers move to viewing the programs of other firms or not viewing at all." (7) They portray broadcasting firms as playing a competitive game, in which "If at least some viewers choose to switch to the programs of other firms, then increasing the number of ad minutes by a firm increases the audience sizes of its rivals." (7) They then analyse the effects of increased competition on the total quantity of advertising minutes offered to advertisers, and the price-per-viewer charged to advertisers.

They conclude that, as more broadcasters enter the market and compete for audiences by reducing the number of ads, the total advertising minutes produced by all broadcasters may decrease. If the quantity of advertising minutes falls, the price-perviewer paid by advertisers should also rise. This model is interesting as a piece of theory because it contradicts the standard assumption of economic theory - that entry of firms into a market will result in greater output and falling prices. ${ }^{36}$ In their model the outcome depends on the number of competitors, the structure of the industry and each competitor's expectation of the others' reactions. This provides an important key to understanding the effects of increased competition on broadcasters' cost structures. ${ }^{37}$

\section{Remodelling Broadcasters}

One of the key omissions from the Steiner/Beebe models has been the effect on broadcasters' cost structures under increased competition, and the consequences of those effects. This is crucial to understanding the medium- to long-term effects of deregulation.

simultaneously on all free-to-air television broadcasting stations.”, ensuring that the audience would have difficulty avoiding these broadcasts. Cocker (1996) recalls that in July 1979 and October 1980, Sir Robert Muldoon was granted time simultaneously on radio and television to make announcements regarding wages policy.

36 A less dramatic outcome might be that the number of advertising minutes offered increases at a lower rate, and the price-per-viewer falls at a lower rate, than one might normally expect.

37 It also reinforces Hotelling's point that competition may lead to socially sub-optimal outcomes; in this case by increasing costs to advertisers, which are then passed on to consumers. 
In the model presented in Figure 12, a broadcaster's programme output is measured in time - in this case, one hour. ${ }^{38}$ The average cost curve for the hour is the total cost of broadcasting for that hour, divided by the number of minutes in the hour.

\section{Figure 12: Broadcasters' Supply and Demand Relationships}

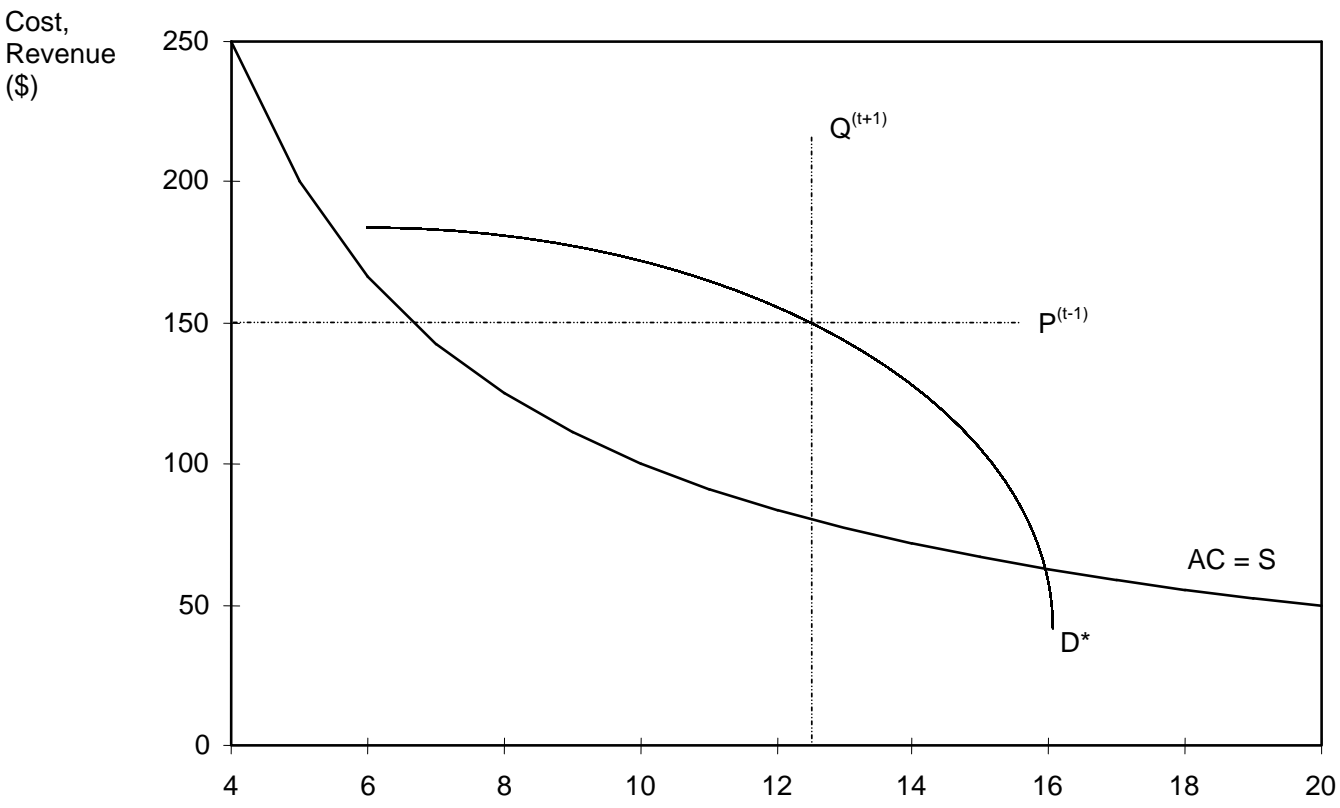

The average cost curve is labelled $\mathrm{AC}=\mathrm{S} .^{39}$ It is also the broadcaster's supply curve for minutes of advertising. That is, any point on the line $\mathrm{AC}=\mathrm{S}$ represents a combination of prices and quantities of advertising that will produce an adequate return on investment. ${ }^{40}$ If the broadcaster can only sell advertising at output/price points below the line, he will eventually go broke. Output/price points above the line represent a "supernormal" profit, or return on investment higher than expected for the level of risk involved.

The demand curve ( $\left.D^{*}\right)$ represents the prices and quantities of advertising that the broadcaster is able to sell. The position of the demand curve is partially determined (in the short term), by the results of the last ratings survey. This is represented by the horizontal line $\mathrm{P}^{(\mathrm{t}-\mathrm{1})}$, which shows the price advertisers are willing to pay for a minute of

38 The graph only shows the $4^{\text {th }}$ to $20^{\text {th }}$ minutes of the hour, which we assume to entail the relevant range of advertising minutes-per-hour.

39 In this case, the cost of production is assumed to be $\$ 1000$ per hour, and the curve is mathematically expressed as $A C=\$ 1000 / 60$. To add realism, it may help to interpret this curve as the cost of producing an hour of programming, during a particular day-part, averaged over a few weeks. We can assume costs will be stable over the period, as will demand for advertising, provided the period does not span the release of ratings results (in the case of radio), or a change in programme schedule (in the case of television).

40 Profit is regarded as the cost of capital and is therefore included with other costs of the firm. The definition of an "adequate" return depends on the other potential investments available and the degree of risk associated with them. 
the station's advertising time. ${ }^{41}$ The position of the demand curve is also partially determined by the quantity of minutes of advertising that the broadcaster can sell. This “outer limit” is represented by a vertical line labelled $\mathrm{Q}^{(\mathrm{t}+1)}$. Following Masson, et al., this limit is set according to the broadcasters' strategy to optimise audience size in the next ratings period. ${ }^{42}$

Over time, with all other influences held constant, $\mathrm{P}^{(\mathrm{t}-1)}$ and $\mathrm{Q}^{(\mathrm{t}+1)}$ will work together to produce $\mathrm{D}^{*}$, which is the set of points at which the two lines would intersect. ${ }^{43}$ The broadcaster is unable to charge a higher price, or produce a greater output of advertising minutes-per-hour, than the points described by this curve. ${ }^{44}$ The audience's dislike of advertising and the presence of competing broadcasters determine the downward slope and the shape of $\mathrm{D}^{*}$. If the broadcaster reduces the number of minutes of advertising, the audience will increase and the broadcaster can command a higher price. However, the curve flattens out as the number of minutes reduces, since advertisers will purchase advertising from other radio stations rather than pay a much higher price. If the broadcaster increases the number of advertising minutes sold, audience size will reduce in future, so she will command a lower price for advertising.

The position of the horizontal line $\mathrm{P}^{(\mathrm{t}-1)}$ is a function of the variables incorporated in the Steiner/Beebe model:

- The number of channels competing for this audience

- The size of the break-even audience

- The value placed on particular audiences by advertisers

- The distribution of audience preferences among programme types

The position of $\mathrm{Q}^{(\mathrm{t}+1)}$ is determined by the variables in the model of Masson, et al, and the effects of advertising on audience attention. In particular:

- The number of channels competing for this audience

- Industry structure (competitive, oligopolistic, monopolistically competitive or monopolistic)

- Each broadcaster's expectation of other broadcasters' reactions to changes in advertising output

- The audience's tolerance for hearing advertisements

- The benefits or positive utility enjoyed by the audience due to the programming broadcast between advertisements

41 The superscript (t-1) indicates that price is a function of audience attention attracted in the previous time period, as reflected in the outcomes of the previous ratings survey.

42 The superscript $(t+1)$ indicates that quantity is a function of the audience attention it expects to attract in the following time period, as reflected in the outcomes of the next ratings survey

43 The factors to be held constant are: neither the station nor any of its competitors change format, competitors do not alter the minutes-per-hour of advertising they broadcast, no new stations enter the market, and audience preferences remain stable.

44 When applied to television broadcasters, the ex post and ex ante effects of ratings on $\mathrm{D}^{(\mathrm{t}-1)}$ and $\mathrm{Q}^{(\mathrm{t}+1)}$ are less pronounced, as ratings are produced continuously (the ratings period is only twenty-four hours), but this does not limit the generality of the model, especially if the quantity of advertising affects audience behaviour over a longer term. 
Having established the model, we can now predict what will happen as more broadcasters enter the market and competition increases.

\section{Broadcasters under Competition}

Our initial model shows that the demand curve $\mathrm{D}^{*}$ lies above the $\mathrm{AC}=\mathrm{S}$ curve. This suggests that this broadcaster is earning a supernormal profit, and therefore has a partial monopoly in her market. This is consistent with the New Zealand radio market prior to deregulation, when radio stations generated substantial economic rents. These rents were partially captured by radio "personalities", who commanded large salaries, and by the Broadcasting Tribunal, which imposed costly warrant requirements on broadcasters. ${ }^{45}$

As additional entrants to the market target the same audience by producing a similar format, we expect to observe two effects: a reduction in the market price that advertisers pay for audiences and an increase in the willingness of audiences to switch stations. This is represented in Figure 13: $\mathrm{P}^{(\mathrm{t}-1)}$ will move down, and $\mathrm{Q}^{(\mathrm{t}+1)}$ will move left. This means $\mathrm{D}^{*}$ will move inward, ultimately arriving at a point of tangency with the $\mathrm{AC}=\mathrm{S}$ curve, as shown by the curve $\mathrm{D}^{\mathrm{c}}{ }^{46}$

\section{Figure 13: Demand under Increased Competition}

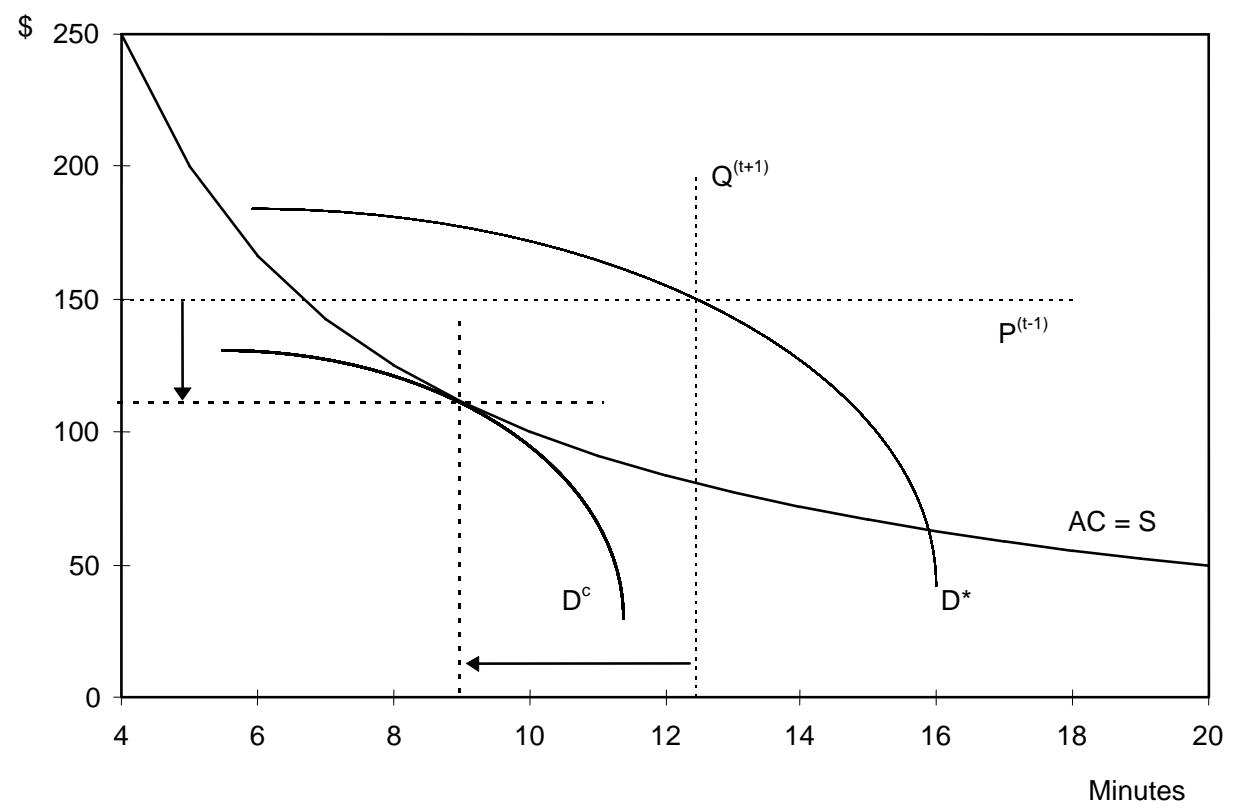

45 Radio stations would also consume some of this surplus by paying for games and prizes to attract audiences during ratings periods. The short-term increase in costs would improve the income of the station over the following period.

46 This is similar the standard model of market entry under monopolistic competition originally theorised by Chamberlin (1962). In fact, increasing number of broadcasters producing similar programmes to compete for the same audience means the market will be monopolistically competitive by definition. 
This model above demonstrates the medium-term result (say 2-3 years after deregulation). Up to this point, the Steiner/Beebe model probably predicts an expansion in services and increasing diversity reasonably accurately.

The predicted conditions were observed in the Auckland radio market immediately post-deregulation "in less than two years the number of Auckland radio stations has doubled from 10 to $20 \ldots$... Once buoyant and profitable, commercial radio is now highly competitive and marginal” (Cocker 1991: 34). The increasing numbers of radio stations did not increase radio's overall share of the advertising market "(Auckland) is a declining market but what should concern the radio sector that its $9 \%$ share, already below the national average of 13\%, is declining even faster.” (Pardon, 1991: 28)

In the longer term, under these conditions, a broadcaster can only increase profits by producing the same audience at a lower cost. That is, by lowering the $\mathrm{AC}=\mathrm{S}$ curve. The outcomes are then opposite to those predicted by the Steiner/Beebe model.

\section{Cost reduction strategies}

To understand how increased competition impacts on broadcasters' cost structures, we need to understand something about the nature of the broadcasting business. Hay (1986: 20) describes broadcasting as a “...distribution service.... A warehousing (and) packaging business which gets its components from various sources and assembles them in a package to suit its customers' specific needs." The various components that go into making up the package are either purchased from outside the station (music, sports, and syndicated news services) or made within the station (local news, current affairs and investigative journalism). Other elements of the package are “...produced within the organisation as part of the packaging. These include continuity announcing, promos and advertisements." There are also the off-air costs of promoting the radio station in other media, to attract an audience, and the costs of marketing, market research and advertising sales - which will all be affected by increasing competition. Following Chamberlin (1962), these off-air costs can be described as selling costs: the costs of persuading the viewers or listeners to switch to your channel. The cost, that is, of obtaining audience attention.

Under competitive pressure to reduce costs, a commercial broadcaster will look at any or all of the following strategies to reduce its average cost of producing an audience.

Outsourcing: It is often cheaper to buy, rather than make, programme inputs especially the labour-intensive inputs like news. Ready-made products like syndicated news services cost less than maintaining a staff of journalists. And indeed, even as the number of radio stations has increased, the number of journalists working in radio has fallen dramatically since deregulation, as radio stations increasingly take external feeds from Independent Radio News or RNZ news, rather than meet the expense of maintaining independent newsrooms.

In the case of television, the cost of making programmes in Britain or the America is met by the revenues generated by their domestic audiences, so these programmes may 
be sold into the New Zealand market at prices that will always undercut the costs of local production. ${ }^{47}$

A variation on the tendency to buy rather than make programming is the increasing use of reality-based programming and sports on television. In both cases the footage is supplied without the need to write scripts, hire actors, or pay other costs associated with creating drama. The "drama" is a characteristic of the events themselves, so the costs are limited to the costs of recording the event, obtaining the right to broadcast it and packaging it for broadcast.

Vertical Integration: The proliferation of channels is creating relative scarcity of premium television programmes. That is, the output of programmes is not increasing at the same rate as the increase in the amount of broadcast time available. ${ }^{48}$ The broadcasters must compete to purchase libraries of television programmes and films and obtain the broadcast rights to key sporting events.

The international television industry is moving toward global competition among powerful oligopolies, vertically integrated from production to distribution, with the final delivery, billing and collection of revenue being undertaken through local franchises such as Sky TV in New Zealand. ${ }^{49}$

Economies of Scope: Economies of scope exist where a group of competing companies gain mutual advantage by sharing common resources. ${ }^{50}$ Radio broadcasters can capture economies of scope by sharing costs, especially selling costs, between stations. The ratings survey allows the industry to share the cost of identifying and verifying the existence of an audience to advertisers. The Radio Bureau now handles advertising sales for most New Zealand radio stations. There is a possibility that this may lead to a cartel or near-cartel situation in the industry, which could increase the cost of advertising.

Economies of Scale: a stable of channels can broadcast from the same premises, sharing the costs of audience research and marketing, buildings, programming costs and announcing staff. Radio and television stations can also distribute a single programme in multiple markets. A station located in Auckland can produce a programme heard all over the country, with advertisements slotted in for local audiences. The advent of digital technology and high-speed data transmission capability has greatly reduced the cost and enhanced the flexibility of networking in the past decade.

47 Although New Zealand production companies can enter co-production deals with overseas broadcasters to make programmes that will sell into overseas markets, in the absence of subsidies this would still prevent programming being made locally for strictly local audiences, such as a Maori language audience.

48 An effect of this relative scarcity is that broadcasters will tend to increasingly compete for existing mass audiences rather than find new niche markets.

49 Arguably, the inclusion of intellectual property rights in the Uruguay round of the General Agreement on Tariffs and Trade reflects the desire of multinational broadcasters to protect their interests and maximise returns from this trend.

50 The most common example is Silicon Valley, where a grouping of software companies is able to attract and thereby share a pool of talented computer programmers. 
Volunteer Labour: Some radio stations and television services are able to continue making labour-intensive programming by utilising volunteer labour. In New Zealand, student radio, community access radio and Radio Rhema's Christian network all rely on amateur broadcasters to provide content which they would not otherwise be able to afford to either buy or make. Community television is somewhat inhibited by comparison, due to the cost of equipment and the complexity of the production process (television production typically requires a co-ordinated effort of a trained team, whereas most radio programmes can be produced by individuals working alone).

\section{Long-Term Outcomes}

In radio, economies of scale are driving the industry toward oligopolistic networks in the major metropolitan markets. Currently, The Radio Network (formerly Radio New Zealand's commercial channels) owns over 50\% of the radio industry in New Zealand, providing "branded" channels in most main centres and many provincial centres. The other major players are Radio Pacific, with a single national network, Radio Otago, which dominates the lower South Island, and CanWest - owners of the TV3 television network - which recently acquired More FM's network of urban and provincial stations. This trend was clearly evident by 1994 (Shanahan, 1994).

The predicted effects on news production were also clearly evident by that time:

“A sharp 30 percent decline in (Radio New Zealand) news staffing since 1989 to 130 jobs overall has led to several sole-charge positions in the provinces and much smaller teams in city newsrooms. All major media players have undergone similar cost-cutting,... As a result, reporters with minimal experience can often find themselves working alone and without experienced mentors immediately on hand. The danger is the development of bad habits, low standards and lack of depth in news gathering.

"Another consequence is the lack of time to work on investigative pieces or pursue the type of contacts work that leads to news scoops. The majority of stories are done over the phone, with RNZ aiming to "Cover the bases” with its news gathering.” (Geary, 1994)

This was before Radio New Zealand sold the commercial radio stations.

In television, precisely the same effects are being realised - only on a global level. The advent of CNN News, BBC World, HBO Movie channel and MTV, is indicative of the future shape of the television industry. These branded channels may increase the range of services available to New Zealand audiences, but those services will provide international, as opposed to local, regional, or national, news and cultural content.

The recent history of regional television indicates that regional free-to-air television cannot capture sufficient economies of scale to survive. This may change with the increasingly rapid spread of cable television, since the marginal cost of distributing one of fifty or so channels over cable will be so low as to make local and regional television viable. However, regional television has so far shown itself to be predominantly a vehicle for selling audiences to regional advertisers - it has been less successful at supplying local or regional programming, including news, to local audiences. 


\section{Conclusions}

Recall that the Report of the Officials Co-ordinating Committee advised the Labour government that "Additional competition should also serve to increase the editorial independence and diversity of the media." (13)

That advice was incorrect. The model and accompanying explanation presented above demonstrate that this will not be the case, either in theory or in practice. Increased competition will only increase programming diversity up to a point, in the short-term. Precisely the opposite will occur in the medium- to long-term, as increasing competition will produce the following tendencies:

- Less local news and drama, as these are labour-intensive products.

- Less investigative journalism and current affairs production (i.e. less news that is "made" or discovered, rather than bought or delivered in the form of PR handouts and press releases).

- Branded channels providing homogenous services to nation-wide radio audiences and global television audiences.

- An oligopolistic industry structure, which may drive up costs to advertisers.

These tendencies are driving the industry toward greater homogeneity and reduction of audience choice. The RCBRT (1986: 254), summed-up the issues of scale of production economies, diversity and vertical integration in this paragraph:

"Competing television companies, because of their altogether grander scale of cost than radio and therefore their demand for correspondingly greater markets, have shown no tendency anywhere, even in markets of continental size, to settle for less than all they can seize of the broadest mass audiences available. Even in radio the United States witnessed the rise of three networks, while in television it took the Courts and anti-monopoly legislation to make three network companies out of two. Of the hypothesized segmentation and profitable pursuit of minority audiences there are few signs outside the great cities with two or more times the population of New Zealand gathered in one conurbation. Mr Rupert Murdoch's ambitions for a fourth channel, for example, rest not on innovative programming for neglected viewers but on rescreening thousands of old films bought up with the company that owned them.”

It can be stated with certainty that officials provided poor advice to the Government, based on the following facts:

- The argument advanced by Treasury, in its submission to the RCBRT, was based on a selective use of the assumptions underlying the Steiner/Beebe model.

- The selective use of the model was not explained to the RCBRT.

- The assumptions chosen by Treasury to support its use of the model were not tested against the real situation in local or foreign radio and television markets.

- The RCBRT explicitly rejected this aspect of the Treasury submission, preferring to rely on its own experience of foreign radio and television markets (the Commissioners travelled to Japan, the United States, Canada and the United Kingdom in May 1985). (RCBRT, 1986: 20).

- Officials ignored the RCBRT's rejection of this argument, when providing subsequent advice to the Government (i.e. in Doug Andrew's letter to the Minister of Finance of 22 February 1988, and in the report of the Officials Committee (13), as noted above) 
- Officials were aware of the economies of scale that deregulation would make available. This was explicitly mentioned in the report of the officials co-ordinating committee, in connection with what they saw as the desirable effects of lifting restrictions on foreign ownership (11).

In this discussion so far, "diversity" has been assumed to be somehow important. It is necessary to be clear about what diversity entails, and why it is important. One meaning is that more diversity will provide audiences with a greater range of choices for their personal enjoyment. This is a relatively trivial matter. The other meaning is the matter of real concern, and that has to do with the function of the news media in a democratic society. Recall the preamble to the RCBRT's Terms of Reference, which charged the Commissioners with the task of deciding how to:

"..widen the choice, and improve the quality, of programmes, to secure independence, depth, and impartiality in news and current affairs programmes, and to reflect New Zealand's cultural and social variety...”

A similar concern is expressed in a statement of the philosophical approach taken by the Australian Broadcasting Tribunal:

"The Tribunal believes that a broadcasting system... ought to reflect the widest possible range of variety, information and opinion. It should be flexible, diverse, editorially independent and accountable to the public.” (Australian Broadcasting Tribunal, 1977: 6)

And a lack of variety in information and opinion should concern us. We have already noted that increasing competition will reduce the level of information and variety of opinion at local and regional level on radio, and regionally and nationally in television.

Harking back to our earlier discussion of media effects, a possible outcome of the tendency toward vertical integration and monopolistic competition is that the media will become increasingly ubiquitous and consonant, (to use the terms employed by Elisabeth Noelle-Neumann). That is, networked programming and news sourced from press agencies and radio news bureaux will tend to repeat the same stories, in the same homogenous manner, across all media. This may in turn produce increasingly powerful agenda-setting and "spiral of silence" effects: audiences fed on an homogenous diet of what the media tell them to think about, may tend to suppress their own opinions, in favour of mute acquiescence to the social cues they receive.

Fox (1996) reinforces Atkinson's (1989) point about mediation and Baudrillard's (1995) notion of "hyperreality"

"...there is a consciousness or fleeting-consciousness about things political and governmental. It is not that the people are dumb, it is that too many passively consume symbols, like any TV offering, without sustained intellectual effort to make any sense of it; not dumb but ignorant. The decline of unions, political parties, ethnic neighborhoods and other mediating institutions leaves voters and citizens without mooring lines, so to speak, adrift in hyperspace with sensory overload. Remember, an entire industry has grown up of pollsters, focus group facilitators, media consultants, and political advertising artists whose efforts are directed not toward disseminating truth but so construing some concatenation of Babel as to deliver victory to their employer."

"The symbol or logo becomes more important than the functional product. Similarly in politics symbols, often deliberately misleading, replace deliberation over policy. Willie Horton becomes a logo for Massachusetts penal policy, "read my lips" for a fiscal policy, 
and Clinton a modifier signifying "Big-government-tax-and-spend" when attached to "health plan" or "welfare reform". ${ }^{51}$

We shall return to explore this theme in more depth in the final chapters. Other than the diversity argument, officials presented the beneficial outcomes of deregulation in terms of improved economic welfare and efficiency. It is to those concepts that we now turn our attention.

51 Page numbers are omitted, as the article was downloaded as a text file from a database. 


\section{Chapter 7 Welfare and Consumer Preferences}

The discussion in the previous chapter demonstrated that an increase in the number of broadcasters would not necessarily increase diversity of programme content in the short term, and may well produce the opposite effect in the medium or long term. However, it is possible that the increase in radio and television stations could be managed in such a way as to prevent this from happening. If that were the case, would a competitive, deregulated media environment still produce better outcomes than a regulated one?

The argument presented by Treasury says that commercial competition in free-to-air broadcasting will tend to produce the range of programmes demanded by audiences. ${ }^{52}$ This is the "consumer sovereignty" argument. It contends that the aggregation of individual consumers' preferences, expressed by their willingness to pay for goods and services, will call into supply the goods and services that society requires, given that markets operate efficiently. More than that, the market will also ensure that society's scarce resources are put to the best use, as the market will allocate scarce resources to the production of goods and services in the proportions that reflect consumers' demands. This allocation of resources and outputs will maximise society's well-being, or welfare.

This concept has its flaws. ${ }^{53}$ However, it has a powerful intuitive appeal, and can be robustly demonstrated in economic theory. Such is the power of this idea that, if one suspects there may be an exception to its rule, the burden of proof lies with the challenger. In this chapter, it is proposed that none of the existing systems of funding broadcasting meet the conditions required for allocative efficiency - at least, that is, as far as radio and television audiences are concerned, rather than advertisers. What is more, the consumption of electronic media does not conform to one of the fundamental simplifying assumptions that underlies the notion of consumer sovereignty.

In the first section of this chapter, we explore different methods of funding broadcasting services and test whether (or how), each of them is responsive to consumer demand. This clarifies the circumstances under which the various funding mechanisms may fail to provide broadcasting services to some audiences, and introduces the idea of "merit goods”.

In the second section, we review the concept of consumer sovereignty, as it applies to the consumption of mass media - especially the assumption that consumers' preferences are exogenous and therefore determine which programmes are broadcast.

52 Assuming, that is, that the entry risks noted in the previous chapter are a relatively short-term effect that the market may overcome in time.

53 Not the least of which is that future generations cannot express their demands for products which are produced with depletable resources, leading to over-consumption of those resources in the present (O’Connor, 1991). 
In the third section, we extend the ideas of welfare economics and allocative efficiency to incorporate the distribution of externalities. This raises some issues regarding the use of subsidies and quotas to fund broadcasting services. It also illuminates one of the most important issues addressed in this thesis: the nature of the rights to broadcasting outputs that New Zealand's citizens hold, explicitly or implicitly.

\section{Audience Welfare}

Television provides satisfactions to those who watch it. It increases their utility, or happiness - but by how much? And what is it worth to them? It is impossible to directly measure every consumer's utility, or state of happiness. However, one can observe that a consumer prefers one (affordable) set of goods to another and assume that the preferred set of goods provides greater utility-it makes them better off, or happier-than any other affordable set of goods. To define a numeric measure of utility, economists use a proxy: the consumers' "willingness-to-pay”:

"Given two situations represented by the two consumption bundles... we want to measure how much the consumer would be willing to pay (or be paid) to be in one situation rather than the other. The resulting number turns out to be closely related to certain ways of measuring utility and is useful for evaluation of proposed policy changes.” (Varian, 1987: 243)

In Figure 14(a), an individual chooses to consume a particular amount of good $G\left(\mathrm{G}^{*}\right)$, and a particular amount of all other goods $\left(\mathrm{A}^{*}\right)$. This is their preferred consumption bundle, at point $\mathrm{X}$. 
(a) Individual's Consumption Choice

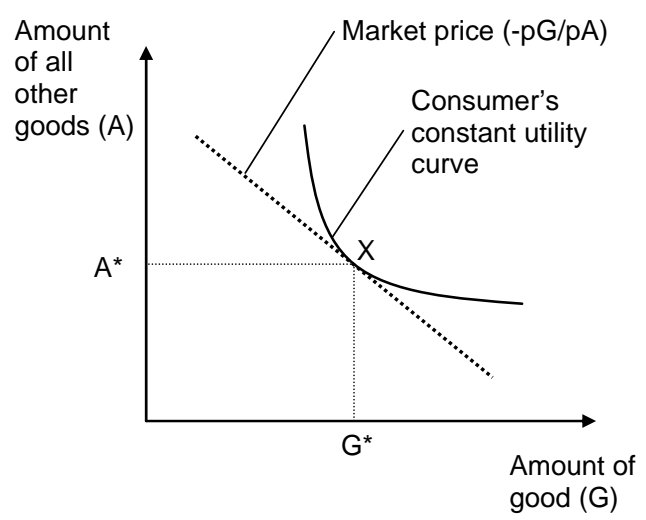

(b) Aggregate Consumption and Welfare

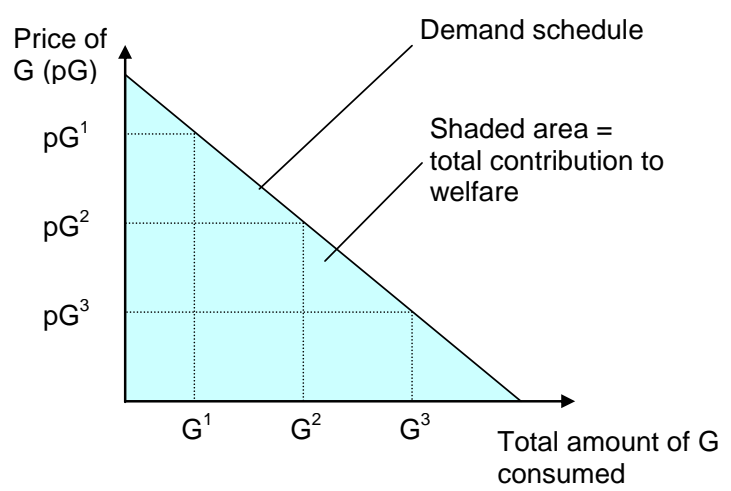

Passing through this point, we see a sloped line, representing the relative price of A and G. ${ }^{54}$ We also see a curved line, which represents a set of trade-offs that would keep the consumer equally happy. This is the constant utility curve, which needs to be carefully interpreted:

- To persuade this consumer to purchase a combination of $A$ and $G$ that was at a point left and upward along the curve, thus giving up some of $G$ while remaining equally content, one would have to offer her more A (money) than the market price.

- To persuade her to purchase a combination of $A$ and $G$ that was at a point right and downward along the curve, thus consuming less of $A$ while remaining equally content, one would also have to offer her more $G$ (the good) than the market price.

- If her income increased she could consume more of $G$ and $A$, her overall utility would have increased, so her constant utility curve would lie somewhere above and to the right of the one shown here.

- If the price of $G$ increased she would consume less of $G$ relative to A. The slope of the price line would become steeper (while the point at which it intersects the vertical axis would not change), and her utility curve would move to the left. Thus, an increase in the price of $G$ represents a decrease in their total utility, and an effective cut in overall income. ${ }^{55}$

This person's consumption choice is a function of three things: their total income, the price of good G, and the utility or satisfaction that they obtain from consuming G. The model shows us how the consumer has chosen to maximise her utility, given the income she has and the price of good $\mathrm{G}$ relative to all other goods.

54 If they spend their entire income, then Income $=\left(\mathrm{P}^{\mathrm{A}} \mathrm{x} A\right)+\left(\mathrm{P}^{\mathrm{G}} \mathrm{x} \mathrm{G}\right)$ By manipulating this equation, we obtain the function $\mathrm{A}=\left(\right.$ Income/ $\left.\mathrm{P}^{\mathrm{A}}\right)-\mathrm{P}^{\mathrm{G}} / \mathrm{P}^{\mathrm{A}}$.G The coefficient $-\mathrm{P}^{\mathrm{A}} / \mathrm{P}^{\mathrm{G}}$ is the slope of the line.

55 This is a very simple example, for explanatory purposes only. Any good intermediate level microeconomics textbook (e.g. Varian, 1987), will explain the finer points of this type of model. 
In Figure 14b, we see what might happen to the total consumption of good $G$ as its price changes, aggregated across a whole economy. ${ }^{56}$ At price $\mathrm{pG}^{1}$, only a few consumers will be able to afford $G$, and the amount $G^{1}$ will be consumed. As the price falls ( $\mathrm{pG}^{2}$, $\left.\mathrm{pG}^{3}\right)$, more of $\mathrm{G}$ is consumed $\left(\mathrm{G}^{2}, \mathrm{G}^{3}\right)$. Theoretically, we could raise the price until none of good $G$ was consumed, or lower it until we knew how much was consumed if the price were zero.

The line through these points is the demand schedule for good G. The area under the demand schedule is a way of representing the total value of good $G$ to all consumers. ${ }^{57}$ This area can be regarded as good G's total contribution to the welfare of society, relative to the welfare provided by all other goods, expressed as a monetary value. It is intimately linked to the concept of the utility or happiness provided to each consumer by their consumption of $\mathrm{G}$, and therefore to the utility of all consumers.

As Varian has said, this concept can be used to evaluate proposed policy changes. It can be used in one of two ways: one compares the relative contribution to welfare of different policies, in order to show which is policy is preferable to others. ${ }^{58}$ The other estimates the absolute contribution to welfare of a policy initiative, in order to decide whether to proceed with it. ${ }^{59}$

\section{Welfare and Market Failure}

The key ideas were demonstrated by Treasury (1985), with a model similar to Figure 15. The audience for Police Stop! ${ }^{60}$ is large, but viewers place a relatively low value on the programme: if they were charged for watching it, audience numbers would decrease rapidly, and fall to zero when the price rose to $\$ 1.00 .{ }^{61}$

The audience for People's Century ${ }^{62}$ is much smaller, but viewers place a relatively high value on the programme. If they had to pay for watching it, audience numbers

\footnotetext{
56 Assuming all other prices remained constant.
}

57 Demand curves can actually be known for quite small ranges of price and output, in reality.

58 Spence and Owen (1975) use a formal mathematical model to compare the relative contribution to welfare of four polar cases: advertiser-supported TV or pay TV, with either limited or unlimited channels. At the time, the Federal Communications Commission forbade per-program charges for most programs (103), so the key policy question was whether, by allowing pay-per-view television, economic welfare would be improved.

59 Noll, et al., (1973) estimated that, at that time, households consuming free-to-air television valued it at $4 \%$ of after-tax household income. This amount was about seven times the advertising revenues generated by the industry at that time. They argued from this basis that providing more television channels would improve economic welfare.

60 A programme comprised of video footage of police chases and examples of bad driving, with an admonitory narration provide by a retired racing driver. This was shown weekly in prime time for much of 1998.

61 We assume the price charged to viewers is zero - as is generally the case in commercial free-to-air radio and television.

62 A BBC documentary exploring some of the important events of the $20^{\text {th }}$ century, through the recollections of "ordinary" people that were present at these events. This was shown in a late evening timeslot in 1998. 
would fall to zero when the price rose to $\$ 5.00$. Calculating the total welfare on this basis, we see that the Peoples Century produces twice the social benefit of Police Stop!

\section{Figure 15: Comparative Welfare of Programmes}

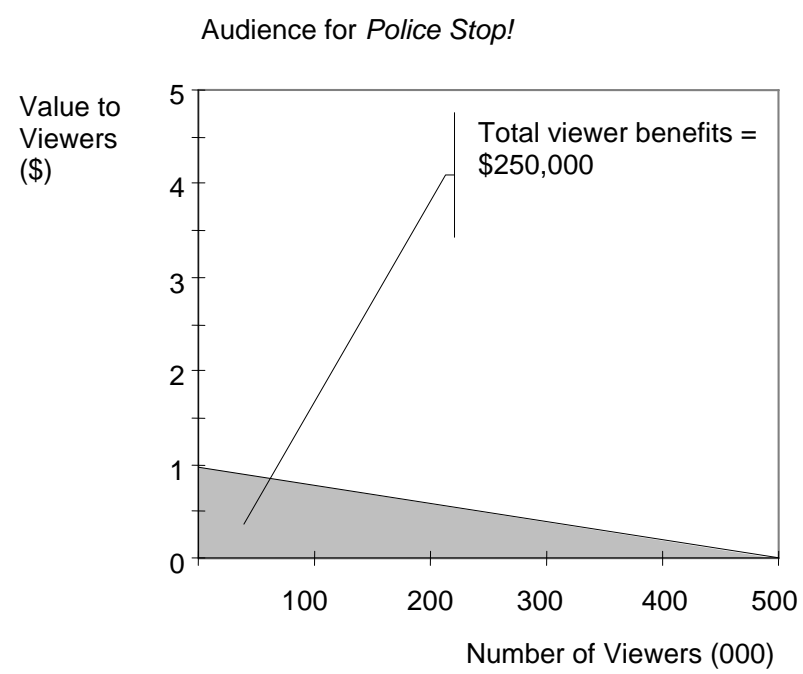

Audience for People's Century

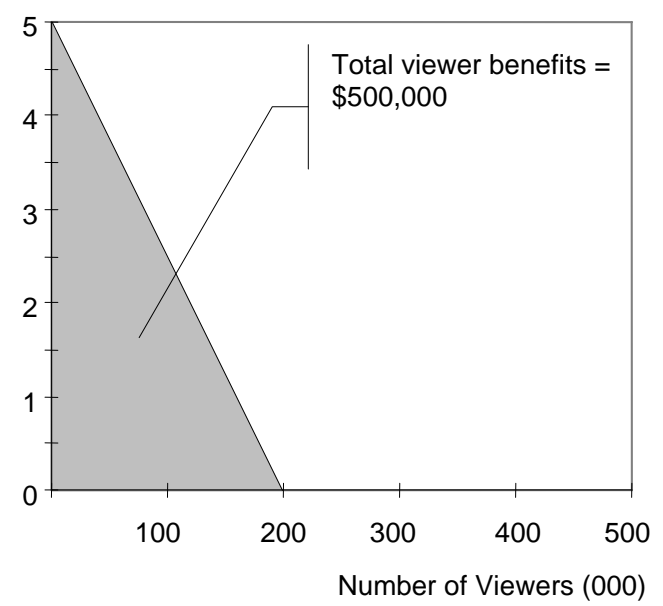

This does not tell us that viewers should be charged a price for viewing television, in order to decide which programmes should be shown. ${ }^{63}$ It tells us that People's Century is more intensely preferred by its audience, than Police Stop! is preferred by its audience. This intensity of preference means that Peoples Century produces a greater contribution to social welfare than does Police Stop!.

Note that we are talking as if there are two different audiences. This implies that, if only one programme could be shown, the interests of the Police Stop! audience should be sacrificed in favour of the People's Century audience. It is also worth noting how this model relates to the analysis in the previous chapter:

- The Steiner/Beebe model predicts that if there were two channels one would show Police Stop! and the other a programme of a similar type for an audience of 250,000 viewers each. Steiner correctly assumes that the intensity of audience preference is not reflected in a broadcaster's programming choices.

- Noam would argue, on the basis of audience numbers alone, that the public broadcaster would show Peoples Century to its smaller audience in response to their political demands. However, the idea of total welfare provides a stronger justification for public broadcasting to show the programme than Noam's "squeaky hinge” principle.

63 The Peacock Committee on financing the BBC saw this as an inevitable outcome of technological development. Its first recommendation was that all television sets sold in the UK market be required to be fitted with a "peritelevision socket" in anticipation that the broadcasting license fee would eventually be phased out by pay-per-view television. (Peacock Committee, 1986: 136) 
So far we have talked only of the gross social benefit. However, resources are consumed in the production and distribution of programmes. These resources could be consumed elsewhere in the economy, so the production costs should also be incorporated, in order to reflect net social benefit. Say an episode of Police Stop! costs $\$ 20,000$ to produce. The programme cannot be on-sold and the cost is borne entirely by the broadcaster, therefore the net social benefit of Police Stop! is \$230,000. An episode of Peoples Century costs $\$ 100,000$ to produce - but the BBC has recouped its cost in the UK and sells it to the broadcaster for $\$ 5,000{ }^{64}$ The net social benefit of Peoples Century (to New Zealand) is $\$ 445,000$. Clearly, the equation favours Peoples Century even more.

However, this is not how things work in reality, for free-to-air commercial broadcasting. The decision whether to broadcast Peoples Century or Police Stop! depends on three things:

- The cost of the programme

- The size of the audience it attracts (which may be unrelated to its cost of production)

- The advertisers' valuation of the audience

Figure 16 shows how a broadcaster might decide which of the two programmes to show, given that advertisers were willing to pay 10c per viewer, per programme. This clearly demonstrates the issue of market failure on the demand side: the market acknowledges the size of an audience, but not the intensity of its preferences. Under these circumstances market failure could be overcome if:

- the cost of People's Century was subsidised by $\$ 15,000$

- advertisers valued the audience for People's Century at 17.5c per viewer, and the audience for Police Stop! at 10c per viewer.

In either case, the broadcaster would acquire equal benefit from either programme. ${ }^{65}$

64 While the social benefit figures are entirely fictional, the costs are based on those reported by Horrocks (1995; 88-89), and the 1995 NZoA funding schedule for “low-budget” documentary series.

65 Note, however, that the cost of 'producing' the audience: the additional cost to the broadcaster of establishing the value of the audience, through audience research, promotion and so forth (the "selling costs"), would have to be added to the programme costs. 
This analysis does not apply in the same way to the demand of advertisers for

\begin{tabular}{|c|c|c|c|c|c|c|}
\hline \multicolumn{7}{|c|}{ Accounting analysis } \\
\hline Programme & Audience size & $\begin{array}{l}\text { Price per } \\
\text { Viewer }\end{array}$ & \multicolumn{2}{|c|}{$\begin{array}{l}\text { Audience } \\
\text { Value }\end{array}$} & $\begin{array}{l}\text { Programme } \\
\text { Cost }\end{array}$ & Net Margin \\
\hline Peoples Century & 200,000 & $\$ 0.10$ & \multicolumn{2}{|c|}{$\$ 20,000$} & $\$ 5,000$ & $\$ 15,000$ \\
\hline Police Stop & 500,000 & $\$ 0.10$ & \multicolumn{2}{|c|}{$\$ 50,000$} & $\$ 20,000$ & $\$ 30,000$ \\
\hline \multicolumn{7}{|c|}{ Economic welfare analysis } \\
\hline Programme & Audience size & \multicolumn{2}{|c|}{ Total Social Benefit } & \multicolumn{2}{|c|}{ Programme Cost } & $\begin{array}{l}\text { Net Social } \\
\text { Benefit }\end{array}$ \\
\hline Peoples Century & 200,000 & \multicolumn{2}{|c|}{500,000} & \multicolumn{2}{|r|}{$\$ 5,000$} & $\$ 445,000$ \\
\hline nalian ctann & Enn nnก & \multicolumn{2}{|c|}{ acn nกn } & \multicolumn{2}{|r|}{$\operatorname{sann} n \cap n$} & dason nan \\
\hline
\end{tabular}

audiences. The advertisers' intensity of preference is taken into account in deciding which programmes will be shown, and advertisers' welfare may also be taken into consideration. We may infer from this analysis that, if a government chose to pursue a policy that encouraged commercial free-to-air broadcasting, it was also accepting that the total welfare of society should be measured primarily by the welfare that would accrue to advertisers. There is nothing inherently "wrong” about such a choice. Indeed, it could easily be argued that improving the welfare of advertisers oils the wheels of commerce and improves the welfare of society as a whole in other ways. However, it is wrong to argue that this policy would significantly improve the welfare of the audiences.

\section{Licence Fees and Welfare}

If audiences could pay directly for the programmes that they wished to watch, their preferences would be better reflected. However, rather than looking at Pay TV next, we will have a look at how the level of the license fee affects audience welfare.

Fraser (1996) provides a formal model for the payment of broadcasting licence fees. In it, broadcasting is treated as an excludable public good. That is, if someone purchases a television, it is assumed that they will also pay the licence fee. ${ }^{66}$ The license fee is a lump-sum tax on television owners, where payment of the fee entitles the purchaser to consume the total output of the public good. ${ }^{67}$. Because consumers are self-selecting they have a choice of paying the fixed price or not consuming at all. Some consumers are forced to pay for more than they would ideally consume, in order to consume any at all; others consume less than they want, since they are unable to purchase more or different outputs at the stated price.

\footnotetext{
$66 \quad$ Fee evaders are excluded from the model.

67 It may help to think of this model as applying in Britain before the advent of the independent television channels: the BBC funded by the licence fee, and no other services available.
} 


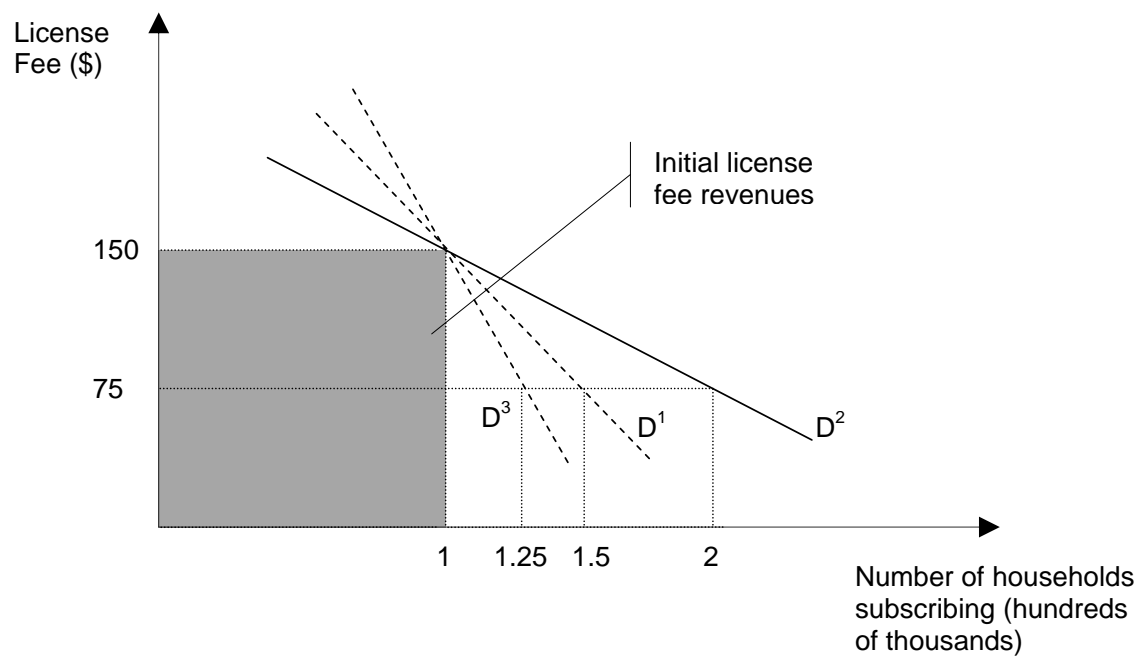

Figure 17 demonstrates one of the key ideas discussed in Fraser's article. With a licence fee set at $\$ 150$, there will be 100,000 subscribers providing revenues of $\$ 15 \mathrm{~m}$. This sum also represents the total welfare of the society derived from television viewing.

We want to know how consumers will respond if the licence fee is raised or reduced. ${ }^{68}$ In this Figure 17 it is halved, to $\$ 75$. One possible outcome, shown here by the line $\mathrm{D}^{1}$, is that the drop in the licence fee leads to an increase in the number of subscribers to 150,000 . While this means a television service becomes available to a larger audience, revenues fall to $\$ 11.25 \mathrm{~m}$ in total, and society's total welfare therefore also falls. In the other cases, shown by the line $\mathrm{D}^{2}$ and $\mathrm{D}^{3}$, the number of subscribers increases to 200,000 but revenues remain the same $(\$ 15 \mathrm{~m})$, or the number of subscribers increases to 125,000 , but revenues fall.

Fraser finds that important considerations to be taken account of in the model are the economies of scale in production of the good, and the society's concern for egalitarianism.

- The presence of economies of scale means that lowering the fee in order to attract more consumers, if it reduces the total licence fee income $\left(\mathrm{D}^{3}\right)$, might decrease the level of programme output by a greater amount (in hours of broadcast time), than the fall in revenue. It would therefore reduce the total social benefit by more than the fall in revenue, since the output of programming would also fall.

68 The economic concept being outlined here is known as the "own-price elasticity of demand”, which refers to consumer responses to a change in price for one good, while the prices of all other goods are held constant. 
- A more egalitarian society, with a more equal dispersion of income will naturally increase the number of potential subscribers, whereas a less equal income dispersion will restrict the number of subscribers, and may also reduce welfare overall.

- By contrast to this model, with its self-selecting consumers, mandatory taxation could be used to provide the good. This may increase the welfare of society overall, but reduce welfare for the poor (depending on the regressiveness of the tax system).

- Fraser's model reminds us that license-fee funded public broadcasting services are not a free good, except to fee-evaders. Every viewer is charged the average cost of providing the broadcast service, regardless of the amount they consume, or the intensity of their preference for the programmes provided. Some viewers obtain greater-than-average benefits, while others gain less. Importantly, the overall social benefit of the service will depend on the level at which the license fee is set, and the efficiency with which programmes are produced.

The idea of a license fee presumes that the broadcaster will be a discriminating monopolist, of the type proposed by Steiner (page 50, above), on the assumption that a discriminating monopolist will seek to serve all audiences. If the monopolist also takes into account the intensity of consumers' preferences it would also provide a programme mix that produces the highest net social benefit.

The paradigm falters when consumers are able to privately purchase programmes. Rather than paying a licence fee, consumers might prefer to decide for themselves whether to spend the money on cable, satellite or pay TV services, in order to receive the programmes they want. In New Zealand, people who are able to receive a free television service (free, that is except for the cost of watching advertisements), are legally obliged to pay a broadcasting licence fee which subsidises the cost of services they may not wish to consume. Unless they do so, they are supposed to forego watching (colour) television at all.

\section{Pay TV}

Fraser's model provides a basis for modelling the provision of pay TV services. The only difference is that payment of the subscription fee is voluntary for pay TV, and the service is excludable - so there is no possibility of "free riders" obtaining the service and not paying for it. Most consumers of pay TV in New Zealand currently do not pay on a per-programme basis. Rather, they pay a monthly fee to receive an entire programme of sport, or news, or movies. ${ }^{69}$ This effectively excludes some audiences from receiving particular programmes (such as live All Black test matches). However, it begs the question of whether the welfare loss to those households is so significant that government intervention should be required to mitigate it.

69 Cable services are often "bundled”, meaning that one pays a higher price for a bundle of services, but a lower price than paying for each of the services separately. Sometimes one pays a lower price than paying for any of the services separately. This practice requires viewers to over-consume, relative to their actual preferences. 
In Figure 18, we see how pay TV channels price a live test match. The $\mathrm{AC}=\mathrm{S}$ curve tells us that the cost of supplying the programme (including the cost of purchasing the live broadcast rights) is $\$ 400,000$. The viewers' demand schedule lies above part of the $\mathrm{AC}=\mathrm{S}$ curve, implying that some viewers are willing to pay more than the average supply cost. The broadcaster maximises his profits by charging $\$ 3.00$ per subscriber for this match, which provides him with a tidy profit of $\$ 200,000 .^{70}$ There is a loss of welfare to viewers who would like to watch the live match, but who cannot or will not pay the asking price of $\$ 3.00$.

\section{Figure 18: Pay TV and Welfare - mixed systems}
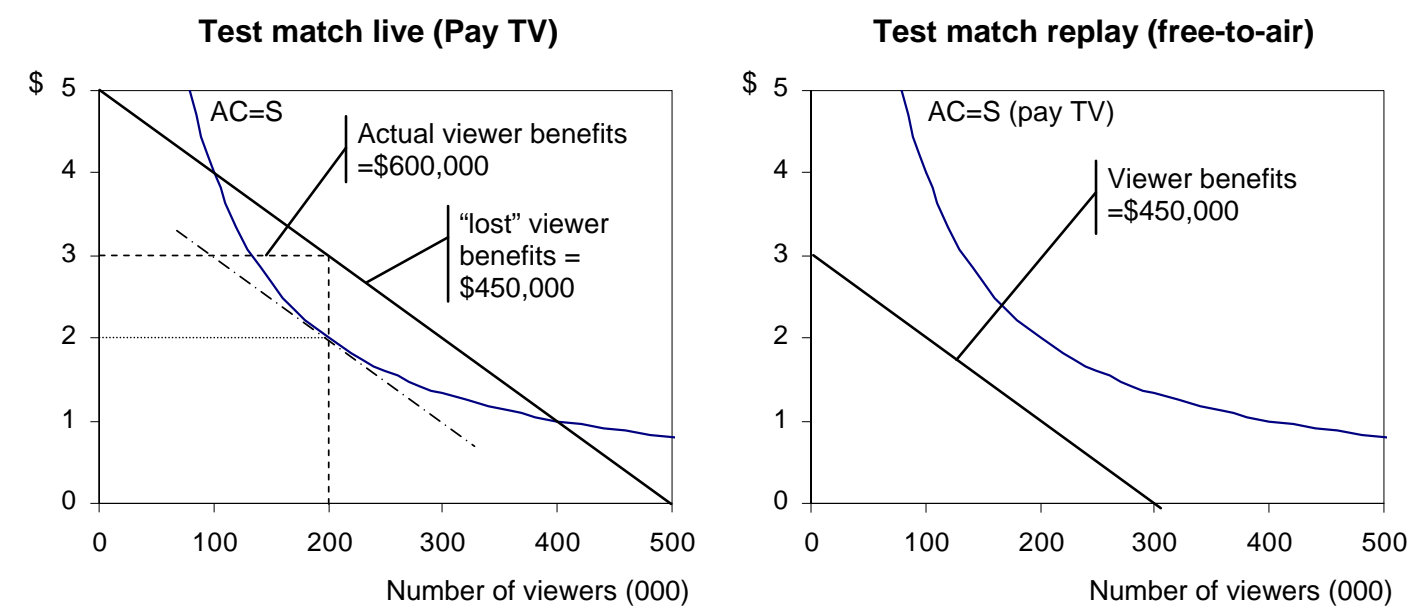

When delayed coverage of the match is replayed on free-to-air television, it attracts the residual audience of 300,000, who pay no money to receive the broadcast. ${ }^{71}$ There will only be a welfare loss if the residual audience is not large enough, or not valuable enough, for advertisers to meet the supply cost.

This model predicts that many, if not all, of the programmes that are intensely preferred by large audiences will tend to migrate to pay TV. Free-to-air television will therefore increasingly tend to broadcast less intensely-preferred programming which attracts large audiences, and is relatively cheap to produce. People who would willingly pay to watch their most-preferred programmes, but who cannot afford to, will be disadvantaged.

\section{Advertising and Welfare}

Wildman and Owen (1985), developed a model that incorporates the welfare effects of advertising. ${ }^{72}$ In this, advertisements are treated as a disutility, and therefore

\footnotetext{
70 The profit maximising point is found at the maximum vertical distance between the $\mathrm{AC}=\mathrm{S}$ and Demand curves, which is where both curves have the same slope, as shown.

71 Wildman and Owen (1994: Chapter 2) discuss the practice of "windowing”, which is the practice of staggering the release of a "text" in various media as a form of price discrimination.

72 Their incentive for doing so was the American Justice Department's successful challenge, in 1981, to the National Association of Broadcasters' rules capping the amount of advertisements that members could broadcast (Owen and Wildman, 1992: 125).
} 
“...commercial time may be treated as a non-monetary price that viewers pay to see programs supported by advertising." (126) ${ }^{73}$

Figure 19, which appears in Owen and Wildman (1992: 126), demonstrates the general proposition that advertising minutes can be incorporated in a welfare model. The model shows how the number of viewers decreases as the number of commercial minutes increases, creating a welfare loss for those viewers unwilling to pay the "price" of being bombarded with advertising. ${ }^{74}$

At some point on the schedule, the loss of revenue from diminishing audience minutes will exceed the gain in revenue from increasing advertising minutes. However, the power of this restraint on broadcasters will depend critically on the own-price elasticity of demand for audience minutes in advertising markets, the shape of the audience's willingness-to-pay (that is, withstand advertising) schedule, and the expected reactions of other broadcasters. ${ }^{75}$

\section{Figure 19: Demand as a Function of Advertising}

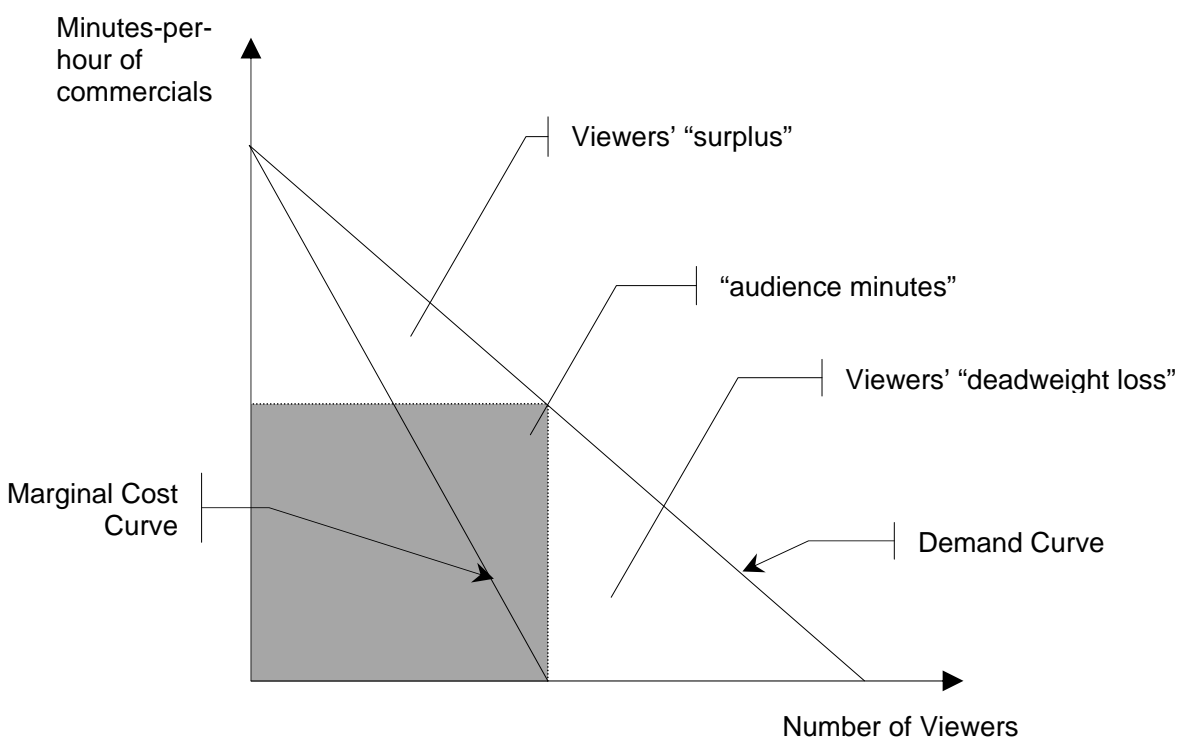

Advertising diminishes the net benefits received by viewers, even though it increases the net benefits received by advertisers. One could measure the relative welfare benefits quite easily. Say the audience for one hour of prime-time television is 100,000 viewers,

73 The concept of treating advertisements as an explicit cost to the user of media services is spreading. The Economist (23/8/97: 15), notes that a Swedish telephone company offers free calls to callers willing to be interrupted by brief commercial breaks.

74 They assume that, because the marginal cost of supply is zero, the marginal viewer should pay nothing, rather than the average cost (hence the presence of a marginal cost curve). This is a theoretical error, which renders their treatment of Pay TV, in the same book, nearly incomprehensible.

75 The last point is that which Masson, et al. (1990) theorised, and which was incorporated into the analysis of supply-side market failure, above. 
and in that hour they watch 15 minutes of advertising. If we priced that time at $\$ 10$ per hour, the value of those audience minutes would be $\$ 250,000$ - a measure, in other words, of the price that the audience is "paying" for watching that hour of television. This might be compared to either the price paid by advertisers for those 15 minutes, or the net social benefit of the programme being broadcast, as a means of determining whether there are "too many" ads on television. ${ }^{76}$

Horrocks (1995) also reports that some critics of the Broadcasting Act wanted “...the broadcasting fee to be used to buy BBC programmes directly or to fund the removal of advertising from some days of the week.” (98) Inevitably, however, if viewers prefer not to have any advertisements, they must be prepared to pay for broadcasting by some other means - a higher licence fee, higher personal taxes, or by subscribing to a pay TV service.

\section{Treasury's use of Welfare Economics}

This section has introduced the concept of welfare economics and demonstrated how it may be used in a number of ways to analyse the broadcasting industry. We have also used it to demonstrate that free-to-air media are not really "free" at all; consuming advertisements is simply one among a variety means of paying for broadcasting services, each of which has implications for the way the benefits of viewing (or not viewing) will be distributed. We have used it to demonstrate that commercial free-to-air broadcasting could optimise the welfare of audiences - although they may optimise the welfare of advertisers.

This was acknowledged by Treasury in the part of its submission dealing with welfare and advertising-supported television (1986: 31, 36). However, the submission then goes on to employ the Steiner/Beebe model reviewed in the previous chapter to argue that: "With a more efficient spectrum allocation system,... and with no unnecessary regulatory constraints on the development of alternatives such as cable TV and UHF... there is no reason why an advertising-supported system with a competitive structure should not provide a large degree of programme diversity” (36).

The submission then acknowledges that this would not meet the needs of all audiences, especially smaller ones with intense preferences: "Some gaps in programming where audience benefits exceed costs might still remain however, and it is to private methods of dealing with these that we now turn" (36). There follows a brief review of club or subscription-supported broadcasting and pay TV.

The submission then turns its attention to tax-funded broadcasting, with a lengthy explanation that the government would have difficulty assessing consumer preferences in the absence of an explicit price mechanism. It concludes that tax-funded broadcasting will generally be less efficient than pay TV unless:

- Pay and subscription broadcasting fail to produce net welfare benefits, due to high transactions costs, and

\footnotetext{
76 The presence of supernormal profits (that is, profits that are higher than expected for the investment
} risk involved in broadcasting) would suggest a prima facie case for undertaking such an analysis. 
- The benefits of tax-funded broadcasting outweighed all relevant costs, including the cost of raising taxes and the information costs of discovering audience preferences.

This part of the Treasury submission is not an assessment of the welfare costs and benefits of public broadcasting, vis-à-vis other means of funding radio and television. It is an argument against tax-funded broadcasting, based on the idea that the information costs would probably be too high. However, the radio and television industries do in fact meet the costs of obtaining information about audience preferences (through ratings and market research), and seem to do so efficiently. In principle it would not be more difficult or expensive to assess the intensity of audience preferences.

There is, however, a more fundamental issue regarding the application of welfare economics to media audiences, which flows from one of its fundamental assumptions: the idea that consumer preferences are exogenously determined. This was not addressed at all in the Treasury analysis.

\section{Welfare and Endogenous Preferences}

The basic concept of welfare economics is that the market will supply what the consumer desires, rather than the consumer demanding what the market supplies. In the model presented in Figure 14a, we started with an observation of a consumer's preferred bundle of goods. We did not enquire what sort of psychological satisfaction (utility) the consumer obtained from the goods, nor did we lift the veil to discover how consumers' preferences were formed. Therefore we assumed that the consumer's preferences were exogenous (determined outside the model). This is an assumption that underpins welfare economics models because consumers' revealed preferences (i.e. what they actually choose to consume), are observable and therefore provide a factual foundation for the theory. The consumers' motives for purchasing goods, and the psychological satisfactions they obtain from their consumption, are not observable. As we attempt to discover these, we move from objective fact to subjective assessment - and the economic theory rapidly starts to lose its pseudo-scientific gloss.

Clearly, exogenous preference formation ought not be assumed, in discussing media economics, unless one also assumes that the media has little or no influence over audience preferences. As we have already seen in Chapter 1, the nature and extent of media influence is a matter of considerable debate in the social sciences. Although there is no agreed view on the matter, it is possible to use some of the ideas about media influence that we have reviewed to investigate the issue of endogenous vs exogenous preference formation, as it relates to consumption of media itself.

Figure 20 presents a four-quadrant model of some possibilities regarding media influence and the formation of consumers' media consumption preference. The top left quadrant assumes that the media does influence audiences (in the long-term), and that media consumers will develop a taste for the products supplied by the market. This reflects what is known as the Lord Reith's “BBC knows best” principle, which Treasury repeats in its submission:

"It is occasionally [pointed out] to [the BBC] that we are apparently setting out to give the public what we think they need - and not what they want, but few know what they want, and very few what they need"(49). 
Much has been made, in debates about broadcasting policy, of the "BBC knows best" view. It is often condemned for its elitism, and for its implicit support of a particular view of what constitutes "quality" culture. However the idea of endogenous preference formation need not be linked to "elite" broadcasting only. John McCready, as head of programming for TVNZ, introduced New Zealand to Australian rugby league by playing it every Friday night. He also refused to accept New Zealand on Air funding for Shortland Street until NZoA agreed to support it for an entire year, on the grounds that it would take the New Zealand audience that long to develop a taste for home-grown situation drama of this type. His assessment that the audience would form a preference for these programmes was correct; Shortland Street is now an institution on our screens, and Rugby League is so popular that it is now screened predominantly on pay TV.

The top right quadrant hypothesises that media consumption choices are exogenous and the media influences the choice of media consumed. At the extreme, this might be logically impossible. However, it is also possible that media consumption choices could be initially shaped by external influence (such as ethnic culture or religious belief), and that the audience only consumes media messages that fit with - and subsequently reinforce - those preferences. They are rational utility maximisers in the strict sense proposed by Steiner's model: they watch their first preference or nothing at all.

In the lower right quadrant, we have media consumers who fit Fiske's neo-Marxist mould: their media consumption preferences are shaped exogenously, and the media is not influential. This is the "active audience" who co-opt media messages and their meanings into their own world view. These are also the rational utility-maximising media consumers proposed by Treasury, in defiance of the notion that the media are influential in forming consumers tastes for media itself - whereas economic logic would dictate otherwise. ${ }^{77}$

77 That is, as proposed in the "economic" argument presented under the heading Economics and Media Effects, page 20, above. 


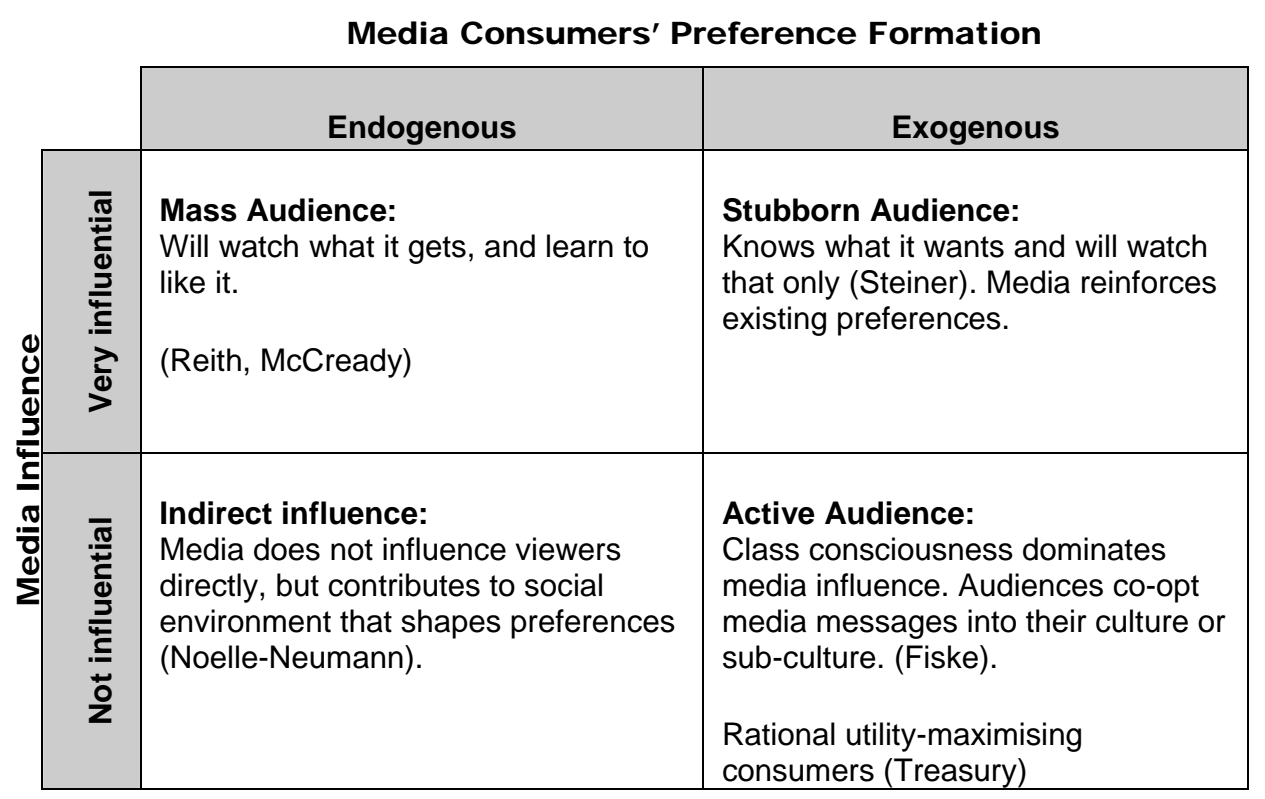

In the lower left quadrant, we have media consumers whose tastes for media consumption are formed by the media, but where we presume the media are not influential in forming those tastes. Again, this may be logically impossible at the extreme. However, it is conceivable that the media contribute to the formation of a social environment or atmosphere that is influential. In that case the media may influence peoples’ preferences, even though it is not directly influential.

It is probably possible to identify individuals who fit any or all of these categories. It is also likely that these 'pictures' of the audience will be used in policy debates, depending on the position of the person making claims about media influence and policy outcomes.

However, if we accept that the media does have an influence on consumer choice, then we must assume that audience taste formation is at partially, if not predominantly, endogenous. The clearest picture we have of media influence, is that media is influential in a socially mediated context. That is, the media has a weak direct influence on audiences, but a pervasive indirect influence, which is mediated by peoples' peer groups and other sources of social "cues". Also, media is likely to be more influential in a cultural climate that supports conformism, and where the media are both ubiquitous and consonant. The strength of these effects will therefore depend to some extent on the broadcasting policy environment, as well as other cultural and communications policies - and the extent of their congruence with other policies and social institutions. ${ }^{78}$

78 The debate raised by Steiner, Beebe and others about diversity of broadcasting outputs revolves around an implicit presumption that the media should offer a diverse range of programmes. This could be taken to mean that the media ought to satisfy a wide range of exogenously-formed preferences (i.e., satisfy the consumers in the right two quadrants of Figure 20). On the other hand, 
Obviously, the idea that consumer preferences are endogenous undermines the whole notion of consumer sovereignty. Whereas the Treasury analysis ignores this issue, the Peacock Committee (1986) gives it serious consideration: ${ }^{79}$

“ (if) consumers' tastes are not formed by consciously conducted trial-and-error processes but by "outside" forces, notably by advertisers who can manipulate consumer choices.... (this) implies that replacing the license fee with advertising revenue for the BBC would not be in the interests of listeners of viewers.” (28)

It also addresses the "BBC knows best” argument:

"The principle behind this argument clearly appeals to those who regard broadcasting as a public service designed to influence and not merely to reflect the public's preferences for programmes...(if this were accepted) a free market in broadcasting services, if technically possible, should not be encouraged.” (28)

The committee goes on to say that different ways of funding broadcasting embody value judgements, which it could not avoid taking a position on. In its conclusions and recommendations, it recognises that consumer sovereignty is imperfect, and that some people may come to enjoy what they do not already, or "...will accept guidance or stimulus from others where they perceive that their knowledge or taste is limited." (128). In short, the Peacock Committee's recognition that preference formation might be endogenous led it to support an ongoing role for public broadcasting.

\section{Direct Benefits}

To finish off this chapter, we will return to one of the issue of "deadweight losses" is created in some circumstances, when a consumer cannot, or will not, consume a product because the price (psychological or monetary), is too high.

They divide the possible rationales for public television into two categories: those that provide direct benefits (which accrue to the viewers of public television), and those that provide external benefits (which accrue to people who do not watch public television). The next chapter deals with the notion of external benefits.

Noll, et al (1977) state that government intervention that produces direct benefits to viewers can be justified on either of two grounds:

(1) When the benefits to the viewers exceed the costs of providing the service, or

(2) When society desires to redistribute income to viewers by subsidising their television viewing.

it could be argued that the media should provide diversity in order to prevent it from having undue influence on the population's political and other preferences (mitigate the media's effects on consumers in the left-side quadrants of Figure 20).

79 It is unclear whether the committee was referring to endogenous formation of consumer preferences for media itself. 
However, they take the view that discussion of such matters is really outside their purview: "The best measure of the value of public television to (viewers) is the amount they are willing to pay for it.” (215). This position is explained in a footnote:

"This is the conventional view of economists that consumers are rational. Alternatively, one could take the position that most viewers do not know what they like - or what is good for them - and, therefore, that a group has to be empowered to make programming decisions "in the public interest". This view is not only elitist and undemocratic, but also permits no further examination of the proper role and scope of broadcasting. We ignore the "BBC knows best” approach simply because, as economists, we have little of substance to say about it." (215; footnote 8)

They follow this statement with an explanation of how the expansion of programming choices with the arrival of cable TV would “...increase viewing options so much that public television will no longer serve a worthwhile purpose.” (216) This is Noam's "mixed systems" argument, which is explained above (page 52).

Treasury agrees that government should not pay for goods which people cannot, or will not, pay for themselves:

"The proposition that Government should fund programmes for which people would not be willing to pay the supply costs even if they could, is usually referred to as a "merit good" argument. This is best seen as a non-economic proposition, because economics usually assumes that consumers are sovereign - individuals judgements of the benefits they receive from consuming goods or services are the appropriate criteria for assessing consumer welfare.” (48)

This argument attempts to draw a boundary around what is and what is not "economics". It is very clearly an ideological statement, which seeks to define and protect the boundaries of a "closed system" of thought. It consigns social, legal, cultural considerations to the realm of political (and therefore irrational and inefficient) decision-making processes.

\section{Summary}

We began this chapter by stating the general assumptions linking the idea of consumer sovereignty to economic welfare, and the optimal allocation of society's scarce resources. The first section then showed us that:

- Commercial free-to-air radio and television will respond to the advertisers' demand for different audiences to consume. This will increase social welfare to the extent that it increases the welfare of advertisers. ${ }^{80}$

- Alternative means of paying for broadcast services have different welfare impacts: the license fee will exclude some audiences, as will pay TV. The existence of mixed pay and free-to-air systems will tend to divide audiences into "haves" and

80 The analysis in the previous chapter, however, also suggests that an oligopolistic media market, which will tend to emerge as increasing numbers of frequencies are made available, could make this market inefficient, compromising advertisers’ potential welfare gains. 
"have-nots". Audiences pay for "free-to-air” commercial broadcasting by suffering the negative welfare impacts from advertising.

The second section showed us that the presence of endogenous consumer preferences should encourage a cautious approach to the application of welfare economics and its methods when discussing broadcasting policy.

It is not possible to make a detailed critical assessment of the manner in which the Treasury submission to the RCBRT treats its approach to welfare economics because it:

- Ignores the welfare impacts of advertising on audiences.

- Does not seriously consider the welfare impacts of tax-funded broadcasting preferring instead to put forward a rhetorical argument about the information costs of discovering audience preferences.

- Ignores the possibility that the media may influence consumers' preferences for media outputs.

Finally, it dismisses the notion that audience welfare could be improved by government provision of direct benefits, by refusing to contemplate that such considerations are worthy of economists' attention. 


\section{Chapter $8 \quad$ Rights and Property Rights}

Deregulation does not necessarily mean the removal of regulation. It may also refer to a process whereby goods or services are allocated by the market, which had until then been allocated by the authority of the state or by common law (the polity). Brian Easton (1997: 29), quotes this passage from Pusey (1993: 15):

"A first assumption of social democrats everywhere is that nation societies (and federations such as the emerging Europe) have not one co-ordinating mechanism but two. On the one side they have states, bureaucracies and the law, and on the other, economies, markets and money. It is with these structures we collectively coordinate our relations with the rest of the world, our work, our social interactions, and most other aspects of life we understand as 'civil society' and normatively define with notions of citizenship, democracy and human rights."

In order for market regulation to take effect, it is necessary to specify, create and allocate property rights. This may take one of two forms: the creation of property rights where no rights previously existed, or the transformation of rights, which had been created within the polity, into property rights.

A primary purpose of broadcasting deregulation was to create property rights out of the right to broadcast, so that the difficulties of the Broadcasting Tribunal process could be overcome. Treasury claimed this would also lead to greater allocative efficiency:

"Open competitive access to the radio spectrum will tend to promote the development of efficient broadcasting systems... (resulting) in a more efficient pattern of resource use and consumption than the existing or alternative developments because it will be based more directly on consumer preferences and opportunity costs." (from points ix and x, Treasury 1985: 2)

The piece of economic theory that proposes and justifies the creation of well- specified property rights, their allocation and their efficient exchange is known as the Coase Theorem.

\section{The Coase Theorem and Allocative Efficiency}

The Coase Theorem was first outlined in an article by Ronald Coase titled The Federal Communications Commission (Coase, 1959). He developed it further in The Problem of Social Cost (Coase, 1961). The Coase Theorem is often misunderstood. Veljanovski (1982) identifies five interpretations of its meaning in the literature of economics, and notes that:

"...there is a continuing controversy among economists surrounding the validity of the Coase Theorem. No year passes without several articles in the most respected journals refuting the theorem and a corresponding number reaffirming it."

The theorem therefore needs to be handled with some care. We will describe it first, then look at its meaning as it applies to broadcasting rights. 
The Coase Theorem can be demonstrated in the model presented in Figure 21. Recall the diagram in the previous chapter that shows how an individual chooses to maximise her utility given her income and a set of prices (Figure 14a, on page 68). If you duplicate that diagram then rotate the copy so that its corner (origin) is at the top right, then fit the two diagrams together, you have an Edgeworth box. This represents a twoperson economy (although it may equally represent two groups of people). We will call them person $\mathrm{A}$ and person $\mathrm{B} .{ }^{81}$

\section{Figure 21: Edgeworth Box Depiction of the Coase Theorem}

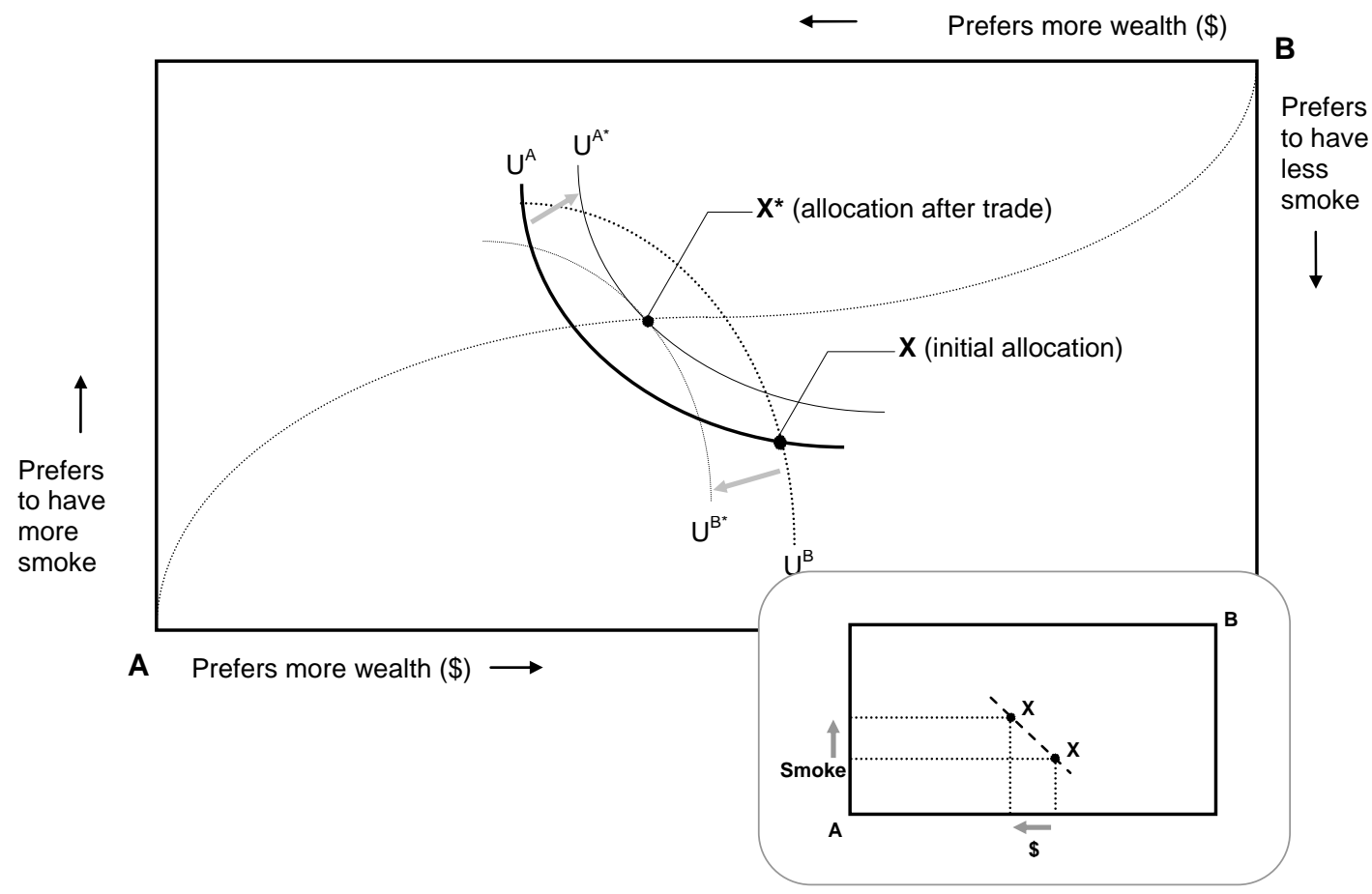

In this example, the economy has only two goods: wealth and smoke. Person A is a smoker and prefers to be able to smoke more. Person B is a non-smoker, and prefers that there is less smoke (therefore that person A will smoke less). The right to smoke is a property right specifying the total amount of smoke that may be produced, which $\mathrm{A}$ and B must somehow share. In this little economy there is also fixed amount of wealth (representing "all other goods"). This is how the model works:

- Initial allocations of wealth and smoke are set at point X.

- Both $\mathrm{A}$ and $\mathrm{B}$ have utility curves $\left(\mathrm{U}^{\mathrm{A}}\right.$ and $\left.\mathrm{U}^{\mathrm{B}}\right)$, convex to their respective origins (at bottom left and top right of the box), representing their constant utility trade-offs between wealth and smoke. These must both pass through point $\mathrm{X}$.

- It is possible for A and B to trade with each other, to any point within the "lens" shape created by these initial utility curves. In this case they trade to point $X^{*}$.

81 In a two-dimensional diagram, we can only have two people in this economy. Using mathematics, we could create a multi-dimensional "space” with as many people as we please. Conceptually, this could represent an entire economy. 
- At $\mathrm{X}^{*}$ their new utility curves $\left(\mathrm{U}^{\mathrm{A}^{*}}\right.$ and $\left.\mathrm{U}^{\mathrm{B}^{*}}\right)$, are both "higher", or further from their respective origins, than they were before. This means both are better off than before.

- The curves $\mathrm{U}^{\mathrm{A}^{*}}$ and $\mathrm{U}^{\mathrm{B}^{*}}$ are at a point of tangency. This means that now neither can be better off without making the other worse off. If A moves to a "higher" utility curve, B must move to a "lower" utility curve and vice-versa.

- The point of tangency lies on a line running from A's origin to B's, which is called the 'contract curve'. This represents all the possible points of tangency between their respective sets of utility curves.

- In the little insert box, you can see the slope of the straight line running through points $\mathrm{X}$ and $\mathrm{X}^{*}$ represents the agreed price, or the amount of wealth $\mathrm{A}$ has paid and the amount of smoke A has gained for it. In this type of model, the line always slopes downward to the right, as you must give up some wealth in order to gain more property.

The most important thing to remember from this, is that it describes precisely what economists mean by allocative efficiency. That is, an efficient allocation has been achieved when people can buy and sell property, in a free market, to a point where none can be made better off without making others worse off. It also demonstrates the link between consumer sovereignty and allocative efficiency: it shows that individuals, who are the best judges of their own needs, are able to freely contract with each other. These contracts will decide what gets produced, in what amounts, and therefore how society's scarce resources can be allocated without any intervention by the state. Indeed, intervention by the state would "distort" this efficient allocation.

The most widely accepted definition of the Coase Theorem is: Where adequately specified property rights exist in any good, and in the absence of transactions costs, any initial point of allocation will allow an efficient allocation to be achieved.

This is one of the most powerful and elegant arguments in economic theory (more so in its mathematical form), and it is the foundation stone upon which broadcasting deregulation rested. However, the theorem it is not as straightforward to apply as it first seems, and it needs to be treated with a great deal of care, especially when applied to broadcasting.

\section{Creating property rights}

In order to create a market in tradable rights to smoke, certain conditions have to be met. In the model presented above, these would be:

- Total amount of smoke: Someone has to decide how much smoke will be produced in total (perhaps measured in cigarettes per hour).

- Divisibility: The property right must be adequately divisible. If we specified the amount of smoke as in packs of cigarettes per day, then the unit of rights might be too large for A and B to trade within the "lens" and no trade would be possible.

- Alienability: In order to sell something, you have to be able to transfer your right to that thing to someone else, or alienate it. That means you must also have an unambiguous right that is “... assigned to one identifiable person, the 'owner', rather than a vague collection of people, as common property....” (Fountain, 1988: i)

- Specification of property right: Someone has to decide precisely what we mean by "smoke". Does it mean only cigarette smoke, or does it include cigar smoke? 
Should high-tar cigarettes are counted as equal to low-tar cigarettes? If the amount of smoke is measured in cigarettes per hour, should the size of the room that A and $\mathrm{B}$ share be included in the specification of the rights?

- Enforceability: Someone needs to decide who will monitor the output of smoke and, if there is a dispute over the amount of smoke in the air, someone will have to judge whether person A or person B is correct in claiming that their rights have been violated.

- An acceptable initial allocation: Someone has to decide where the initial allocation point is.

- Legitimacy: For the initial allocation to be accepted by A and B, as well as all the other matters, both will have to accept that the decision-making process is legitimate. That means someone also has to decide (or A and B have to agree) how the decision should be made.

All of these decisions are legal and political matters, or matters of policy. ${ }^{82}$ They are not made in the market, but by society's other co-ordinating mechanism: the law, the Government, and the Government's advisors. Given that all these decisions can be made, it is possible to create a market that will efficiently regulate the production of smoke.

\section{Initial Allocation}

One interpretation of the Coase theorem is any initial allocation point will produce equally efficient outcomes. This claim is dangerously wrong, and it is important to understand why.

The point is demonstrated in Figure 22, below. Let us say the initial allocation of rights was entirely in favour of person $\mathrm{A}$, the smoker, at point $\mathrm{X}^{\mathrm{A}}$. This means $\mathrm{A}$ has rights to all the smoke (A and B have equal wealth). Given that both have "normal" utility curves, they will trade along a downward-sloping line, to a point represented as point $\mathrm{X}^{* \mathrm{~A}}$. This indicates that person $\mathrm{B}$ has paid person $\mathrm{A}$ to smoke less.

If the initial allocation of rights was entirely in favour of person $\mathrm{B}$, the non-smoker, at point $X^{B}$, then $B$ has rights to all the smoke. $A$ and $B$ will trade along the other sloping line, to a point represented as point $\mathrm{X}^{*^{\mathrm{B}}}$, indicating that person $\mathrm{A}$ has paid person $\mathrm{B}$ so they can smoke.

As the diagram shows, the different initial allocation produces very different outcomes, in terms of the wealth and the right to smoke (or not-smoke) of the two people.

82 Coase argues that statutory regulation of radio frequencies was unnecessary and, given time, the Courts would have developed a body of law delimiting property rights, that could have been later supplemented by regulation (Fountain, 1988: 3). He is essentially claiming that common law has greater legitimacy than the law-making capacity of an elected legislature. 


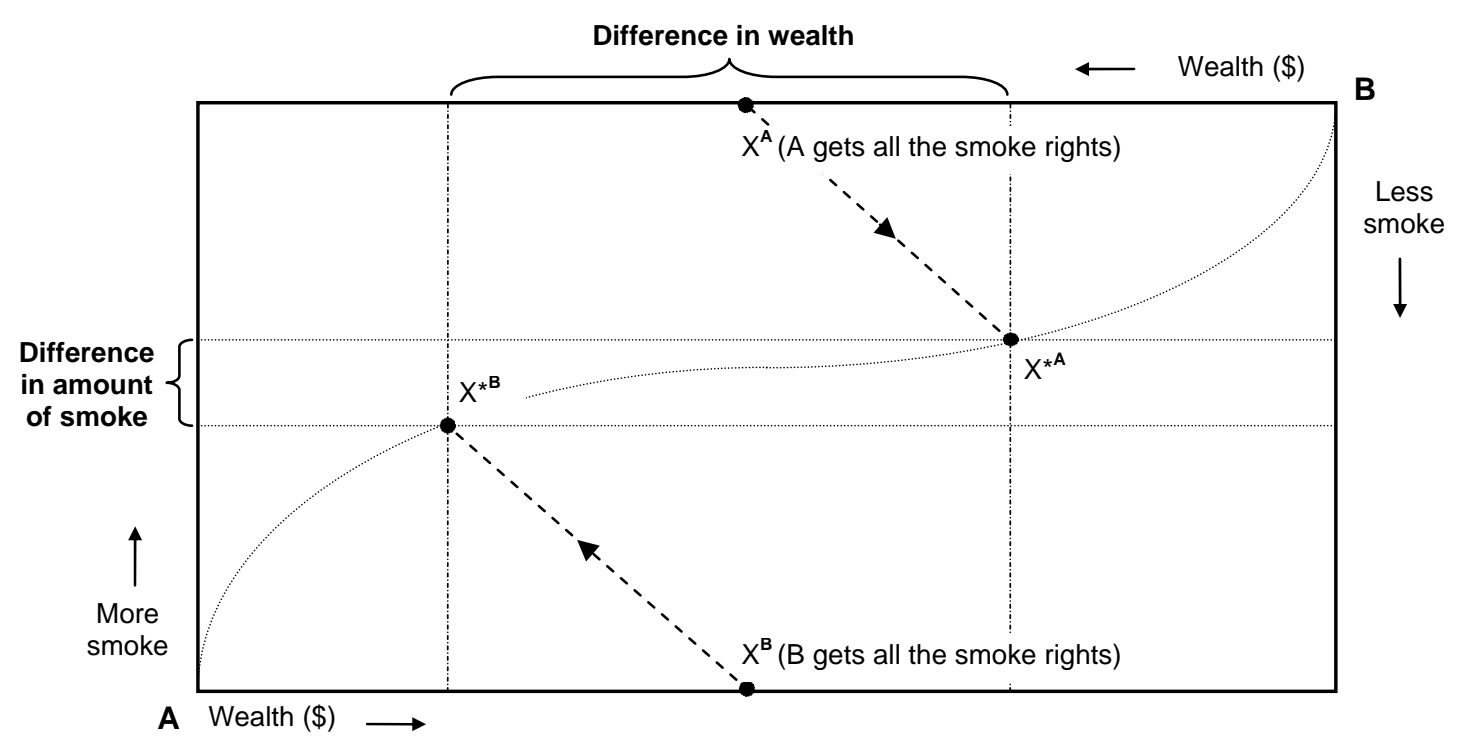

If A gets the initial allocation, A ends up both wealthier and with a greater amount of property rights than B. Furthermore, A suffers no loss (and possibly some gain) in utility after the two parties have traded, by definition. The only case in which an equal allocation could be reached after trade, is if both A and B were utterly indifferent as to the amount of smoke created - in which case smoke would have no value at all, by definition.

The decision as to initial allocation is probably the single most important aspect of deregulation, as it has significant impacts on the equity and wealth of affected parties.

\section{Transactions Costs}

When the government created property rights out of the right to broadcast, it could have allocated the rights equally to every citizen (person A) or it could have allocated all the rights to broadcasters (person B). If broadcasters wanted to have a right to broadcast, they would have to pay the audience. If, on the other hand, citizens wanted to have the right to broadcast, they would have to pay the broadcaster for it.

The first option might incur high transactions costs. Fountain, outlining the work of DeVany et al. (1969), mentions the possibility of allocating "interference" rights to the audience, but notes that "...the transactions costs involved in negotiating with large numbers of broadcast receiver owners would be prohibitive, thereby reducing the value of transmission rights." (16, footnote 30) The idea of transactions cost is important: if the cost of making a contract were too high, neither party could move from $\mathrm{X}$ to $\mathrm{X}^{*}$ and allocative efficiency could not be achieved. However, Fountain is wrong in one respect: it is not necessary for "broadcast receiver owners" to hold their property rights severally and individually.

We can demonstrate this with the model in Figure 22, above. Under the first allocation, in favour of person A, the audience could collectively engage an agent who would negotiate with broadcasters over the price they had to pay to acquire the right to broadcast. This was in effect the role played by the Broadcasting Tribunal, prior to 
deregulation. If the rights were allocated in the second manner, in favour of person B, the audience could collectively appoint an agent to purchase broadcasting rights from broadcasters on their behalf. This is the role currently played by New Zealand on Air.

\section{Allocative Efficiency}

Prior to deregulation, the Broadcasting Tribunal had some power to control the content of broadcasts. It imposed conditions on warrants that compelled broadcasters to produce particular outputs, such as local news and current affairs. The effect was similar in theory to the effect of a fixed quota, which is demonstrated by the model in Figure 23, below.

Figure 23: Efficiency and Quotas

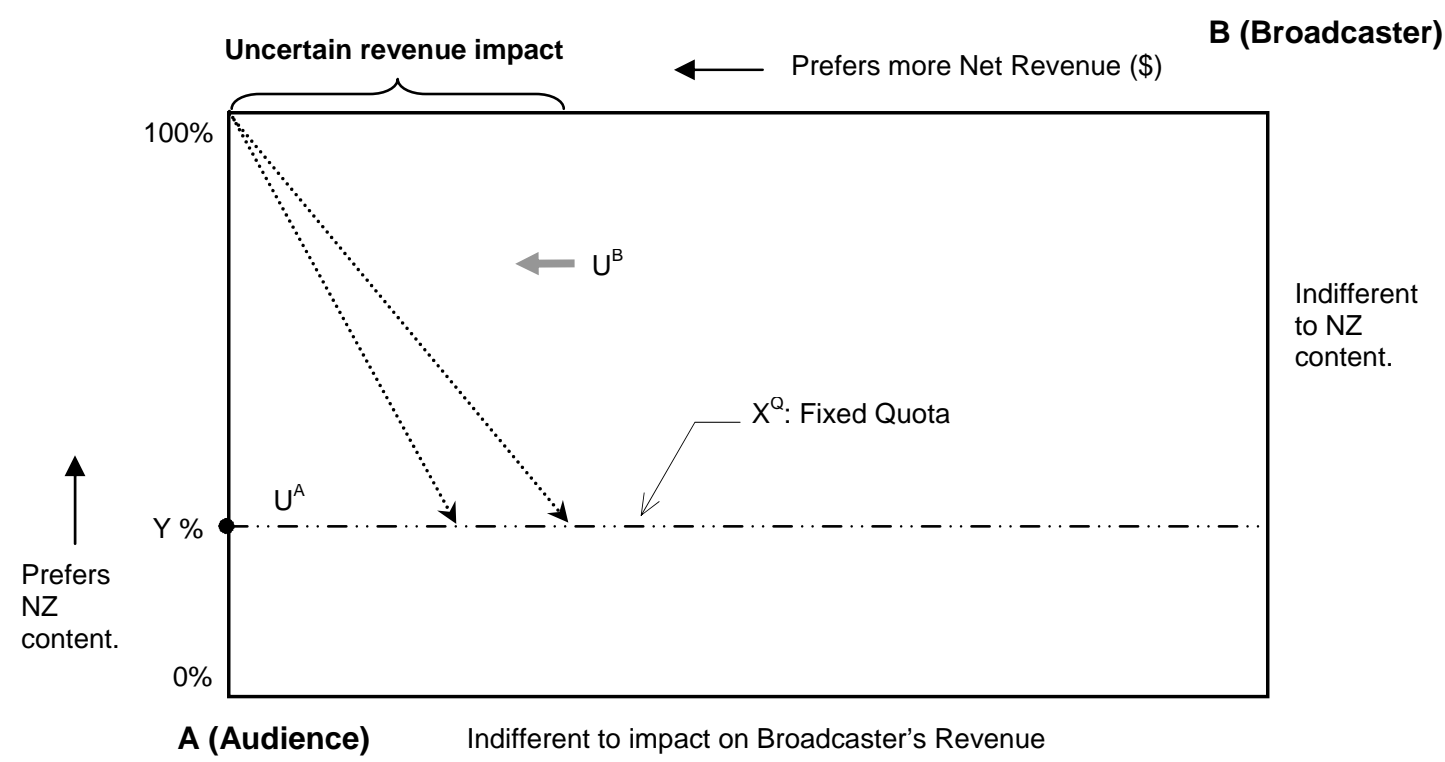

As one can see, this quota dictates the amount of New Zealand content produced, but it is indifferent to the effect on broadcasters' revenue. It cannot answer the question is an efficient allocation of society's resources being spent on New Zealand content?

The next model, in Figure 24, shows what situation under the current scheme for subsidising particular outputs through New Zealand on Air. How much New Zealand content A obtains is dependent largely on the amount B wants to acquire, and the price they agree. However, B is under no obligation to produce any output of New Zealand content at all (being indifferent). ${ }^{83} \mathrm{~A}$ is obliged to spend the entire license fee, which means that $\mathrm{B}$ has power to set the terms of trade in his favour.

83 Quite literally, in Television New Zealand's case, as the State Owned Enterprises Act requires it to maximise its return to shareholding Ministers unless they specifically request otherwise. 
This means we know how much money is going to be spent, but we are uncertain about

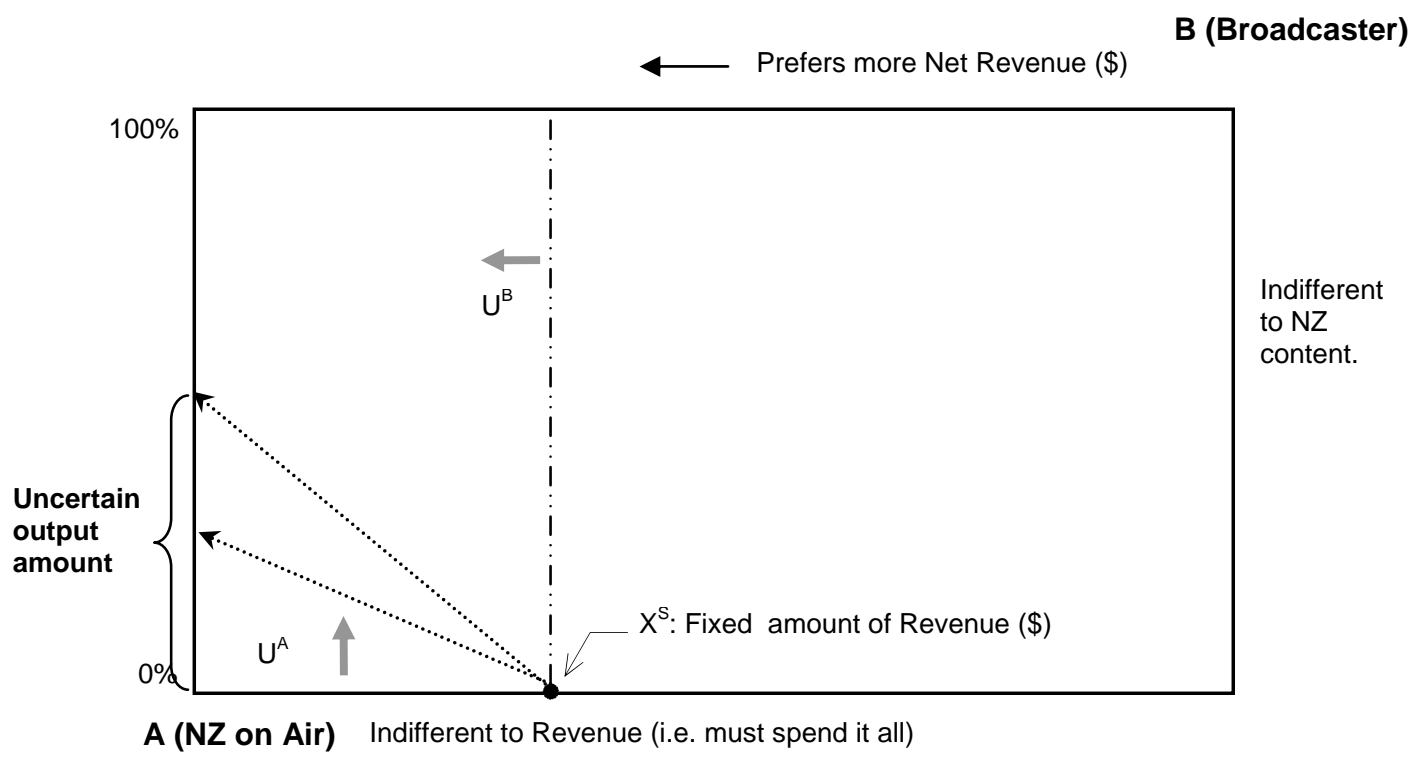

the amount of output that will be created. Theoretically then, the subsidy scheme is no more allocatively efficient than the quota scheme, because it cannot answer the question is the amount of resource being spent on New Zealand content sufficient to produce the desired outcome?

This tells us more about the concept of allocative efficiency than it does about the relative merits of subsidies and quotas. Recall in the last section of Chapter 2 we outlined the difference between synthetic and analytic statements. A synthetic statement is true by definition “...the statement that all men are animals does not really make any assertion about the facts about men, but only reveals part of what we mean by the word 'man'.'(Stevenson, 1987: 19). To say allocative efficiency has been achieved does not make a meaningful assertion about whether the proper amounts of society's scarce resources are being applied to producing particular goods and services. It simply means they can be bought and sold in a market. It also implies that market value is the only reliable measure of value.

The Coase Theorem is normative, in the sense that it suggests as many rights as possible ought to be allocated and exchanged in the market because then, and only then, can society establish their "true" value. In short, the Theorem is an argument in favour of a political philosophy that prefers regulation by the market to regulation by the polity. It is not a prescription for good governance per se. $^{84}$

84 Allocative efficiency does not create economic growth (it does not make the "box" bigger), although was purportedly one of the purposes of introducing microeconomic reform. Greater allocative efficiency in input markets could lead to greater productivity. However, this could equally mean producing a constant amount of output with fewer resources - likely to lead to economic contraction - or greater output with the same resources - which would accompany, but not necessarily lead to, economic growth. 


\section{Political Rights and Property Rights}

The choice between regulation by the polity or by the market touches on a very important issue: the need, when developing policy, to distinguish between property rights and other sorts of rights, such as social or political rights. We will review two cases: the creation of property rights where no rights previously existed, and the transformation of rights, which had previously existed by the authority of statute or common law, into property rights.

We begin with the case where no specific right exists - such as the implied right to bear children - and we wish to consider regulating the rate of childbirth. James Tobin (1970) gives an example of how property rights could be created where previously this liberty had existed. ${ }^{85}$ Suppose, for instance, the Government sought to follow China's lead and restrict population growth:

"Should each and every mother be limited to two children or less? Or should each woman be issued two - or two and a fraction tickets, whatever is consistent with zero population growth - and be allowed to transfer whole or fractional tickets to other women? Or should the government fix an annual quota of births and auction the tickets to the highest bidders?

"The first system is the most egalitarian, but excludes many voluntary transfers of 'birth rights' that would in principle increase the utility of all parties concerned. The second system allows such transfers, but also opens up the possibility that rights to have children will be concentrated in the rich. At least the poor and others who give up their rights will be well compensated. This is not the case under the third system, the auction, where the rich can still buy up the rights but to the benefit of the general taxpayer rather than of would-be mothers who lose out in the auction.” (271)

The first of Tobin's options implies a form of state regulation, the second and third options are varieties of market regulation: one makes an initial allocation of rights to mothers, makes an initial allocation to the state.

No doubt some readers will find the very idea of trading in birthrights offensive, and argue that these rights can only be held equally by all mothers. Tobin coined the term specific egalitarianism to describe the idea that "...certain scarce commodities should be distributed less unequally than the ability to pay for them." Among these "commodities" he counts votes:

"There are some rights and privileges, and some duties, which the society desires to distribute precisely equally among its members,... The distribution is supposed to be wholly independent of income and wealth. Furthermore the distribution is supposed to be independent of individuals' preferences; society would not approve of an individual's voluntary assignment of his share to someone else even if the assignee were of equal or lower income.... Allowing a free market in votes could not augment the power of the electorate as a whole; it would only serve to distribute it differently.” (269)

85 Using liberty in Hohfeld's (1961) sense; a liberty being a right each person holds equally and which confers no obligations on others to observe it - unlike a claim-right, such as a property right, which imposes an obligation on others not to interfere with one's property. 
This is clearly a case where a political right should not be converted from a political right to a property right: it is a founding principle of representative democracy that the right to vote is inalienable - it cannot be transferred to another person.

There is a special case of inalienable possessions that we must pay particular attention to in this country - the rights of Maori under article two of the Treaty of Waitangi. Under the second article of the Treaty, the Crown guaranteed Maori tino rangatiratanga over their taonga (among other things). This was taken by the Waitangi Tribunal to mean "...fullness of control..." over “...all their valued customs and possessions...”. (Waitangi Tribunal 1986: 20, 22) ${ }^{86}$ The Waitangi Tribunal decision in 1986 found that te reo Maori (the Maori language), was a valued possession in this sense. A subsequent report established that fullness of control over te reo Maori implied "a secure place in broadcasting." (1990: 41) Thus the Tribunal finds that te reo Maori is a taonga that belongs to Maori and it must not be 'taken' from them either deliberately or by acts of omission. The Privy Council underpinned that interpretation in 1994:

"With the passage of time, the 'principles' which underlie the Treaty have become much more important than its precise terms. Foremost among those 'principles' are the obligation which the Crown undertook of protecting and preserving Maori property, including the Maori language as part of taonga, in return for being recognised as the legitimate government of the whole nation by Maori.” (517)

With all due respect to the Privy Council it is incorrect on one point - taonga are not property; at least, not in the way that English law and economic theory implies. The following explanation is quoted in Mauss (1925), which Elsdon Best (1909), attributes to Tamati Ranaipiri:

"Suppose you have some particular object, taonga, and you give it to me; you give it to me without a price. We do not bargain over it. Now I give this thing to a third person who after a time decides to give me something in repayment for it ( $u t u)$, and he makes me a present of something (taonga). Now this taonga I received from him is the spirit (hau), of the taonga I received from you and which I passed on to him. The taonga which I receive on account of the taonga that came from you, I must return to you.... I must give them to you since they are the hau of the taonga which you gave me. If I were to keep this second taonga for myself I might become ill or even die. Such is the hau, the hau of the of personal property, the hau of the taonga, the hau of the forest...”

Mauss (1925), O’Connor (1991), and Weiner (1992), all elaborate on and discuss the paradigm of exchange invoked by taonga, hau and utu (Hay, 1996). The essence of their findings is that taonga are "inalienable possessions", as Weiner puts it. Treating taonga on Maori terms, rather than as property, implies that they cannot be exchanged for cash. Nor can Maori be compensated in cash if the Crown has failed in its duty to protect a taonga. The only possible recourse - and the only way the Crown can restore its legitimacy - is to restore mana Maori by restoring the taonga itself (in this case te reo Māori).

86 Under international law, the native language version of such treaties carries greater weight in legal interpretation than a version in the language of the non-indigenous party. 


\section{Market Regulation}

Although certain political and social rights may be inalienable, the method of market regulation may by used to protect them. Let us take the example the right of Maori to receive Maori language broadcasts.

Hay (1996) proposes that a secure place in television broadcasting for Maori could be created by endowing an allocation of Maori language content on television broadcasters. These endowments could conceivably be tradable, so that the broadcaster who regards the endowment as a disutility can pay another broadcaster to take his share. ${ }^{87}$ All the conditions for the establishment of an effective market can be met:

- Amount to be produced: The total amount of Maori language programming should be sufficient to produce a certain number of hours per evening overall. The amount has to be sufficient to play an effective role in restoring te reo Māori.

- Divisibility: Channels should be able to trade in segments of time or programme type. One may choose to retain Maori language sports commentaries while selling off drama, for instance.

- Alienability: It is the ability of broadcasters to transfer rights among themselves this refers to, not an ability to diminish the right itself.

- Adequate specification: The fundamental specification, driven by the Waitangi Tribunal's findings, is that programmes shall be in te reo Māori. Further division into categories of documentary, drama, news, light entertainment, sport, etc., would present some specification difficulties - but these should not insurmountable.

- Enforceability: The output of television channels is sufficiently observable for competitors and consumers to monitor broadcasters' performance. Thus, the costs of monitoring would be relatively low. Adequate sanctions for non-performers would be relatively simple to determine.

- An acceptable initial allocation: all television channels, including cable and UHF pay TV channels could be required to broadcast a certain number of minutes-perevening of Maori language content in prime-time. There would inevitably be arguments about how this should be apportioned according to the size of the population, or size of Maori population, that a channel reaches.

- Legitimacy: Such a system would be legitimate within the terms of New Zealand's constitutional arrangements, and would increase the legitimacy of the Crown in Maori eyes. Broadcasters, and non-Maori audiences, might not agree.

Such a scheme is not the only means of restoring te reo Māori, of course. Nontransferable quotas, regulation or direct funding for Maori broadcasting from the public purse are other options. However market regulation could equally be applied to broadcasting outputs to protect the rights of other ethnic groups, children, women or citizens generally. It might also be used to regulate things such as excessive advertising, gratuitous violence or explicit sexual content. The major constraint would be the time and effort involved in establishing each and every one of these rights as property rights,

87 The endowment in this case takes the form of an obligation, or duty, rather than a right. However one is simply the correlative of the other, so no significant difficulty should arise. 
deciding the initial allocations, and the subsequent transactions costs of negotiating trades between broadcasters, which would impose enormous efficiency costs on the broadcasting market.

\section{External Benefits}

The Coase Theorem can be used to discuss a special case where property rights are created to regulate the allocation and production of externalities. An externality is a byproduct of a production process which imposes burdens (or supplies benefits), to parties other than the intended consumer of a commodity. For example, both air and water pollution are "negative" externalities, which impose burdens on society and the environment. The producer, and the consumer of the commodity he produces, does not directly bear the cost of pollution. It is a cost borne by society as a whole. As Tobin suggests, overpopulation is a negative externality, which may outweigh the private rights or liberties of would-be parents. Excessive levels of violence on television might also affect society as a whole in detrimental ways.

Externalities can also be positive. Apple orchards and beehives provide mutual positive externalities to the producers of honey and apples. They each supply an external benefit to the producers and consumers of both products. The idea of positive externalities, or "external benefits" is mentioned in the Treasury submission, only receives three paragraphs in the Treasury submission, in three paragraphs. First, Treasury sets out the economic concept of externalities-based justifications for tax-funded broadcasting:

"A possible justification for not taking audience preferences as given is if the benefits or costs of broadcasting particular programmes fall on non-viewers or non-listeners as well as on the programme audience.” (42)

Treasury then summarises three categories of externality that may be employed in defence of public broadcasting

“ The external benefits that are sometimes held to exist from certain programme types include the 'contribution to cultural heritage' that radio and television can make (this argument is made in terms of the interests of future generations), the 'experimental value of public radio and TV' (which is held to provide spill-overs into better quality commercial broadcasting), and 'diversity in public affairs programming' (the idea that, for example, viewers of a wide range of social and political viewpoints make 'better' or more-informed voting choices, such that non-viewers benefit from more desirable social or political outcomes).” (42, Treasury's parentheses)

The submission does not elaborate. We, however, shall digress and return to Treasury's third paragraph below. The categories of external benefit outlined above are taken from in Noll, et al. (1973: 213-215). It is instructive to explore these justifications for government intervention greater depth.

Noll, et al., when setting out these justifications, sound a note of caution about taking external benefits arguments seriously:

"Regardless of the merits of a primarily non-commercial system, the stakes of the commercial broadcasters in maintaining their current paramount position are too great to make undermining their position a viable policy alternative. The remainder of this chapter deals with the narrow issue of a modest expansion in the present non-commercial system.” (210) 
They later argue that it would be "...presumptuous and disingenuous for the fanciers of public TV to argue that a broader social welfare is served by pleasing them.” (213) In keeping with this view, they set out a series of arguments dismissing each justification for public television. These are set out below, along with a counter-argument to demonstrate that none of their dismissals is inarguable.

\section{Contribution to Cultural Heritage}

Noll et al. say one form of external benefit is that which accrues to future generations their cultural inheritance. Just as present-day lovers of drama benefit from Shakespeare's plays, "If public television supports and extends the production of culture in the present, future generations will benefit." (213) However, this holds for any medium that produces culture, and television is “...a relatively expensive medium for augmenting the cultural legacy. Only if certain culture unique to television is highly valued would support for public television be an efficient way to increase the cultural inheritance of future generations." (213) This point is repeated in the Treasury submission:

“...it seems difficult to argue that a cultural service delivered via broadcasting -say television drama - is any more "cultural" or publicly beneficial than, cultural services delivered by other media - say live theatre.” (43)

In response to the first part of this argument, we might say that television is not relatively expensive if its power and reach are taken into account. The contribution that a programme like Tangata Whenua or Kenneth Clark's Civilisation can make to one generation of viewers is enormous because, and only because, the programmes were broadcast on television.

The second part of the argument is breathtakingly specious: Noll, et al. and Treasury both deny McLuhan's dictum that the medium is the message. How could Fred Dagg have become part of New Zealand's cultural legacy without television? Why else is New Zealand's cultural heritage used to sell Japanese utility vehicles and McDonalds' "Kiwiburgers” on television? A nation's cultural legacy is self-evidently dependent on, and contiguous with, the means available for its transmission and dissemination.

\section{Experimental Value}

There may be an argument that public television's lesser dependence on commercial success can lead to greater experimentation and risk-taking. Noll, et al dismiss this argument on the grounds that "No public broadcasting programme has switched to the commercial system... Moreover, the commercial system has yet to copy from the American public system...” (214)

We have already explored the possibility that a commercial media environment will tend to be risk-averse, in the section titled "Competition and Market Entry", on page 50. In this case, there is a potential role for public funding to underwrite risk, as New Zealand on Air has done for Shortland Street, and for Mai FM.

\section{Setting a Standard}

This is a justification Noll et al only imply, within a footnote to their argument on experimentation. They note that public TV may have provided a "comparative norm" 
for commercial programming: "One example is the influence the popularity and technical success of Sesame Street may have had on commercial children's programs." (214: footnote 5). ${ }^{88}$ In New Zealand, Easton (1994a), argues along similar lines for public news services:

“...public-owned radio and television set a standard for reportage not only for broadcasting, but in the printed media.... they are constrained and encouraged to separate opinion from fact. Otherwise we turn to Radio New Zealand and TVNZ."

The presence of a public broadcaster therefore causes other broadcasters to lift their game, and this is an external benefit to consumers of the media other than those who tune in to the public broadcaster.

The counter-argument to this is that Government provision of a good prevents private entrepreneurs from entering the market, which creates a self-justifying claim for continued government provision (i.e. Noam's argument, page 52 above). This is sometimes described as the government “crowding out” private investment. However, crowding-out may be deliberately undertaken by the government to prevent private sector suppliers from providing goods of an unacceptably low standard. Housing New Zealand might thereby crowd-out slum landlords from the housing market, for instance. $^{89}$

\title{
Diversity in Public Affairs Programming
}

A public broadcaster, being less concerned about audience maximisation, can give alternative and non-mainstream views more attention. Allowing a greater range of views improves the democratic process by enabling citizens to make better informed judgements when choosing governments. Noll et al provide two counter-arguments to this proposition:

\begin{abstract}
"First, only viewers will receive the entertainment (sic) value of the programs. Second, if political or social change does come about because public television provides a forum to a hitherto unrepresented view, the broadcasts must have caused the distribution of opinions on the issue among viewers to shift in favour of the change... However, since nonviewers presumably made a conscious choice not to view the programming... and since their distribution in terms of political values and socioeconomic characteristics is unlikely to be identical with that of the viewers, the two groups need not reach identical conclusions about the benefits to be derived from the social change that resulted from the new programming." (214)
\end{abstract}

Both of these arguments ignore the fundamental proposition that the benefits of an improved democratic process may accrue to non-viewers, which was the original hypothesis. The last part of their argument assumes that viewers' political proclivities and viewing choices are directly correlated, and that they only prefer to watch programmes that reinforce their political views. This places the viewer in the top right

88 Their footnote admits that their earlier argument, regarding experiment and risk, may not be entirely true.

89 This would make Housing New Zealand the biggest slum landlord in the country - but at least the Government would guarantee its slum meets minimum conditions. 
quadrant of Figure 20 (page 80), where the audience's viewing preferences are entirely exogenous, and the media is powerfully influential.

What Noll et al have failed to recognise is the fundamental difference between news production and news distribution. Hay (1986), describes media as a kind of warehouse operation, where various elements are brought together, repackaged and refined, and sent out for distribution. News is a very good example: many radio stations take a preproduced news feed from a bureau service, and all news rooms and bureaux take the bulk of their stories from press releases and other media. This means that very little news is produced, in an economic sense, other than a relatively small output of investigative journalism. A story that is broken by one broadcaster will bring it to bring it to the attention of other news programmes, and place it on the media "agenda".

Palmer also makes a claim that the mere existence of the news media service produces external benefits:

"Despite the fact that the mass of people are not interested in the political process, or informed about it, the media do perform the function of keeping the politicians on their toes. The media are an important linkage in the political system and therefore of constitutional significance.” (1992: 202)

He is saying that the media can produce external benefits for society because politicians believe it has influence, regardless of how powerful that influence really is, or who consumes the news (perhaps a form of "Third Party" effect).

$\Theta \quad \Theta \quad \Theta$

It is worth noting that Noll et al were rebutting the findings of the Carnegie Commission (1967), which proposed the formation of a federal Corporation for Public Television. A minor point, but Treasury's submission did fail to mention it. Clearly, these justifications for the government to intervene in the broadcasting market are worthy of some consideration, notwithstanding the dismissive treatment they suffer at the hands of Noll et al.

Treasury did not apparently think they were. Its third paragraph on the subject of external benefits simply cautions against the wisdom of investigating them further:

"The justification for government intervention on the basis of such spill-over benefits should be evaluated with caution. Information on the extent of such positive externalities is difficult and costly to obtain with any precision, and if the level of benefits is not substantial the costs involved in the government intervening to support such activities may outweigh the benefits of doing so.” (43)

This reinforces the point made at the end of the previous section: because there are no property rights in externalities there can be no market for them and therefore their value cannot be "properly" assessed. It is a restatement of Coase's tautology.

\section{The Right to Broadcast}

Coase (1959) built his concept of externalities and property rights on the concept that radio signal interference is a negative externality that can be regulated by the market, providing adequate property rights can be defined in "interference”. Coase’s original 
conception had been along the same lines as the smoke example that opened this chapter: he believed one could somehow establish a total quantity of "interference", and allow the market to regulate the amount of interference created.

This notion has generated a considerable literature in the economics journals, which Fountain (1988) summarised for the Department of Trade and Industry. In the event, this proved to be nonsensical, and the interference problem was dealt with by the careful specification of Time, Area, Spectrum (TAS) packages. The Radiocommunications Act 1990 defines TAS packages which broadcasters purchase when they acquire the right to transmit radio signals. The right to broadcast was thus defined in the act as a right of non-interference. That is, a right that prevents other broadcasters from transmitting signals in the same time and place, and on the same frequency, as the holder of the right.

Although Coase's original idea could not be put into practice, the economics profession has adamantly stuck with Coase's other argument: that the radio frequency spectrum is a form of property that, like any other input to a production process, can and should be allocated by a market. Coase's argument to this effect is eleoquent:

"Mr. Justice Frankfurter seems to believe that federal regulation is needed because radio frequencies are limited in number and people want to use more of them than are available. But it is a commonplace of economics that almost all resources used in the economic system (and not simply radio and television frequencies) are limited in amount and scarce, in that people would like to use more than exists. Land, labor, and capital are all scarce, but this, of itself, does not call for government regulation. It is true that some mechanism has to be employed to decide who, out of many claimants, should be allowed to use the scarce resource. But the way this is usually done in the American economic system is to employ the price mechanism, and this allocates resources to users without the need for government regulation.” (Coase, 1959: 14)

Coase's article is a wonderful example of economic rhetoric, which appears to wilfully misrepresent two of the fundamental issues at stake: the nature of the right and the issue of scarcity. Discussing what is really 'owned', when one has acquired the right to broadcast, and comes up with this:

"What does not seem to have been understood is that what is being allocated by the Federal Communications Commission, or, if there were a market, what would be sold, is the right to use a piece of equipment to transmit signals in particular way....” (1959: 33)

We have already recognised that the right to broadcast is in fact the right to make a claim on the scarce attention of the audience. This right in turn could imply that the audience's interests should be taken into account. Coase's argument is made in response to a passage from the judgement of Mr. Justice Frankfurter in National Broadcasting (NBC) v. United States, 319 U.S. (1943), which he quotes this passage from:

"The facilities of radio are not large enough to accommodate all who wish to use them. Methods must be devised for choosing from among the many who apply. And since Congress could not do this, it committed the task to the Commission.

"The Commission was, however, not left at large in performing this duty. The touchstone provided by Congress was the 'public interest, convenience or necessity'. ...The facilities of radio are limited and therefore precious; they cannot be left to wasteful use without detriment to the public interest...” (Quoted in Coase, 1959: 13) 
It is not just that rights to broadcast are scarce relative to the demand for them. It is that the right to broadcast is also a privilege, because it allows one person to do something that others cannot. Stoljar gives this definition:

“(a privilege is) ....a special or exceptional advantage, granted or belonging only to certain individuals or classes of individuals: an advantage, in short, which ordinary persons do not normally have.

“...privileges are best seen in relation to... individuals who instead of the common run rather represent the select few.” (1984: 68)

One of the determining characteristics of a privilege then, is its relative scarcity. In the case of broadcasting, it is the privilege of being able to select and transmit particular ideas, views and information. It is a social and political right, which confers on its holder much greater powers than to the right to freedom of speech shared equally by all citizens.

One minor point, before we end this section, but one worth mentioning: in the case NBC v. US, the Supreme Court was being asked to declare illegal certain regulations that the Federal Communications Commission (FCC) had implemented to restrict and manage the practice of "chain broadcasting" (networking). As the Judge notes, after an extensive process of public enquiry the FCC found that some networking practices were contrary to the public interest, including having the effect of preventing “...station licensees from exercising their statutory duty of determining which programs would best serve the needs of their community.” (NBC v. US 319 US: 199). That is, precisely the effects of deregulation and competition which were outlined in Chapter 6, above. It appears the Coase finally won his argument on behalf of the monopolists, nearly fifty years later and almost half a world away.

\section{Conclusions}

This chapter has demonstrated the ideas of the Coase theorem, which says that the market can regulate externalities, when it is possible to:

(a) adequately specify property rights,

(b) make an equitable initial allocation of those rights, and

(c) ensure subsequent trades can be made with low transactions costs.

Applying this concept to broadcasting policy, we saw that:

- Property rights should not be confused with social or political rights.

- It is possible to transform social or political rights into property rights in some circumstances, however it is by no means a straightforward task and the transformation may have important equity effects.

- Other than Māori, and those who have purchased broadcast frequencies, New Zealand's citizens have no right to broadcast, nor any right to receive broadcasts, in either a formal or de facto sense.

- The subsidy scheme, which exists to provide socially desirable broadcasting outputs, disadvantages New Zealand on Air in its negotiations with broadcasters on the audience's behalf 
- The Radiocommunications Act effectively gives broadcasters the power of veto over any programme New Zealand on Air may think beneficial.

- Property rights cannot be created in broadcasting externalities, where they cannot be accurately and completely specified as rights.

- The Treasury submission makes only passing reference to the idea of externalities; briefly mentioning the justifications for public broadcasting then dismissing them as being difficult to measure (presumably meaning to assess their value in 'welfare' terms, which is, by definition, impossible for externalities).

- Noll et al go to greater length to dismiss the Carnegie Commission's justifications for public broadcasting, but their arguments are far from compelling.

- Finally, the Treasury submission showed insufficient knowledge of the historical background for the Coase Theorem and its application as an argument in broadcasting policy. A simple check, using the widely available electronic legal databases of U.S. court decisions, would have been useful.

The chapter has sought to demonstrate some of the issues that arise when applying economic theory to the creation, specification and distribution of rights as they relate to broadcasting policy. Broadcasting deregulation in New Zealand, following Coase's original argument, treats the right to broadcast as a property right to a scarce economic resource, not a political and social privilege.

This chapter began with the statement "Deregulation does not necessarily mean the removal of regulation." We have focused predominantly on how property rights can be created, or how rights created by the polity can be transformed into property rights. There is another possibility is that deregulation could mean certain rights created by the polity are extinguished altogether - implying that they provided no social or private benefit. 


\section{Chapter $9 \quad$ Broadcasting Policy and Law}

In the previous chapter we saw how the Radiocommunications Act 1990 treats the right to broadcast strictly as a scarce economic resource, following the argument of Ronald Coase (1959) and a considerable body of economic literature since (Fountain, 1988). However, the right to broadcast can also be described as a scarce right, or privilege, that permits the holder to convey information to an audience. These privileges confer on their holders a far more powerful right than the ordinary citizens' right to freedom of speech and opinion.

In this chapter we discuss what the citizens' right to free speech implies, whether New Zealand's citizens have such rights, and the extent to which the government could be obliged to protect them. This leads to some important conclusions about the outcomes of broadcasting policy in New Zealand, and the quality of broadcasting policy advice offered by officials in 1986-88 and since.

\section{Free Speech and Discourse}

John Stuart Mill made the definitive statement why people should have a right to freedom of expression, and the nature of the external benefit it produces:

"Were an opinion a personal possession of no value except to the owner; if to be obstructed in the enjoyment of it were simply a private injury; it would make some difference whether the injury was inflicted on only a few persons or on many. The peculiar evil of silencing the expression of an opinion is, that it is robbing the human race; those who dissent from the opinion, still more than those who hold it. If the opinion is right, they are deprived of the opportunity of exchanging error for truth: if wrong, they lose, what is almost as great a benefit, the clearer perception and livelier impression of truth, produced by its collision with error." (1972: 85)

He is clearly saying that freedom of speech is not simply a matter of private consumption choice. It confers a strong 'external benefit' on society's members. He later implies that freedom of thought and opinion is not merely a negative right, but one which needs to be given effect, as a positive right, in order for society to enjoy its benefits:

"Unless opinions favourable to democracy and aristocracy, to property and to equality, to cooperation and to competition, to luxury and to abstinence, to sociality and individuality, to liberty and discipline, and all other standing antagonisms of practical life, are expressed with equal freedom, and enforced and defended with equal talent and energy, there is no chance of both elements obtaining their due;...” (115)

Also, immediately after that, he proposes this is how society can overcome its "bounded rationality":

"Truth, in the practical concerns of life, is so much a question of the reconciling and combining of opposites, that very few have minds sufficiently capacious and impartial to make the adjustment with an approach to correctness, and it has to be made by the rough process of a struggle between combatants fighting under hostile banners.” (115) 
Mill's ideas have been influential in the development of representative democracy around the world, including New Zealand. His ideas about freedom of thought and expression are reflected in the right to freedom of expression and communication New Zealand citizens possess, which appears in the New Zealand Bill of Rights Act 1990:

"14. Freedom of expression-Everyone has the right to freedom of expression, including the freedom to seek, receive, and impart information and opinions of any kind in any form." (Chen and Palmer: 471)

This implies citizens have a negative right, which permits them to enjoy freedom of thought and opinion unconstrained by the actions of either the state or other citizens. This negative right may be a necessary condition for the existence of a free society, but it is not sufficient to fully encompass the role of the media in a representative democracy.

\section{Agency Theory}

To do this, we can turn to Principal-Agent theory and the idea of Transaction Cost Economics (TCE), which were outlined in Chapter 2. The idea of a contract is one way of explaining representative democracy: at a general election, citizens enter a "contract" with the political party they vote for, based on what they know of its politicians and their policies. In a liberal democracy, we might describe citizens as the principals in this transaction, and their parliamentary representatives as their agents. Recall the fundamental assumptions of TCE:

- Agents are prone to opportunism, or "self-interest seeking with guile”.

- A contract incurs transactions costs. Ex ante costs are those of negotiating and specifying a contract, which fall before the contract is agreed. Ex post costs are those of monitoring, enforcing and altering contracts once they are in place.

- Ex ante and ex post information bears an explicit cost, which may be a transaction cost for either party.

- Both parties enter the contract with limited information (or "bounded rationality").

- Either party may possess information the other does not, which they may use strategically to extract benefit from the transaction at the expense of the other.

The role of the media is critically important in this political contracting arrangement. Citizens have very little direct contact with politicians, other than through the media, therefore the information with which they make their voting choices is a function of the media to a very large extent. In the late $20^{\text {th }}$ century, the reality is that the electronic media - television in particular - has an extraordinary influence over how people make their voting choices.

Public Choice theorists would go further than this, and claim that the political parties generally have their own interests, or the interests of their supporters, at heart, and thus have a general tendency toward opportunism and the strategic use of information. This tendency might be revealed in the form of false or vague election promises, omitting to describe or declare policies prior to an election, or - in an MMP environment - failing to declare potential coalition partnerships, for instance. This would suggest that television news and current affairs programmes have an important role to play in assisting citizens to understand their voting choices by investigating and explaining the parties' policies in the lead up to an election. 
Voters do not make their decision purely on the basis of proposals and promises in the lead up to an election. They also pay attention to the performance of the government and of Her Majesty's loyal opposition during the term of a Parliament. One could say they monitor their representatives, whether in government or in opposition, to see if they are performing in accordance with the terms of the contract made at the time of the previous election.

The need to produce valuable ex ante and ex post information for citizens goes well beyond Mill's concept of a general right to the freedom of expression. It implies there is a twofold need for the media to act as an agent on behalf of citizens: first, to scrutinise the policy proposals of parties and candidates prior to an election, in order to make a well-informed voting choice. Second, to hold elected representatives to account in the court of public opinion during the term of a Parliament. In order for a representative democracy to function properly, government policy should ensure that the media function effectively in both these roles.

\section{Media and the Constitution}

The notion that a particular country is a representative democracy (as opposed to a dictatorship, monarchy or other form of political arrangement), is embodied in its constitutional arrangements. In a chapter of Sir Geoffrey Palmer's (1992) New Zealand's Constitution in Crisis a chapter is devoted to the subject of the media in politics. The diagram in Figure 25 demonstrates the centrality of the media to New Zealand's constitutional arrangements.

Figure 25: Media in the New Zealand Constitutional System

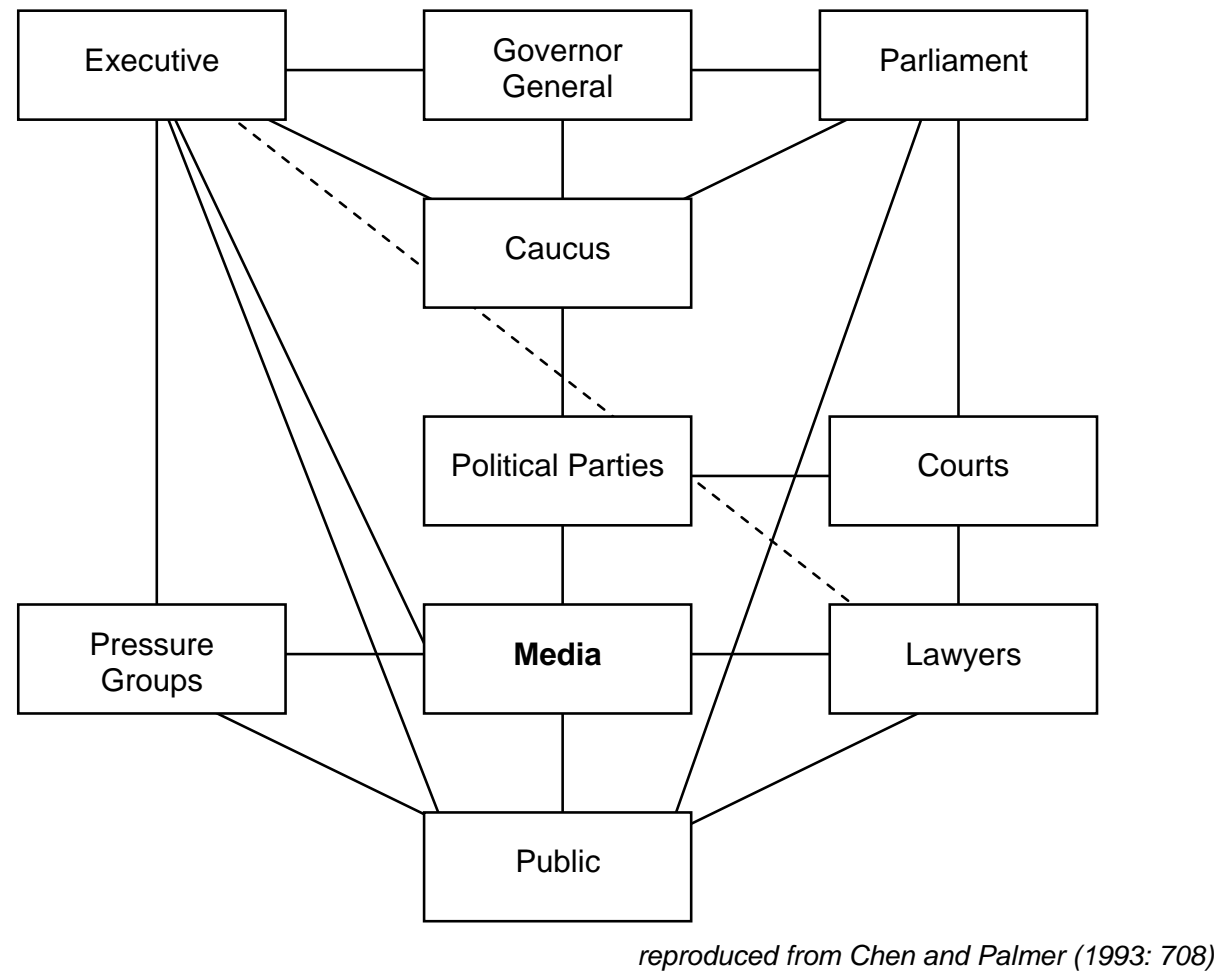


Palmer focuses especially on the role of television news:

"All news reporting involves oversimplification of reality but television political news in New Zealand involves the most distortion. TV decides what the most important news is, decides how to present it, selects which parts to emphasise. Everyone in New Zealand politics knows the television news is the most important factor in moulding opinion of government policy and politicians. That is the reality of modern representative politics. Journalists are more than gatekeepers. Their activities help to determine what people think. That is why the media has constitutional significance.” (1992: 213)

There are a variety of means for ensuring media fulfils its constitutional function. These might include quotas, laws, regulations, the specification of the property rights held by broadcasters, and direct ownership of broadcasting organisations by the state. In any of these cases a potential conflict of interest arises, as Palmer points out:

"If it is not the media's responsibility to provide the material to keep the public well informed about their government, then it must be responsibility of the government itself. That immediately raises a conflict of interest for the government.”(1992, 202)

In determining broadcasting policy, the government can create legal responsibilities that the media must conform to, or it can assume those responsibilities itself, or it can employ some mixture of these means to achieve the desired ends. In any case, it is faced with a potential conflict of interest.

The government is not simply an agent of New Zealand's citizens; it is in the position of a fiduciary (that is, an agent that holds considerable power over its principal, as is the case with doctors, lawyers or accountants). Where a fiduciary relationships exists, there is the almost inevitable possibility that agents can abuse their power, or will be prone to conflicts of interest. It is very often desirable that an independent party is able to protect the rights of the principal, and most often it is the courts that offer this protection. In the case of the fiduciary relationship between citizens and the state, it is the doctrine of the separation of powers and the constitutional power of the courts to review government policy and actions, which provide this protection.

\section{The Australian Case}

That New Zealand citizens have right to political information and public debate, and that this right can and should be protected by the courts, can be inferred from the judgement of the Australian High Court in Australian Capital Television v Commonwealth (1992) 108 ALR 577.

The case arose in 1991, when the Australian Government enacted an amendment to the Broadcasting Act 1942. The amendment placed a ban on political advertising in the lead-up to an election. It obliged broadcasters to provide free air time, which the Australian Broadcasting Tribunal would allocate to political parties under rules specified in the Broadcasting Act. The amendment did not apply to news and current affairs programmes. 
The intention of the amendment was to limit the excessive influence of political parties who could afford more television and radio advertising in the run-up to an election than poorer parties. $^{90}$ It also intended to limit the vulnerability of political parties to the potentially corrupting influence of the need to obtain large sums of money to pay for television advertising, which is necessary to get elected or re-elected.

The amendment was declared illegal by the Australian High Court. Although the judges saw merit in its intended purpose, they held that it interfered with the Australian citizens' right to freedom of political discourse by effectively excluding any person or body, other than an elected politician or political party, from the ability to purchase political advertising during an election period:

“Employers organisations, trade unions, manufacturers' and farmers' organisations, social welfare groups and societies generally are excluded from participation otherwise than through (news and current affairs programmes).” (Per Mason CJ, 589)

An interesting feature of this case is that there is no express right to freedom of expression in the Australian Constitution, along the same lines as section 14 of the New Zealand Bill of Rights Act 1990. The Court's decision was built on two principles: first, the requirement in the Australian constitution that Senators and members of the House of Representatives be "directly chosen by the people" implies that Australia is constitutionally a representative democracy. Second, the judges reasoned, it is in the nature of representative democracy that citizens have a constitutional right to convey and receive opinions, arguments and information concerning matters intended or likely to affect voting in an election for the Senate or the House of Representatives:

"The notion of a free society governed in accordance with the principles of representative parliamentary democracy may entail freedom of movement, freedom of association and, perhaps, freedom of speech generally. But as far as free elections are an indispensable feature of a society of that kind, it necessarily entails, at the very least, freedom of political discourse. And that discourse is not limited to communication between candidates and electors, but extends to communication between members of society generally.” (Gaudron, J: 562)

"Absent such a freedom of communication, representative government would fail to achieve its purpose... government would cease to be responsive to the needs and wishes of the people and, in that sense, would cease to be truly representative.” (Mason, CJ: 594)

"Freedom of communication in the sense just discussed is so indispensable to the efficacy of the system of representative government for which the constitution makes provision that it is necessarily implied in the making of that provision (Mason, CJ: 596)

In other words, the right did not have to be expressly mentioned in the Australian constitution, as it was clearly implied by its authors.

90 The amendment implemented the recommendations of a report of the Joint Standing Committee on Electoral Matters, titled Who Pays the Piper Calls the Tune (Report No 4, June 1989). 
The court was also saying that it is a defining characteristic, or necessary condition, of a representative democracy that its citizens have this right, that it is protected by law and policy and given effect in practice.

It is only because Australia has a written constitution that the court assumed the power to declare the amendment illegal. The extent and limitations on this power were stated in another Australian case regarding the freedom of the press:

"The courts cannot assume a jurisdiction which the constitution does not confer. A court cannot hold a law invalid merely on the ground that the law is not for the peace, order and good government as the court sees it. The only foundation for judicial review of legislation is the subjection of both the Parliament and the courts to the supreme law of the Constitution and the Constitution reposes the function of determining whether a proposed law is for the peace, order and good government of the Commonwealth in the Parliament exclusively.” (Brennan J: 44) ${ }^{91}$

New Zealand does not have a written constitution, and the New Zealand courts have never had justification for declaring an Act of Parliament illegal. They may declare an action intended or undertaken by the government to be illegal, where it is not expressly or implicitly permitted by statute. ${ }^{92}$

The New Zealand courts have used this power sparingly, as the court is quite properly loath to restrain the powers of the citizens' elected representatives. However, in any case where the Crown is acting as the citizens' fiduciary and a conflict of interest exists, there is arguably a greater burden placed on the courts to intervene to protect the rights of citizens against potentially unconstitutional actions taken by the executive.

\section{The New Zealand Case}

The reasoning of the Australian High Court can be applied to describe the nature and extent of the right to freedom of political discourse implied in New Zealand's unwritten constitution: first, section 10 of the Constitution Act 1986 states that:

\section{HOUSE OF REPRESENTATIVES-}

(1) There shall continue to be a House of Representatives for New Zealand....

(4) The House of Representatives shall have as its members those persons who are elected from time to time in accordance with the provisions of the Electoral Act 1956, and who shall be known as "members of Parliament".

Second, the intention and entire effect of the Electoral Act 1956 is to ensure New Zealand has a system of representative democracy.

If the reasoning of the Australian High Court were accepted by the New Zealand courts, they would agree that New Zealand citizens also have a right to engage in and to receive

\footnotetext{
$91 \quad$ Nationwide News Pty Ltd v. Wills (1992) 177 CLR 1

92 Most famously, in Fitzgerald v Muldoon [1976] 2 NZLR 615
} 
political discourse and public debate. This right is more specific than that implied in the Bill of Rights Act 1990, and it implies the existence of a fiduciary relationship between the government and New Zealand's citizens. It is a relationship that the courts could intervene in, to protect citizens' rights from actions or policies of the government that may be interpreted as unconstitutional.

\section{Diminished Protection}

The Broadcasting Act 1976 implied that New Zealanders had certain rights to political discourse and information, and the provisions of the Act protected those rights in a variety of ways. When broadcasting was deregulated in 1989, these protections were significantly diminished. In principle, and quite possibly in effect also, this eroded the implied rights themselves.

\section{Broadcasting Act 1976}

One protection created by the Broadcasting Act 1976 resided in the conditions that the Broadcasting Tribunal was able to attach to broadcasting rights (warrants). Section 80 provided for the Tribunal, in determining who should be allocated a warrant, to have regard to:

“(a) The extent to which the proposed service is desirable in the public interest:...”

"(b) The needs of New Zealand or the locality or localities proposed to be served, in respect of broadcasting services:..." and

"(h) The requirement that frequencies be best utilised in the public interest:”

These protections were eliminated when the Radiocommunications Act 1990 created property rights out of the right to broadcast, and provided for the Government to auction these rights without attaching any obligation to serve the interests of New Zealand's citizens. This occurred in spite of the RCBRT noting in its report that it would be possible and even desirable to attach such obligations to broadcasting rights prior to auctioning them (RCBRT, 1986: 260-261). This would have been a simple and effective means of avoiding the difficulty and expense encountered by applicants for the TV3 warrant. As we saw in the last chapter, this was simply a matter of adequately specifying the property right.

\section{The Broadcasting Corporation}

The Broadcasting Act 1976 also set out powers and functions of the Broadcasting Corporation that required it to protect the citizens' right to public discourse, in the following sections:

17 (1)(a); "To carry on public broadcasting services, and to develop, extend and improve those services in the public interest..",

22(a) "To ensure that each Service operates as a public service to provide and produce programmes which inform, educate and entertain"

(b) To establish a system for the gathering of news for radio; and to make such news available for the Services.”, 
24(1); "[The Corporation shall have regard to]

(a) "The provision of a range of programmes which will cater in a balanced way for the varied interests of different sections of the community",...

(d) "The accurate and impartial gathering and presentation of news, according to recognised standards of objective journalism.”,...

(e) "The principle that when controversial issues of public importance are discussed, reasonable efforts are made to represent significant points of view either in the same programme or in other programmes within the period of current interest.”

When the 1976 Act was repealed (by section 89 of the Broadcasting Act 1989), these protections of the public interest were extinguished or significantly diminished, especially in respect to television. The Radio New Zealand Act 1995 has subsequently restored some of those protections for listeners to the National Programme and Concert Programme, but not to other radio audiences.

Television New Zealand is required by section 4 of the State Owned Enterprises Act 1986 to have as one of its principal objectives to operate as a successful business and to be as profitable and efficient as comparable businesses which are not owned by the Crown. This implies that it is private sector broadcasters who should set the standard for Television New Zealand to meet - not the other way round.

Section 7 of the Act permits the Crown to buy particular broadcasting outputs (programmes) directly from TVNZ. However, that power could not be used to purchase news and current affairs programming, if it were held to be in conflict with section 7 (1)(b) of the State-Owned Enterprises Amendment Act 1988. That section prevents any Minister from giving directions to TVNZ regarding "the gathering or presentation of news or the preparation or presentation of current affairs programmes".

Essentially, the government has little or no power to give effect to citizens' rights to receive political debate through its ownership of Television New Zealand. In fact, the SOE Amendment Act could be interpreted as rendering it illegal for the government to use such power.

\section{The Broadcasting Commission}

The only avenue left for the government to protect the citizens' right to receive public debate is through the funding allocated by New Zealand on Air (NZoA). However, section 36 of Broadcasting Act 1989 only empowers NZoA to fund programmes that "..reflect and develop New Zealand identity and culture" and that "...provide for the interests of women children, persons with disabilities and minorities in the community." There is nothing that permits it to fund programmes of news, current affairs or investigative journalism.

Even if it had such a power, the unfettered nature of the broadcasting rights created by the Radiocommunications Act 1990 means that broadcasters effectively have the ability to veto any programme that NZoA might wish to provide funding for, as it is required by section 39 (e) of the Broadcasting Act to only fund programmes which "...if produced, would be broadcast." The broadcasters also have complete power to decide when a programme will be broadcast, and whether it will be shown at a favourable time.

In summary, the public's rights were supposed to be protected predominantly by the diversity-increasing effects of competition, which did not exist in theory or eventuate in 
practice, ${ }^{93}$ and by funding through NZoA. It therefore appears that a citizen's right to receive and participate in public debate was severely eroded when the Broadcasting Act 1989 and Radiocommunications Act 1990 were passed, and Broadcasting Act 1976 was repealed.

However, would the courts see it that way? What might the courts have done at the time to prevent this from happening? And what might they do to prevent the government from further eroding that right?

\section{Judicial Intervention}

It is easy to imagine that a group of citizens, fearful the Crown would be unable to protect their right to receive public debate about political issues, could take a case to the High Court to prevent the sale of Television New Zealand. They could cite the judgement in ACTV v. Commonwealth and claim that the sale would be in breach of the New Zealand constitution. We do not have to imagine what the response of the Court would be. That is evident from the decision of the Court of Appeal in New Zealand Maori Council v. Attorney General [1992] 2 NZLR 576.

As part of the corporatisation process, the assets of the old BCNZ were transferred to the Crown for a brief period of time. Before they could be transferred into the ownership of Television New Zealand Ltd, the New Zealand Maori Council sought a High Court declaration that the proposed transfer was illegal. The appellants contended that the transfer would diminish the Crown's ability “...to fulfil its obligation to protect the Maori language and culture through broadcasting and without establishing any adequate system or process to achieve the protection...”(576).

There is clearly a parallel between this actual case and the hypothetical one proposed above. To review the arguments, and assess the court's probable decision in this hypothetical case, one has only to read the decision of the Court of Appeal in NZMC v A-G, replacing references to the Treaty with "constitution" and references to the Maori language with "public debate” (and so forth). The following paragraphs are reproduced from the opinion and judgement of Mr Justice McKay:

"The aim of the appellants was to ensure a [public debate] content in mainstream broadcasting, this being argued to be essential if the if [public debate] was to be preserved. The concern was that if the assets were transferred, the Crown would no longer have the same options available to it, and would no longer be able to discharge its duty under the [constitution] in respect of the protection of [public debate]. (590:18)

"(the appellants submitted that)...these policies had at no time, either before or after the decisions were taken, been assessed or reassessed in terms of the Crown's [constitutional] obligation to protect [public debate]. The risk to [public debate] was in its absence from mainstream services. It would not be heard in prime time without either the establishment of a public broadcaster, or a power in either the (Broadcasting Commission) or the Crown to impose a quota. Both of these possible solutions had been considered by the government but

93 According to the analysis in Chapter 6, and to Cocker (1993), Comrie (1996), Atkinson (1989, 1994) and others. 
rejected for doctrinal reasons relating to the commercial operation of State enterprises. They had never been measured against [constitutional] obligations. (597: 25)

"It was submitted that the deregulation of broadcasting in New Zealand had been shown by the evidence filed on behalf of the appellants to be an experiment without parallel in other countries, and one which was likely to fail, and which entailed unacceptable risk for [public debate] programming. Local and overseas broadcasters, including a number with experience in the broadcasting needs of [representative democracy], had reviewed the practices in other jurisdictions and concluded that the New Zealand broadcasting system would not deliver protection to [public debate]. (598: 1)

"(the Solicitor-General, in reply)... stressed that the taonga is [public debate], not broadcasting. The Government had to recognise that broadcasting had other major functions in our society, in addition to the protection of [public debate].

He submitted that [public debate] programmes could only be of mass appeal or interest to a minority group. The Government's position on the mainstreaming issue was that it had considered and rejected a number of possible options for increasing [public debate] programmes on mainstream television, including the use of quotas... Quotas were regarded by officials as expensive, inefficient and inequitable.... (600: 24)

"(the Solicitor-General) pointed out that... the shareholding Ministers had the power under section 13 (of the SOE Act) by written notice to direct the Board of Directors to include certain provisions in its Statement of Corporate Intent, these including provisions relating to its objectives, the nature and scope of the activities to be undertaken, and any activities for which the Board would seek compensation from the Crown. Treasury's view was that this power should be used sparingly because it would necessarily reduce the accountability of the Board. The power is also limited by section 7 of the State-Owned Enterprises Amendment Act 1988 which precludes any direction as to a particular programme, and as to the gathering or presentation of news or current affairs. There is also power under section 7 to enter into an agreement for the provision of particular services by a state enterprise in return for payment by the Crown. These mechanisms, it was submitted, meant that that Crown retained a capacity to ensure that it satisfied its [constitutional] obligations in areas where these required the use of broadcasting...(600: 50) ${ }^{94}$

"(the Solicitor-General) also drew attention to the functions of the Broadcasting Commission under section 36 of the Broadcasting Act 1989. As already mentioned, that section in its final form included as one of the functions of the Commission the promotion of [public debate]. By section 44 the Commission must comply with any directions given to it by notice in writing by the Minister. One such direction was the requirement that the Commission apply at least $6 \%$ of the broadcasting fee revenue to [public debate]. (601: 11)

\section{Decision}

“....(TVNZ) is required under section 4 of the State Owned Enterprises Act 1986 to have as one of its principal objectives to operate as a successful business and to be as profitable and efficient as comparable businesses which are not owned by the Crown. Such an enterprise is unlikely to include [public debate] broadcasts in prime time. It will be more profitable to devote that time to programmes which will maximise the viewing audience, not only for the programme being shown but also for the programmes which follow.... (601: 49)

94 Naturally, the Solicitor-General would refrain from making either this argument, or the argument in the following paragraph, in our hypothetical case. Neither argument would support the Crown's claim that it had the power to protect citizens' rights to public debate on prime-time television. 
"The only way in which [public debate]... programmes are likely to be included in prime time under the Crown's proposals is if the privilege is paid for by the Broadcasting Commission.... Even if the company were compensated for the loss of viewers and of advertising revenue... (it) may well prefer to forgo the short term profit that might be achieved by a generous payment by the Commission because of concern at the longer term effects. (602: 1)

"The option of a quota has been rejected as a matter of policy.... Quotas would seem more likely to be effective if applied to all channels so that none would be unfairly disadvantaged in comparison with the others. Each would then have an incentive to present its [public debate] broadcast in the most attractive manner so as to hold both Maori and non-Maori viewing audiences. However, there is no longer any power to impose quotas on private broadcasters. (602: 22)

"There is a great deal in the evidence to support (the criticism of Mr Justice McGechan, in the High Court) of the Crown's approach to the restructuring of broadcasting, and his conclusion that there had been a failure to observe the [constitution] in the lack of proper enquiry and consultation. There was a failure to assess the proposed changes from the point of view of their impact on [constitutional] obligations. (602: 39)

"The Court is being asked to pass judgement on the on the ...question whether the Crown has adequately performed its [constitutional] obligations in respect of [public debate], and to offer guidance to the Crown in this wider area.... As has been pointed out earlier in this judgement, [constitutional] rights cannot be enforced in the courts except so far as they have been given recognition in statute. If the proposed transfer of assets would be contrary to the principles of the [constitution], then it can be restrained. It cannot be restrained merely because the Crown has already restructured broadcasting in a way which may have diminished its capacity to comply with the [constitution], and as a means of putting pressure on the Crown to adopt policies regarded as more appropriate for achieving such compliance. (603: 16)."

The Mr Justice McKay was saying that it was not proper for the court to direct the government in matters of policy. In NZMC v. A-G, the majority of the bench deferred to McKay's opinion and submitted much briefer opinions of their own in support. The appeal was dismissed, and the transfer went ahead - largely on the basis that promises made by the Crown to fulfil its Treaty obligations must to be accepted by the court in good faith. ${ }^{95}$

In the hypothesised case presented above, it is conceivable that the bench would have supported the dissenting opinion of (now) Lord Cooke of Thorndon, who said:

“...I cannot avoid the unwelcome conclusion that the present television policy, which is carried out partly by statutes and partly by administrative decisions, is inconsistent with the principles of the [constitution]. (584)

"In essence the present broadcasting assets are subject to a major [constitutional] claim: namely that they should be retained for use consistent with [constitutional] principles, rather than being disposed of to implement a policy providing no realistic way of protecting [public debate]. (585)

95 The amount of Maori language programming available on primetime television, seven years later (nil), might well give the courts to reassess the crown's promises in future cases. 
"Plainly [section 14 of the Bill of Rights Act, section 10 of the Constitution Act and the whole of the Electoral Act were] enacted as a guarantee and a protection to the [citizens of New Zealand]. Previous cases have shown that the [these Acts are] not impotent to prevent action inconsistent with [constitutional] principles. The fact that the action is legislative or administrative pursuant to legislation does not affect whether or not it is inconsistent with those principles. (585)

He later notes that Part VI of the Broadcasting Act 1989 makes provision for political parties to meet the cost of broadcasting political advertisements in the lead up to an election and says, in making his judgement:

"These particular provisions (in part VI) are justified in the interest of democracy. They might not be suitable as a pattern for [public debate] broadcasting, but they suggest that some special arrangements for such broadcasting would likewise be feasible and justified in the interest of honouring [constitutional] obligations.

"Beyond any dispute counsel for the appellants were right in at least one of their assertions. They spoke of the court's task in this case as "ungrateful". So it is, but for the reasons given I would see no alternative but to allow the appeal and grant the relief sought." (568)

In ACTV v. Commonwealth the issue at hand was whether an action of the legislature restricted the freedom of communication in a manner that was not sufficiently justified by an Act, no matter how worthy its intentions. The Chief Justice of the Australian High Court noted that the Court has the task of balancing competing interests:

"Whether... restrictions are justified calls for a balancing of the public interest in free communication against the competing public interest which the restriction is designed to serve, and for a determination whether the restriction is reasonably necessary to achieve the competing public interest....

"In weighing the respective interests involved and assessing the necessity for the restriction imposed, the Court will give weight to the legislative judgement on these issues. But, in the ultimate analysis, it is for the Court to determine whether the constitutional guarantee has been infringed in a given case. And the Court must scrutinize with scrupulous care restrictions affecting free communication in the conduct of elections for political office for it is in that area that the guarantee fulfils its primary purpose. (per Mason, CJ: 598)

In NZMC v. A-G, the issue at hand was whether the legislature had failed to protect a freedom of communication guaranteed by the Treaty. The Solicitor-General had presented the appellants as a minority interest group, who were holding the Crown to ransom to get their own way. The court effectively sacrificed the interests of a minority in favour of a policy adopted by the representatives of the majority. However, had the case been taken in the manner hypothesised, it is entirely conceivable that the bench might have followed Lord Cooke's opinion and prevented the transfer. A policy which affects the interests of all New Zealand citizens should surely be scrutinised more thoroughly by the Courts, and with less reliance on the Crown's expression of good intentions, than a policy that affects a small minority of Maori language speakers.

It is interesting to speculate whether the Court would have reached the same conclusion it did, if Maori had claimed that it was their rights to receive political discourse and debate, as British citizens under article three of the Treaty, that the Crown had failed to protect. That might well have provided the courts with sufficient justification to deny the transfer of assets. 
One might also speculate whether this case could have been taken against the whole of the Broadcasting Act 1989 and the Radiocommunications Act 1900, and if the courts might be sufficiently provoked to do as Lord Cooke implied they might, and take the unprecedented step of declaring an Act of Parliament illegal. ${ }^{96}$

\section{Acts of Omission}

The issues we are concerned here do not involve the constitutional role of the courts. We are concerned with the outcomes of broadcasting policy, the quality of the policy advice on which the government relied when it deregulated broadcasting, and therefore the constitutional role of the public servants that proffered that advice.

The analysis presented here clearly indicates an answer to one of the questions asked at the beginning of this thesis; 'What should be the outcomes of broadcasting policy?'. ${ }^{97}$ It must surely be uncontroversial to say that one of the outcomes of broadcasting policy must be the protection of New Zealand citizens' rights to receive and participate in public debate and political discourse. One might go further and argue that broadcasting policy should endeavour to guarantee, or give effect to, the exercise of those rights.

It is for the government, as the representatives of the people, to decide what should be the outcomes of broadcasting policy. However, it is entirely proper for public servants to advise the government as to what the outcomes of policy might be, when those outcomes are expressed or implied by the laws that Parliament has already passed. Officials would be derelict in their professional duty if they did not advise the government - in the strongest terms - what the outcomes of policy should be when those outcomes are implied by New Zealand's constitution, or by documents such as the Treaty that are a foundation of the Crown's legitimacy.

We asked the question 'Was the Treasury submission to the RCBRT good policy advice?' at the beginning of this thesis. For our answer, we need only consider that the advice neglected to consider an issue as fundamental and self-evident as the protection of the citizens' right to freedom of political discourse. The quality of broadcasting policy advice offered subsequently can be judged by the following facts:

- Officials failed to incorporate into their advice the findings of the Royal Commission, which established to determine the will of the people and advise the government accordingly.

- Acting on official advice, Parliament has passed legislation that could conceivably have been judged illegal, creating an unwelcome constitutional precedent.

- A situation now exists in which the courts could quite possibly restrain the government from selling Television New Zealand Ltd or its assets.

96 Sir Geoffrey Palmer kindly provided his personal opinion on this analysis while it was at an earlier stage of development than that presented here. He believed the court's decision would depend on whether the judges of the bench were inclined toward judicial activism. Only by presenting the case to the court could one know for certain.

97 Section 2 (1) of the Public Finance Act states that “ 'Outcomes' means the impacts on, or the consequences for, the community of the outputs or activities of the Government.” It is this meaning that is intended here. 
- Officials evidently did not deem the change of electoral system, from first-past-thepost to mixed-member proportional representation after the 1993 referendum, sufficient cause to review the constitutional role of broadcasting policy.

We must recall that none of this apparently intended by the government. The government depends heavily on the advice of its officials, and a great deal of policy depends on officials' professional ability. Citizens also depend on officials to act as "public servants" and offer the government advice that reflects the public interest, (to the extent it can be clearly defined). There is a constitutional convention that public servants will offer the government's Ministers politically neutral advice, without fear or favour. This is one means by which our system of parliamentary democracy protects the fiduciary relationship between citizens and state. However, constitutional conventions have little legal force. Joseph (1993) describes thus:

“(conventions)...coordinate the practices of government and provide means for co-operation between the organs; '[they]...provide the flesh which clothes the dry bones of the law; they make the legal Constitution work; they keep it in touch with the growth of ideas'. Constitutional convention acts as a restraining influence on legal power. The most important conventions promote responsible government; they ensure public affairs are conducted in accordance with the people's wishes expressed through their representatives in Parliament." 98

He goes on to imply that they offer only weak protection to the citizens' interests:

"Conventions, not being laws, are unenforceable in the courts. They are obeyed for a variety of reasons: sheer inertia, habit, the desire to conform, or the belief that it is right and proper to obey them, or because politicians wish the machinery government to go on.

"Their application can be a matter of intense debate. Conventions seek to restrain political adventurers. Their very existence may be denied and their relevance disputed. And when the dust settles, no one may be the wiser.” (238-239)

If official advisors fail to observe the constitutional conventions regarding neutrality, balance and integrity, or fail in their professional duty, the government may be none the wiser. If officials respect the democratic process and ensure that their advice incorporates the views of bodies such as the RCBRT, the government can at least be assured that they will gain what J.S. Mill called “...the clearer perception and livelier impression of truth..." as a result of "...the rough process of a struggle between combatants fighting under hostile banners.”

In the case of broadcasting policy implemented in 1988 this was not the case, and in the next chapter we see how this could eventually bring the system of representative government into disrepute and compromise the legitimacy of the Crown.

\section{Conclusions}

In the previous chapter, we reviewed some of the economic theory of property rights. We focused especially on how the creation of property rights might imply that rights

98 The internal quote is from Sir Ivor Jennings' (1959) The Law and the Constitution, $5^{\text {th }}$ ed pp 81-82 
could be created where none existed, or social and political rights might be transformed into property rights with adequate specification. We barely mentioned the idea that certain rights might also be extinguished or the government's protection of them may be diminished as part of the deregulation process.

In this chapter, we have seen that New Zealand's citizens do have an express right to freedom of expression. This appears to be a negative right, making it illegal for the government to restrict that freedom. We have also seen that the Broadcasting Act 1979 imposed requirements on the BCNZ and private broadcasters to have regard for the public interest. This gave effective protection to the New Zealand citizen's right to receive and engage in political debate and discourse, suggesting that this was a positive right. When broadcasting was deregulated, this protection was diminished in principle and, as many commentators have claimed, also in effect. ${ }^{99}$

Recall the basic proposition of Agenda-Setting theory: "The press may not be successful in telling people what to think, but it is stunningly successful in telling its readers what to think about.” (Cohen, 1963: 13) Recall also, that what the media omits from the agenda often produces the most important effect (Leitch, 1992; Fox 1988). In this chapter some profoundly important issues for New Zealand's future have been traversed:

- The erosion of protections for New Zealand citizens' fundamental right to freedom of political discourse.

- The constitutional role of the Treaty of Waitangi and the meaning of claims brought before the Waitangi Tribunal.

- The ability of the courts to protect a citizen's fundamental rights and the proposal that New Zealand should have a written constitution.

We might legitimately ask why the media has failed to place these issues, among many others, on the 'agenda' for public debate. For our answer, we need look no further than the institutional arrangements for broadcasting created by the Broadcasting Act 1989, the Radiocommunications Act and the State Owned Enterprises Act. More particularly, we must look to the advice of the officials who proposed and developed these arrangements, and later defended them before the courts.

If the reader feels a sense of outrage or despair at this situation, there is one source of solace this analysis can offer. As matters stand, any citizen of New Zealand could bring an injunction to prevent the Government from selling Television New Zealand Ltd with some confidence that they would succeed.

99 Comrie (1996: 382) cites Atkinson (1989, 1994), Palmer (1992), Edwards (1992), Campbell (1989, 1992) as examples. 


\section{Chapter 10 Policy and Social Control}

The previous chapter led us to some conclusions about what the outcomes of media policy might be, in respect to the relationship between the citizens and the state. A subtler and possibly far more important issue is the way media policy influences the relationship between the state, society and the market, and the sorts of external benefits and harms it might create in doing so.

\section{Social Control}

Recall what the original "media effects" researchers found, when trying to determine the influence of the media on individuals:

“....mass communication 'ordinarily does not serve as a necessary and sufficient cause of audience effects, but rather functions among and through a nexus of mediating factors and influences,' including selective perception, exposure, attention and retention; group dynamics; and opinion leadership.” (Lasora, 1992, quoting Klapper, 1960)

Elisabeth Noell-Neumann's research explored the way media creates social "cues" about appropriate behaviour, which influence the way people interact with each other and with society as a whole (pg 6, above). She took as a starting point the idea of Ferdinand Tonnies (1922: 138) that "Public opinion always claims to be authoritative. It demands consent or at least compels silence, or abstention from contradiction”.

These findings all reflect a principle known in organisational psychology known as social control. Tushman and O'Reilly emphasise the importance of organisational culture in this regard:

"In the same way that... formal control processes guide behaviour, culture serves as a social control system. If we care about others, for instance, we like them and want them to like us, and if we have some agreement about what is important, we are under their control. That is, if I care about you and we agree about what is important and how to act, whenever we are together, we effectively control each other.” (103)

This idea of "social control" is well developed in the literature on organisational behaviour, particularly in regard to small-group behaviour and teamwork. ${ }^{100}$ It may be contrasted with the idea of "formal control", which relies on rules, regulations and the implicit or explicit use of coercive power. ${ }^{101}$

100 Tushman and O’Reilly’s bibliography is good starting point, as is any undergraduate text book on Organisational Behaviour. For an insightful demonstration of how social control has affected some critical political decisions, see Irving L Janis (1989) “Groupthink: The Desperate Drive for Consensus at any Cost”

101 The contrast stands between what Althusser describes as the respective roles of "ideological state apparatuses” and "repressive state apparatuses”. 
The creation and maintenance of social control depends on two things: the degree of consensus among team members about what "what is important and how to act" and the intensity or commitment with which those values and beliefs are held. As the grid diagram in Figure 26 shows, if both consensus and intensity are high, social control can be effective. If both are low, only formal control and (actual or implied) coercion can be effective - otherwise there would be no possibility of society at all. ${ }^{102}$

Figure 26: Social Control and Formal Control

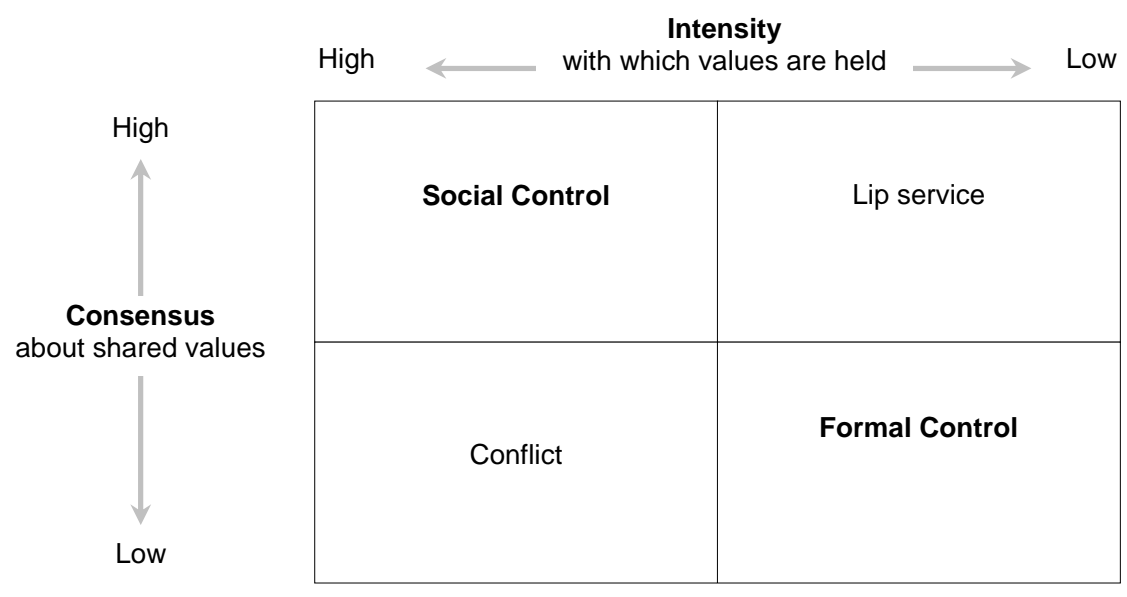

Recall the model employed in Chapter 4 to describe changes to New Zealand's policy framework in the 1980's. Tushman and O'Reilly used their model to explain the idea that a firm, which seeks to pursue its business strategy effectively, should attempt to create 'congruence' between its internal organisation, its organisational culture and it human resource management policies. This congruence creates a cognitive environment that motivates incentivises and even compels the firm's employees to fulfil its business strategy. The term cognitive environment is not Tushman and O'Reilly's, it has been coined here to emphasise the importance of individual perception and shared perception in creating social control:

- Cognitive, because cognition consists of two parts; the sensory stimulus which is the material or physical element of perception, and the interpretation and attribution of meaning to the stimulus, which is the psychological or ideological element of perception.

- Environment, because an environment affects - and sometimes determines - the way we live, but we can also manipulate it and control it to some extent. The greatest influence we have on the environment is the en masse sum of many individuals' actions or inactions, which may be affected by government policy.

102 Anarchists or Anarcho-syndicalists might disagree, however the reality is probably that both types of utopia would rely on strong social control in practice. 
What we mean when we use the word 'society' is exactly this; a cognitive environment within which we exist, comprised of laws, rules, norms, practices, values, beliefs and symbols, which the people living in a given time and place share in common.

An example might help to illuminate this idea: every one of us carries money. These pieces of paper, metal and plastic have no value, in "reality". That is, if one were lost in the bush, they would be useless and therefore worthless. Yet in our daily reality, money is the very signifier of value. This is because the perception that money has value is reinforced every time we get it or spend it. Because we make laws to prevent money from being forged, or defaced, or devalued. Because we create songs, stories, television programmes and magazines that reinforce the idea. Ultimately, money has value because, and only because, we share a common belief that it does. Therefore we have high level of consensus. Our cognitive environment constantly reinforces this belief - it "demands consent or at least compels silence, or abstention from contradiction" and therefore ensures that the belief is held with high intensity.

The cognitive environment creates and sustains a whole range of such shared beliefs: the law must be obeyed, people have rights, we should drive on the left. It also creates and sustains less obvious characteristics of a society, such as the extent of trust and mutual co-operation, which Fukuyama (1995) calls social capital. ${ }^{103}$ There is little possibility of opting out, except retreat into the life of a hermit, emigration (if only to a different cognitive environment), or suicide. Failure to share this commonly-held state of what Marx called 'false consciousness' could result in referral to the mental health system or imprisonment (Ignatieff, 1984: 50). The cognitive environment is therefore a public good, in the sense that everybody in society consumes it, and there is little private choice in the matter.

\section{Constructing Control}

The cognitive environment is not natural. It is an artificial construct, which can be manipulated to change society or defend the status quo. This idea echoes Louis Althusser's (1971) conception of the role played in society by Ideological State Apparatuses and Repressive State Apparatuses referred to in Chapter 2. However, where Althusser sees effects of these apparatuses as always oppressive, the concept expressed here is that the cognitive environments they create are the natural, or if one prefers inevitable, condition of humankind.

One has to be a little careful about the use of the terms natural and artificial in this context. Althusser seems to imply that people could or should live in a society which does not employ the regulatory mechanisms of either formal control or social control. This would imply that the 'natural' condition of humankind is the state of war, as famously described by Thomas Hobbes in 1651:

103 Fukuyama presents social trust as instrumentally valuable: it reduces social transactions costs and therefore increases economic efficiency. However, it may be necessary for people to believe trust and other social virtues are intrinsically valuable, in order that have the effects he indicates. 
"Hereby it is manifest, that during the time men live without a common power to keep them all in awe, they are in that condition which is called war; and such a war, as is of every man, against every man.” ([1651] 1942: 82)

It is simply inconceivable that a modern society, with a sophisticated division of labour and ubiquitous market, could exist without the regulatory mechanisms of formal and social control to hold people "all in awe". That is, they are inevitably required for the good functioning of society. John Locke expressed a similar sentiment, using the language and concepts of his era to propose that this is the natural condition of humankind (believing that what is natural essentially reflects the will of God):

"If he find that God has made him and all other men in a state wherein they cannot subsist without society, and has given them the judgement to discern what is capable of preserving and maintaining that society, can he but conclude that he is obliged, and that God requires him to follow those rules which conduce to the preserving of society?” (1960: 49) ${ }^{104}$

Althusser seems to oppose the idea that society can employ the regulatory mechanisms of formal and social control, but he does not offer a viable alternative (except, perhaps to substitute those that support capitalism with those that support communism). Locke implies that these mechanisms are available for the good management of society, and that it is within the bounds of human reason to decide how they should be employed. More than that, he proposes that we have a responsibility to do just that. The argument in this chapter follows that line of reasoning, although the author believes the obligation is to society itself and one's fellow citizens, rather than to God.

\section{Government and Social Control}

Tushman and O'Reilly argue that organisational polices should seek to manipulate the values, beliefs and behaviours of employees in order to create social control. This reduces the transactions costs involved in forming and monitoring contract-based agency relationships. ${ }^{105}$

In the same way, social, economic and cultural policies can be manipulated to affect the cognitive environment of a society, and thereby reduce the need for the state to use its coercive (or repressive, to Althusser) powers. If we use the model as a metaphor for social and political organisation, we need to make explicit our assumptions about the constitutional arrangements and governance roles that apply within the society in question. The model could be used to describe the policy elements of a state that is a liberal democracy or a regime that is based on the principles of monarchy, communism, Islamic law, or apartheid, for example. In any society, with any given form of constitutional arrangements, the media is an important agent in the formation and maintenance of social control, along with other "ideological apparatuses", including the society's religious, educational and cultural institutions. The cognitive environment

104 The quote was not published in Locke's “Two Treatises”. It appears in Laslett's introduction to this edition, where it is quoted from Locke’s journal for 1678, pp 201-2. The language has been modernised.

105 Social control, or mutually agreed and reinforced behaviour, may be what Oliver Williamson (1985) means, but does not fully explain, when he refers to "relational contracting". 
constructed by these will largely determine that society's acceptance of (or support the state's justifications for), full employment, ethnic cleansing, inflation, purdah, compulsory unionism, carless days, biculturalism, solo motherhood, homosexual, paid parental leave, or sex and violence on television, for instance.

Each would imply different conceptions of what should be the ultimate outcomes of strategy, how the leadership is chosen, and on what basis the society distributes benefits and harms to its members. The extent and influence of social control is therefore connected to the legitimacy of the state and the fundamental assumptions that create and sustain that legitimacy. Scruton (1982) provides the following definition of legitimacy, which neatly makes the connection between social control and legitimacy, by placing it in opposition to formal control and repression:

"What makes people believe a government to be, or accept it as being, legitimate? This is a question to which a politician, however sceptical or indifferent... will always give his attention. If a people have the rooted belief that only democratic election, say, or only hereditary succession, confers legitimacy, they can be governed in some other way only by force.” (264)

We can continue to develop the metaphor along these lines: Tushman and O'Reilly propose that a firm should shape its organisational culture to aid the pursuit of business strategy. While the legitimacy of this sort of manipulation may be offensive to some people, employees who find a firm's "social control" system oppressive may ultimately seek employment elsewhere. In some cases, where the firm's culture condones antisocial behaviour such as sexual harassment, for instance, employees may seek remedy in the courts.

Applying the metaphor to society as a whole, the formal control of the law probably does not influence a person's behaviour nearly so powerfully as does their response to the values, beliefs and behaviours of other people. The state does attempt to influence social behaviour quite explicitly, through television campaigns about drink-driving, safe driving, finding employment, dobbing in beneficiaries, enrolling to vote and so forth, and many of these appeal to peoples existing values and beliefs. (Andreasen, 1995; Kotler \& Roberto, 1989). ${ }^{106}$ People do flee from their countries of origin to seek asylum, or simply emigrate, if the political or social environment is hostile to their beliefs and values. In some countries - especially those with a written constitution - citizens do have recourse to the courts if the government performs acts or passes legislation that offend the values and beliefs entailed in the constitution.

There is, of course, a crucial difference between a business and a liberal-democratic state. A business creates congruence between the means for formal and social control in order to pursue the strategies of the firm, in the interests of its shareholders. A country's citizens might not want the state to pursue strategies of its own, or to reflect the interests of a minority of society's members. More than that, they may not wish the state to be involved in creating and maintaining 'social control' at all, unless they accept

106 In New Zealand, Colmar Brunton Research has developed expertise in this area, which has been applied in some of the State-sponsored television advertising campaigns mentioned here - the Land Transport Safety Authority and the Department of Labour. 
it as a legitimate activity of government. In a liberal-democratic society, the legitimacy of government rests on the assumption that it is elected by the people to represent their interests. It follows, logically, that there would be a conflict of interest if the government were actively involved in manipulating the cognitive environment to its own ends. It therefore also follows that a sustainable liberal democratic society requires the existence of a media that is independent of the direct influence of government policy. ${ }^{107}$

\section{The Domain of Freedom}

In a liberal democratic society, the media provides the arena in which people can voice competing claims about the nature and extent of social control. This is, of course, the essence of the idea proposed by Mill at the beginning of this chapter: every ideology, even his own version of liberalism, should be subject to constant scrutiny and challenge in order to determine the 'truth'. However, the contemporary liberal perspective is that nobody should compelled to agree to one version of 'truth' about what is good for society. The struggle is not to discover truth, it is to determine what should be the fundamental set of shared values and beliefs people consent to, which form the basis of social control.

At the beginning of Chapter 8, we noted Pusey's comment that “...(social democratic) societies... have not one co-ordinating mechanism but two. On the one side they have states, bureaucracies and the law, and on the other, economies, markets and money." (1993: 15). This analysis suggest that in fact they (and all other societies) have a third regulatory system: the system of social control. This form of regulation resides in the set of shared beliefs, values, history and culture that comprises the peoples' cognitive environment.

Tobin (1970) proposed that the market is the "domain of inequality" and that the polity was the domain of equality - in the sense of an equality of rights. In a liberaldemocratic society, it is a fundamental assumption that the domain of social control is also the domain of freedom: freedom of thought, opinions, religious beliefs, cultures. At the bare minimum, this freedom is a negative right; it is a freedom from the interference of the state. However, it is not a domain of absolute freedom; it implies a freedom from the harmful interference of others, which rightfully places limitations on the freedom to express thoughts and opinions, or to broadcast messages, that could harm others. This concept, and its relation to broadcasting policy in liberal democracy, is demonstrated in Figure 27. In this diagram we see the interaction of the three domains, the notions of sovereignty that each implies, and some of the information each uses or depends on to function effectively.

107 It also follows that other institutions, such as universities and the judiciary, should be beyond the direct interference of the executive, to provide a critique of and a restraint on the way in which the state constructs and maintains social control. Peter Lambley, in The Psychology of Apartheid (1980), describes how these institutions might not be all they seem in some societies. Sham democratic institutions created by the Broederbond in apartheid South Africa gave the illusion of respectability to the outside world and solace to the English-speaking whites, while “...it was possible they served a pathological function quite different from the role the played in other countries.”(55) 
The state is the domain of equality because each citizen has an equal right to vote, and because all citizens are equally subject to the rule of law. The state formally obtains legitimacy by combining the individual sovereignty of each citizen, but less formally by governing in the public interest. The government depends on policy advice, opinion polls, and such public debate as appears on the media agenda to govern effectively. The courts rely on law and legal precedent, but they are also sensitive to the prevailing climate of public opinion. Both rely on the media as sources of information about the world, and as a means of communicating policies and decisions that contribute to the creation and sustenance of social control.

The market is the domain of inequality, because where a market economy exists, one does not expect each person will have equal shares of income and property. Each consumer is sovereign in the sense that they are free to make choices regarding their purchases, within the constraints imposed by their wealth. Prices provide much of the information they require to make their purchase decisions, but advertising and marketing are also influential. Producers do not simply observe consumers' purchasing decisions in order to manage production, they also rely on market research and social trends. Both producers and consumers therefore rely on media in important ways to ensure the efficient functioning of the market.

Figure 27: Three Domains and Broadcasting Policy

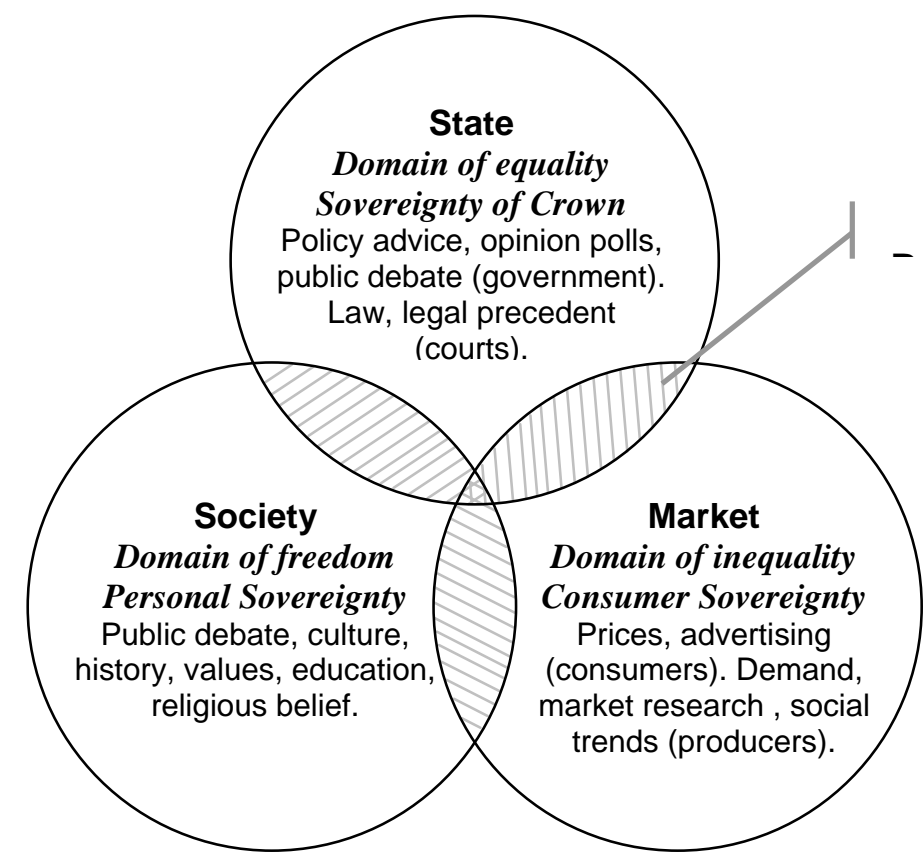

Society is the domain of freedom, because a liberal society resists the notion that any ideology (particularly the ideology of the Church, as Mill was arguing), should have absolute dominion over people's thoughts, beliefs and culture. People must therefore have freedom of thought, opinion, religious belief, cultural expression and values (within the constraint that none should compromise any other person's freedoms). It is in this domain that liberal political theory assumes each individual is sovereign in respect of deciding their own values and beliefs, and in respect of their voting choices. It here also, that liberal economic theory implies people might "exogenously" decide 
their lifestyle and consumption choices. In both cases, freedom requires diversity of choice and diverse sources of information.

Finally, the domain of freedom is also the fountainhead of social control. In order for society to regulate itself freely, some fundamental values and beliefs must be commonly shared. The process of working out the extent of consensus and the intensity of acceptance can only occur freely through open conversation and public debate. Liberal ideology dictates that this process should not be restricted by the state, nor should the governing party or coalition use the power of the state to promote its own ideology within this domain. Likewise, the profit-maximising motives of producers in media markets should not override the rights of individuals to obtain access to public debate, or to contribute to the conversation. Protection against the intrusion of the other two domains must also be an outcome of broadcasting policy.

\section{The Role of Policy}

There are considerable dangers entailed in the notion of social control and the act of explicitly shaping society's cognitive environment. One is that the policies that shape and control society's ideological apparatuses may be captured by a self-interested subset of society, who turn them to their own ends. That subset may be a religious or

\begin{tabular}{|c|c|}
\hline neo-liberalism (economic) & liberal democracy (political) \\
\hline $\begin{array}{l}\text { The audience is comprised of sovereign } \\
\text { consumers in a market society. }\end{array}$ & $\begin{array}{l}\text { The audience is comprised of citizens in a } \\
\text { liberal society with representative democracy. }\end{array}$ \\
\hline $\begin{array}{l}\text { The essence of freedom resides in the } \\
\text { consumer's ability to purchase what goods and } \\
\text { services they please, in a free market. }\end{array}$ & $\begin{array}{l}\text { The essence of freedom resides in each citizen } \\
\text { having rights, obligations and liberties equal } \\
\text { with those of every other. }\end{array}$ \\
\hline $\begin{array}{l}\text { Consumers act on their personal judgement of } \\
\text { their own best interests. The aggregation of } \\
\text { individual's preferences will determine the best } \\
\text { allocation of society's scarce resources. This } \\
\text { will create a far better allocation of scarce } \\
\text { resources than the arbitrary decisions made in } \\
\text { the political arena. }\end{array}$ & $\begin{array}{l}\text { Citizens are capable of making informed } \\
\text { judgements as voters. They are willing to and } \\
\text { able to make choices about what is best for } \\
\text { society as a whole, and to see their self-interest } \\
\text { in that context. Their representatives in } \\
\text { Parliament will govern on their constituents' } \\
\text { behalf. }\end{array}$ \\
\hline $\begin{array}{l}\text { The state is "neutral", and has only a minimal } \\
\text { role to play in society. It is largely concerned } \\
\text { with the creation and maintenance of a system } \\
\text { of property rights and enforceable rules of } \\
\text { exchange. }\end{array}$ & $\begin{array}{l}\text { The state is the embodiment of the collective } \\
\text { will of the people, and is expected to play } \\
\text { whatever role the people choose for it. }\end{array}$ \\
\hline $\begin{array}{l}\text { Sovereignty resides in the market. The market } \\
\text { exercises its influence through the actions of the } \\
\text { "invisible hand". }\end{array}$ & $\begin{array}{l}\text { Sovereignty resides in Parliament. It is the } \\
\text { executive, comprised of Government Ministers, } \\
\text { which exercises the will of Parliament. }\end{array}$ \\
\hline $\begin{array}{l}\text { It is principally economists and lawyers who } \\
\text { understand the function and ultimate purpose of } \\
\text { the invisible hand. It is they who should create } \\
\text { and maintain the rules within which it functions. }\end{array}$ & $\begin{array}{l}\text { It is the citizens' representatives who should } \\
\text { understand and scrutinise the activities of the } \\
\text { executive. It is they who pass laws that formally } \\
\text { regulate society and the economy. }\end{array}$ \\
\hline $\begin{array}{l}\text { The consumer can access information in one of } \\
\text { two ways: either by making sequential trial-and- } \\
\text { error choices, thereby basing their consumption } \\
\text { only on the material element of cognition, or by } \\
\text { purchasing information from other sources. }\end{array}$ & $\begin{array}{l}\text { The citizen must have access to information and } \\
\text { the ability to use it - they should be informed } \\
\text { and educated. They should have access to a } \\
\text { range of views and information, on which they } \\
\text { can and should make an informed voting } \\
\text { decision. }\end{array}$ \\
\hline $\begin{array}{l}\text { Information is a private good, obtained on the } \\
\text { basis of a personal utility maximising decision. } \\
\text { Its consumption is a matter of personal choice, } 123 \\
\text { and its production and distribution should be } \\
\text { governed by the market. }\end{array}$ & $\begin{array}{l}\text { Information is a public good; its production, } \\
\text { distribution and consumption are matters of } \\
\text { constitutional importance, and should be } \\
\text { guaranteed by the polity. }\end{array}$ \\
\hline
\end{tabular}


Figure 28 sets out the basic ideological conflict that underlay broadcasting deregulation in the mid-late 1980s. ${ }^{108}$

The right column represents the liberal democratic view held by the RCBRT, which sought to promote the ideals of liberal democracy both in the conduct of its enquiry and in its determinations. ${ }^{109}$ The left column reflects the view of Treasury and the Department of Trade and Industry officials who advised the government. It was their neo-liberal view of what constitutes a good society that has decisively structured the broadcasting policy framework.

There is nothing intrinsically 'wrong' with the view expressed in the left column, or 'good' about that presented in the right. The neo-liberal view is one valid explanation of the way people can and should choose to consume products offered to them by the media industry. What might be 'wrong' with the policy framework it has created, is that it compels audiences to behave in the way implied by one ideology, and prevents or restricts their ability to behave in the way implied by the other. It therefore constructs the cognitive environment in a way that reflects a particular ideology, one that discounts the value of social capital and could compromise the legitimacy of the Crown.

It discounts the value of social capital because if supports the idea of a neutral state which, as Mulgan (1989) complained, if one looks to its policies "...one usually searches in vain for their vision of who we are or where we are going." The neutral state provides no leadership, in other words, and is ineffective at creating consensus about values and beliefs, relying instead on the attempt to crudely impose them from above.

It could compromise the legitimacy of the Crown because of its effect on the cognitive environment and peoples' perception of politicians. Politicians' views and behaviours are constantly misrepresented on television news; as "arrogant" (Tau Henare, when dropped from the Maori Affairs portfolio after a policy conflict), or "very naughty" (Ian Revell, attempting to use his position as Deputy Speaker to subvert the rule of law). As Atkinson (1994) demonstrates, sound bites are becoming shorter, which means that politicians are increasingly represented as people with (literally) very little to say. It is reasonable to presume that citizens wish to be governed by people they respect, who are capable of articulating and defending their ideas, beliefs and policies. If they are prevented from perceiving their representatives in this way, the credibility of democratic political institutions will inevitably be eroded.

Finally, by creating a cognitive environment in which people increasingly see themselves as consumers, rather than citizens, the whole idea and practice of representative democracy could be eroded: people may begin to perceive participation in the democratic process as a state-imposed obligation, to be resented or even resisted.

108 There could easily be a third column representing the Maori perspective. Its omission here is deliberate, in the sense that the conflict expressed was between two conceptions of the audience that derive from English political and legal philosophy, and neither took proper account of Maori cultural beliefs and values.

109 This is perhaps more evident in the preamble to the RCBRT's Terms of Reference (see page 36, above) than it is in the body of its report. 
Unhappily, the government's policy advisors may not have been fully conscious of the ideological and rhetorical nature of their advice, and the effect it could have on the legitimacy of the Crown.

\section{Rhetoric and Ideology}

This chapter - and indeed, much of this thesis - has been a pains to present ideas about society as if they can and should be spoken of in the language of business and economics (hopefully with some success). However, to only speak about society in this way would be to ride roughshod over people's right to speak about society and their beliefs and values in their own way and in their own language. ${ }^{110}$

The reason for employing the language of business and economics in this thesis betrays its rhetorical strategy. The intended audience is policy analysts and advisors working in the public sector. In order to persuade these people of the importance and validity of certain ideas the author has thought it necessary to address them in their own language in order to overcome the peculiar deafness economists, especially, appear to have when addressed in other ways:

"Economists are deaf on the job to history or philosophy; most of them yawn at talk of geography or psychology; they do not take seriously the incantations of anthropology or sociology; although they want to talk to law and political science they do not want to listen.... The suggestion that the study of literature or communication or even the nonliterary arts might speak to them would be regarded by many economists as absurd." (Klamer \& McCloskey, 1988: 4)

Keohane, a political scientist by training, makes the same point, and connects the idea of economists' "deafness" to the way economic theory can be unselfconsciously ideological:

"Most mainstream economists do not converse with other social scientists; they preach to them. And they do so in two ways:

1. By instructing us about the form of explanation that we should use: that is, deductive accounts, beginning with individual interests and the structure of constraints, using the axiom of rationality to derive equilibrium behaviour and outcomes.

2. By prescribing social and political (as well as economic) policies to us, allegedly on the basis of their economic analysis.” (Keohane, 1988: 240-241)

Heilbroner (1988) apologises for economists who do this. He says many genuinely believe they are doing something valuable and necessary; that they think their views are rarely wrong, but often misunderstood. They therefore believe they are making:

“... an earnest and sincere effort to explain society as (they) themselves perceive it: an effort to speak the truth at all costs. What is 'ideological' about such an effort is not its hypocrisy but its absence of historical perspective, its failure to perceive that its pronouncements are a

110 It is for this reason precisely, that this thesis has used Maori broadcasting issues to illuminate some points of the analysis, but has refrained from presenting a detailed analysis of Maori claims in broadcasting and their effect on Maori society during the period under examination. 
belief system, conditioned like all belief systems by the political and social premises of the social order.” (1988: 41)

It is when economists working in government hold these beliefs rigidly, as a closed system of belief (per Stevenson, in Chapter 2 above), or when they refuse to acknowledge the limited application of economic ideas, that they endanger the practice of representative democracy. Nelson (1987) says that economists working in the policy process rarely have an opportunity to undertake detailed and comprehensive analysis. They are more often required to apply economic concepts intuitively, to rapidly changing situations or in response to urgent requests for input.

This might go some way toward explaining the rhetorical and ideological use of economic theory in Treasury's submission to the RCBRT, but it is not intended to excuse it. It is the professional duty of a policy advisor to take into account a range of theoretical and conceptual perspectives when developing policy advice.

\section{Summary and Conclusions}

We have covered a considerable amount of ground in this chapter, and it is worthwhile summarising the key points. These are:

- Societies have a third regulatory system, beside the polity and the market; it is the system of social control, or shared values, beliefs and culture. This distributes significant benefits and harms to members of society - some can be gauged in monetary terms, many only in pleasure or misery.

- People in society live within a cognitive environment that creates positive and negative externalities for society's members. Positive externalities might include the level of social trust and co-operation, neighbourliness, honesty, respect for the law and tolerance of others' opinions (these increase social capital). Negative externalities might include racism, sexism or other forms of bigotry, the acceptance of violence as a legitimate means of solving disputes and intolerance of others' social and political claims (these decrease social capital).

- Liberal democratic societies imply that there should be a domain of freedom, which entails a negative freedom - freedom from interference with their political, cultural religious and other beliefs. It also entails a positive freedom - the freedom and the ability to engage in the "social conversation" in which people discuss and debate the values and beliefs they might share, and which create the social and formal control to which they are all subject.

It is not the intention of this thesis to bend and push and force broadcasting policy into the shape required for economic analysis and public administration. It has been written to persuade a very small community of broadcasting policy advisors, and a wider community of policy analysts, that there is a great deal more to broadcasting policy than the narrow pursuit of allocative efficiency. Hopefully, it has also demonstrated to noneconomists that the concepts of economics and public administration can provide powerful tools for describing and analysing broadcasting policy issues. The power of economic thinking is increased, rather than diminished, when it acknowledges its own limitations and defers to the insights provided by other ways of talking and thinking about the world. 
The story of broadcasting deregulation is, sadly, a story about economists preaching to others and not listening. When officials refused to acknowledge that their insights might have been understood, and understood only too well, they went away and used their position of power to implement their ideas anyway. This could only happen because New Zealand had an 'elective dictatorship' at the time.

Lord Cooke says in NZMC v. A-G: "(Mr Justice McGechan) appears to me to have refrained from carrying his reasoning to its logical conclusion...”(579) There are some conclusions of this analysis we should not shy away from, nor the 'ungrateful task' they impose. Cocker (1996) accused officials of capturing the development and implementation of broadcasting policy in the years 1986-88. There must also be a prima facie case that the Ministry of Commerce's Broadcasting Policy Unit has "captured" broadcasting policy advice since 1988. A proper evaluation of the Broadcasting Policy Unit's performance since the broadcasting reforms were implemented would require more attention than this thesis can afford. However, over a span of ten years, it apparently has not expressed to the government any doubts or reservations about the integrity of the current broadcasting policy framework, or its social or constitutional impact. This despite the persistent challenge from Maori and numerous critiques of the broadcasting system presented in academic and other literature, some of which have been referred to here. 


\section{Chapter 11 Public Broadcasting}

In the conclusions to Chapter 9, we noted that the government is likely to be unable to sell Television New Zealand Limited, as deregulation has so significantly eroded some of the protections previously offered to the public interest. It could continue to operate this State-Owned Enterprise to maximise its financial return, or it could consider reestablishing it as a public broadcasting channel. If it were to pursue the latter option, then it will be necessary to create new institutional arrangements and possibly new legislation. In order to do this effectively, we need to have some principles to work from, and perhaps first even define precisely what we mean by public broadcasting.

The Government currently owns two advertising-funded television channels, which are not expected to pursue social as well as commercial objectives. Perhaps, therefore, the two state-owned television channels should not be regarded as public broadcasters, even though they are publicly owned. Hugh Rennie expressed his frustration with the way in which the issue is debated:

"Our public broadcasters call their competitors private broadcasters. Our private broadcasters call themselves independent broadcasters, and snipe at the public broadcasters as state broadcasters. Services which take money in return for time in their broadcasts are commercial. Those which take money from (the) government or audience are noncommercial.

"By implication, non-commercial broadcasting is the same as public broadcasting. Commercial broadcasting is everything else, and in the thinking of some, inferior. What nonsense. Good broadcasting is not about ownership, or the presence or absence of advertising. It is about what goes to air.” (1990: 19)

This chapter explores the meaning of the concept of Public Broadcasting, using some of the tools provided by economics and public administration theory. The first section outlines Eli Noam's ideas about government intervention, based on public choice theory. These demonstrate particular ideas about what we will call "State Broadcasting". The second section uses Principal-Agent theory to propose a definition of the essential characteristics of public broadcasting. The third section reviews the BBC definition of public broadcasting, and tests it against some of the economic theories and concepts traversed in earlier chapters. The fourth section summarises the discussion on broadcasting economics and policy.

\section{State Broadcasting}

New Zealand has a rich history of government intervention and control of broadcasting (Gregory, 1985). It could be argued that New Zealand has never really had "Public Broadcasting", rather, it has had "State Broadcasting”. This section employs Eli Noam's (1988, 1991), public choice model to explore what that term might mean.

Public choice theory, which we summarised in the section titled Public Administration, in Chapter 2, gives an economic explanation of why politicians and would administrators take decisions that distort market allocations. Eli Noam has produced a model that is similar to those of Hotelling, Steiner and Beebe, but which also allows him to discuss public choice theory in the context of programme diversity. He talks of 
the "pitch", or range of programmes a broadcaster might provide, across a continuum from low culture to high culture "In radio these pitches are often referred to as formats, such as all-news, classical music and 'easy listening'." (47). Viewers are ranked by pitch preference along this continuum. He notes one could imagine a variety of such continuums, all of which simultaneously influence each viewers choice, but the analysis can simplified to one without losing the essence of the argument.

Noam assumes a normal distribution of audience numbers around the centre of the continuum, and that there is a limit to the spread of the pitch any one broadcaster can manage. Therefore, each pitch has a centre, $\mathrm{P}$, and a distance from the centre of $\pm \mathrm{B}$.

\section{Figure 29: Eli Noam's concept of "Pitch"}

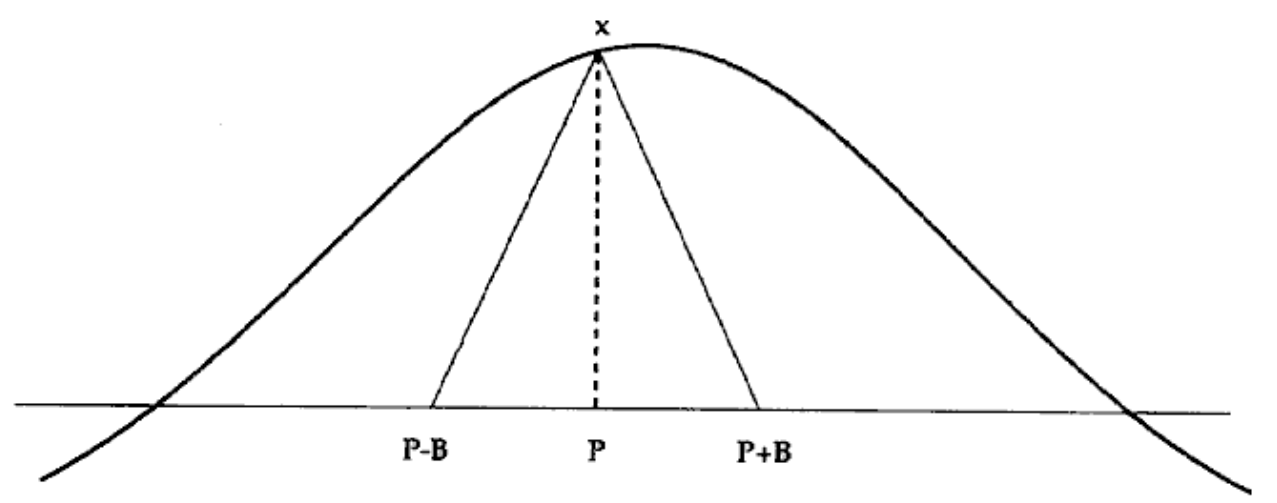

Scanned Image: from Noam (1991:46)

The profit-maximising pitch for a single channel will be set at the centre of the distribution (i.e. slightly to the right of where it appears in Figure 29). Subsequent entry of channels into the market will be placed to maximise the audience within their pitches, and may lead to a reduction in $\mathrm{B}$, and a narrowing of the triangle representing the audience which the pitch attracts. The result is very similar to the results of the Steiner/Beebe model, but the model is less rigid about the concept of programme type (i.e. viewers may prefer a range of programmes, rather than a single type). It also acknowledges that channels may adapt their range of programming in response to competition.

Noam uses this framework to describe a continuum spanning a spectrum of political opinion, from left-wing to right-wing, with a population of voters that are normally distributed around a preference for the political centre. Given a single channel, operated by a government-controlled broadcasting organisation, programming choices may follow various goals of the government. The possibilities given by Noam are:

- Public Benefit: The government aims to please the maximum number of citizens, by providing programmes the citizenry like. The pitch will be identical to the profitmaximising pitch, at the centre of the distribution.

- Vote Maximisation: The party in control aims to maximise its own votes. In a twoparty system, both parties will promise a centrist pitch, hoping to maximise their own votes. With multiple parties the outcomes are less definite, however coalitions will tend to promote a centrist position. Unstable solutions are also possible. 
- Spoils System: The government rewards its supporters with programmes of their preference. The pitch will be set to satisfy the maximum number of supporters of the victorious party.

- Propaganda: Television could be used as a means of widening and securing the voter base of a party. However, a straight "party line" programme will alienate opposition voters, who will become non-viewers. Therefore the pitch will be sufficiently near the interests of opposition viewers to attract their attention.

Noam says that, under the Public Benefit or Vote Maximising assumptions, the government will provide a stable diet of programming for a majority audience. Under either the Spoils or Propaganda assumptions, a change of government will lead to programming instability, as changes of government bring about changes of programming policy unless, that is:

“...parties may agree to a form of broadcasting that they will never fully control, even if they have an electoral majority; however, the other party will never control it either. This attitude is more likely where the strength of voting blocs is relatively similar, majorities change periodically, and the ideological differences between parties are bridgeable.” (Noam, 1991: 50)

Another possibility, which Noam does not predict, is that politicians may collude, explicitly or otherwise, to create a broadcasting system that is unable to effectively fulfil its role as the fourth estate and hold them to account in the court of public opinion.

Although Noam's model does not add much, if anything, to the Steiner/Beebe model in terms of analytical sophistication, it does provide another, perhaps more intuitively understandable, description of the basic issues surrounding programme types and audience preferences. Its treatment of the way political (rather than policy) decisions might influence broadcasting output is fairly crude, but it at least recognises that viewers' preferences can be expressed through direct lobbying. It also makes explicit the idea that the political motives of politicians may also be a consideration in determining what broadcasting outputs will be produced. ${ }^{111}$

Noam's model describes "state broadcasting", because it presumes that the state intervenes in broadcasting markets to pursue policy outcomes that are deemed desirable by the government of the day, or to the advantage of the political party which controls the executive.

\section{Public Broadcasting}

If what Noam describes is state broadcasting, then what do we mean by public broadcasting? The idea of principal-agent relationships applied to the relationship between citizens and state in Chapter 9 is a very useful starting point.

111 The influence does not need to be as crude and direct as the examples given by Noam. In Australia recently, vote-maximising decisions were undoubtedly the primary motivator for passage of "antisiphoning” legislation, which prevents some sports events from being shown solely on Pay TV. 


\section{Principals and Agents}

If the idea of public broadcasting means anything at all, it is that it is an institution that should serve the public rather than the state or other interested parties. We can do this using Principal-Agent theory. However, we must first extend the theory we have outlined so far include the idea of a client. There is the unstated assumption of Principal-Agent theory, which is that the end of every chain of Principal-Agent relationships there must be a third party or subject, to whom the principal's intentions refer. This insight arises from a special instance of the principal-agent relationship in which the principal is simultaneously the subject, and at the mercy of the agent. That is, the principal is the client of his or her agent. Badian offers this definition:

"The client may be described as an inferior entrusted, by custom or by himself, to the protection of a stranger more powerful than he, and rendering certain services and observances in return for this protection.... There are many ways of forming this relation of trust, some resting on status and some on contract (in the widest sense of these terms)."112

Thus the patient is a client of her doctor, or the litigant the client of his lawyer. The principal re-enters the principal-agent relationship as a third party: the subject. The agent is also referred to as a fiduciary of the principal in such circumstances.

If citizens are principals and the Government their agent, then a Minister is a principal and a departmental Chief Executive is his or her agent. The Chief Executive is then a principal and the departmental employee an agent, and at the end of this chain of relationships is the citizen who deals with that employee. That citizen is both the principal at the beginning and the subject at the end of that chain of relationships therefore a client of the state.

This idea from agency theory is fundamental to understanding the principal-agentsubject relationships in broadcasting. Figure 30 shows a set of four such relationships. The two on the top line represent the view of broadcasting from the perspective of the economic theory we have reviewed in the foregoing chapters.

112 Quoted in White $(1985,199)$ 

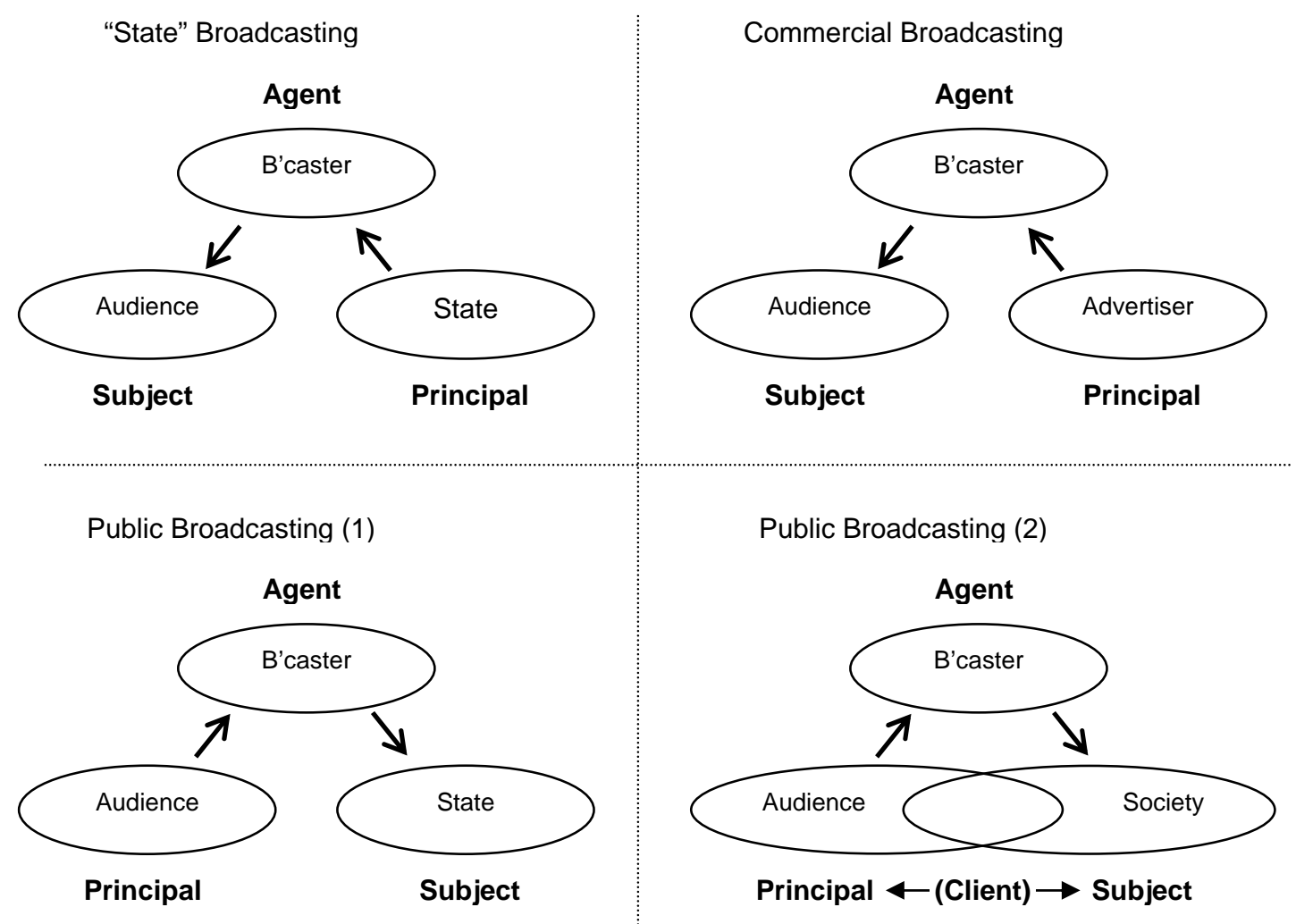

State Broadcasting represents the relationship implied in the public choice model outlined by Noam. It also depicts the role of the state in broadcasting according to Treasury's policy prescriptions. That is, the State is the principal, engaging the broadcaster as an agent to pursue its social or political objectives in respect of a subject, who is the audience.

Commercial Broadcasting implies the same relational direction. The advertiser is the principal, who contracts with the broadcaster-again the agent-for the opportunity to convey a message to the subject: the audience.

Public Broadcasting has two variants. In both, the direction of the principal-agent relationship is the opposite from either state or commercial broadcasting. In the first variant, depicted in the bottom left quadrant, the audience is a principal who engages the broadcaster as an agent to supply information and analysis regarding the activities of the state (and, one might argue, other members of the social and political elite). In the second variant, depicted in the bottom right quadrant, the audience is once again the principal, but now stands as a client of the broadcaster. This is the essence of the role the media plays in "holding a mirror" to society in such a way that it can give effect to the desire for social change or stability.

The public broadcasting relationships do not show potential role played by the state as a facilitator or broker of these transactions. In the presence of a potential conflict of interest there is a somewhat difficult problem of establishing effective governance relationships for public broadcasting. Especially when the subject - who may have a 
strong disincentive to withstand the sort of scrutiny the principal desires - has the opportunity and the power to intervene in the relationship between principal and agent.

\section{The BBC Definition}

Having established this fundamental principle, we can explore some of the other dimensions of what we might mean by public broadcasting, with reference to the analysis presented in previous chapters. The BBC's definition provides a handy framework for this exploration. The BBC's Broadcasting Research unit, in a publication titled The Public Service Idea in British Broadcasting, set out eight principles for public broadcasting. These are:

- Geographic universality

- Catering for all interests and tastes

- Catering for minorities

- Concern for national identity and community

- Detachment from vested interests and government

- One broadcasting system to be funded by the corpus of users

- Competition in good programming rather than for numbers

- Guidelines to liberate programme makers and not restrict them

These principles seem laudable on first sight, but what do they really mean? The economic ideas outlined in previous chapters can help us interrogate each of these principles, and perhaps achieve more clarity about which are truly fundamental to the idea of public broadcasting.

\section{1 - Geographic universality}

This principle implies that government should intervene to supply radio and TV to audiences that are unable to pay the full supply cost. This is effectively a transfer of income to those people, which implies that the provision of broadcasting services is a "merit good". That is, a good the government believes people should receive, whether or not they are willing to pay for it. Merit goods, such as defence, may also have the characteristics of "public goods", which are defined as being non-rival in consumption (an additional consumer does not deplete the amount available for others) and nonexcludability (being freely available for everybody to consume). Free-to-air radio and television services have these characteristics also.

Ensuring widespread coverage of radio and television services is one means of ensuring citizens' have access to public debate and, as the previous two chapters have argued, that access is a merit good because it is a fundamental and inalienable right of citizenship. However, there are limits to which any principle can be pursued, and it is not evident that citizens who choose to reside in the remotest parts of the country should have radio and television services provided to them regardless of cost. The public interest in access to public debate does have to be weighed against other uses for public money. 


\section{2 - Catering for all interests and tastes}

This principle implies that public broadcasters should fulfil the discriminating monopolist role proposed by Steiner. The BBC had, of course, acted in such a capacity for many years, until the advent of commercial private sector broadcasting in the United Kingdom. As we have seen, this principle is probably irrelevant when a public broadcaster coexists in "mixed system" that includes commercial broadcasters. Private suppliers will meet a great deal of the audience's needs, and it is not at all clear that a public broadcaster needs to duplicate those services.

However, the principle could also be taken to imply that a diversity of views, values, beliefs and lifestyles should be represented by the public broadcaster (or by broadcasters generally). This would be consistent with the idea that broadcasting has a role to play in sustaining the "domain of freedom".

\section{3 - Catering for Minorities}

This principle implies that public broadcasting should fulfil the role of providing broadcasting for audiences too small and too specialised for commercial or pay-perview broadcasters to service. It is the role predicted for public broadcasting by Noam in the section titled Mixed Public/Private Systems (page 52).

When a public broadcaster co-exists with commercial broadcasters and provides complementary programming, this principle would restrict it to only serving audiences which the commercial media did not or could not provide for-a sort of ghetto for minority audiences and interests. This role is filled in New Zealand by community access radio stations, which receive a small subsidy from the license fee revenues. In Australia, the existence of these community services is seen as an integral part of broadcasting policy and a complementary adjunct to public broadcasting, not a substitute for it (Australian Broadcasting Tribunal, 1977).

However, we have proposed that the essence of broadcasting policy resides in a deciding what things audiences should, or should not, pay their scare attention to. If people should pay attention to the policies and activities of their elected representatives, for instance, and this is part of the role of a public broadcaster, then it must be empowered to compete vigorously with other broadcasters to claim the scarce attention of audiences. To defer to private sector broadcasters and seek only to complement their programming is to fail in that essential task.

\section{4 - Concern for national identity and community}

This principle can be seen as referring to cultural heritage as one of the external benefit justifications for public broadcasting outlined in the previous chapter. In the previous chapter we saw that the real interest here is in the ecology of the cognitive environment and the production and maintenance of social control.

\section{5 - Detachment from vested interests and government}

If a Government should assist in the creation and maintenance of public broadcasting, then this principle raises important issues for institutional arrangements, especially concerning the accountability of the public broadcaster to Parliament. If a public broadcaster is to create and defend the "domain of freedom" effectively, then it must be 
free of the conflict of interest that ownership by the government could imply. Its empowering act must also provide it with sufficient independence from political interference and avoid conferring only very prescriptive or very limited powers and functions.

On the other hand, a public broadcaster is necessarily an organ of the state and subject to the sovereignty of the Crown. It must therefore be held accountable to the public and to its representatives for the effective and efficient use of its funding.

\section{6 - One broadcasting system to be funded by the corpus of users}

This principle was explored in Chapter 7, particularly under the heading Licence Fees and Welfare, on page 72 . We have seen that the "one system" principle is viable when the public broadcaster is a discriminating monopolist. However, in the presence of pay TV and private sector competition, many fee-payers will be forced to pay for outputs which they do not consume and have no desire to consume. As we have seen in Chapter 7, advertising also impose "psychic costs" on audiences, causing them to turn off. The idea that audiences should individually pay for public broadcasting conflicts with the intention of providing services equally to all citizens. The idea that the public broadcaster is funded directly by its users, rather than being beholden to advertisers or government budget decisions, is part of the principle of detachment or independence.

Again, it is a matter of striking a balance between competing interests, and asking whether it is necessary to uphold a principle at any cost. A fully non-commercial public television channel would be prohibitively expensive to operate, and advertising will almost inevitably be required.

It may be a matter of finding creative solutions to defend the principle of independence and minimise the impact on the government budget. For instance, a commercial public television service could still be relatively independent of the influence of advertisers, given appropriate mechanisms for selling advertising time. The total amount of advertising time could be determined before programme schedules were decided the time could be auctioned to brokers. These brokers could then sell time to advertisers at "spot" prices, after programme schedules were announced. This "futures market" approach, or something similar, might be well worth exploring.

\section{7 - Competition in good programming rather than for numbers}

This principle was also addressed in Chapter 7. It could be interpreted as meaning a public broadcaster should provide programming that reflects the intensity of audience preferences, as well as audience size - thereby optimising the social welfare provided by its programmes. We should recall that welfare economics has a propensity to conflate the idea of intensity of preference with the concept of willingness to pay, and therefore does not provide much guidance for what constitutes good programming, if it is to be supplied as a merit good.

This principle might prevent a public broadcaster from being fully self-funding under from commercial advertising revenue, as the requirement to obtain revenue from advertising would tend to promote the maximisation of audience size, rather than audience welfare. Some amount of public appropriation may still be necessary to reflect the unfunded social benefit that public broadcasting provides. 
Maximising welfare by reflecting intensity of audience preference, or broader social benefits, rather than simply audience size, poses something of a measurement problem, if a public broadcaster were to be held accountable for its performance by Parliament. Again, this would require some creative solutions to be devised, and the tools provided by economic theory or market research could provide answers.

\section{8 - Guidelines to liberate programme makers and not restrict them}

If this principle were applied to NZ on Air arrangements for providing subsidies to broadcasting firms, it could relate to the issue of diversity outlined in Chapter 6, particularly under the heading The Effects of Deregulation, where we saw that a free market could be risk-averse. Funding arrangements that help writers and producers overcome the risk-aversion of programmers might increase diversity. The Experimental Value justification for public broadcasting as a provider of external benefits might also apply, and it can be related to the arguments explored in Chapter 7, under the heading Welfare and Endogenous Preferences, which noted the Peacock Commission's claim that rational utility-maximising consumers of media might look to expand their aesthetic and intellectual horizons, rather than pander to their existing preferences. This could only happen if programme makers are able to explore creative directions.

The principle was probably intended, however, as a statement about the internal management of a public broadcasting organisation, and therefore Tushman and O'Reilly's ideas about organisational strategy and organisational culture would apply. A public broadcaster and its programme makers should be guided by a sense of mission and vision to uphold and defend the rights and interests of the public it serves, rather than prescriptive systems of formal or bureaucratic control.

\section{Conclusions}

At the beginning of this chapter we posed the question "What do we mean by public broadcasting?" We can see that some parts of the BBC definition of public broadcasting rely on a description of what the BBC once was - an independent corporation and a discriminating monopolist, facing little or no competition, and able to secure an independent source of revenue through the broadcasting licence fee. In the presence of substantial competition for audience attention from private broadcasters, that description is outmoded, and it would be foolhardy to suggest that all of the BBC principles could be applied wholesale to public broadcasting now or in the foreseeable future, in the form they were originally intended.

However, in the light of the analysis presented here, we can see that some of these principles can still be employed to describe some of the fundamental ideas about creating and protecting the domain of freedom in a liberal democratic society. PrincipalAgent theory has provided an argument that public broadcasters have the role of putting the audience's interest above those of advertisers, the government or broadcasters themselves. 


\section{Chapter 12 Conclusions and Recommendations}

The introduction to this thesis posed three questions:

- 'Was the Treasury submission to the RCBRT good policy advice?'

- 'Was the Treasury submission good use of economic theory in a policy setting?'

- 'What should be the outcomes of broadcasting policy?'

Having reviewed the can now answer those three questions.

\section{Quality of policy advice}

The first question posed by this thesis was 'Was the Treasury submission to the RCBRT good policy advice?'

Recall that our investigation has focused on the recommendations flowing from the analysis in Section Three of Treasury's submission, which was titled "Economics of Broadcasting and Government Intervention". There were four recommendations, which we can divide into two groups of two. The first two relate Treasury's proposal to open up broadcasting to competition by selling broadcasting rights in a market.

\section{Figure 31: Treasury's Spectrum Recommendations}

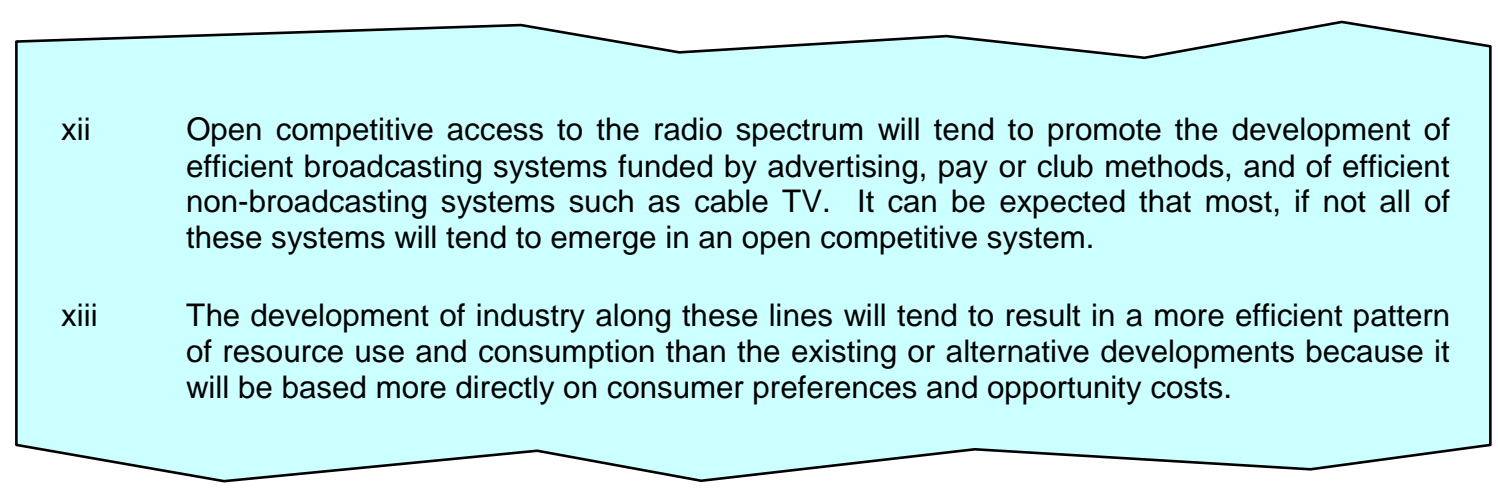

The analysis in Chapter 6 showed us that indeed there would be an expansion of channels under increased competition. However, we have also seen that this will tend to create more homogenous and monopolistic radio and television services, with significantly less production of local and regional programming.

The second of these conclusions is very dubious. We have seen that the development of market-led broadcasting might lead to the efficient production of audiences, based more directly on the preferences of advertisers. However, in an increasingly monopolistic market, even this advantage to advertisers may be eroded.

It is not clear that audiences' preferences would be more effectively reflected in programming choices, or that audience welfare would be increased, either by the sale of unencumbered broadcasting rights or by the development of cable or broadcast pay TV. When the consumption choices of a significant proportion, probably the majority, of the 
audience are influenced by the output of the media, the theoretical foundation on which this conclusion stands disintegrates.

The RCBRT was not antagonistic toward Treasury's proposal to sell broadcasting rights, as it recognised that obligations to protect the public interest could be attached to those rights prior to sale. If the conclusions in Treasury's submission were weak, then subsequent advice to the government from the Officials Committee was that much poorer for not acknowledging the RCBRT's suggestion as a viable option.

Treasury's argument in favour of allocative efficiency eventually extinguished the implied political and social rights held by citizens, which had been wielded on their behalf by the Broadcasting Tribunal.

The second two of Treasury's recommendations relate directly to this idea. These recommendations were justifications for the commercialisation of the BCNZ, driven by Treasury's desire to separate the commercial and social objectives of what it saw as a government trading enterprise.

\section{Figure 32: Treasury's Commercialisation Recommendations}

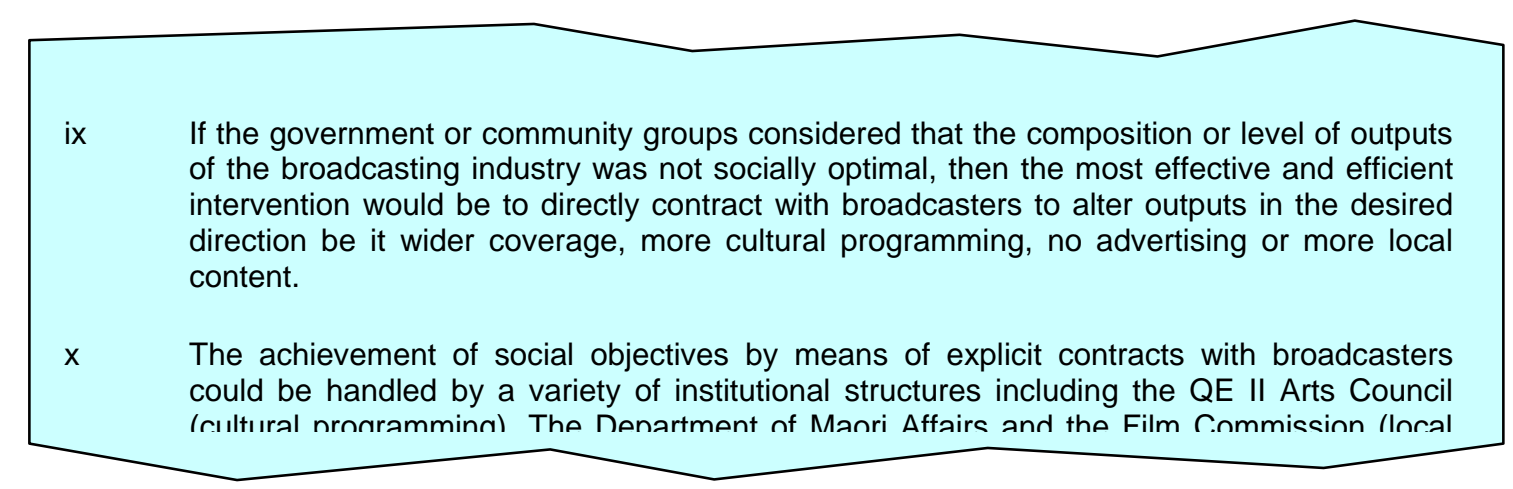

Treasury may well have been well justified in expressing doubt that the government needed to be an owner of broadcasting services. However, a perfectly feasible option would have been to transfer the BCNZ's assets to an independent not-for-profit public broadcasting trust or corporation. ${ }^{113}$

The second set of recommendations justified the transformation of a television broadcaster, which could have acted as the citizens' agent and provided a measure of transparency into their relationship with the state, into a fully commercial enterprise.

The first conclusion of this thesis must be that the Treasury submission was poor policy advice. The outcomes of this advice have been:

113 Had that transfer included Radio New Zealand's commercial radio network and two commercial television channels, a politically independent BCNZ would also have had an independent source of income. Provided the trust had been established with an appropriate deed, it might have become a true public broadcaster. 
- The development of a monopolistically competitive media industry environment, with potentially excessive levels of cross-media ownership and excessive levels of ownership aggregation within media sectors.

- Potentially excessive sales of radio frequency spectrum in the broadcast frequency bands, which may be a contributing factor to the above outcome.

- Insufficient provision of radio and television frequencies for non-commercial broadcasters (i.e. community access, ethnic and Maori broadcasting)

- Ongoing disputes between the Crown and Maori regarding the outcomes of broadcasting policy in regard to the Crown's Treaty obligations.

- Lack of consideration for the role that broadcasting policy may have in sustaining a liberal democratic polity in New Zealand and, consequently, the erosion of democratic principles and practices within the polity.

A subsidiary conclusion must be that the Government has not received significantly better broadcasting policy advice since the current framework was implemented in 1989/90.

\section{Quality of economic analysis}

The second question posed at the beginning was 'Was the Treasury submission good use of economic theory to this policy issue?'

No matter what aspect of economic theory it discusses, at the end of almost every part of the third section Treasury makes a similar conclusion:

"Consideration of the means of providing tax funded broadcasting led to the conclusion that it was unnecessary for the Government to operate publicly owned and operated stations to achieve its objectives, and that, in the interests of efficiency, it would be preferable for the Government, perhaps through delegated bodies, to use funds from general taxation to buy non-commercial programmes for transmission by public broadcasting.” (44)

"Arguments for and against tax funded broadcasting apply with equal force to (programme) content regulation.... Where the government wished to influence the mix of broadcasting services which are supplied, a tax funded mechanism of the type outlined in part Ei seems likely to be preferable on all grounds than a system of content and coverage regulation.” (47)

"If there are distribution or merit grounds for government intervention in broadcasting, the issue is to achieve the objectives as efficiently as possible, and the efficient solution would in most cases be a general revenue financed subsidy for particular broadcasting outputs.” (49)

It is clear from the discussion in this thesis that these conclusions do not flow logically from the "Economic Theory of Broadcasting and Government Intervention", and that Treasury was using economic theory rhetorically to justify a policy of commercialisation and the sale of broadcasting rights.

The most generous interpretation that can be placed the actions of the officials concerned was were well-intentioned but inept. They might have been well-intentioned to the extent they saw themselves as "entrepreneurs for efficiency" (Nelson 1987) who were "...making an earnest and sincere effort to... speak the truth at all costs." (Heilbroner, 1988). They therefore sought to enhance the sovereignty of media consumers and create a more rational allocation of society's scarce resources in respect of broadcasting. They may have been inept in two senses: first, if failed to recognise the 
rhetoric underlying the Coase theorem and much of the subsequent literature on the economics of broadcasting that explicated Coase's ideas. Second, if they failed to perceive that their plan for broadcasting deregulation necessarily involved the transformation of social and political rights into property rights. This failure of perception then led to the Crown's protection of those rights being significantly eroded. The explanation of well-intentioned ineptitude is sufficient to judge the quality of the economic analysis, and we may therefore refrain from attributing more sinister interpretation to officials' actions.

If economists express horror when it is proposed they should employ rhetoric to influence policy, the economic analysis presented to the RCBRT must exemplify what they most fear. Economic theory has two qualities to offer any policy issue: rigour and restraint.

Economics provides a powerful set of tools that can provide a rigorous analytical framework for analysing a wide variety of policy issues. The diagram presented in Figure 33 displays the economic relationships we have explored in this thesis. Hopefully, the discussion has brought clarity and definition to many aspects of broadcasting policy, to readers who are unfamiliar with the economist's way of talking about the world.

Figure 33: Economic Relationships among Audience, Broadcaster and Advertiser

On the other hand, economics, like any form of discourse about human society, cannot

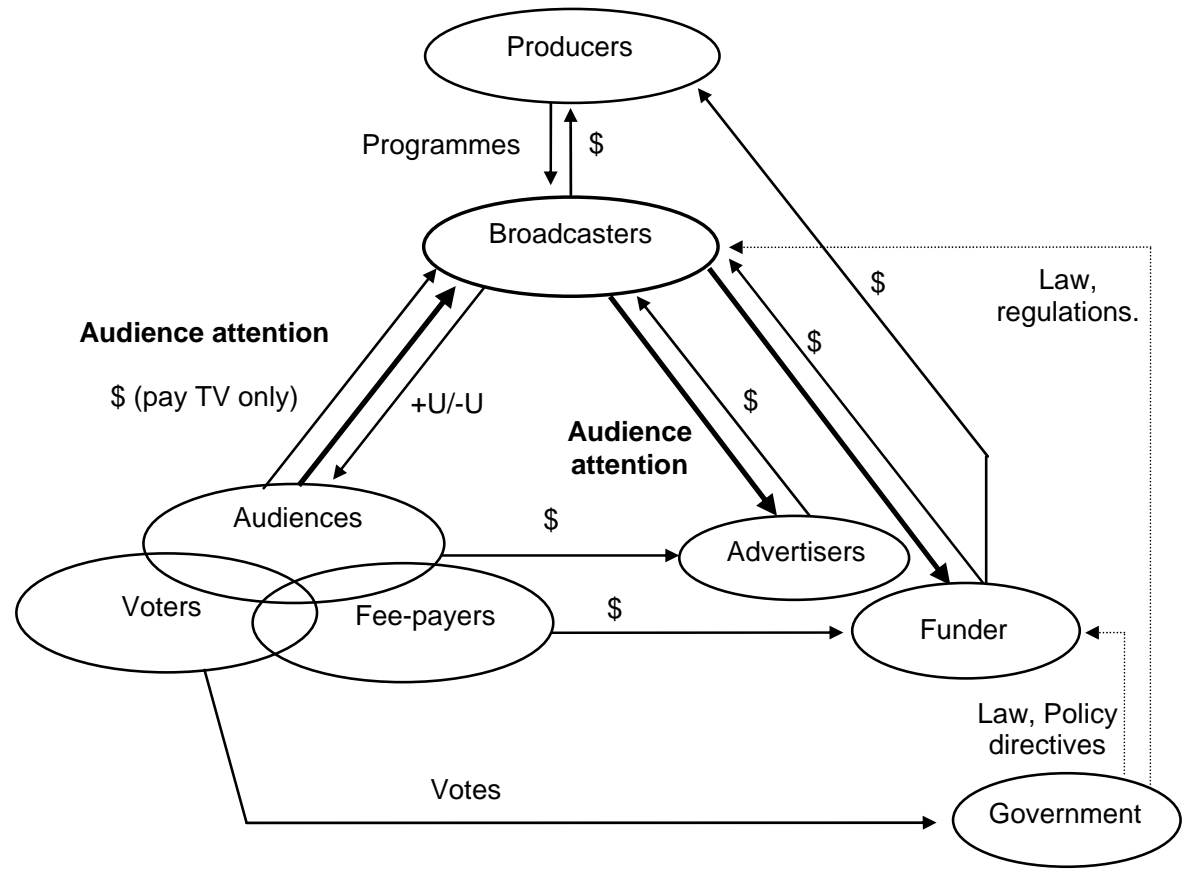

explain everything. One of the qualities of good economic analysis must be that it displays restraint; an awareness of its limitations and a respect for the insights and provided by other disciplines. This is especially necessary in respect to a policy issue 
where conflicting ideas, beliefs, values and ideologies are an intrinsic aspect of the analysis.

The Treasury submission, and much of the subsequent policy advice that was based on it, displayed neither rigour nor restraint.

\section{Outcomes}

As we have stated in Chapter 9, it is for the government, not unelected officials, to decide the outcomes of broadcasting policy. However, officials can and should advise the government in respect to outcomes if: they are expressed in existing legislation, or they are implied by the constitution and/or fundamental assumptions underpinning the social and political order, or they will self-evidently contribute to the peace, order and good government of society. Within those constraints, the advice regarding the outcomes of broadcasting policy that flows from the analysis presented in this thesis is can be simply stated.

Broadcasting, along with other media, should be regulated (either by market mechanisms, or directly by legislated power, or some combination of these), to:

1. Sustain and enhance New Zealand's system of representative government and the legitimacy of the Crown by:

(a) Protecting and guaranteeing citizens' rights to receive and to participate in public debate on matters of government policy.

(b) Assisting voters in making informed and competent voting decisions.

(c) Providing electors with a means of scrutinising and monitoring the performance of their elected representatives.

(d) Honouring the Crowns' guarantee to Maori, in article two of the Treaty of Waitangi, to protect their tino rangatiratanga and the tāonga of te reo Maori.

2. Sustain and enhance the existence of a free society based on social democratic principles by:

(a) Ensuring every member of society is protected from interference with their free possession and expression of political, cultural religious and other beliefs.

(b) Providing society with the means to discuss, debate, decide on and modify the beliefs and values that its members must share in some degree to regulate itself without the intrusion of the state.

In creating these outcomes, it must at all times be borne in mind that it is what the audience should pay its scarce attention to that must ultimately be the focus of broadcasting policy, in regard to creating social, political or economic outcomes. And the first guiding principle must be that the decision is for the audience to make in the first instance and for its elected representatives in the second. Broadcasters, advertisers and unelected officials should not presume to make these decisions on behalf of either. 


\section{Recommendations}

A fine principle of policy analysis is that a policy problem should not be presented to the government without also recommending a course of action or a solution to that problem. There are a number of critical problems that this analysis has identified:

1. The policy of deregulating broadcasting significantly eroded the protections of citizens’ rights that were embodied in the Broadcasting Act 1989.

2. As a consequence of this, it is unlikely that the Crown can legally sell Television New Zealand Limited, as such a sale could credibly be blocked by the courts.

3. There are ongoing problems associated with Maori claims in broadcasting under the Treaty of Waitangi, and current policy is unlikely to resolve these effectively.

4. There may be a problem with official 'capture' of broadcasting policy, and the government's current sources of broadcasting policy advice are therefore unlikely to contribute effectively to resolving the aforementioned problems.

There are two sets of recommendations that fall out of this analysis, the short-term and long-term. Both are rely on the premise that New Zealand is constitutionally a liberal democracy and should strive to continue developing its political and social institutions in that direction.

\section{Immediate Priorities}

The first set of recommendations relates to steps that can be taken immediately. These recognise that, despite evident flaws in the underlying theory, the existing institutional arrangements are not so unsound that relatively minor adjustments could produce significantly improved outcomes for society and provide a sound platform for longerterm developments.

It is recommended that the Government take the immediate steps to:

1. Place a moratorium on the sale of Television New Zealand Limited and Radio New Zealand Limited, including their subsidiary companies, until the future of public broadcasting has been reviewed by a Royal Commission established for that purpose (see below).

2. Inform the TVNZ Board of Directors that the Crown requires only an $11 \%$ Return on Shareholders' equity (the standard public sector cost of capital). Any surpluses above that are to be reinvested in the business and/or used in accordance with recommendation 3 , below.

3. Request that Television New Zealand Limited immediately submit a Statement of Intent incorporating into the objects of the organisation a strategy to inform New Zealand citizens regarding the policies offered by political parties in the lead up to the 1999 General Election and the performance of their elected representatives thereafter.

4. Distinguish between two aspects of broadcasting policy advice:

(a) advice regarding the management of the radio frequency spectrum, and 
(b) advice regarding the social, cultural and political impacts of broadcasting policy.

5. Cease purchasing policy advice described in 4 (b) above, from the Ministry of Commerce, effective immediately, and

6. Commence purchasing this advice from the Department of Internal Affairs, where it would sit more comfortably with that Department's roles in respect to (among other things) heritage, history, community, identity and cultural affairs.

7. Repeal section 44 of the Broadcasting Act 1989, thereby removing the ability of the Minister of Broadcasting to direct the Commission in regard to government policy. All future influence over the Broadcasting Commission should take the form of amendments to the Act.

8. Amend section 36 of the Broadcasting Act 1989 to include a subsection that reads:

"(h) To ensure that a range of broadcasts is available to provide for the interests of New Zealand's citizens by:

(i) improving the quality and scope of radio and television scrutiny of Parliament and the Executive, and

(ii) improving the range and depth of information available to assist them in making voting decisions at General elections.”

This will provide that funding for current affairs and investigative journalism can be made available to private sector broadcasters, and to TVNZ should it fail to meet its required rate of return.

\section{Broadcasting Policy Review}

The longer-term recommendations reflect the conclusion that the economic analysis underpinning the current broadcasting framework was profoundly flawed, and so influential in determining the existing institutional arrangements, that a proper review of broadcasting policy arrangements is required. This should focus on the outcomes of broadcasting policy suitable for liberal democracy, in the first instance. It should incorporate such economic analysis as can be applied to ensure those outcomes are efficiently achieved.

It is therefore recommended that the Government:

1. Establish a Royal Commission, with broad terms of reference, to review the economic, political, social and cultural dimensions of broadcasting policy. To that end, the Commission should review:

(a) The nature and the proper extent of the social and political obligations of the electronic media in a liberal democratic polity. This should include, but not be limited to, audio and visual signals that are distributed by cable, fibreoptic and other narrow-casting methods and terrestrial and satellite broadcast transmission. 
(b) The purpose, functions and institutional arrangements of public broadcasting including recommendations regarding its future funding, independence from government and accountability to Parliament.

(c) Past and potential future claims in broadcasting by Maori under the Treaty of Waitangi, and the ongoing relationship between the Crown and Maori in respect of broadcasting policy. This implies that the composition of the Commission and its Terms of Reference should reflect the principles of partnership under the Treaty of Waitangi.

(d) The specification of property rights in spectrum created under the Radiocommunications Act 1989, and whether these specifications can be changed to incorporate an obligation to serve the public interest.

(e) Spectrum allocation policies and processes, with special attention to the means by which broadcasting rights are allocated to not-for-profit community broadcasters and the effect of policies on industry structure and media content.

(f) The desirability of either re-establishing a Broadcasting Tribunal, or changing the powers and functions of the Broadcasting Standards Authority to enable it to allocate broadcasting rights to not-for-profit community broadcasters, and to attach and enforce obligations to the rights currently held by users of radio frequency spectrum that is, or may be, used for radio and television broadcasting.

(g) The purpose and function of the Broadcasting Standards Authority and New Zealand on Air.

(h) The desirability of limiting cross-media ownership and aggregation of media ownership, including the effectiveness of existing powers and provisions of the Commerce Act for achieving such limits.

The broadcasting industry is undergoing almost rapid and accelerating transformation. The effects of digital technology will have a major impact in the sector over the next few years. Although no explicit discussion of these matters has been raised in this thesis, it will also be necessary for the Commission to have regard to these matters.

Most importantly, it should advise the government in respect to the fundamental principles regarding social and political outcomes that should inform broadcasting policy in a well-functioning representative democracy.

A well thought-out guiding philosophy that focuses on the outcomes of broadcasting policy for society will, above all else, assist the continued development and responsiveness of policy in a rapidly changing social, political and technical environment. 
Althusser, L. (1971) “Ideology and Ideological State Apparatuses” in Essays on Ideology London: Verso

Alvarado, M. and Thompson, J., eds, (1990) The Media Reader London: BFI Publishing

Andreasen, A (1995) Marketing Social Change : Changing Behavior to Promote Health, Social Development, and the Environment San Francisco: Jossey-Bass

Atkinson, J. (1989) "Mass Communications, Economic Liberalisation and the New Mediators” Political Science (41)2 85-108

Atkinson, J. (1994) "The State, the Media and Thin Democracy” in Andrew Sharp (ed) Leap Into the Dark: The Changing Role of the State in New Zealand Since 1984 Auckland: Auckland University Press

Australian Broadcasting Tribunal (1977) Self-regulation for Broadcasters: A Report on the Public Enquiry into the Concept of Self-regulation for Australian Broadcasters Canberra: Australian Government Publishing Service

Badian, E. (1958) Foreign Clientelae Oxford: Oxford University Press

Baudrillard, J. (1995) The Gulf War Did Not Really Take Place Sydney: Power Publications

Beebe, J.H. (1977) “Institutional Structure and Program Choices in Television Markets” Quarterly Journal of Economics 91: 15-37

Besen, S. M. (1976) “The Value of Television Time” Southern Journal of Economics 42: 435-441

Best, Elsdon (1909) “Maori Forest Lore” Transactions of the New Zealand Institute XLII: 433-481

Boston, J., Martin, J., Pallot, J. and Walsh, P. (1996) Public Management: The New Zealand Model Auckland: Oxford University Press

Brown, B. and Cave, M. (1992) "The Economics of Television Regulation: A Survey with Application to Australia” The Economic Record 68: 377-394

Cameron, L. (1987) Personal Letter to Brian Easton, 27 April.

Campbell, G. (1989) “Top of the Evening” NZ Listener 34: 18-21

Campbell, G. (1992) “Inside the Richard and Judy Show” Listener and TV Times (August 15) 16-20

Carnegie Commission on Educational Television (1967) Public Television: A Program for Action: the report and recommendations of the Carnegie Commission on Educational Television New York: Bantam Books

Chamberlin, E. H. (1962) The Theory of Monopolistic Competition: A Re-orientation of the Theory of Value Cambridge, Mass.: Harvard University Press,

Chen, M. and Palmer, G. Public Law in New Zealand: Cases, Materials, Commentary and Questions Auckland: Oxford University Press

Coase, R.H. (1959) “The Federal Communications Commission” Journal of Law and Economics 2(October): 1- 40 
Coase, R.H. (1960) “The Problem of Social Cost” Journal of Law and Economics 3(October): 1- 44

Cocker, A. (1991) “Auckland Radio: Marketing to Survive” Management (July): 34-41

Cocker, A. (1996) A Toaster with Pictures: The Deregulation of Broadcasting in New Zealand Unpublished doctoral dissertation, Auckland University

Cohen, B., (1963) The Press and Foreign Policy Princeton: Princeton University press

Collins, R., Garnham, N. and Locksley, G. (1988) The Economics of Television: The UK Case London: Sage

Comrie, M. (1996) The Commercial Imperative in Broadcasting News: TVNZ from 1985 to 1990 Unpublished doctoral dissertation, Palmerston North: Massey University

Cumberpatch, G. and Howitt, D. (1989) A Measure of Uncertainty: The Effects of the Mass Media London: John Libbey

Cunningham, S. (1992) Framing Culture: Criticism and Policy in Australia Sydney: Allen and Unwin

Curran, J. (1990) "The New Revisionism in Mass Communication Research: A Reappraisal”, European Journal of Communication 5: 135-164.

Danziger, M. (1995) "Policy Analysis Postmodernized: Some Political and Pedagogical Ramifications” Policy Studies Journal 23(3): 435-450

Deleon, P. (1994) "Reinventing the Policy Science: Three Steps back to the Future.” Policy Sciences 27: 77-95

DeVany, A., Eckhart, R., Meyers, C., O’Hara, D., and Scott, R. (1969) “ A Property System for Market Allocation of the Electromagnetic Spectrum: A legal-EconomicEngineering Study” Stanford Law Review 21(June): 1499-1561

Easton, B. (1987) “Economy: Second Opinion” NZ Listener 115(2456): 59; 21 Mar 1987

Easton, B. (1990) “Broadcasting: 1985-1990 Commercialism vs Culture” Landfall (44)3: 276-290

Easton, B. (1994a) “Broadcast Views” NZ Listener (57) June 18

Easton, B. (1994b) "Economic and other Ideas behind the New Zealand Reforms" Oxford Review of Economic Policy 10(3): 78-94

Easton, B. (1997) The Commercialisation of New Zealand Auckland: Auckland University Press

Edwards, B. (1992) “The 'cootchi coo' News” in Comrie, M. and McGregor, J., eds, Whose News? (15-25) Palmerston North: Dunmore Press

Fairclough, N. (1992) Discourse and Social Change Polity Press, Oxford

Farmer, D. (1995) The Language of Public Administration; Bureaucracy, Modernity and Postmodernity University of Alabama Press

Fiske, J. (1987) Television Culture New York: Methuen

Fountain, J. (1988) The Economics of Radio Spectrum Management, Department of Trade and Industry, Wellington

Fox, C.J. (1996) "Reinventing Government as Postmodern Symbolic Politics” Public Administration Review 56(3): 256-262 
Fox, D. (1988) “The Mass Media: A Maori Perspective” in The Royal Commission on Social Policy Volume 4: Social Perspectives, Wellington: Government Print

Fox, D. (1998) “Time to Step Aside” Mana (21) 20-26

Fraser, C.D. (1996) “On the Provision of Excludable Public Goods” Journal of Public Economics, 60: 111-130.

Fukuyama, F. (1995) Trust: The Social Virtues and the Creation of Prosperity London: Penguin

Geary, S. (1994) “News Structures” Chapter 9 of The Radio Book 1994 Christchurch: New Zealand Broadcasting School

Goldfinch, S. (1998) “Remaking New Zealand’s Economic policy: Institutional Elites as Radical Innovators 1984-1993” Governance: An International Journal of Policy and Administration 11(2): 177-207

Gregory, R. (1979) The Rise and Fall of the New Zealand broadcasting Corporation, 1962-1973: A Study in Political and Administrative Relationships PhD Thesis, Victoria University.

Gregory, R. (1985) Politics and Broadcasting: Before and Beyond the NZBC Palmerston North: Dunmore Press

Gregory, R. (1989) “Political Rationality or ‘Incrementalism’? Charles E. Lindblom’s enduring contribution to public policy making theory" Policy and Politics 17(2): 139-153

Harris, P. (1995) “'Intimacy’ in New Zealand Politics: A Sceptical Analysis” Political Science 47(1): 1-33

Hay, D. (1986) "Broadcasting Pinned Down for Economic Analysis” National Business Review (October 17 ${ }^{\text {th }}$ ): 20

Hay, D. (1996) "Giving/Taking, Buying/Selling, Speaking/Silence: Te Reo Maori in Prime-time” Continuum: The Australian Journal of Media and Culture 10: 94107

Hayek, F. von (1945) The Road to Serfdom London: Routledge \& Son

Hayek, F. von (1952) The Counter-revolution of Science: Studies on the Abuse of Reason Glencoe Ill.: Free Press

Heilbroner, R. (1988) "Rhetoric and Ideology” Chapter 4 in Klamer, et al., eds, The Consequences of Economic Rhetoric Cambridge: Cambridge University Press

Hobbes (1946 [1651]) Leviathan Oxford: Basil Blackwell

Horrocks, R. (1995) "Strategic Nationalisms: Television Production in New Zealand" Sites 30(Autumn): 85-107

Hotelling, H. (1929) “Stability in Competition” Economic Journal 39 (1): 41-57, reproduced in M. Ricketts, ed., (1988) Neoclassical Economics Vol 1 Aldershot: Edward Elgar. 114-130

Ignatieff, M, (1994) The Needs of Strangers London: Chatto and Windus

Iyengar, S., Peters, M. and Kinder P. (1982), "Experimental Demonstrations of the 'notso-minimal' Consequences of Television News Programs” American Political Science Review 76(4)

James, C. (1986) The Quiet Revolution Wellington: Allen and Unwin, 
Janis, I. (1989) “Groupthink: The Desperate Drive for Consensus at any Cost” Classic Readings in Organisational Behaviour Ott, J., ed, California: Brooks/Cole (Originally published in Psychology Today Magazine, 1971)

Jesson, B. (1987) Behind The Mirror Glass: The Growth of Wealth and Power in New Zealand in the Eighties. Auckland: Penguin

Jesson, B. (1989) Fragments of Labour: The Story Behind the Labour Government Auckland: Penguin

Jones, P. (1989) “The Ideal of the Neutral State” Chapter 2 of R. Goodin and A. Reeve, eds, Liberal Neutrality London: Routledge

Joseph, P. (1993) Constitutional and Administrative Law in New Zealand Sydney: The Law Book Company

Katz, E. (1988) “On Conceptualizing Media Effects” Applied Social Sciences Psychology Annual 8 362-3

Kennemar, D, ed., (1992) Public Opinion, the Press and Public Policy Westport \& London: Praeger

Keohane, R. (1988) “The Rhetoric of Economics as Viewed by a Student of Politics” Chapter 15 in Klamer, et al., eds, The Consequences of Economic Rhetoric Cambridge: Cambridge University Press

Klamer, A. and McCloskey, D. (1988) "Economics in the Human Conversation” Chapter 1 in Klamer, et al., eds, The Consequences of Economic Rhetoric Cambridge: Cambridge University Press

Klamer, A., McCloskey, D. and Solow, R. eds. (1988), The Consequences of Economic Rhetoric, Cambridge: Cambridge University Press

Klamer, A., McCloskey, D. and Solow, R., eds, (1988) The Consequences of Economic Rhetoric Cambridge: Cambridge University Press

Klapper, J. (1960) The Effects of Mass Communication New York: Free Press

Kotler, P and Roberto, E. (1989) Social Marketing : Strategies for Changing Public Behavior New York : Free Press, London: Collier Macmillan

Lambley, P. (1980) The Psychology of Apartheid Athens, Ga.: University of Georgia Press

Lang, G. and Lang, K. (1983) The Battle for Public Opinion: The President, the Press and the Polls During Watergate, New York: Columbia University Press

Lasora, D. (1992) "Policymakers and the Third Party Effect", Chapter 10 of Kennemar, D., ed., Public Opinion, the Press and Public Policy Westport \& London: Praeger

Leitch, S. (1990) Newstalk Palmerston North: Dunmore Press

Leitch, S. (1992) “The Media and Politics”, Chapter 3 in Hyam Gold, ed., New Zealand Politics in Perspective, $3^{\text {rd }}$ Edn. Auckland: Longman Paul,

Lindblom, C. (1959) “The Science of Muddling Through” Public Administration Review 19(2): 79-88

Locke, T. (1960) Two Treatises of Government New York: Cambridge University Press (Mentor imprint)

Majone, G (1989) Evidence, Argument and Persuasion in the Policy Process New Haven, Ct.: Yale University Press

Marshall, A. (1961 [1898]) Principles of Economics London: MacMillan 
Maslow, A. (1987) Motivation and Personality NY: Addison-Wesley

Masson, R., Mudambi, R. and Reynolds, R. (1990) "Oligopoly in Advertiser-Supported Media” Quarterly Review of Economics and Business 30: 3-16

Mauss, Marcel (1925) The Gift: Forms and Functions of Exchange in Archaic Societies, trans. Cunningson, W.W. Norton [1954].

McCloskey, D. (1986) The Rhetorics of Economics Sussex: Harvester Press

McCombs, M. and Shaw, D. (1972) “The Agenda-Setting Function of Mass Media” Public Opinion Quarterly 36(2), 176-187

McGregor, J. and Comrie, M. (1995) Balance and Fairness in Broadcasting News (1985-1994) Palmerston North: Massey University

Mill, J. (1972) Utilitarianism, On Liberty and Considerations of Representative Government London: Dent/Everyman

Mitchell, A. (1972) The Half-Gallon Quarter-Acre Pavlova Paradise Christchurch: Whitcombe and Tombs

Morley, D. (1980) The Nationwide Audience London: British Film Institute

Mulgan, R (1992a) “The Elective Dictatorship in New Zealand”, Chapter 29 in Hyam Gold, ed. New Zealand Politics in Perspective, $3^{\text {rd }}$ Edition. Auckland: Longman Paul

Mulgan, R (1992b) “The Principles of Rogerpolitics” Public Sector 15(1): 16-17

Mulgan, R. (1989) “The New Radicalism” University of Auckland Winter Lectures 7 June 1989; Maidment Theatre. Reported in the NZ Herald, as "Socialism lure dimmed by rival from right”; 8 June 1989, pg 2.

Nelson, R. (1987) “The Economics Profession and the Making of Public Policy” Journal of Economic Literature (25)1: 49-91

New Zealand Gazette (for Broadcasting Tribunal decisions, 1977 - 83)

Noam, E. (1988) “A Public and Private-Choice Model of Broadcasting” Public Choice 55: $163-187$

Noam, E. (1991) Television in Europe Oxford: Oxford University Press,.

Noelle-Neumann, E. (1984) The Spiral of Silence: Public Opinion, our Social Skin Chicago: University of Chicago Press

Noll, R., Peck, M. and McGowan, J. (1973) Economic Aspects of Television Regulation Washington: Brookings Institute

O’Connor, Martin (1991) Honour the Treaty? Property Right and Symbolic Exchange. (Policy Discussion Paper No. 11), Department of Economics, University of Auckland.

O'Connor, M. (1991) Time and Environment Ph.D Thesis, University of Auckland.

Officials' Coordinating Committee on Broadcasting (August 1988) Report on Implementation of Broadcasting Policy Reform Wellington: Department of Trade and Industry,

Osborne, D. and Gaebler, T. (1993) Reinventing Government: how the Entrepreneurial Spirit is Transforming the Public Sector New York: Plume

Owen, B. and Braeutigam, R. (1978) The Regulation Game: Strategic Use of the Administrative Process Cambridge, Mass.: Ballinger 
Owen, B. and S. Wildman (1992) Video Economics Cambridge and London: Harvard University Press

Owen, B. Beebe, J. and Manning, W. (1974) Television Economics Toronto: Lexington Books

Palmer, G. (1987) Unbridled power: an interpretation of New Zealand's constitution and government 2ed Auckland: Oxford University Press

Palmer, G. (1992) New Zealand's Constitution in Crisis: Reforming our Political System Dunedin: John McIndoe

Pardon, D. (1991) "Radio Fights the Wrong Battle” Marketing 10(5): 28-31

Peacock Committee (1986) Report of the Committee on Financing the BBC London: Her Majesty's Stationery Office

Privy Council New Zealand Maori Council v Attorney General [1994] 1 NZLR 513

Pusey, M. (1993) "Reclaiming the Middle Ground... From New Right Economic Rationalism" in S. King and P. Lloyd, eds, Economic Rationalism: Dead End or Way Forward? Sydney: Allen and Unwin.

Radio New Zealand Act (1995)

Rennie, H. (1990) "Public Sector Broadcasting in New Zealand” Chapter 5 of G. Hawke, ed., Access to the Airwaves: Issues in Public Sector Broadcasting Wellington: Victoria University Press for the Institute of Policy Studies

Roeh, I. and Cohen, A. (1992) "One of the bloodiest days: A comparative analysis of open and closed television news" Journal of Communication (46)2, 129-135

Rosenberg, A. (1988) "Economics is Too Important to be Left to the Rhetoricians." Economics and Philosophy 4:129-49.

Rothenberg, J. (1962) "Consumer Sovereignty and the Economics of TV Programming” Studies in Public Communication 4: 45-54.

Royal Commission on Broadcasting and Related Telecommunications (1986) Report of the Royal Commission on Broadcasting and Related Telecommunications Wellington

Russell, M. (1990) “Politics tampers with TV direction” Sunday Star, May 6: A6

Salmon, C. and Moh, C. (1992) "The Spiral of Silence: Linking Individual and Society through Communication”, Chapter 9 of D. Kennamer, ed., Public Opinion, The Press and Pubic Policy Westport and London: Praeger

Salmond, A. (1976) Hui: A Study of Maori Ceremonial Gatherings 2ed Auckland Reed Methuen,

Scruton, R. (1983) A Dictionary of Political Thought London: Pan/Macmillan

Shanahan, M. (1994) “A Little Crystal Ball Gazing: The Future of Radio in New Zealand” Chapter 11 of The Radio Book 1994 Christchurch: New Zealand Broadcasting School

Simon, H. (1947) Administrative Behaviour Glencoe, Ill.: Free Press

Spence, A.M. and Owen, B. (1975) “Television Programming, Monopolistic Competition and Welfare” Quarterly Journal of Economics 91: 103-126.

Steering Committee on Broadcasting (July 1988) Restructuring of the Broadcasting Corporation of New Zealand on State Owned Enterprise Principles Wellington 
Steiner, P.O. (1952) "Program Patterns and Preferences, and the Workability of Competition in Broadcasting” Quarterly Journal of Economics 66: 194-223.

Stevenson, L. (1987) Seven Theories of Human Nature $2^{\text {nd }}$ Ed, Oxford: Oxford University Press

Throgmorton, J. (1991) “The Rhetorics of Policy Analysis” Policy Sciences 24: 153179

Tobin, J. (1970) “On Limiting the Domain of Inequality” Journal of Law and Economics 13(3): 262-277

Tonnies, F. (1922) Kritik der Offentlichen Meinung Berlin: J. Springer

Treasury (1984) Economic Management Wellington: Government Printer

Treasury (1985) Treasury Submission to the Royal Commission on Broadcasting and Related Telecommunications Wellington

Tushman, M. and O’Reilly, C. (1997) Winning Through Innovation: A Practical Guide to Leading Organizational Change and Renewal Boston: Harvard Business School Press

Varian, H. (1987) Intermediate Microeconomics, New York and London: W.W. Norton

Veljanovski, C. (1982) “The Coase Theorems and the Economic Theory of markets and Law” Kyklos (35) 53-74

Waitangi Tribunal (1986) Te reo Maori Report: Wai 11 Wellington: Department of Justice

Waitangi Tribunal (1990) Report on Claims Concerning the Allocation of Radio Frequencies: Wai 26 and Wai 150 Wellington: Brooker and Friend

Weaver, D. (1987) "Media Agenda-Setting and Elections: Assumptions and Implications” in David L. Paletz (ed.), Political Communication Research New Jersey: Ablex

Weiner, A. (1992), Inalienable Possessions: the Paradox of Keeping-While-Giving, Berkeley: University of California Press,

White (1985) “Agency as Control” Chapter 8 of Pratt, J. and Zeckhauser, R. Principals and Agents: the structure of business Boston: Harvard Business School Press

Wildavsky, A. (1979) Speaking Truth to Power: The Art and Craft of Policy Analysis Boston: Little, Brown.

Williamson, O. (1985) The Economic Institutions of Capitalism: Firms, Markets, Relational Contracting New York: Free Press

Windschuttle, K. (1995) “The Poverty of Media theory” Paper Presented at the Annual Conference of the Journalism Education Association University of Canterbury. 